\title{
Cochrane
}

Library

Cochrane Database of Systematic Reviews

\section{Planned early birth versus expectant management for women with preterm prelabour rupture of membranes prior to 37 weeks' gestation for improving pregnancy outcome (Review)}

Bond DM, Middleton P, Levett KM, van der Ham DP, Crowther CA, Buchanan SL, Morris J

Bond DM, Middleton P, Levett KM, van der Ham DP, Crowther CA, Buchanan SL, Morris J.

Planned early birth versus expectant management for women with preterm prelabour rupture of membranes prior to 37 weeks' gestation for improving pregnancy outcome.

Cochrane Database of Systematic Reviews 2017, Issue 3. Art. No.: CD004735.

DOI: 10.1002/14651858.CD004735.pub4.

www.cochranelibrary.com

Planned early birth versus expectant management for women with preterm prelabour rupture of membranes prior to 37 weeks' gestation for improving pregnancy outcome (Review)

Copyright $\odot 2017$ The Cochrane Collaboration. Published by John Wiley \& Sons, Ltd. 
TABLE OF CONTENTS

HEADER 1

ABSTRACT

PLAIN LANGUAGE SUMMARY

SUMMARY OF FINDINGS

BACKGROUND

OBJECTIVES

METHODS

RESULTS

Figure 1.

Figure 2.

Figure 3.

Figure 4.

Figure 5.

Figure 6.

Figure 7.

Figure 8.

Figure 9.

Figure 10

Figure 11

DISCUSSION

AUTHORS' CONCLUSIONS

ACKNOWLEDGEMENTS

REFERENCES

CHARACTERISTICS OF STUDIES

DATA AND ANALYSES

Analysis 1.1. Comparison 1 Any planned birth versus expectant management: by type, Outcome 1 Neonatal infection/sepsis.

Analysis 1.2. Comparison 1 Any planned birth versus expectant management: by type, Outcome 2 Neonatal infection confirmed with positive blood culture.

Analysis 1.3. Comparison 1 Any planned birth versus expectant management: by type, Outcome 3 Respiratory distress syndrome.

Analysis 1.4. Comparison 1 Any planned birth versus expectant management: by type, Outcome 4 Caesarean section. ........... Analysis 1.5. Comparison 1 Any planned birth versus expectant management: by type, Outcome 5 Perinatal mortality. ........... Analysis 1.6. Comparison 1 Any planned birth versus expectant management: by type, Outcome 6 Intrauterine death. ........... Analysis 1.7. Comparison 1 Any planned birth versus expectant management: by type, Outcome 7 Cord prolapse. ................. Analysis 1.8. Comparison 1 Any planned birth versus expectant management: by type, Outcome 8 Gestational age at birth (weeks).

Analysis 1.9. Comparison 1 Any planned birth versus expectant management: by type, Outcome 9 Neonatal death. ................ Analysis 1.10. Comparison 1 Any planned birth versus expectant management: by type, Outcome 10 Suspected neonatal infection.

Analysis 1.11. Comparison 1 Any planned birth versus expectant management: by type, Outcome 11 Neonatal treatment with antibiotics.

Analysis 1.12. Comparison 1 Any planned birth versus expectant management: by type, Outcome 12 Need for ventilation. .... Analysis 1.13. Comparison 1 Any planned birth versus expectant management: by type, Outcome 13 Duration of oxygen therapy (days).

Analysis 1.14. Comparison 1 Any planned birth versus expectant management: by type, Outcome 14 Umbilical cord arterial $\mathrm{pH}$.

Analysis 1.15. Comparison 1 Any planned birth versus expectant management: by type, Outcome 15 Birthweight (g). ............ Analysis 1.16. Comparison 1 Any planned birth versus expectant management: by type, Outcome 16 Apgar score less than 7 at 5 minutes.

Analysis 1.17. Comparison 1 Any planned birth versus expectant management: by type, Outcome 17 Abnormality on cerebral ultrasound.

Analysis 1.18. Comparison 1 Any planned birth versus expectant management: by type, Outcome 18 Periventricular leukomalacia.

Planned early birth versus expectant management for women with preterm prelabour rupture of membranes prior to 37 weeks' gestation for improving pregnancy outcome (Review)

Copyright (c) 2017 The Cochrane Collaboration. Published by John Wiley \& Sons, Ltd. 
Analysis 1.19. Comparison 1 Any planned birth versus expectant management: by type, Outcome 19 Cerebroventricular haemorrhage.

Analysis 1.20. Comparison 1 Any planned birth versus expectant management: by type, Outcome 20 Necrotising enterocolitis. Analysis 1.21. Comparison 1 Any planned birth versus expectant management: by type, Outcome 21 Severe respiratory distress.

Analysis 1.22. Comparison 1 Any planned birth versus expectant management: by type, Outcome 22 Admission to neonatal intensive care unit.

Analysis 1.23. Comparison 1 Any planned birth versus expectant management: by type, Outcome 23 Length of stay in neonatal intensive care unit (days).

Analysis 1.24. Comparison 1 Any planned birth versus expectant management: by type, Outcome 24 Duration (days) from birth to neonatal hospital discharge.

Analysis 1.25. Comparison 1 Any planned birth versus expectant management: by type, Outcome 25 Chorioamnionitis. ........ Analysis 1.26. Comparison 1 Any planned birth versus expectant management: by type, Outcome 26 Endometritis. ............... Analysis 1.27. Comparison 1 Any planned birth versus expectant management: by type, Outcome 27 Postpartum fever. .......... Analysis 1.28. Comparison 1 Any planned birth versus expectant management: by type, Outcome 28 Placental abruption. ..... Analysis 1.29. Comparison 1 Any planned birth versus expectant management: by type, Outcome 29 Induction of labour. ..... Analysis 1.30. Comparison 1 Any planned birth versus expectant management: by type, Outcome 30 Use of epidural/spinal anaesthesia.

Analysis 1.31. Comparison 1 Any planned birth versus expectant management: by type, Outcome 31 Vaginal birth.

Analysis 1.32. Comparison 1 Any planned birth versus expectant management: by type, Outcome 32 Operative vaginal birth. .. Analysis 1.33. Comparison 1 Any planned birth versus expectant management: by type, Outcome 33 Caesarean section for fetal distress.

Analysis 1.34. Comparison 1 Any planned birth versus expectant management: by type, Outcome 34 Duration (days) of maternal hospitalisation.

Analysis 1.35. Comparison 1 Any planned birth versus expectant management: by type, Outcome 35 Duration (days) of antenatal hospitalisation.

Analysis 1.36. Comparison 1 Any planned birth versus expectant management: by type, Outcome 36 Duration (days) of maternal hospitalisation (excluding trials with antenatal discharge).

Analysis 1.37. Comparison 1 Any planned birth versus expectant management: by type, Outcome 37 Time (hours) from randomisation to birth.

Analysis 1.38. Comparison 1 Any planned birth versus expectant management: by type, Outcome 38 Disability at 2 years, abnormal CBCL.

Analysis 1.39. Comparison 1 Any planned birth versus expectant management: by type, Outcome 39 Disability at 2 years, abnormal ASQ.

Analysis 1.40. Comparison 1 Any planned birth versus expectant management: by type, Outcome 40 Maternal satisfaction. .... Analysis 1.41. Comparison 1 Any planned birth versus expectant management: by type, Outcome 41 Breastfeeding $>12$ weeks.

Analysis 2.1. Comparison 2 Any planned birth versus expectant management (subgroup analysis by corticosteroid usage), Outcome 1 Neonatal infection.

Analysis 2.2. Comparison 2 Any planned birth versus expectant management (subgroup analysis by corticosteroid usage), Outcome 2 Neonatal infection confirmed with positive culture.

Analysis 2.3. Comparison 2 Any planned birth versus expectant management (subgroup analysis by corticosteroid usage), Outcome 3 Respiratory distress syndrome.

Analysis 2.4. Comparison 2 Any planned birth versus expectant management (subgroup analysis by corticosteroid usage), Outcome 4 Caesarean section.

Analysis 2.5. Comparison 2 Any planned birth versus expectant management (subgroup analysis by corticosteroid usage), Outcome 5 Chorioamnionitis.

Analysis 2.6. Comparison 2 Any planned birth versus expectant management (subgroup analysis by corticosteroid usage), Outcome 6 Endometritis.

Analysis 3.1. Comparison 3 Any planned birth versus expectant management (subgroup analysis by gestational age for inclusion in trial), Outcome 1 Neonatal infection.

Analysis 3.2. Comparison 3 Any planned birth versus expectant management (subgroup analysis by gestational age for inclusion in trial), Outcome 2 Neonatal infection confirmed with positive culture.

Analysis 3.3. Comparison 3 Any planned birth versus expectant management (subgroup analysis by gestational age for inclusion in trial), Outcome 3 Respiratory distress syndrome.

Analysis 3.4. Comparison 3 Any planned birth versus expectant management (subgroup analysis by gestational age for inclusion in trial), Outcome 4 Caesarean section.

Planned early birth versus expectant management for women with preterm prelabour rupture of membranes prior to 37 weeks' 
Analysis 3.5. Comparison 3 Any planned birth versus expectant management (subgroup analysis by gestational age for inclusion in trial), Outcome 5 Chorioamnionitis.

Analysis 3.6. Comparison 3 Any planned birth versus expectant management (subgroup analysis by gestational age for inclusion in trial), Outcome 6 Endometritis.

Analysis 4.1. Comparison 4 Any planned birth versus expectant management (subgroup analysis by antibiotic use), Outcome 1 Neonatal infection.

Analysis 4.2. Comparison 4 Any planned birth versus expectant management (subgroup analysis by antibiotic use), Outcome 2 Neonatal infection confirmed with positive culture.

Analysis 4.3. Comparison 4 Any planned birth versus expectant management (subgroup analysis by antibiotic use), Outcome 3 Respiratory distress syndrome.

Analysis 4.4. Comparison 4 Any planned birth versus expectant management (subgroup analysis by antibiotic use), Outcome 4 Caesarean section.

Analysis 4.5. Comparison 4 Any planned birth versus expectant management (subgroup analysis by antibiotic use), Outcome 5 Chorioamnionitis.

Analysis 4.6. Comparison 4 Any planned birth versus expectant management (subgroup analysis by antibiotic use), Outcome 6 Endometritis.

Analysis 5.1. Comparison 5 Any planned birth versus expectant management (subgroup analysis by timing of early delivery), Outcome 1 Neonatal infection.

Analysis 5.2. Comparison 5 Any planned birth versus expectant management (subgroup analysis by timing of early delivery), Outcome 2 Neonatal infection confirmed with positive culture.

Analysis 5.3. Comparison 5 Any planned birth versus expectant management (subgroup analysis by timing of early delivery), Outcome 3 Respiratory distress syndrome.

Analysis 5.4. Comparison 5 Any planned birth versus expectant management (subgroup analysis by timing of early delivery), Outcome 4 Caesarean section.

Analysis 5.5. Comparison 5 Any planned birth versus expectant management (subgroup analysis by timing of early delivery), Outcome 5 Chorioamnionitis.

Analysis 5.6. Comparison 5 Any planned birth versus expectant management (subgroup analysis by timing of early delivery), Outcome 6 Endometritis.

ADDITIONAL TABLES

APPENDICES

WHAT'S NEW

HISTORY

CONTRIBUTIONS OF AUTHORS

DECLARATIONS OF INTEREST

SOURCES OF SUPPORT

DIFFERENCES BETWEEN PROTOCOL AND REVIEW

INDEX TERMS 
[Intervention Review]

\section{Planned early birth versus expectant management for women with preterm prelabour rupture of membranes prior to 37 weeks' gestation for improving pregnancy outcome}

Diana M Bond ${ }^{1}$, Philippa Middleton², Kate M Levett 3 ,4, David P van der Ham5 ${ }^{5}$ Caroline A Crowther6,7, Sarah L Buchanan ${ }^{8}$, Jonathan Morris 9,10

1Department of Perinatal Research, Kolling Institute of Medical Research, University of Sydney, St Leonards, Australia. ${ }^{2} \mathrm{Healthy}$ Mothers, Babies and Children, South Australian Health and Medical Research Institute, Adelaide, Australia. ${ }^{3}$ School of Medicine, The University of Notre Dame, Sydney, Australia. ${ }^{4} \mathrm{NICM}$, School of Science and Health, University of Western Sydney, Penrith South DC, Australia. ${ }^{5}$ Department of Obstetrics and Gynaecology, Martini Hospital Groningen, Groningen, Netherlands. ${ }^{6}$ Liggins Institute, The University of Auckland, Auckland, New Zealand. ${ }^{7} \mathrm{ARCH}$ : Australian Research Centre for Health of Women and Babies, Robinson Research Institute, Discipline of Obstetrics and Gynaecology, The University of Adelaide, Adelaide, Australia. ${ }^{8}$ Department of Obstetrics and Gynaecology, Royal North Shore Hospital, St Leonards, Australia. ${ }^{9}$ Sydney Medical School - Northern, The University of Sydney, St Leonards, Australia. 10Department of Perinatal Research, Kolling Institute of Medical Research, University of Sydney, St Leonards, Australia

Contact address: Diana M Bond, Department of Perinatal Research, Kolling Institute of Medical Research, University of Sydney, Building 52, Level 2, Royal North Shore Hospital, St Leonards, NSW, 2065, Australia.diana.bond@sydney.edu.au.

Editorial group: Cochrane Pregnancy and Childbirth Group.

Publication status and date: New search for studies and content updated (conclusions changed), published in Issue 3, 2017.

Citation: Bond DM, Middleton P, Levett KM, van der Ham DP, Crowther CA, Buchanan SL, Morris J. Planned early birth versus expectant management for women with preterm prelabour rupture of membranes prior to 37 weeks' gestation for improving pregnancy outcome. Cochrane Database of Systematic Reviews 2017, Issue 3. Art. No.: CD004735. DOI: 10.1002/14651858.CD004735.pub4.

Copyright @ 2017 The Cochrane Collaboration. Published by John Wiley \& Sons, Ltd.

\section{A B S T R A C T}

\section{Background}

Current management of preterm prelabour rupture of the membranes (PPROM) involves either initiating birth soon after PPROM or, alternatively, adopting a 'wait and see' approach (expectant management). It is unclear which strategy is most beneficial for mothers and their babies. This is an update of a Cochrane review published in 2010 (Buchanan 2010).

\section{Objectives}

To assess the effect of planned early birth versus expectant management for women with preterm prelabour rupture of the membranes between 24 and 37 weeks' gestation for fetal, infant and maternal well being.

\section{Search methods}

We searched Cochrane Pregnancy and Childbirth's Trials Register (30 September 2016), and reference lists of retrieved studies.

\section{Selection criteria}

Randomised controlled trials comparing planned early birth with expectant management for women with PPROM prior to 37 weeks' gestation. We excluded quasi-randomised trials.

\section{Data collection and analysis}

Two review authors independently evaluated trials for inclusion into the review and for methodological quality. Two review authors independently extracted data. We checked data for accuracy. We assessed the quality of evidence using the GRADE approach. 


\section{Main results}

We included 12 trials in the review (3617 women and 3628 babies). For primary outcomes, we identified no clear differences between early birth and expectant management in neonatal sepsis (risk ratio (RR) 0.93, 95\% confidence interval (Cl) 0.66 to $1.30,12$ trials, 3628 babies, evidence graded moderate), or proven neonatal infection with positive blood culture (RR $1.24,95 \% \mathrm{Cl} 0.70$ to 2.21 , seven trials, 2925 babies). However, early birth increased the incidence of respiratory distress syndrome (RDS) (RR $1.26,95 \% \mathrm{Cl} 1.05$ to $1.53,12$ trials, 3622 babies, evidence graded high). Early birth was also associated with an increased rate of caesarean section (RR $1.26,95 \% \mathrm{Cl} 1.11$ to 1.44, 12 trials, 3620 women, evidence graded high).

Assessment of secondary perinatal outcomes showed no clear differences in overall perinatal mortality (RR $1.76,95 \% \mathrm{Cl} 0.89$ to $3.50,11$ trials, 3319 babies), or intrauterine deaths (RR $0.45,95 \% \mathrm{Cl} 0.13$ to $1.57,11$ trials, 3321 babies) when comparing early birth with expectant management. However, early birth was associated with a higher rate of neonatal death (RR 2.55, 95\% Cl 1.17 to $5.56,11$ trials, 3316 babies) and need for ventilation (RR 1.27, 95\% Cl 1.02 to 1.58, seven trials, 2895 babies, evidence graded high). Babies of women randomised to early birth were delivered at a gestational age lower than those randomised to expectant management (mean difference (MD) - 0.48 weeks, $95 \% \mathrm{Cl}-0.57$ to -0.39 , eight trials, 3139 babies). Admission to neonatal intensive care was more likely for those babies randomised to early birth (RR $1.16,95 \% \mathrm{Cl} 1.08$ to 1.24 , four trials, 2691 babies, evidence graded moderate).

In assessing secondary maternal outcomes, we found that early birth was associated with a decreased rate of chorioamnionitis (RR 0.50 , $95 \% \mathrm{Cl} 0.26$ to 0.95 , eight trials, 1358 women, evidence graded moderate), and an increased rate of endometritis ( $\mathrm{RR} 1.61,95 \% \mathrm{Cl} 1.00$ to 2.59, seven trials, 2980 women). As expected due to the intervention, women randomised to early birth had a higher chance of having an induction of labour (RR $2.18,95 \% \mathrm{Cl} 2.01$ to 2.36 , four trials, 2691 women). Women randomised to early birth had a decreased total length of hospitalisation (MD -1.75 days, $95 \% \mathrm{Cl}-2.45$ to -1.05 , six trials, 2848 women, evidence graded moderate).

Subgroup analyses indicated improved maternal and infant outcomes in expectant management in pregnancies greater than 34 weeks' gestation, specifically relating to RDS and maternal infections. The use of prophylactic antibiotics were shown to be effective in reducing maternal infections in women randomised to expectant management.

Overall, we assessed all 12 studies as being at low or unclear risk of bias. Some studies lacked an adequate description of methods and the risk of bias could only be assessed as unclear. In five of the studies there were one and/or two domains where the risk of bias was judged as high. GRADE profiling showed the quality of evidence across all critical outcomes to be moderate to high.

\section{Authors' conclusions}

With the addition of five randomised controlled trials (2927 women) to this updated review, we found no clinically important difference in the incidence of neonatal sepsis between women who birth immediately and those managed expectantly in PPROM prior to 37 weeks' gestation. Early planned birth was associated with an increase in the incidence of neonatal RDS, need for ventilation, neonatal mortality, endometritis, admission to neonatal intensive care, and the likelihood of birth by caesarean section, but a decreased incidence of chorioamnionitis. Women randomised to early birth also had an increased risk of labour induction, but a decreased length of hospital stay. Babies of women randomised to early birth were more likely to be born at a lower gestational age.

In women with PPROM before 37 weeks' gestation with no contraindications to continuing the pregnancy, a policy of expectant management with careful monitoring was associated with better outcomes for the mother and baby.

The direction of future research should be aimed at determining which groups of women with PPROM would not benefit from expectant management. This could be determined by analysing subgroups according to gestational age at presentation, corticosteroid usage, and abnormal vaginal microbiological colonisation. Research should also evaluate long-term neurodevelopmental outcomes of infants.

\section{PLAIN LANGUAGE SUMMARY}

\section{Is it better for the baby to be born immediately or wait for labour to start if the waters break without contractions before 37 weeks of pregnancy?}

\section{What is the issue?}

If a pregnant woman's waters break without contractions before 37 weeks of pregnancy there are two options: for the baby to be born as soon as possible, or to wait for labour to start naturally. We need to carefully look at the risks and benefits of both options.

\section{Why is this important?}

Being born too early can increase the chance of problems linked to prematurity, such as breathing difficulties and longer stays in the neonatal intensive care unit. However, staying in the womb may cause infections for both mother and baby that can lead to serious health problems and even death. This review aims to find out which is the best option.

\section{What evidence did we find?}


We included 12 trials that involved 3617 women with preterm prelabour rupture of the membranes. Women were randomly selected to either early birth or expectant management (wait for birth).The women were between 25 to 37 weeks of pregnancy. The studies happened in 16 countries between 1977 and 2013. Overall, the 12 studies were assessed as being at low or unclear risk of bias and the evidence was of moderate to high quality.

We found no difference in the rate of infant infection or infant death before birth between the two groups. However, early birth increased the risk of infant death after birth, as well as breathing problems, with the newborn needing extra help to breathe. The babies of women who had a planned early birth were more likely to be admitted to neonatal intensive care, and were born earlier than babies of women who waited to give birth. Early birth also increased the rate of caesarean section, induction of labour and the risk of infection of the lining of the womb but decreased the risk of infection in the membranes. Women had a longer hospital stay if they were randomised to waiting.

\section{What does this mean?}

In women whose waters break before 37 weeks of pregnancy, waiting for labour to begin naturally is the best option for healthier outcomes, as long as there are no other reasons why the baby should be born immediately. 


\section{S U M M ARY O F F I N D I N G}

Summary of findings for the main comparison. Planned early birth compared to expectant management for preterm prelabour rupture of membranes prior to 37 weeks' gestation

Planned early birth compared to expectant management for preterm prelabour rupture of membranes prior to 37 weeks' gestation

Patient or population: women with preterm prelabour rupture of membranes prior to 37 weeks' gestation

Settings: USA, the Netherlands, Mexico, Albania, Australia, New Zealand, Argentina, South Africa, Brazil, UK, Norway, Egypt, Uruguay, Poland, and Romania

Intervention: planned early birth

Comparison: expectant management

\begin{tabular}{|c|c|c|c|c|c|c|}
\hline \multirow[t]{3}{*}{ Outcomes } & \multicolumn{2}{|c|}{ Illustrative comparative risks ${ }^{\star}(95 \% \mathrm{CI})$} & \multirow{3}{*}{$\begin{array}{l}\text { Relative effect } \\
(95 \% \mathrm{CI})\end{array}$} & \multirow{3}{*}{$\begin{array}{l}\text { No of partici- } \\
\text { pants } \\
\text { (studies) }\end{array}$} & \multirow{3}{*}{$\begin{array}{l}\text { Quality of the } \\
\text { evidence } \\
\text { (GRADE) }\end{array}$} & \multirow[t]{3}{*}{ Comments } \\
\hline & Assumed risk & Corresponding risk & & & & \\
\hline & $\begin{array}{l}\text { Expectant manage- } \\
\text { ment }\end{array}$ & Planned early birth & & & & \\
\hline \multirow{2}{*}{$\begin{array}{l}\text { Neonatal infec- } \\
\text { tion/sepsis } \\
\text { Follow-up: } 28 \text { days }\end{array}$} & \multicolumn{2}{|l|}{ Study population } & \multirow{2}{*}{$\begin{array}{l}\text { RR } 0.93 \\
(0.66 \text { to } 1.3)\end{array}$} & \multirow{2}{*}{$\begin{array}{l}3628 \\
\text { (12 studies) }\end{array}$} & \multirow{2}{*}{$\begin{array}{l}\oplus \oplus \oplus \ominus \\
\text { moderate } 1\end{array}$} & \\
\hline & 37 per 1000 & $\begin{array}{l}34 \text { per } 1000 \\
\text { ( } 24 \text { to } 48)\end{array}$ & & & & \\
\hline \multirow{2}{*}{$\begin{array}{l}\text { Neonatal respiratory } \\
\text { distress syndrome } \\
\text { Follow-up: } 28 \text { days }\end{array}$} & \multicolumn{2}{|l|}{ Study population } & \multirow{2}{*}{$\begin{array}{l}\text { RR } 1.26 \\
\text { (1.05 to } 1.53)\end{array}$} & \multirow{2}{*}{$\begin{array}{l}3622 \\
\text { (12 studies) }\end{array}$} & \multirow{2}{*}{$\begin{array}{l}\oplus \oplus \oplus \oplus \\
\text { high }\end{array}$} & \\
\hline & 84 per 1000 & $\begin{array}{l}109 \text { per } 1000 \\
\text { (89 to } 131)\end{array}$ & & & & \\
\hline \multirow[t]{2}{*}{ Need for ventilation } & \multicolumn{2}{|l|}{ Study population } & \multirow{2}{*}{$\begin{array}{l}\text { RR } 1.27 \\
\text { (1.02 to } 1.58)\end{array}$} & \multirow{2}{*}{$\begin{array}{l}2895 \\
\text { (7 studies) }\end{array}$} & \multirow{2}{*}{$\begin{array}{l}\oplus \oplus \oplus \oplus \\
\text { high }\end{array}$} & \\
\hline & 86 per 1000 & $\begin{array}{l}\mathbf{1 1 0} \text { per } 1000 \\
(88 \text { to } 136)\end{array}$ & & & & \\
\hline \multirow{2}{*}{$\begin{array}{l}\text { Admission to neonatal } \\
\text { intensive care } \\
\text { Follow-up: } 28 \text { days }\end{array}$} & \multicolumn{2}{|l|}{ Study population } & \multirow{2}{*}{$\begin{array}{l}\text { RR } 1.16 \\
\text { (1.08 to } 1.24)\end{array}$} & \multirow{2}{*}{$\begin{array}{l}2691 \\
\text { (4 studies) }\end{array}$} & \multirow{2}{*}{$\begin{array}{l}\oplus \oplus \oplus \ominus \\
\text { moderate } 1\end{array}$} & \\
\hline & 428 per 1000 & $\begin{array}{l}497 \text { per } 1000 \\
\text { (462 to } 531)\end{array}$ & & & & \\
\hline \multirow[t]{2}{*}{ Caesarean section } & \multicolumn{2}{|l|}{ Study population } & \multirow{2}{*}{$\begin{array}{l}\text { RR } 1.26 \\
\text { (1.11 to } 1.44)\end{array}$} & \multirow{2}{*}{$\begin{array}{l}3620 \\
\text { (12 studies) }\end{array}$} & \multirow{2}{*}{$\begin{array}{l}\oplus \oplus \oplus \oplus \\
\text { high }\end{array}$} & \\
\hline & 172 per 1000 & $\begin{array}{l}\mathbf{2 1 7} \text { per } \mathbf{1 0 0 0} \\
\text { (191 to } 248)\end{array}$ & & & & \\
\hline
\end{tabular}




\begin{tabular}{|c|c|c|c|c|c|c|c|}
\hline \multirow{3}{*}{\multicolumn{2}{|c|}{ 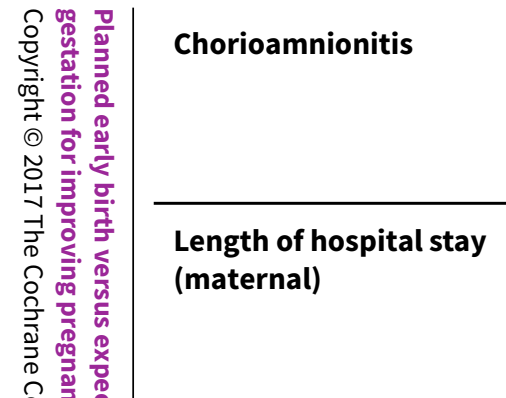 }} & \multicolumn{2}{|l|}{ Study population } & \multirow{2}{*}{$\begin{array}{l}\text { RR } 0.50 \\
\text { (0.26 to } 0.95 \text { ) }\end{array}$} & \multirow{2}{*}{$\begin{array}{l}1358 \\
\text { (8 studies) }\end{array}$} & \multirow{2}{*}{$\begin{array}{l}\oplus \oplus \oplus \ominus \\
\text { moderate } 2\end{array}$} & \multirow{8}{*}{ 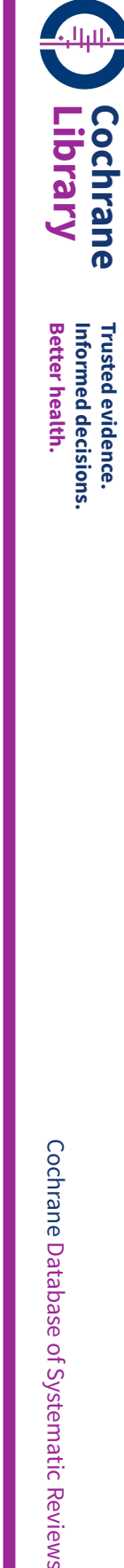 } \\
\hline & & 103 per 1000 & $\begin{array}{l}\mathbf{5 1} \text { per } 1000 \\
\text { (27 to } 98)\end{array}$ & & & & \\
\hline & & $\begin{array}{l}\text { The mean length of } \\
\text { hospital stay (mater- } \\
\text { nal) in the expectant } \\
\text { group was } \\
\mathbf{7 . 6} \text { days }\end{array}$ & $\begin{array}{l}\text { The mean length of hospital stay (ma- } \\
\text { ternal) in the early birth group was } \\
\mathbf{1 . 7 5} \text { days lower } \\
\text { (2.45 to } 1.05 \text { lower) }\end{array}$ & $\begin{array}{l}\text { MD }-\mathbf{1 . 7 5}(-2.45 \text { to } \\
-1.05)\end{array}$ & $\begin{array}{l}2848 \\
\text { (6 studies) }\end{array}$ & $\begin{array}{l}\oplus \oplus \oplus \ominus \\
\text { moderate } 3\end{array}$ & \\
\hline \multirow{5}{*}{ 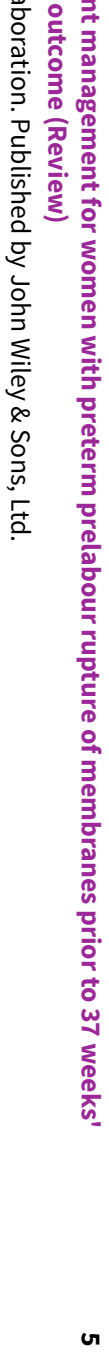 } & \multicolumn{6}{|c|}{$\begin{array}{l}\text { *The basis for the assumed risk (e.g. the median control group risk across studies) is provided in footnotes. The corresponding risk (and its } 95 \% \text { confidence interval) is } \\
\text { based on the assumed risk in the comparison group and the relative effect of the intervention (and its } 95 \% \mathrm{Cl} \text { ). } \\
\text { CI: Confidence interval; RR: Risk ratio; }\end{array}$} & \\
\hline & \multicolumn{6}{|c|}{$\begin{array}{l}\text { GRADE Working Group grades of evidence } \\
\text { High quality: Further research is very unlikely to change our confidence in the estimate of effect. } \\
\text { Moderate quality: Further research is likely to have an important impact on our confidence in the estimate of effect and may change the estimate. } \\
\text { Low quality: Further research is very likely to have an important impact on our confidence in the estimate of effect and is likely to change the estimate. } \\
\text { Very low quality: We are very uncertain about the estimate. }\end{array}$} & \\
\hline & \multirow{2}{*}{\multicolumn{6}{|c|}{$\begin{array}{l}\text { 1Wide confidence interval crossing the line of no effect, and the lines of appreciable benefit and harm. } \\
\text { 2Some statistical heterogeneity }\left(I^{2}=48 \%\right) \text {. } \\
\text { 3Statistical heterogeneity: } I^{2}=63 \% \text {, likely due to differences in women's management. }\end{array}$}} & \\
\hline & & & & & & & \\
\hline & & & & & & & \\
\hline
\end{tabular}




\section{B A C K G R O U N D}

\section{Description of the condition}

Preterm prelabour rupture of the membranes (PPROM) occurs when there is rupture of the membranes prior to term and prior to the onset of labour. PPROM complicates pregnancy for $1 \%$ to $2 \%$ of all women and is associated with $30 \%$ to $40 \%$ of preterm births (less than 37 weeks) (Arias 1982; Lee 2001; Mercer 2000; Mercer 2005).

\section{Description of the intervention}

The purpose of this review is to determine the optimal management for women and their babies with pregnancies complicated by PPROM. This could either be planned delivery soon after rupture of the membranes or expectant management. Planned early birth involves the birth of the baby near to the time of rupture of the membranes and may be by induction of labour or caesarean section. Expectant management involves observation of the mother and baby and awaiting the spontaneous onset of labour in the absence of any complications that may necessitate delivery. Women with PPROM who are managed expectantly may then have the delivery of their baby planned for term if labour has not ensued.

\section{How the intervention might work}

The management of PPROM is dependent upon the gestation at which rupture of the membranes occurs. The health benefits for the fetus in continuing a pregnancy after PPROM may be considerable, particularly in the late second and early third trimesters. However, there is currently no consensus as to the optimal management of PPROM in women in whom the fetus is relatively mature, at gestations near to term such as in the late second trimester and third trimester of pregnancy. The aim of care for women with PPROM is to maximise the benefits of further fetal maturity while avoiding the potential harms of remaining in utero.

There are treatments such as antibiotics and antenatal corticosteroids that can reduce associated complications for the mother and baby in pregnancies complicated by PPROM. The use of antibiotics in PPROM significantly improves neonatal and maternal morbidity including prolongation of pregnancy, reduction in neonatal infection, reduced need for oxygen therapy and less risk of abnormal cerebral ultrasound (Kenyon 2001; Kenyon 2003). In addition, antenatal corticosteroids have been shown to reduce the risk of neonatal respiratory distress, intraventricular haemorrhage (bleeding within the ventricles of the baby's brain) and neonatal death in the preterm neonate (Roberts 2006). These beneficial effects of corticosteroids also apply to women with PPROM (Harding 2001).

\section{Why it is important to do this review}

There are recognised maternal and fetal risks associated with PPROM. These complications decrease the nearer to term that PPROM occurs. The recognised complications include ascending infection, cord prolapse (prolapsing of the umbilical cord through the cervix), intrapartum fetal distress and abruption (premature detachment of the placenta from the uterine wall) (Gonen 1989; Major 1995; Mercer 2003). It may be that managing PPROM expectantly by awaiting the spontaneous onset of labour increases the risk to the fetus of these complications. In particular prolonged exposure to intrauterine infection is of major concern for the neonate. In fact it has been demonstrated that neonatal sepsis is twice as common in the setting of PPROM compared with preterm birth after preterm labour with intact membranes (Seo 1992).

There are potential risks associated with planned early delivery in pregnancies complicated by PPROM between 30 and 37 weeks' gestation. In particular the attendant risks of iatrogenic prematurity associated with birth before term but greater than 30 weeks' gestation are significant. These complications may include respiratory distress (Jones 2000; Lewis 1996), sepsis, necrotising enterocolitis (injury to the bowel of newborn babies), intraventricular haemorrhage, prolonged stays in the neonatal nursery, difficulty with thermoregulation and difficulty with breastfeeding (Engle 2008; Robertson 1992). These complications are less common when delivery occurs after 32 weeks' gestation (Mercer 2003). A number of retrospective studies have similarly found a decrease in neonatal morbidity associated with birth at 34 weeks' gestation (Lewis 1996; Neerhof 1999). The incidence of respiratory distress syndrome, hyperbilirubinaemia (high bilirubin within in the babies' blood which results in a yellow discolouration of the neonates' skin referred to as jaundice) and duration of stay in the neonatal nursery was significantly reduced in infants born after 34 weeks' gestation compared with those born before 34 weeks (Lewis 1996; Neerhof 1999). Infants born beyond 34 weeks' gestation do have better outcomes than those born prior to 34 weeks, however those babies born between 34 and 37 weeks' gestation are still physiologically immature and as such do have significantly increased morbidity and mortality as compared with those infants born at term (Engle 2007; Engle 2008).

The previous version of this review (Buchanan 2010), which included seven trials and 690 women, found there was insufficient evidence available at that time to guide clinical practice and that all included trials had methodological weaknesses.

There is consensus on the management of term pregnancies with PROM (prelabour rupture of the membranes) (Middleton 2017). This Cochrane review found that fewer women in the planned compared with the expectant management groups had chorioamnionitis (inflammation of the fetal membranes) and/or endometritis (a postpartum infection of the lining of the womb) (average risk ratio (RR) $0.49,95 \%$ confidence interval $(\mathrm{Cl}) 0.33$ to 0.72 , eight trials, 6864 women). Additionally, early birth appeared to reduce the likelihood of definite or probable early-onset neonatal sepsis (RR 0.73, 95\% $\mathrm{Cl} 0.58$ to 0.92 , sixteen trials, 7314 infants). There was no clear difference in the mode of birth between the groups.

It is evident that there is an increased incidence of chorioamnionitis associated with expectant management in women with PROM (Hannah 1996). Histological evidence of chorioamnionitis is present in up to $50 \%$ of women who deliver preterm and is often not associated with clinical symptoms or signs. Chorioamnionitis is a known significant risk factor for the development of both cystic periventricular leukomalacia (cystic changes around the ventricles of the babies brain) and cerebral palsy (Gaudet 2001; Wu 2000). Therefore, the question remains as to whether there is an increased chance of an adverse neurological outcome in those infants whose mothers are managed expectantly with PPROM by increasing their duration of exposure to often subclinical chorioamnionitis.

The objective of this review is to assess and further define the optimal management for women with PPROM prior to 37 weeks' gestation. 


\section{O B JECTIVES}

To assess the effect of planned early birth versus expectant management for women with preterm prelabour rupture of the membranes between 24 and 37 weeks' gestation for fetal, infant and maternal well being.

\section{METHOD S}

\section{Criteria for considering studies for this review \\ Types of studies}

We considered for inclusion all identified randomised controlled trials (RCTs) comparing planned early birth versus expectant management for women with preterm prelabour rupture of the membranes (PPROM) prior to 37 weeks' gestation. We did not consider quasi-randomised studies for inclusion in the review. We also assessed for inclusion studies that were presented in abstract form only.

In studies in which gestational ages overlapped the lessthan-37-week gestation inclusion criteria, we attempted to extract gestational age-specific data from the studies. We also attempted to contact researchers to provide further information.

\section{Types of participants}

Women with PPROM before 37 weeks' gestation with no specific maternal or fetal contraindications to expectant management.

\section{Types of interventions}

Planned early birth compared with expectant management.

Planned early birth is planned birth soon after PPROM. The mode of birth may either be via induction of labour by any means and a vaginal birth, or by caesarean section.

Expectant management involves planning to wait for birth until the baby is at term.

\section{Types of outcome measures}

\section{Primary outcomes}

Neonatal infection/sepsis:

- proven neonatal infection with positive blood culture within 48 hours of birth;

- proven neonatal infection with positive blood culture 48 hours or more after birth.

Respiratory distress syndrome

Caesarean section

\section{Secondary outcomes}

\section{Fetal/perinatal outcomes}

Perinatal death

Intrauterine death

Cord prolapse

Gestational age at birth

\section{Neonatal outcomes}

Neonatal death
Suspected neonatal infection

Treatment with antibiotics

Treatment with surfactant

Need for ventilation

Days of neonatal ventilation

Duration of oxygen therapy

Oxygen therapy at 36 weeks' postmenstrual age

Cord arterial $\mathrm{pH}$

Birthweight

Apgar score less than 7 at five minutes

Abnormality on cerebral ultrasound:

- cystic periventricular leukomalacia;

- cerebroventricular haemorrhage (including grade of intraventricular haemorrhage).

Necrotising enterocolitis

Admission to neonatal intensive care unit

Admission to neonatal intensive care unit after 24 hours

Length of stay in neonatal intensive care unit

Days from birth to discharge home from hospital

Disability at time of childhood follow-up

\section{Maternal outcomes}

Chorioamnionitis

Endometritis

Postpartum fever

Placental abruption

Induction of labour

Mode of induction of labour

Use of epidural anaesthesia

Vaginal birth

Operative vaginal birth

Caesarean section for fetal distress

Duration of hospitalisation:

- days of antenatal hospitalisation;

- days of postnatal hospitalisation.

Maternal satisfaction:

- views of care;

- preferences of care;

- presence of postnatal depression.

Breastfeeding:

- whether breastfeeding established

- time after birth breastfeeding established.

\section{Search methods for identification of studies}

The following methods section of this review is based on a standard template used by Cochrane Pregnancy and Childbirth.

\section{Electronic searches}

We searched Cochrane Pregnancy and Childbirth's Trials Register by contacting their Information Specialist (30 September 2016).

The Register is a database containing over 22,000 reports of controlled trials in the field of pregnancy and childbirth. For full search methods used to populate Pregnancy and Childbirth's Trials Register including the detailed search strategies for CENTRAL,

Planned early birth versus expectant management for women with preterm prelabour rupture of membranes prior to 37 weeks' 
MEDLINE, Embase and CINAHL; the list of handsearched journals and conference proceedings, and the list of journals reviewed via the current awareness service, please follow this link to the editorial information about the Cochrane Pregnancy and Childbirth in the Cochrane Library and select the 'Specialized Register' section from the options on the left side of the screen.

Briefly, Cochrane Pregnancy and Childbirth's Trials Register is maintained by their Information Specialist and contains trials identified from:

1. monthly searches of the Cochrane Central Register of Controlled Trials (CENTRAL);

2. weekly searches of MEDLINE (Ovid);

3. weekly searches of Embase (Ovid);

4. monthly searches of CINAHL (EBSCO);

5. handsearches of 30 journals and the proceedings of major conferences;

6. weekly current awareness alerts for a further 44 journals plus monthly BioMed Central email alerts.

Two people screen search results and review the full text of all relevant trial reports identified through the searching activities described above. Based on the intervention described, each trial report is assigned a number that corresponds to a specific Pregnancy and Childbirth review topic (or topics), and is then added to the Register. The Information Specialist searches the Register for each review using this topic number rather than keywords. This results in a more specific search set which has been fully accounted for in the relevant review sections (Included studies; Excluded studies; Ongoing studies).

For the 2010 update (Buchanan 2010), we carried out additional author searching. See Appendix 1 for details.

\section{Searching other resources}

We searched reference lists of trials and other review articles. We contacted researchers to provide further information as required. We did not apply any language or date restrictions.

\section{Data collection and analysis}

For the methods used when assessing the trials identified in the previous version of this review, see Buchanan 2010.

For this update, we used the following methods for assessing the 11 additional reports that were identified as a result of the updated search.

The following methods section of this review is based on a standard template used by Cochrane Pregnancy and Childbirth.

\section{Selection of studies}

Two review authors independently assessed for inclusion all the potential studies identified as a result of the search strategy. We resolved any disagreement through discussion or, if required, we consulted a third review author.

\section{Data extraction and management}

We designed a form to extract data based on Cochrane Pregnancy and Childbirth recommendations. For eligible studies, two review authors (DB and JM) extracted the data using the agreed form.
We resolved discrepancies through discussion or, if required, we consulted the third review author (KL). One author (DB) entered data into Review Manager 5 (RevMan) software (RevMan 2014) and two others checked for accuracy (JM, KL).

David $\mathrm{P}$ van der Ham was Chief Investigator and first author of the PPROMEXIL trials and So JM and DB were responsible for data extraction and assessment of all trial reports relating to this study. Jonathan Morris was the Chief Investigator and first author for the NHMRC- (National Health and Medical Research Council) funded PPROMT trial and so data was assessed and extracted independently by PM.

When information regarding any of the above was unclear, we contacted authors of the original reports to provide further details.

\section{Assessment of risk of bias in included studies}

Two review authors (DB and $\mathrm{KL}$ ) independently assessed risk of bias for each study using the criteria outlined in the Cochrane Handbook for Systematic Reviews of Interventions (Higgins 2011). We resolved any disagreement by discussion or by involving a third assessor.

\section{(1) Random sequence generation (checking for possible selection bias)}

We described for each included study the method used to generate the allocation sequence in sufficient detail to allow an assessment of whether it should produce comparable groups.

We have assessed the method as:

- low risk of bias (any truly random process, e.g. random number table; computer random number generator);

- high risk of bias (any non-random process, e.g. odd or even date of birth; hospital or clinic record number);

- unclear risk of bias.

\section{(2) Allocation concealment (checking for possible selection bias)}

We described for each included study the method used to conceal allocation to interventions prior to assignment and assessed whether intervention allocation could have been foreseen in advance of, or during recruitment, or changed after assignment.

We have assessed the methods as:

- low risk of bias (e.g. telephone or central randomisation; consecutively numbered sealed opaque envelopes);

- high risk of bias (open random allocation; unsealed or nonopaque envelopes, alternation; date of birth);

- unclear risk of bias.

\section{(3.1) Blinding of participants and personnel (checking for possible performance bias)}

We described for each included study the methods used, if any, to blind study participants and personnel from knowledge of which intervention a participant received. We considered that studies were at low risk of bias if they were blinded, or if we judged that the lack of blinding was unlikely to affect results. We assessed blinding separately for different outcomes or classes of outcomes.

We have assessed the methods as:

Planned early birth versus expectant management for women with preterm prelabour rupture of membranes prior to 37 weeks 
- low, high or unclear risk of bias for participants;

- low, high or unclear risk of bias for personnel.

\section{(3.2) Blinding of outcome assessment (checking for possible detection bias)}

We described for each included study the methods used, if any, to blind outcome assessors from knowledge of which intervention a participant received. We assessed blinding separately for different outcomes or classes of outcomes.

We have assessed methods used to blind outcome assessment as:

- low, high or unclear risk of bias.

\section{(4) Incomplete outcome data (checking for possible attrition bias due to the amount, nature and handling of incomplete outcome data)}

We described for each included study, and for each outcome or class of outcomes, the completeness of data including attrition and exclusions from the analysis. We stated whether attrition and exclusions were reported and the numbers included in the analysis at each stage (compared with the total randomised participants), reasons for attrition or exclusion where reported, and whether missing data were balanced across groups or were related to outcomes. Where sufficient information was reported, or could be supplied by the trial authors, we planned to re-include missing data in the analyses that we undertook.

We have assessed methods as:

- low risk of bias (e.g. no missing outcome data; missing outcome data balanced across groups);

- high risk of bias (e.g. numbers or reasons for missing data imbalanced across groups; 'as treated' analysis done with substantial departure of intervention received from that assigned at randomisation);

- unclear risk of bias.

\section{(5) Selective reporting (checking for reporting bias)}

We described for each included study how we investigated the possibility of selective outcome reporting bias and what we found.

We have assessed the methods as:

- low risk of bias (where it was clear that all of the study's prespecified outcomes and all expected outcomes of interest to the review were reported);

- high risk of bias (where not all the study's pre-specified outcomes were reported; one or more reported primary outcomes were not pre-specified; outcomes of interest were reported incompletely and so could not be used; study failed to include results of a key outcome that would have been expected to have been reported);

- unclear risk of bias.

(6) Other bias (checking for bias due to problems not covered by (1) to (5) above)

We described for each included study any important concerns we had about other possible sources of bias.

\section{(7) Overall risk of bias}

We made explicit judgements about whether studies were at high risk of bias, according to the criteria given in the Handbook for Systematic Reviews of Interventions (Higgins 2011). With reference to (1) to (6) above, we assessed the likely magnitude and direction of the bias and whether we considered it likely to impact on the findings. In future updates, we will explore the impact of the level of bias through undertaking sensitivity analyses - see Sensitivity analysis.

\section{Assessment of the quality of evidence using the GRADE approach}

For this update we assessed the quality of the evidence using the GRADE approach as outlined in the GRADE handbook in order to assess the quality of the body of evidence relating to the following outcomes for the main comparisons.

- Neonatal infection/sepsis

- Neonatal respiratory distress syndrome

- Need for ventilation

- Admission to neonatal intensive care

- Caesarean section

- Chorioamnionitis

- Length of hospital stay (maternal)

We used the GRADEproGDT (GRADEpro Guideline Development Tool) to import data from RevMan 5.3 (RevMan 2014) to create 'Summary of findings' tables. We produced a summary of the intervention effect and a measure of quality for each of the above outcomes using the GRADE approach. The GRADE approach uses five considerations (study limitations, consistency of effect, imprecision, indirectness and publication bias) to assess the quality of the body of evidence for each outcome. The evidence can be downgraded from 'high quality' by one level for serious (or by two levels for very serious) limitations, depending on assessments for risk of bias, indirectness of evidence, serious inconsistency, imprecision of effect estimates or potential publication bias.

\section{Measures of treatment effect}

\section{Dichotomous dato}

For dichotomous data, we presented results as summary risk ratio (RR) with $95 \%$ confidence intervals $(\mathrm{Cl})$.

\section{Continuous dato}

We used the mean difference (MD) if outcomes were measured in the same way between trials. In future updates if appropriate, we will use the standardised mean difference to combine trials that measure the same outcome, but use different methods.

\section{Unit of analysis issues}

We considered trials including twin pregnancies for inclusion in the review. For trials that included twin pregnancies, for fetal outcomes the denominator used for analysis was the number of pregnancies. However, for neonatal outcomes the denominator used for analysis was the number of individual babies randomised.

\section{Cluster-randomised trials}

Cluster-randomised trials were not eligible for inclusion in this review. 


\section{Cross-over trials}

Cross-over trials were not eligible for inclusion in this review.

\section{Dealing with missing data}

For included studies, we noted levels of attrition. In future updates, if more eligible studies are included, we will explore the impact of including studies with high levels of missing data in the overall assessment of treatment effect by using sensitivity analysis.

For all outcomes, we carried out analyses, as far as possible, on an intention-to-treat basis, that is, we attempted to include all participants randomised to each group in the analyses. The denominator for each outcome in each trial was the number randomised minus any participants whose outcomes were known to be missing.

\section{Assessment of heterogeneity}

We assessed statistical heterogeneity in each meta-analysis using the $\mathrm{Tau}^{2}, \mathrm{I}^{2}$ (Higgins 2003) and $\mathrm{Chi}^{2}$ statistics. We regarded heterogeneity as substantial if $\mathrm{I}^{2}$ was greater than $30 \%$ and either $\mathrm{Tau}^{2}$ was greater than zero, or there was a low $\mathrm{P}$ value (less than 0.10 ) in the $\mathrm{Chi}^{2}$ test for heterogeneity. If we identified substantial heterogeneity (above 50\%), we planned to explore it by prespecified subgroup analysis (Deeks 2011).

\section{Assessment of reporting biases}

In this update, if there were 10 or more studies in the metaanalysis, we investigated reporting biases (such as publication bias) using funnel plots. We assessed funnel plot asymmetry visually. If asymmetry was suggested by a visual assessment, we planned to perform an exploratory analyses to investigate it (Sterne 2011).

\section{Data synthesis}

We carried out statistical analysis using the RevMan software (RevMan 2014). We used fixed-effect meta-analysis for combining data where it was reasonable to assume that studies were estimating the same underlying treatment effect: that is, where trials were examining the same intervention, and the trials' populations and methods were judged sufficiently similar.

If there was clinical heterogeneity sufficient to expect that the underlying treatment effects differed between trials, or if substantial statistical heterogeneity was detected, we used random-effects meta-analysis to produce an overall summary if an average treatment effect across trials was considered clinically meaningful. We treated the random-effects summary as the average range of possible treatment effects and we discussed the clinical implications of treatment effects differing between trials. If the average treatment effect was not clinically meaningful, we did not combine trials. If we used random-effects analyses, we presented the results as the average treatment effect with $95 \%$ confidence intervals, and the estimates of Tau ${ }^{2}$ and $\mathrm{I}^{2}$ tests.

\section{Subgroup analysis and investigation of heterogeneity}

If we identified substantial heterogeneity, we investigated it using subgroup analyses and sensitivity analyses. We considered whether an overall summary was meaningful, and if it was, we used random-effects analysis to produce it.
We carried out the following subgroup analyses.

- Corticosteroid usage versus no corticosteroid usage

- Gestational age at randomisation with stratification into:

* less than 30 weeks' gestation

* 30 to 33 plus 6 weeks' gestation

* 34 to 37 weeks' gestation

- Antibiotic usage versus no antibiotic usage

- Time from randomisation to early birth: less than 24 hours versus greater than 24 hours

We used the following outcomes in subgroup analyses.

\section{Fetal/neonatal outcomes}

Neonatal infection

Neonatal infection confirmed with positive blood culture Respiratory distress syndrome

\section{Maternal outcomes}

Caesarean section

Chorioamnionitis

Endometritis

We assessed subgroup differences by interaction tests available within RevMan (RevMan 2014). We reported the results of subgroup analyses quoting the $\mathrm{Chi}^{2}$ statistic and $\mathrm{P}$ value, and the interaction test $I^{2}$ value.

\section{Sensitivity analysis}

We included all eligible trials in the initial analysis and planned to carry out sensitivity analyses to evaluate the effect of trial quality. We also planned to perform a sensitivity analysis based on the randomisation process, assessing the presence of blinding of assessors to the primary outcome, assessing the quality of treatment allocation and assessing the presence of losses to followup.

\section{RE S U L T S}

\section{Description of studies}

Refer to the Characteristics of included studies and Characteristics of excluded studies tables for further detailed information on individual studies.

\section{Results of the search}

The search of the Cochrane Pregnancy and Childbirth's Trials Register retrieved 14 additional reports for consideration in this updated review, which contributed four additional studies to the review. Five of the reports were based on one study (Morris 2016), six on another (Van der Ham 2012a), four on the third (Van der Ham 2012b) and one on the fourth (Koroveshi 2013). We moved one study from 'excluded studies' in the first review to 'included studies' (Eroiz-Hernandez 1997) in this update as the authors felt the study fitted the inclusion criteria after translation into English. We moved another study from 'ongoing' to 'excluded' as the trial was terminated prematurely due to poor recruitment (Lacaze 2006). One study remained ongoing as we were unable to ascertain the current status (Pasquier 2006). See Figure 1. 
Figure 1. Study flow diagram

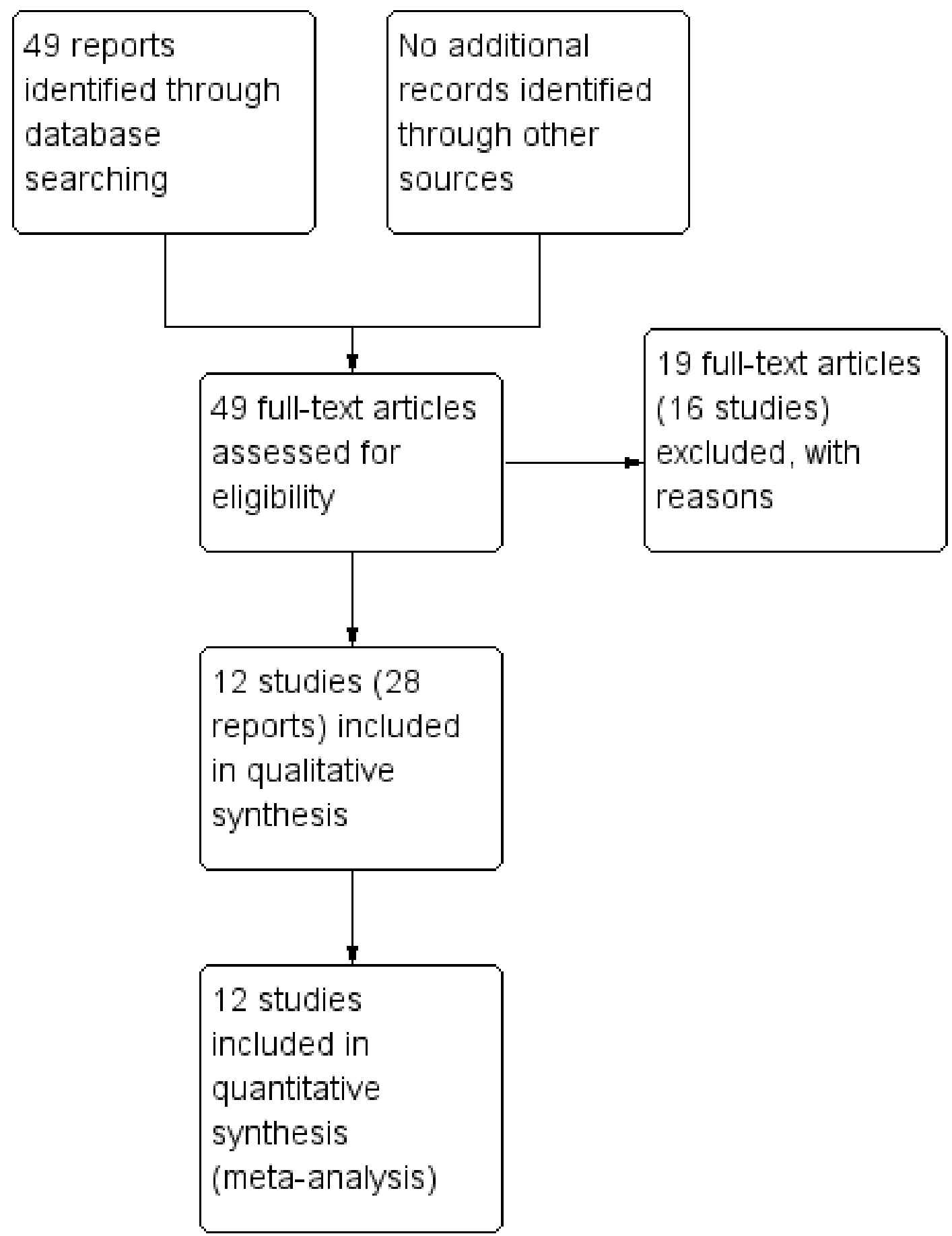

\section{Included studies}

We have included 12 randomised controlled trials in this review, which comprise 3617 women and 3628 babies (Cox 1995; EroizHernandez 1997; Garite 1981; lams 1985; Koroveshi 2013; Mercer 1993; Morris 2016; Naef 1998; Nelson 1985; Spinnato 1987; Van der Ham 2012a; Van der Ham 2012b). One study was performed in Albania (Koroveshi 2013), one in Mexico (Eroiz-Hernandez 1997), two in the Netherlands (Van der Ham 2012a; Van der Ham 2012b), and one, though based in Australia, included a total of 11 countries: Australia, Argentina, Brazil, Egypt, New Zealand, Norway, Poland,
Romania, South Africa, UK and Uruguay (Morris 2016). The other seven studies were performed in the USA. All but one of the included studies were reported in English, but we were able to translate the Mexican study (Eroiz-Hernandez 1997) from Spanish to English. Five studies recruited women from multiple sites (Garite 1981; Iams 1985; Morris 2016; Van der Ham 2012a; Van der Ham 2012b), while the remainder recruited from a single centre only (Cox 1995; Eroiz-Hernandez 1997; Koroveshi 2013; Mercer 1993; Nelson 1985; Naef 1998; Spinnato 1987). The studies were performed between 1977 and 2016. As Koroveshi 2013 was a

Planned early birth versus expectant management for women with preterm prelabour rupture of membranes prior to 37 weeks' 
published abstract only, this study provided limited information for this review and as a result has been excluded from most of the following discussion about participants, interventions and outcomes. Outcomes were included in the analysis only.

A summary of the trials is provided (Table 1 ).

\section{Participants}

The studies included women with pregnancies complicated by preterm prelabour rupture of the membranes (PPROM) of differing gestational ages. Eroiz-Hernandez 1997, Garite 1981, lams 1985 and Nelson 1985 included women with PPROM between 28 and 34 weeks' gestation, while Spinnato 1987 included women from 25 to 36 weeks' gestation. Cox 1995 included women with PPROM at 30 to 34 weeks' gestation. Mercer 1993 included women from 32 to 36 weeks' gestation, while Koroveshi 2013, Morris 2016, Naef 1998; Van der Ham 2012a and Van der Ham 2012b included women from 34 weeks' gestation to 36 weeks' plus six days' gestation. Three trials (Cox 1995; Van der Ham 2012a; Van der Ham 2012b) included twin pregnancies for a total of three pairs of twins randomised to early birth and eight pairs randomised to expectant management. One study (Eroiz-Hernandez 1997), although inclusion criteria specified singleton pregnancies only, reported outcomes for two sets of twins in each group in the analysis.

Importantly, the entry criteria also differed between the studies. Eroiz-Hernandez 1997, Garite 1981, lams 1985, Mercer 1993 and Spinnato 1987 required amniotic fluid sampling to assess fetal pulmonary maturity prior to study entry. Garite 1981 and lams 1985 used a mature lecithin-sphingomyelin (L/S) as an exclusion criteria and then treated the early birth group with corticosteroids, while in contrast Mercer 1993 and Spinnato 1987 used a mature L/S as an inclusion criteria and did not use antenatal corticosteroids. Eroiz-Hernandez 1997 excluded women with 'positive' fetal lung maturity tests based on "tap*, clements* and $650 \mathrm{~nm}$ spectrophotometry" ("we were unsure of the definition of these tests, which may have been an error in translation) and used a different fetal lung maturity protocol of intravenous aminophylline for each arm of the trial. They also required an amniotic fluid index of greater than $5 \mathrm{~cm}$ for trial inclusion. Cox 1995, Morris 2016, Nelson 1985, Naef 1998, Van der Ham 2012a and Van der Ham 2012b did not require documented pulmonary maturity prior to study entry. Exclusion criteria included active labour, chorioamnionitis or non-reassuring fetal status as assessed at the time of randomisation in all the studies. Morris 2016 included an additional broadly defined exclusion as being any other contraindications to continuing the pregnancy, while Van der Ham 2012a and Van der Ham 2012b more specifically included additional exclusion criteria as being: monochorionic multiple pregnancy; major fetal anomalies; haemolysis; elevated liver enzymes and low platelets (HELLP) syndrome; and severe pre-eclampsia (see Table 1).

All of the studies defined determination of gestational age for inclusion by menstrual history or early ultrasound examination to give the most accurate clinical estimate. In the absence of an accurate clinical estimate, seven of the studies used ultrasound at the time of presentation to hospital to date the pregnancy (Garite 1981; Morris 2016; Naef 1998; Nelson 1985; Spinnato 1987; Van der Ham 2012a; Van der Ham 2012b).
All of the trials defined ruptured membranes by clinical assessment with a sterile speculum examination and visualising amniotic fluid passing through the cervical os and pooling in the posterior fornix of the vagina. Six of the trials (Garite 1981; lams 1985; Mercer 1993; Naef 1998; Nelson 1985; Spinnato 1987) also confirmed the presence of PPROM with a Nitrazine test to demonstrate an alkaline $\mathrm{pH}$ and or ferning of a specimen of vaginal fluid on microscopy. Eroiz-Hernandez 1997 used 'cristallography' or the 'flame test' as an additional diagnosis.

Six of the included trials (Cox 1995; Garite 1981; lams 1985; Mercer 1993; Naef 1998; Spinnato 1987) did not allow digital cervical examinations to be performed in the absence of labour.

\section{Intervention}

The intervention assessed by these studies was the effect of early birth on maternal and fetal well being. The timing of intervention for early birth differed between the studies. The mean latency from PROM to birth in four studies (Cox 1995; Mercer 1993; Naef 1998; Spinnato 1987) indicated that birth was planned as soon as practicable from randomisation and less than 24 hours, although this was not explicitly stated in all the trials. One study (EroizHernandez 1997) did not indicate when birth was intended but results indicated a median latency of three days. Nelson 1985 planned for early birth between 24 and 48 hours after initial rupture of membranes and 24 hours after initiation of steroid therapy, while Garite 1981 defined planned early birth as 48 hours after treatment with corticosteroids. lams 1985 had an even longer delay in the early birth group and planned for early birth 48 to 72 hours after PPROM and initiation of steroid treatment. Morris 2016 defined timing of birth as birth scheduled as close to randomisation as possible and preferably within 24 hours. In both Van der Ham 2012a and Van der Ham 2012b women were randomised if not spontaneously delivered within 24 hours after initial rupture of membranes and women randomised to early birth were induced within 24 hours after randomisation.

The only study with a control arm of early birth for PPROM was Eroiz-Hernandez 1997. As a result, for the discussion and analysis, we flipped the definition and results for the 'treatment' group and the 'control' group in this study to be consistent with the rest of the studies, which all defined the control arm as being expectant management. The intention of expectant management was defined in the majority of studies as waiting until spontaneous labour or until there was medical indication to facilitate birth, such as infection or fetal distress. The exceptions were EroizHernandez 1997, Koroveshi 2013 and Nelson 1985, which did not specify the intent of expectant management, although EroizHernandez 1997 did indicate in an outcomes table that the reasons for delivery in the expectant management group were onset of labour, infection, oligohydramnios and fetal distress. lams 1985, Morris 2016, Spinnato 1987, Van der Ham 2012a and Van der Ham $2012 \mathrm{~b}$ allowed women to be discharged home at the discretion of the attending physician or according to local protocol, while the remainder of the studies required the women in the trial to be hospitalised until birth.

The co-interventions also differed between the included studies. Cox 1995, Mercer 1993, Naef 1998 and Spinnato 1987 did not treat the women with corticosteroids or tocolysis. Garite 1981 and lams 1985 treated women in the early birth groups with corticosteroids and tocolysis as required. Nelson 1985 randomised women to 
steroids or no steroid therapy in the early birth group. These women in the early birth group were also treated with tocolytics. Morris 2016 used tocolytics, antibiotics and corticosteroids according to local protocol, whereas Van der Ham 2012a and Van der Ham 2012b only used tocolytics and antibiotics according to local protocol, but gave corticosteroids to women with PPROM less than 34 weeks' gestation. Eroiz-Hernandez 1997 used tocolytics as well as a fetal lung maturity protocol of intravenous aminophylline in the early birth arm, which was repeated weekly in the women randomised to expectant management. Antibiotics were not used unless there were signs of chorioamnionitis, in which case birth was indicated. Naef 1998 was the only trial in which prophylactic antibiotics were used for all women. In this trial all women were treated with ampicillin.

\section{Outcomes}

Neonatal infection was variably defined in the studies. Cox 1995, Garite 1981 and Spinnato 1987 did not document their criteria required for documenting neonatal infection while EroizHernandez 1997, lams 1985, Mercer 1993, Morris 2016, Naef 1998, Nelson 1985, Van der Ham 2012a and Van der Ham 2012b required a positive culture of blood, cerebrospinal fluid or urine in addition to clinical features of sepsis for diagnosis.

Chorioamnionitis was defined in all of the studies as maternal temperature associated with uterine tenderness, maternal or fetal tachycardia, or both, and/or foul smelling amniotic fluid in the absence of any other cause of identifiable infection. None of the studies confirmed the presence of clinical chorioamnionitis pathologically with a histological examination of the placenta and fetal membranes. Eroiz-Hernandez 1997 additionally included in their diagnosis a leucocyte count of 15,000 in maternal blood at the start of the study or a $50 \%$ increase from the baseline reading.

\section{Excluded studies}

We excluded 16 studies from the review (see Characteristics of excluded studies). Fayez 1978 used a quasi-randomisation schema in which women were randomised to either early birth or expectant management based on odd or even hospital record numbers. We also excluded Parsons 1989 and Bergstrom 1991 as these were prospective but not randomised trials.

We excluded six trials (Cararach 1994; Gloeb 1989; Griffith-Jones 1990; Ladfors 1996; Mateos 1998; Van Heerden 1996) because the gestational age criteria for trial entry included women both prior to term and at term. We attempted to obtain information of the subgroup of women with PPROM prior to term in these trials; however, this was not successful.

We excluded another five studies because they assessed interventions other than the effect of birth on maternal and fetal well-being in women with PPROM (Decavalas 1995; El-Qarmalawi 1990; Haghighi 2006; Miodovnik 1988; Perez 1992).

We excluded one study because it was available in abstract form only and did not quantify outcomes that we could include in a metaanalysis (Makhlouf 1997).

Lacaze 2006 was moved from 'ongoing' in the previous review to 'excluded' in this review as the trial had been terminated due to poor recruitment and there were no outcome data available.

\section{Risk of bias in included studies}

Please see Figure 2 and Figure 3 for summary of risk of bias assessments.

\section{Figure 2. Risk of bias graph: review authors' judgements about each risk of bias item presented as percentages across all included studies}

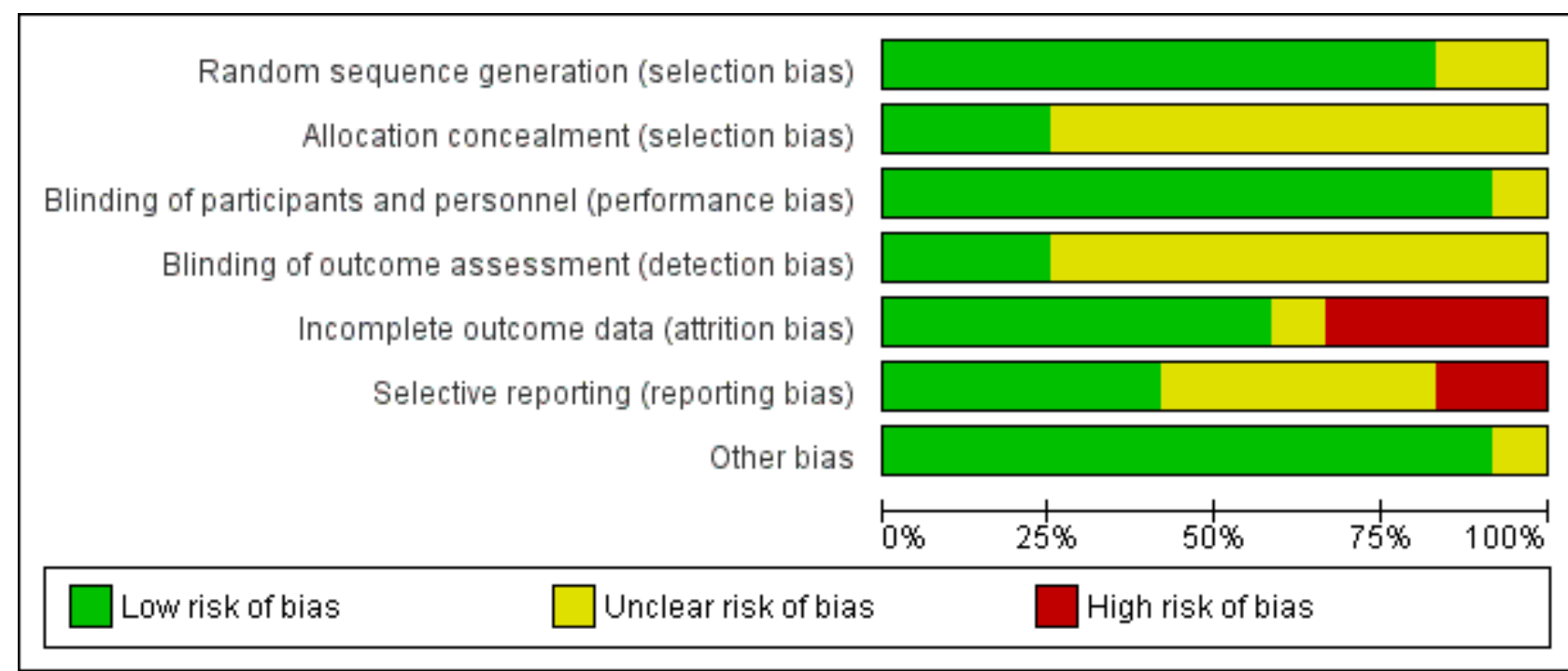


Figure 3. Risk of bias summary: review authors' judgements about each risk of bias item for each included study

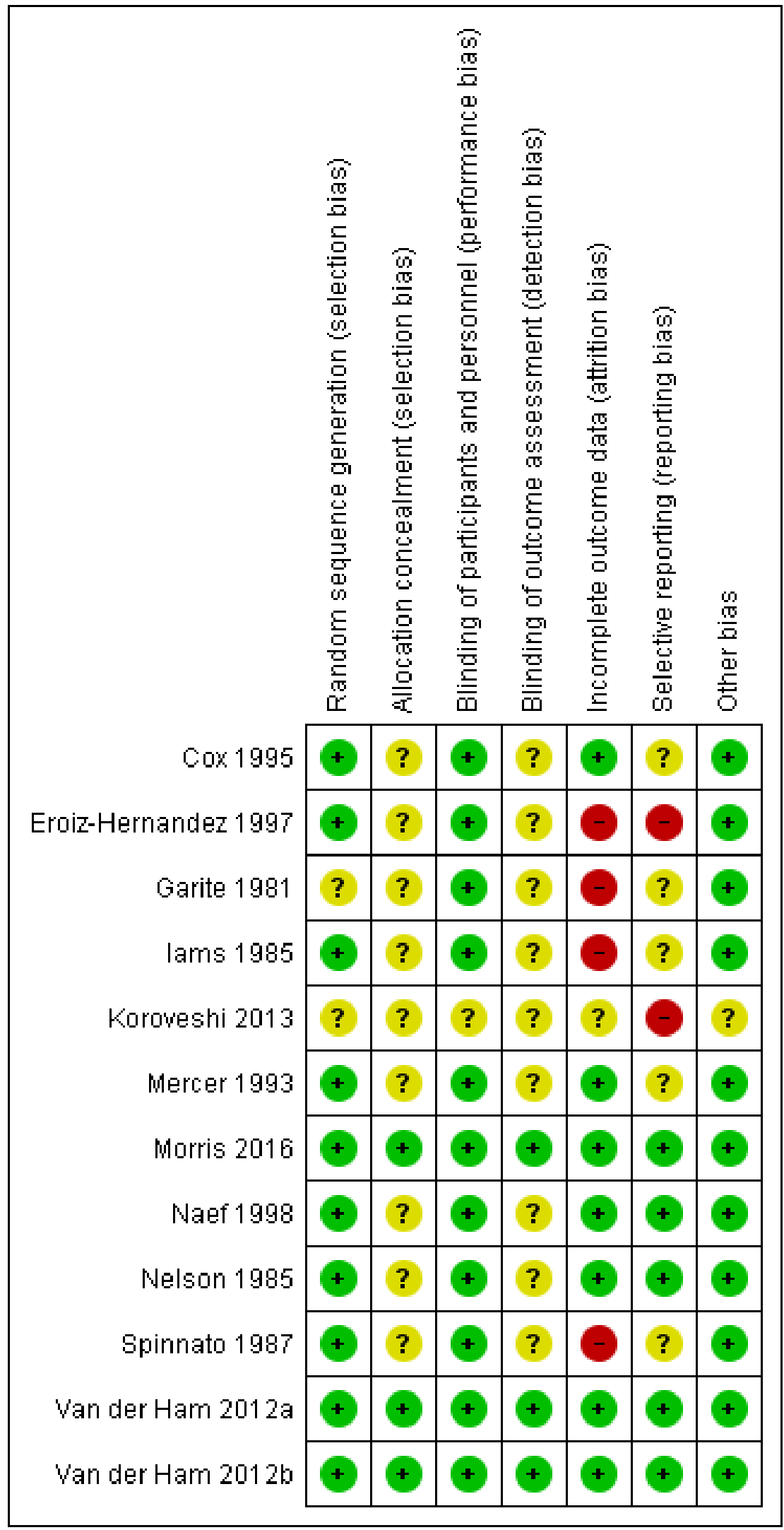

Planned early birth versus expectant management for women with preterm prelabour rupture of membranes prior to 37 weeks' 
The trials were of variable methodological quality but overall of low to unclear risk of bias.
We assessed publication bias using funnel plots (Sterne 2011). We noted no visual asymmetry (Figure 4; Figure 5; Figure 6; Figure 7; Figure 8; Figure 9; Figure 10; Figure 11).

Figure 4. Funnel plot of comparison: 1 Any planned birth versus expectant management: by type, outcome: 1.1 Neonatal infection/sepsis

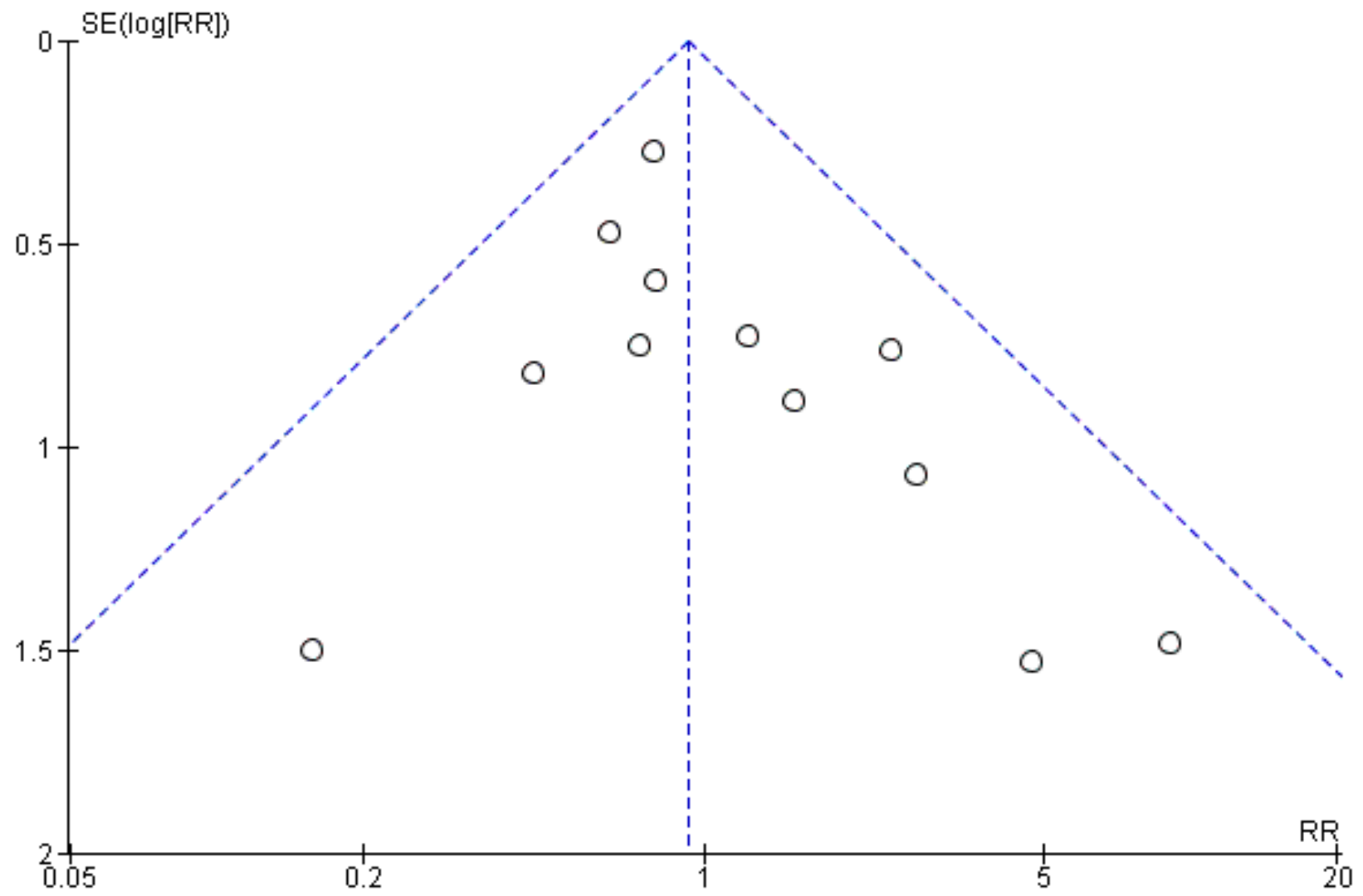


Figure 5. Funnel plot of comparison: 1 Any planned birth versus expectant management: by type, outcome: 1.3 Respiratory distress syndrome

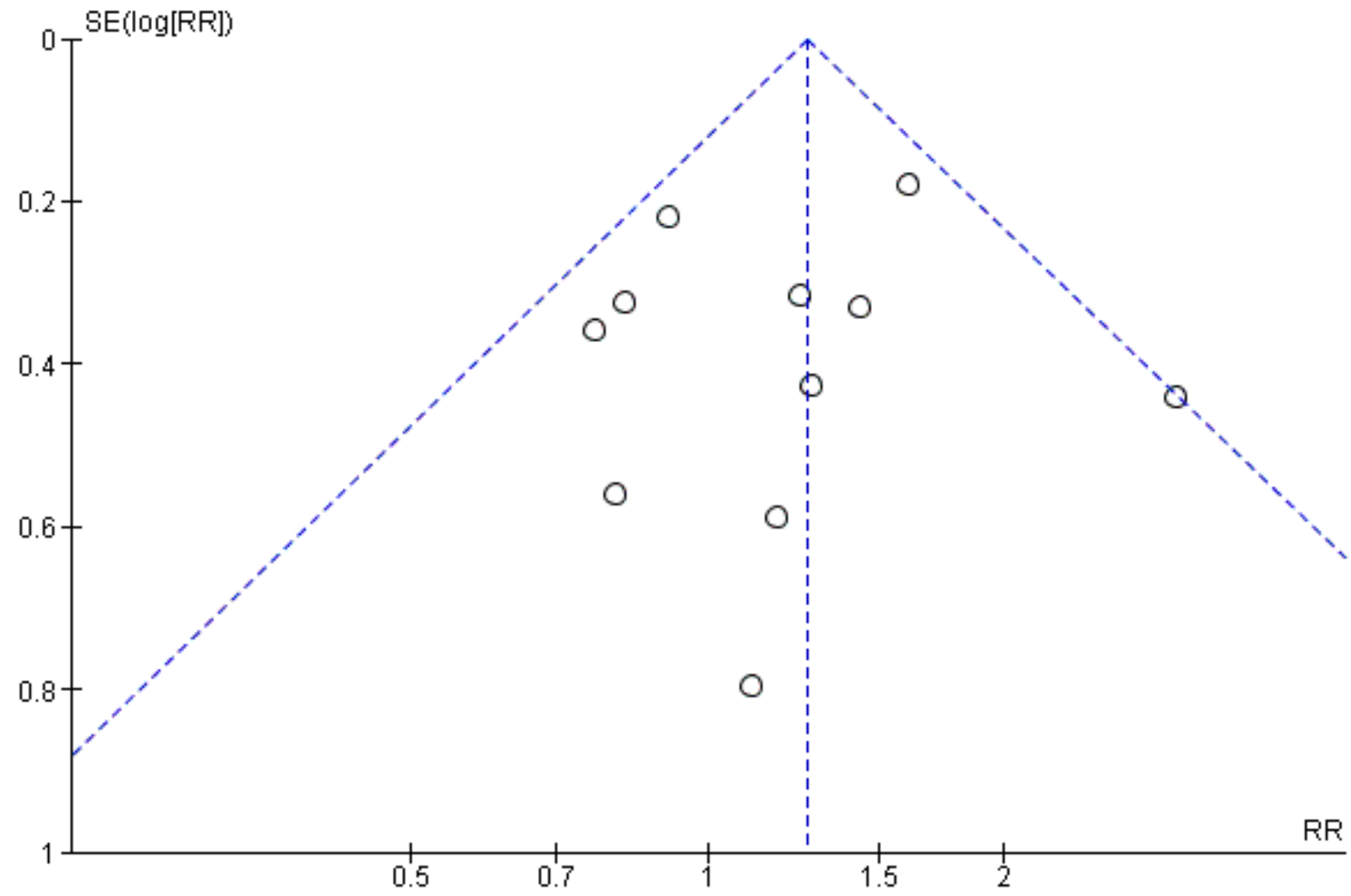


Figure 6. Funnel plot of comparison: 1 Any planned birth versus expectant management: by type, outcome: 1.4 Caesarean section

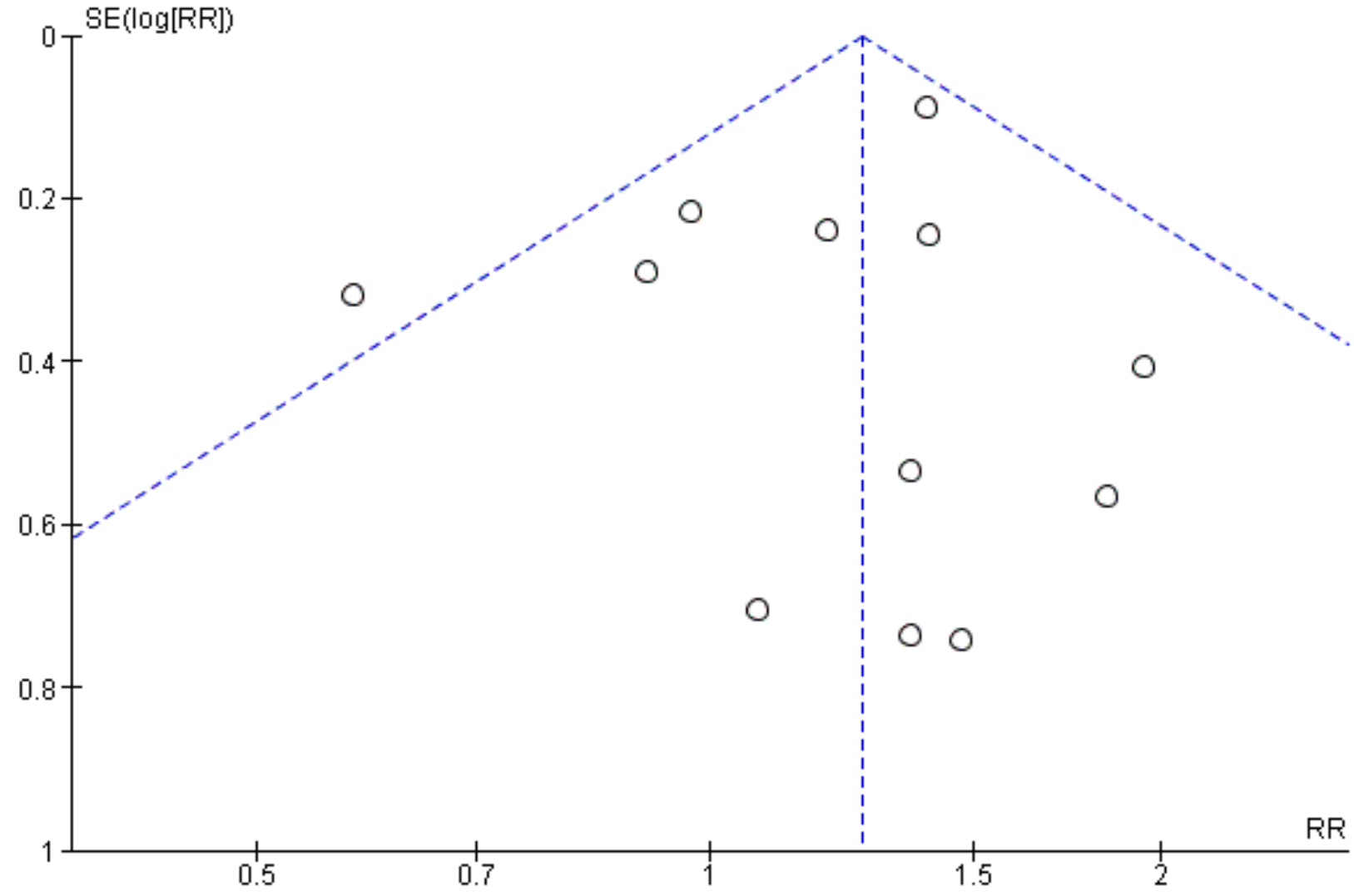


Figure 7. Funnel plot of comparison: 1 Any planned birth versus expectant management: by type, outcome: 1.5 Perinatal mortality

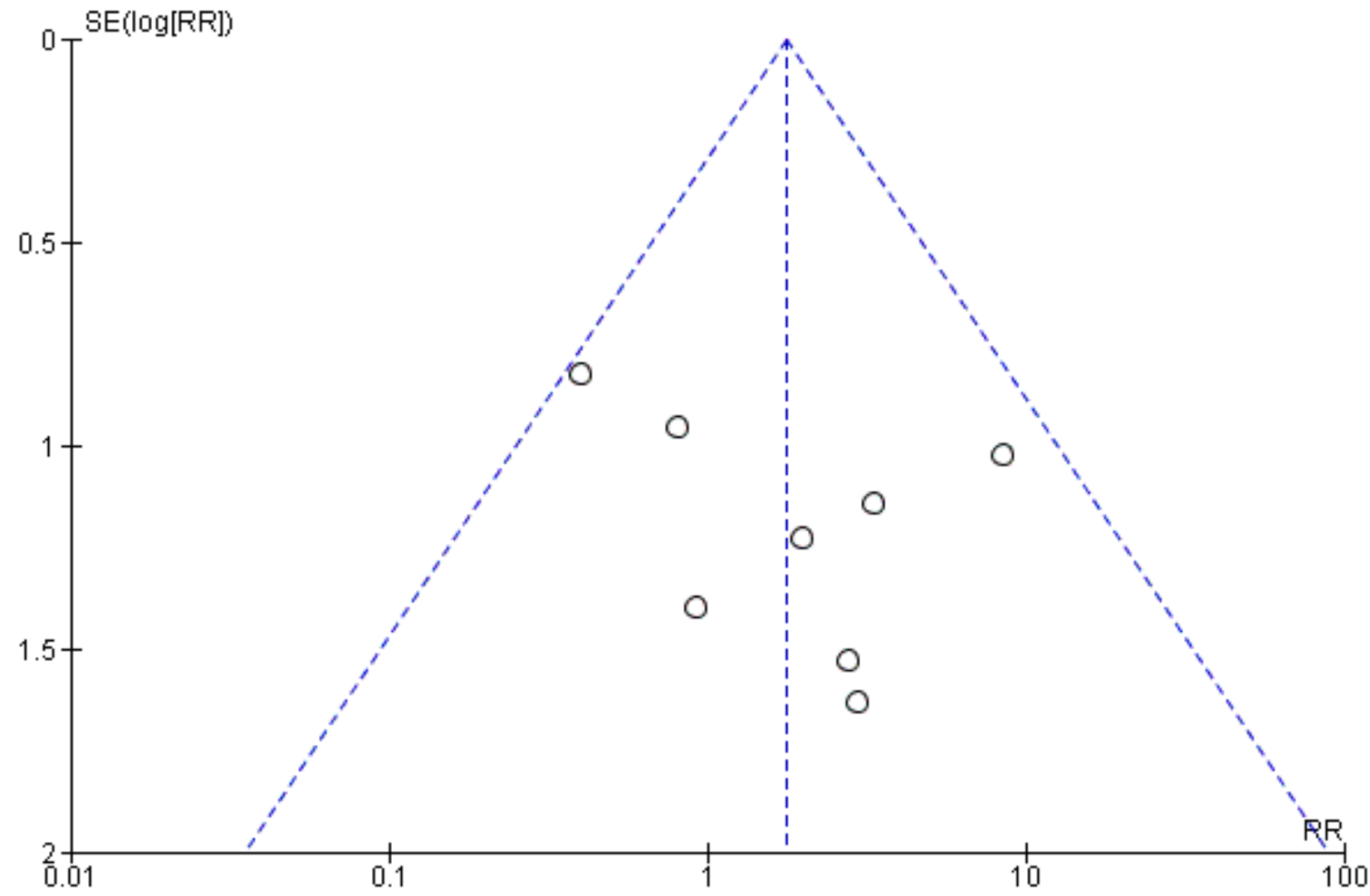


Figure 8. Funnel plot of comparison: 1 Any planned birth versus expectant management: by type, outcome: 1.6 Intrauterine death

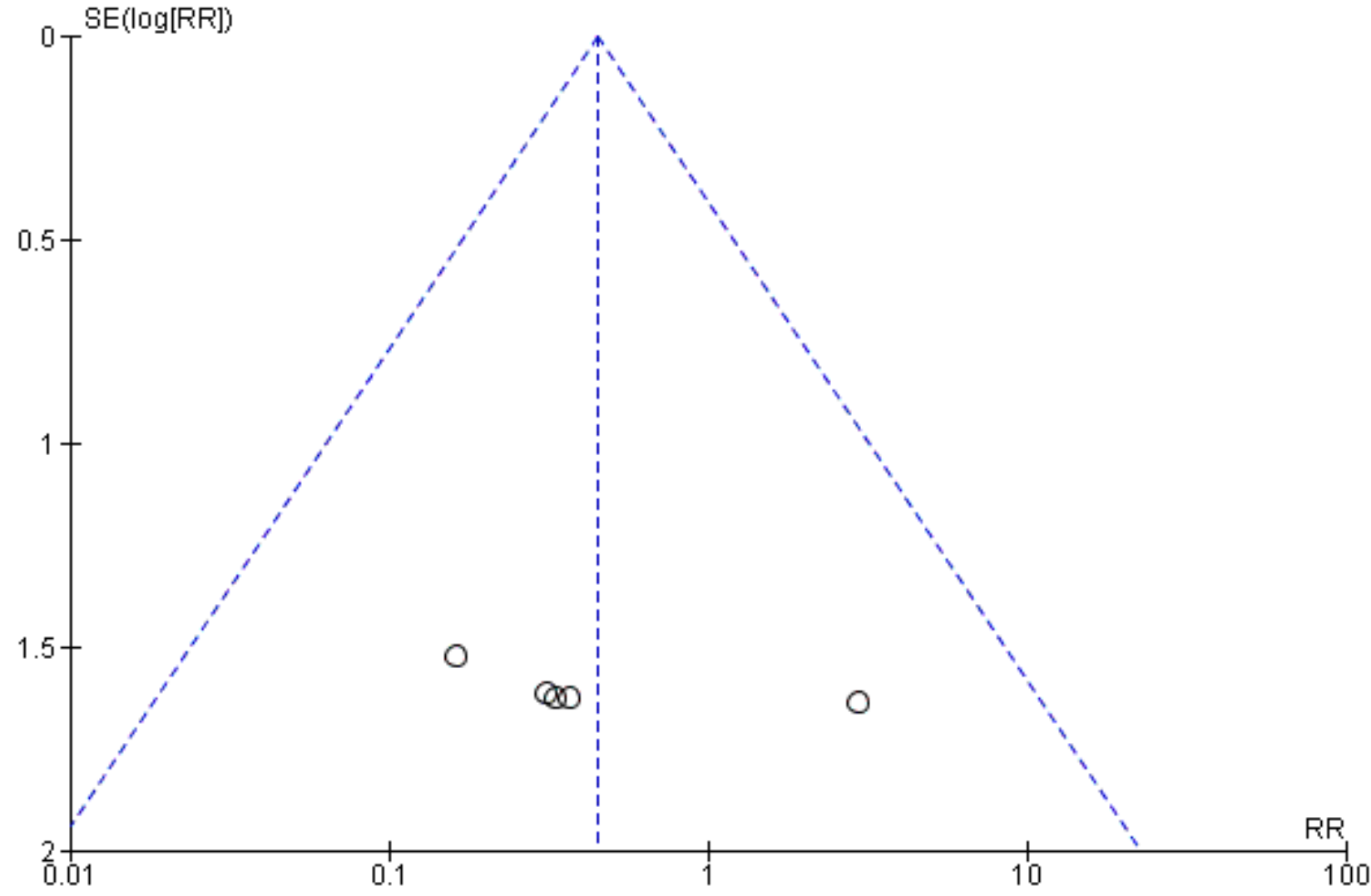


Figure 9. Funnel plot of comparison: 1 Any planned birth versus expectant management: by type, outcome: 1.9 Neonatal death

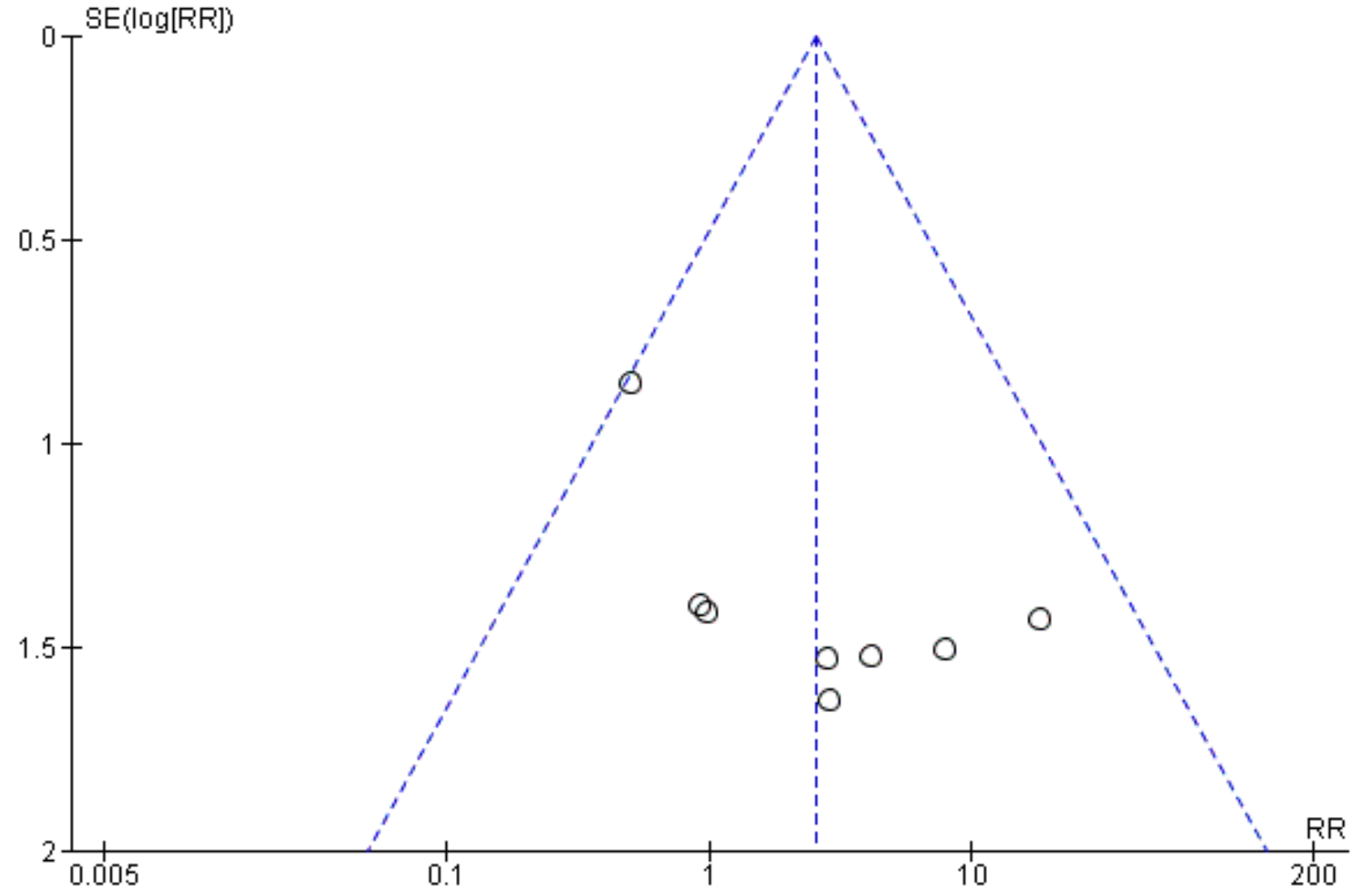


Figure 10. Funnel plot of comparison: 1 Any planned birth versus expectant management: by type, outcome: 1.15 Birthweight (g)

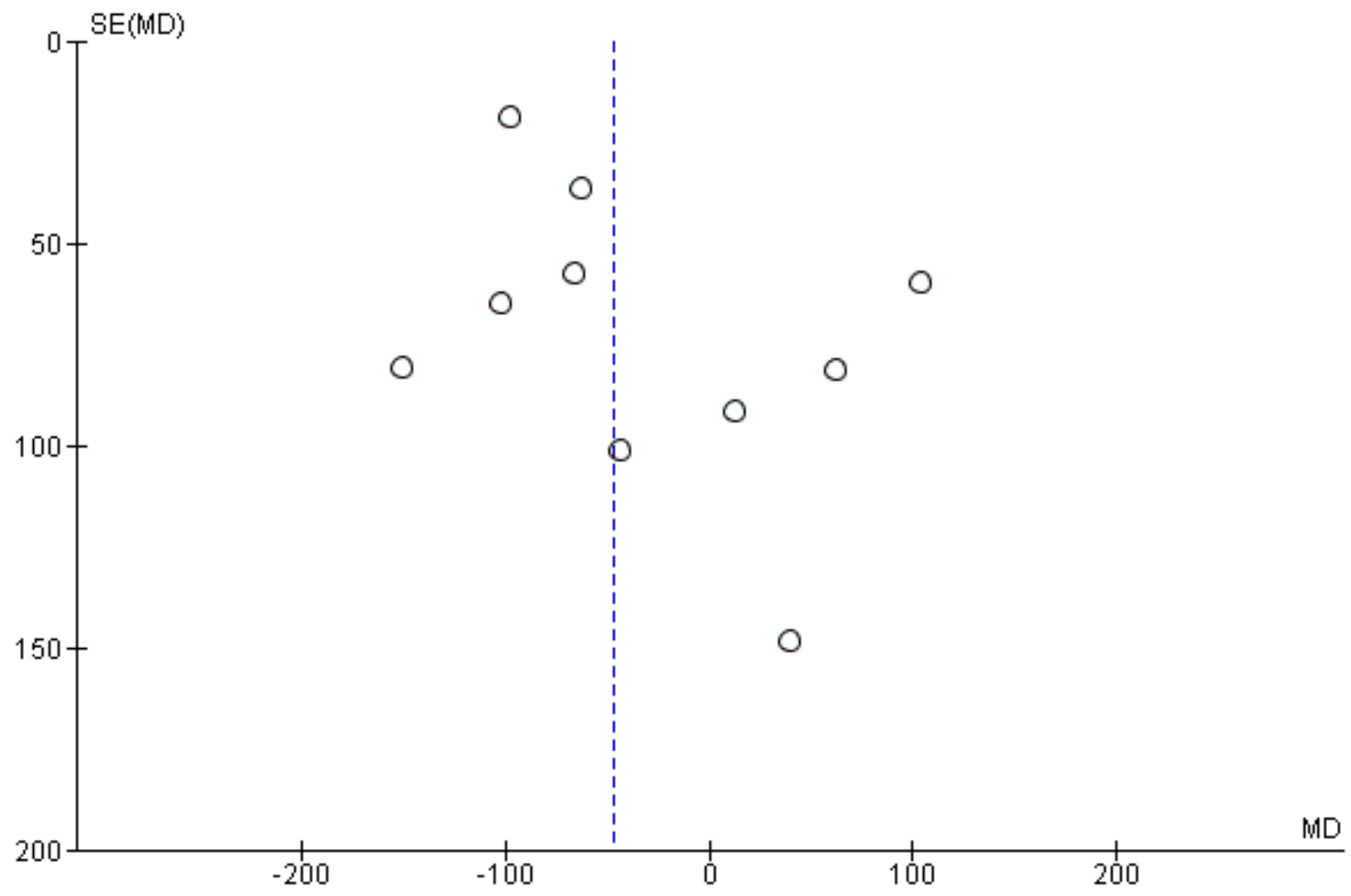


Figure 11. Funnel plot of comparison: 1 Any planned birth versus expectant management: by type, outcome: 1.31 Vaginal birth

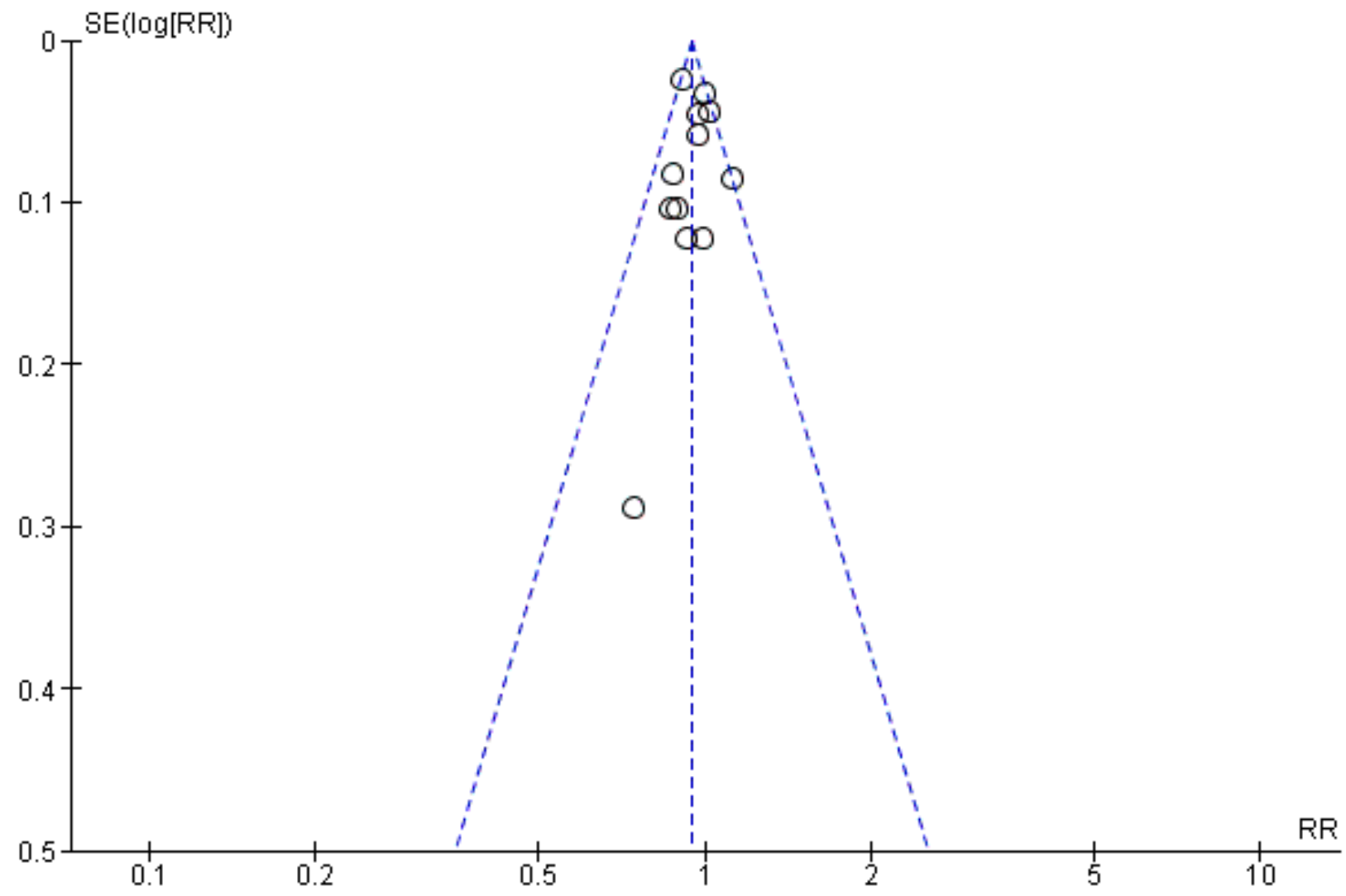

\section{Sensitivity analysis}

We did not perform sensitivity analyses for this version of the review, due to very small differences in the potential risk of bias between the included studies. We assessed heterogeneity with subgroup analyses of outcomes.

\section{Allocation}

\section{Random sequence generation}

Ten of the 12 included trials discussed the method of randomisation (Cox 1995; Eroiz-Hernandez 1997; lams 1985; Mercer 1993; Morris 2016; Naef 1998; Nelson 1985; Spinnato 1987; Van der Ham 2012a; Van der Ham 2012b). This involved computergenerated randomisation sequences, randomisation cards and random number tables. Garite 1981 and Koroveshi 2013 did not report on the method of randomisation.

\section{Allocation concealment}

Allocation concealment was unclear in all of the studies except Morris 2016, Van der Ham 2012a and Van der Ham 2012b each of which were considered low risk of bias.

\section{Blinding}

\section{Blinding of participants and personnel (performance bias)}

Blinding was not possible due to the intervention, however this is likely low risk of bias due to objective and specific assessment criteria for outcomes, where lack of blinding would not affect treatment decisions or other aspects of care. However, for one trial (Koroveshi 2013), the risk was unclear as the assessment criteria for outcomes was not mentioned.

\section{Blinding of outcome assessment (detection bias)}

Blinding of outcome assessors was only performed in three of the included trials (Morris 2016; Van der Ham 2012a; Van der Ham 2012b). In one trial (Garite 1981), only radiologists for reviewing Xrays prior to diagnosis of hyaline membrane disease were blinded as to treatment allocation. It is not clear in the other trials whether outcome assessors were blinded to treatment allocation.

\section{Incomplete outcome data}

All of the trials reported on short-term outcomes. The only trials that assessed any maternal or neonatal outcomes after discharge from hospital were Van der Ham 2012a, which reported on neurodevelopmental outcomes at two years of age, and Morris 2016, which reported on maternal satisfaction and breastfeeding duration greater than 12 weeks. There was incomplete outcome data in four of the studies (Eroiz-Hernandez 1997; Garite 1981; lams 1985; Spinnato 1987). Eroiz-Hernandez 1997 showed results inconsistent with the number randomised. There was no explanation to account for the inconsistencies and incomplete data. Garite 1981 removed a fetal death that occurred in the expectant management group from the denominator of neonatal outcomes. Iams 1985 excluded five women from analysis after 
randomisation. Three of these women were randomised to the expectant management group and were discharged home and they subsequently delivered their babies in another hospital and were excluded from analysis. Another mother and baby were excluded (also in this trial) due to failure to complete steroid therapy, and an additional neonate was excluded post-randomisation due to the presence of congential abnormalities. Spinnato 1987 excluded 15 women on case review after randomisation. Seven of these women were excluded for preterm labour, four for protocol violation and four others for unspecified reasons. In addition, two perinatal deaths resulting from lethal congenital anomalies were excluded in this trial after randomisation.

\section{Selective reporting}

Selective reporting bias was considered high in two of the trials. Although Koroveshi 2013 was a published abstract only, in which three outcomes as well as secondary unspecified outcomes were reported, the full paper has not yet been published despite completion of the trial in 2011. In Eroiz-Hernandez 1997, outcomes were only reported in results, and not pre-specified. Although the inclusion criteria was singleton pregnancy only, results for caesarean section indicate there were two sets of twins in each group, which was not reported.

\section{Other potential sources of bias}

As Koroveshi 2013 was a published abstract only, it was unclear as to whether or not there were other sources of bias. We did not identify other potential sources of bias in any of the other included studies.

\section{Effects of interventions}

See: Summary of findings for the main comparison Planned early birth compared to expectant management for preterm prelabour rupture of membranes prior to 37 weeks' gestation

We included 12 randomised controlled trials in this review. This included 3617 women and 3628 babies with preterm premature rupture of the membranes randomised to either planned early birth or expectant management.

\section{Primary outcomes}

\section{Fetal/neonatal outcomes}

\section{Infection}

We identified no clear differences in the primary outcomes of probable or definite neonatal sepsis, or both (risk ratio (RR) 0.93 , $95 \%$ confidence interval $(\mathrm{Cl}) 0.66$ to $1.30,12$ trials, 3628 babies, evidence graded moderate, Analysis 1.1), or proven neonatal infection with positive blood culture (RR $1.24,95 \% \mathrm{Cl} 0.70$ to 2.21, seven trials, 2925 babies, Analysis 1.2). No separate data were available for proven neonatal infection with a positive blood culture specifically within 48 hours of birth or after 48 hours of birth. Therefore, we further categorised neonatal sepsis into subgroups of: neonatal sepsis proven with positive blood culture (and included those trials that specified their sepsis outcome was defined by a positive culture); presumed sepsis; and neonatal treatment with antibiotics.

Three trials (Mercer 1993; Van der Ham 2012a; Van der Ham 2012b) reported on suspected neonatal sepsis and found a reduction associated with early birth (RR $0.56,95 \% \mathrm{Cl} 0.36$ to $0.88,829$ babies, Analysis 1.10).

\section{Respiratory distress syndrome}

Early birth increased the incidence of respiratory distress syndrome (RDS) (RR 1.26, 95\% Cl 1.05 to 1.53, 12 trials, 3622 babies, evidence graded high, Analysis 1.3). Included in this outcome is Spinnato 1987 who included RDS in the definition of "transient pulmonary insufficiency" along with respiratory insufficiency of prematurity and transient tachypnoea of the newborn. Three trials included a sub-category of severe respiratory distress, which showed no difference between the two groups (RR $1.54,95 \% \mathrm{Cl} 0.80$ to 2.97 , three trials, 321 babies, Analysis 1.21). However, the definition of severe respiratory distress differed between the trials, and the numbers were too small to adequately assess this outcome.

\section{Maternal outcomes}

\section{Caesarean section}

Early birth was associated with an increased rate of caesarean section (RR $1.26,95 \% \mathrm{Cl} 1.11$ to $1.44,12$ trials, 3620 women, evidence graded high, Analysis 1.4).

\section{Secondary outcomes}

\section{Fetal outcomes}

There was no clear difference in the overall perinatal mortality (RR $1.76,95 \% \mathrm{Cl} 0.89$ to $3.50,11$ trials, 3319 babies, Analysis 1.5), or intrauterine deaths (RR $0.45,95 \% \mathrm{Cl} 0.13$ to $1.55,11$ trials, 3321 babies, Analysis 1.6) when comparing early birth with expectant management. There was no difference in incidence of cord prolapse (RR $1.24,95 \% \mathrm{Cl} 0.33$ to 4.61, four trials, 2722 babies, Analysis 1.7). Babies of women randomised to early birth tended to be born at a gestational age lower than those randomised to expectant management (mean difference (MD) -0.48 weeks, $95 \% \mathrm{Cl}-0.57$ to -0.39 , eight trials, 3139 babies, Analysis 1.8).

\section{Neonatal outcomes}

\section{Neonatal mortality}

Early birth was associated with a higher rate of neonatal death (RR 2.55, 95\% Cl 1.17 to 5.56, 11 trials, 3316 babies, Analysis 1.9). There was a disproportionate increased number of deaths in the planned early delivery arm of one trial (Eroiz-Hernandez 1997). This was the only trial comparing a fetal lung maturity protocol using intravenous aminophylline every eight hours in the early-birth arm and weekly in the expectant-management arm.

\section{Neonatal morbidity}

Early birth was associated with an increased need for neonatal ventilation (RR $1.27,95 \% \mathrm{Cl} 1.02$ to 1.58 , seven trials, 2895 babies, evidence graded high, Analysis 1.12) and increased the arterial $\mathrm{pH}$ in the umbilical cord to above the normal range (MD 0.09, 95\% Cl 0.07 to 0.11 , one trial, 120 babies, Analysis 1.14).

There were no clear differences between the groups in other measures of neonatal morbidities, including neonatal treatment with antibiotics (average RR $0.86,95 \% \mathrm{Cl} 0.63$ to 1.19 , four trials, 2638 babies, $\mathrm{Tau}^{2}=0.08, \mathrm{I}^{2}=80 \%$, Analysis 1.11 ), days of oxygen therapy (RR $-3.05,95 \% \mathrm{Cl}-6.92$ to 0.82 , one trial, 73 babies, Analysis 1.13), birthweight (MD $-47.10 \mathrm{~g}, 95 \% \mathrm{Cl}-96.00$ to 1.80 ), 10 trials, 3263 babies, $\mathrm{Tau}^{2}=2260.76, \mathrm{I}^{2}=44 \%$, Analysis 1.15$)$, Apgar score less 
than seven at five minutes ( $\mathrm{RR} 0.96,95 \% \mathrm{Cl} 0.54$ to 1.69 , five trials, 2700 babies, Analysis 1.16), abnormality on cerebral ultrasound (RR $1.90,95 \% \mathrm{Cl} 0.52$ to 6.92 , three trials, 271 babies, Analysis 1.17), periventricular leukomalacia (RR $1.00,95 \% \mathrm{Cl} 0.14$ to 6.99 , two trials, 707 babies, Analysis 1.18), cerebroventricular haemorrhage (RR 1.19, 95\% Cl 0.40 to 3.52, six trials, 1095 babies, Analysis 1.19), and necrotising enterocolitis ( $\mathrm{RR} 0.81,95 \% \mathrm{Cl} 0.25$ to 2.62 , six trials, 2842 babies, Analysis 1.20).

There was substantial heterogeneity between the trials in assessing neonatal treatment with antibiotics as demonstrated by an $\mathrm{I}^{2}$ of $80 \%$. This was likely due to the differences in clinical practice guidelines between sites regarding antibiotic use. There was also high heterogeneity for birthweight which was likely due to the differences in gestational age at randomisation between trials.

\section{Neonatal hospitalisation}

Admission to neonatal intensive care (RR $1.16,95 \% \mathrm{Cl} 1.08$ to 1.24 four trials, 2691 babies, evidence graded moderate, Analysis 1.22) was higher for those babies randomised to early birth. However, the length of stay in neonatal intensive care for those babies who were admitted to the neonatal intensive care unit (NICU) was no different between the two groups (MD -0.17 days, $95 \% \mathrm{Cl}-1.62$ to 1.27 , four trials, 2121 babies, $\mathrm{Tau}^{2}=1.65, \mathrm{I}^{2}=85 \%$, Analysis 1.23). This may suggest that although fewer babies in the expectant management arm were admitted to NICU, their length of stay in NICU was longer. Furthermore, the duration of days in NICU for one trial (lams 1985) was considerably longer than the other three trials that assessed this outcome. This may be attributed to the earlier gestation at randomisation (28 to 34 weeks as compared to 34 to $36+6$ weeks) as well as being the oldest of the four trials (1985). Changes in clinical practice over time may have influenced time spent in NICU. Two trials (Van der Ham 2012a; Van der Ham 2012b) were excluded from this outcome on the advice of the study author as there was uncertainty regarding the denominator used for the analysis. Overall duration of neonatal hospitalisation (MD 0.67 days, $95 \% \mathrm{Cl}-0.28$ to 1.61 , six trials, 2832 babies, $\mathrm{Tau}^{2}=0.80$, $1^{2}=71 \%$, Analysis 1.24 ) was also no different between those babies in the early birth group compared to the expectant management group.

Heterogeneity for all these outcomes was high. This was likely due to the differences in clinical practice as evidenced by the large number of countries and sites represented in this review. Many hospitals routinely admit babies where the pregnancy is complicated by PPROM to NICU for observation for a specified period of time, whereas others do not.

\section{Long-term disability}

There were no clear differences in neurodevelopmental outcomes at two years of age between children in the early birth group compared to children in the expectant when assessed by the Child Behaviour Checklist (CBCL) (RR 0.64, 95\% Cl 0.26 to 1.59 , one trial, 199 babies, Analysis 1.38) or the Ages and Stages Questionnaire (ASQ) (RR $0.61,95 \% \mathrm{Cl} 0.35$ to 1.05 , one trial, 228 babies, Analysis 1.39). However, the trial was not powered for this outcome and with a $45 \%$ follow-up rate, the numbers may be insufficient for an overall effect.

\section{Maternal outcomes}

\section{Infection}

In assessing maternal outcomes, we found that early birth was associated with a decreased rate of chorioamnionitis (average RR $0.50,95 \% \mathrm{Cl} 0.26$ to 0.95 , eight trials, 1358 women, evidence graded moderate, $\mathrm{Tau}^{2}=0.36, \mathrm{I}^{2}=48 \%$, Analysis 1.25 ). However, early birth was associated with an increased rate of endometritis (RR $1.61,95 \% \mathrm{Cl} 1.00$ to 2.59 , seven trials, 2980 women, Analysis 1.26). There was no difference between early planned birth and expectant management in the risk of postpartum fever (RR $0.52,95 \% \mathrm{Cl} 0.26$ to 1.03 , one trial, 1835 women, Analysis 1.27).

There was substantial heterogeneity between the trials in assessing chorioamnionitis as demonstrated by an $\mathrm{I}^{2}$ of $48 \%$. To analyse the source of heterogeneity we performed a number of subgroup analyses. The subgroup analysis comparing those trials in which early birth occurred less than 24 hours after randomisation reduced chorioamnionitis (RR $0.22,95 \% \mathrm{Cl} 0.17$ to 0.55 , three trials, 342 women), while no difference was seen when planned birth was 24 hours or more from randomisation (RR $1.10,95 \% \mathrm{Cl} 0.62$ to 1.95 , five trials, 1016 women). An interaction test for this difference between subgroups was significant in assessing the subgroup of early birth on chorioamnionitis: $\mathrm{Chi}^{2}=6.02, \mathrm{df}=1(\mathrm{P}=0.01), \mathrm{I}^{2}=$ $83.4 \%$, Analysis 5.5). Likewise, the subgroup analysis for gestational age at randomisation showed a reduction in chorioamnionitis in women greater than 34 weeks' gestation (RR $0.26,95 \% \mathrm{Cl} 0.12$ to 0.57 , three trials, 847 women) compared to women less than 34 weeks' gestation (RR $0.77,95 \% \mathrm{Cl} 0.45$ to 1.30 , four trials, 418 women). However, the interaction test for subgroup differences was not significant, Analysis 3.5.

\section{Other complications}

There were no clear differences in rates of placental abruption between the two groups (RR 1.19, 95\% Cl 0.36 to 3.87, one trial, 1835 women, Analysis 1.28).

\section{Mode of birth}

As expected due to the intervention, women randomised to early birth had a higher chance of having an induction of labour as compared to women randomised to expectant management (RR $2.18,95 \% \mathrm{Cl} 2.01$ to 2.36 , four trials, 2691 women, Analysis 1.29). In Analysis 1.30, the results were probably in favour of the expectant management group, with more women in the planned early birth group using spinal/epidural anaesthesia (average RR 1.28, 95\% $\mathrm{Cl} 0.99$ to 1.65 , three trials, 2562 women, $\mathrm{Tau}^{2}=0.03, \mathrm{I}^{2}=57 \%$, Analysis 1.30). The high heterogeneity for this outcome was likely due to the differences in clinical practice between sites regarding the availability and use of epidural/spinal anaesthesia. The chances of a vaginal birth were lower in women randomised to early birth (RR $0.94,95 \% \mathrm{Cl} 0.91$ to $0.97,12$ trials, 3618 women, Analysis 1.31), although the rate of operative vaginal birth showed no difference (RR $0.85,95 \% \mathrm{Cl} 0.67$ to 1.10 , four trials, 2685 women, Analysis 1.32). Although caesarean section rates were higher in the early birth group, if the reason for the caesarean section was fetal distress, the difference between the early birth group and the expectant management group was not apparent (RR $0.89,95 \% \mathrm{Cl} 0.66$ to 1.20 , seven trials, 2918 women, Analysis 1.33). 


\section{Duration of maternal hospital stay}

Women randomised to early birth showed a decrease in the total length of hospitalisation (MD -1.75 days, $95 \% \mathrm{Cl}-2.45$ to -1.05 , six trials, 2848 women, $\operatorname{Tau}^{2}=0.41, \mathrm{I}^{2}=63 \%$, Analysis 1.34 ), including the length of antenatal hospitalisation (MD -6.30 days, $95 \% \mathrm{Cl}-9.67$ to -2.93 , one trial, 73 women, Analysis 1.33). This result remained consistent in trials which allowed for antenatal discharge between randomisation and birth (MD -1.64 days, $95 \% \mathrm{Cl}-3.06$ to -0.23 , two trials, 213 women, $\mathrm{Tau}^{2}=0.65, \mathrm{I}^{2}=58 \%$, Analysis 1.36). The differences in patient admission management between different sites and countries likely accounted for the high heterogeneity regarding duration of maternal hospital stay.

\section{Time from randomisation to birth}

As expected, the time from randomisation to birth was shorter for those randomised to early birth (MD -79.48 hours, $95 \% \mathrm{Cl}-88.27$ to -70.69, three trials, 2571 women, Analysis 1.37).

\section{Satisfaction and breastfeeding}

There was no difference in overall maternal satisfaction relating to their birth experience when comparing early birth with expectant management (RR $0.99,95 \% \mathrm{Cl} 0.86$ to 1.13 , one trial, 493 women, Analysis 1.40). Likewise there was no difference between the two groups in the number of women who continued to breast feed for longer than 12 weeks following birth (RR $0.95,95 \% \mathrm{Cl} 0.80$ to 1.12 , one trial, 415 women, Analysis 1.41).

\section{Subgroup analyses}

\section{Antenatal corticosteroids}

The trials differed in their use of antenatal corticosteroids in randomised women. Five trials (Cox 1995; Eroiz-Hernandez 1997; Mercer 1993; Naef 1998; Spinnato 1987) did not give antenatal corticosteroids to any of their randomised participants. Two trials (Garite 1981; lams 1985) gave corticosteroids to the women randomised to early birth and not to women randomised to expectant management. One trial (Nelson 1985) gave corticosteroids only to one group of women randomised to early birth and not to the second group or to the expectant management group. One trial (Morris 2016) used corticosteroids according to local protocol, and two trials (Van der Ham 2012a; Van der Ham 2012b) gave corticosteroids to women who ruptured their membranes prior to 34 weeks' gestation. No trials gave antenatal corticosteroids to all their randomised participants. Koroveshi 2013 did not stipulate corticosteroid usage.

There was no evidence of a difference between subgroups for corticosteroid use for the following outcomes: neonatal infection, Analysis 2.1, neonatal infection confirmed with positive culture, Analysis 2.2, RDS, Analysis 2.3, caesarean section, Analysis 2.4, chorioamnionitis, Analysis 2.5, and endometritis, Analysis 2.6, between trials in which no antenatal corticosteroids were used and trials where some antenatal corticosteroids were used.

\section{Gestational age}

Five trials (Koroveshi 2013; Morris 2016; Naef 1998; Van der Ham 2012a; Van der Ham 2012b) randomised women greater than 34 weeks' gestation, and five trials (Cox 1995; Eroiz-Hernandez 1997; Garite 1981; lams 1985; Nelson 1985) randomised women less than 34 weeks' gestation. Two trials (Mercer 1993; Spinnato 1987) included women before and after 34 weeks' gestation.
The test for subgroup differences were not significant for neonatal infection (Analysis 3.1), neonatal infection confirmed with positive culture (Analysis 3.2), RDS (Analysis 3.3), caesarean section, (Analysis 3.4), and chorioamnionitis (Analysis 3.5) between trials that randomised women after 34 weeks' gestation compared to before 34 weeks' gestation. There was a decrease in endometritis in women randomised to early delivery in trials greater than 34 weeks' gestation (RR $0.37,95 \% \mathrm{Cl} 0.10$ to 1.40 , three trials, 2562 women) compared to women randomised in trials less than 34 weeks' gestation (RR $2.23,95 \% \mathrm{Cl} 1.29$ to 3.84 , four trials, 418 women). The test for subgroup differences showed: $\mathrm{Chi}^{2}=5.99, \mathrm{df}=1(\mathrm{P}=0.01)$, $I^{2}=83.3 \%$, Analysis 3.6. There were overall effect differences in RDS and chorioamnionitis showing an increase in RDS in early delivery in trials that recruited women greater than 34 weeks' gestation (RR $1.45,95 \% \mathrm{Cl} 1.10$ to 1.90 , five trials, 2992 babies), and a decrease in chorioamnionitis in expectant management in trials that recruited women greater than 34 weeks' gestation (RR $0.26,95 \% \mathrm{Cl} 0.12$ to 0.57 , three trials, 847 women). This may suggest better infant and maternal outcomes related to expectant management after 34 weeks' gestation. However, these results must be interpreted with caution as there were considerably fewer women in the subgroup less than 34 weeks' gestation compared to more than 34 weeks' gestation.

\section{Prophylactic antibiotics}

One trial (Naef 1998) gave prophylactic antibiotics to all women randomised to the trial. Seven trials (Cox 1995; Eroiz-Hernandez 1997; Garite 1981; Iams 1985; Mercer 1993; Nelson 1985; Spinnato 1987) did not use prophylactic antibiotics. Three trials (Morris 2016; Van der Ham 2012a; Van der Ham 2012b) used prophylactic antibiotics according to local protocol which differed between sites. Morris 2016 provided individual participant data regarding the use of antibiotics for the outcome of neonatal sepsis. Koroveshi 2013 did not mention whether they used prophylactic antibiotics.

The test for subgroup differences were not significant for neonatal infection (Analysis 4.1), neonatal infection confirmed with positive blood culture (Analysis 4.2), RDS (Analysis 4.3), caesarean section (Analysis 4.4), or chorioamnionitis (Analysis 4.5), between trials whether all, none or some women received prophylactic antibiotics. However, there was an increase in endometritis in women randomised to early birth in trials that did not use prophylactic antibiotics (RR $2.23,95 \% \mathrm{Cl} 1.29$ to 3.84 , four trials, 418 women) as compared to trials where some women received prophylactic antibiotics (RR $0.37,95 \% \mathrm{Cl} 0.10$ to 1.40 , three trials, 2562 women). The test for subgroup differences showed: $\mathrm{Chi}^{2}=$ 5.99, $\mathrm{df}=1(\mathrm{P}=0.01), \mathrm{I}^{2}=83.3 \%$, Analysis 4.6. Overall effect differences showed a decrease in chorioamnionitis in expectant management when all or some prophylactic antibiotics were used, suggesting that antibiotics were effective in reducing maternal infections. Again, the results for this subgroup analysis must be interpreted with caution due to the considerably increased number of women in the 'some antibiotics' category compared to those who did not receive antibiotics. Independent participant data analysis would be useful to assess this more comprehensively.

\section{Timing of birth}

The timing of intervention for early birth differed between the studies. The mean latency from PROM to birth in four studies (Cox 1995; Mercer 1993; Naef 1998; Spinnato 1987) indicated that early birth was planned for less than 24 hours, even though this was 
not explicitly stated. One study (Eroiz-Hernandez 1997) did not indicate when birth was intended but results indicated a median latency of three days. Three studies (Garite 1981; lams 1985; Nelson 1985) planned for women in the early birth arm to give birth more than 24 hours after randomisation. Three studies (Morris 2016; Van der Ham 2012a Van der Ham 2012b) intended for women randomised to early birth to have labour initiated within 24 hours. However, the mean latency from randomisation to birth in these trials ranged from 33.9 to 39 hours. Koroveshi 2013 did not indicate or provide data to support timing of early birth. Because of the lack of information related to 'intention' of timing of delivery in four of the trials, we based subgroup analysis on mean latency results rather than intended timing of early birth.

Subgroup analysis by timing of birth showed the tests for subgroup differences were not significant for neonatal sepsis (Analysis 5.1), neonatal infection confirmed with positive blood culture (Analysis 5.2), RDS (Analysis 5.3), caesarean section (Analysis 5.4), and endometritis (Analysis 5.6) between trials where early birth occurred less than 24 hours after randomisation as compared to trials where early birth occurred more than 24 hours after randomisation. However, chorioamnionitis was reduced in women randomised to early birth when planned birth occurred within 24 hours (RR $0.25,95 \% \mathrm{Cl} 0.10$ to 0.61 , three trials, 342 women) as compared to when planned birth occurred more than 24 hours from randomisation ( $\mathrm{RR} 0.76,95 \% \mathrm{Cl} 0.41$ to 1.42 , five trials, 1016 women). The test for subgroup differences showed: $\mathrm{Chi}^{2}=4.06, \mathrm{df}$ $=1(\mathrm{P}=0.04), \mathrm{I}^{2}=75.4 \%$, Analysis 5.5 .

\section{Outcomes not able to be assessed}

There were no data related to secondary neonatal outcomes of treatment with surfactant, days of neonatal ventilation, oxygen therapy at 36 weeks' postmenstrual age, or admission to NICU after 24 hours.

There were no data related to secondary maternal outcomes of mode of induction of labour and days of postnatal hospitalisation.

\section{DISCUSSION}

\section{Summary of main results}

The existing evidence arose from clinical trials in which the protocols differed in their management of women with preterm prelabour rupture of the membranes (PPROM), particularly the use of prophylactic antibiotics, use of corticosteroids, timing of early birth and gestational age at trial entry. However, subgroup analyses of these four factors did not alter the result of the primary outcome of sepsis, which indicated that there was no difference in the incidence of neonatal sepsis between women who gave birth immediately or were managed expectantly in PPROM prior to 37 weeks' gestation.

Planned early birth was associated with an increase in the incidence of neonatal RDS, neonatal mortality and the likelihood of birth by caesarean section. Babies in the early birth arm were more likely to be admitted to neonatal intensive care unit, and receive ventilatory support.

Maternal outcomes indicated early birth was associated with an increased likelihood of induction of labour and endometritis, which was reduced with the use of antenatal antibiotics, and a decreased incidence of chorioamnionitis. The clinical significance of the decreased likelihood of chorioamnionitis following early planned birth but an increased risk of endometritis is difficult to interpret. Chorioamnionitis was defined clinically and by those not blinded to treatment allocation so there is a possibility of bias in reporting this outcome. Long term follow-up studies are necessary to ascertain whether there are any sequelae beyond the neonatal period that may result from these exposures. Chorioamnionitis was decreased when randomisation occurred greater than 34 weeks of gestation and if birth occurred within 24 hours of randomisation. However, not all trials assessed this outcome on women randomised to early birth as the presence of chorioamnionitis was an exclusion criteria. The length of time between randomisation and birth as well as overall length of maternal hospitalisation was longer in women randomised to expectant management. The three trials which reported on suspected neonatal infection showed an increase in babies who were managed expectantly, however the numbers were too small to be interpreted with confidence.

\section{Overall completeness and applicability of evidence}

The applicability of findings from the meta-analysis to other populations and settings is limited by several factors. Firstly, the gestational age for inclusion into the studies was often wide. As the perinatal complications associated with PPROM change with gestational age, the management of women with a pregnancy complicated by PPROM requires a stratified approach based largely on gestational age. However, the addition of four trials with inclusion criteria between 34 and 37 weeks' gestation provided some meaningful gestational age-based management for women at 34 or more weeks' gestation.

Secondly, a number of trials included co-interventions in addition to the timing of birth such as corticosteroids, tocolysis and antibiotics which may also limit the applicability of these findings. Since the publication of these earlier trials it has been clearly demonstrated that a number of these co-interventions are of benefit for the mother and baby in the setting of PPROM. There is a beneficial effect for both the mother and the baby in the use of prophylactic erythromycin in the setting of PPROM (Kenyon 2001; Kenyon 2003) similar to the demonstrated beneficial effects of antenatal corticosteroids for women with PPROM, particularly for the neonate at gestations less than 34 weeks (Harding 2001). Only one of these trials (Naef 1998) used prophylactic antibiotics for all women. However, Morris 2016 provided data for those women who did receive prophylactic antibiotics that contributed a substantial number towards the analysis. None of the trials used corticosteroids for both the early birth and expectant management groups. Using corticosteroids for both the early birth and expectant management groups in women at gestations less than 34 weeks would have provided clinically meaningful information and would have removed the confounder of steroids in assessing the effect of early birth on maternal and neonatal outcomes.

\section{Quality of the evidence}

Overall, all 12 studies were assessed as being at low or unclear risk of bias. Some of the studies lacked an adequate description of methods and the risk of bias could only be assessed as unclear. In five of the studies there were one or two domains where the we judged the risk of bias as high. However, this was unlikely to change the magnitude of effect. We used GRADE profiling to assess neonatal outcomes of infection/sepsis, RDS, need for ventilation, and admission to NICU: and maternal outcomes of caesarean 
section, chorioamnionitis, and length of hospital stay. The results show the quality of evidence across all critical outcomes to be moderate to high. Downgrading was mainly due to imprecision where few events resulted in wide confidence intervals, and inconsistency as evidenced by heterogeneity.

\section{Potential biases in the review process}

The inclusion criteria for this review were intentionally broad, with the aim of being able to better examine all of the possible evidence available. These trials differed with respect to inclusion criteria, cointerventions and the timing of the early birth intervention. The results provided by the subgroup analysis should be interpreted with caution due to the large differences in numbers of women between the subgroups.

We acknowledge that there was the potential for bias at all stages in the reviewing process. We attempted to minimise bias in a number of ways; for example, two review authors independently carried out data extraction and assessed risk of bias. David P van der Ham was Chief Investigator and first author of the PPROMEXIL trials and so JM and DB were responsible for data extraction and assessment of all trial reports relating to this study. Jonathan Morris was the Chief Investigator and first author for the NHMRC- (National Health and Medical Research Council) funded PPROMT trial and so data was assessed and extracted independently by PM. However, we acknowledge that such assessments involve subjective judgments, and another review team may not have agreed with all of our decisions.

\section{Agreements and disagreements with other studies or reviews}

We are not aware of any other reviews addressing this question. Most of the studies included in this review concur with expectant management as not having an increased risk to neonatal outcomes. The exceptions are Mercer 1993 and Naef 1998 which concluded that early birth resulted in decreased infection for both mothers and infants. However, these trials were underpowered to adequately assess this outcome.

\section{AUTHORS' CONCLUSIONS}

\section{Implications for practice}

Current evidence does not demonstrate a difference in neonatal sepsis between women who give birth immediately or are managed expectantly in preterm prelabour rupture of the membranes (PPROM) prior to 37 weeks' gestation. Early planned birth is associated with an increase in the incidence of neonatal respiratory distress syndrome, neonatal mortality, endometritis, induction of labour, and the likelihood of birth by caesarean section, and a decreased incidence of chorioamnionitis. In pregnancies complicated by preterm premature rupture of the membranes a policy of expectant management with careful observation is associated with better outcomes for the mother and baby.

\section{Implications for research}

Future randomised trials should be adequately powered to evaluate the effect of the different management strategies on long-term childhood health, behaviour and cognitive outcomes. Also, future research should be aimed at identifying women with PPROM who would not benefit from expectant management by comparing gestational age at presentation, corticosteroid use and abnormal vaginal microbiological colonisation in both groups. An independent participant data analysis could be considered to address these differences.

\section{ACK N O WLEDGEMENTS}

As part of the pre-publication editorial process, this review was commented on by three peers (an editor and two referees who are external to the editorial team), a member of the Pregnancy and Childbirth Group's international panel of consumers and the Group's statistical adviser.

This project was supported by the National Institute for Health Research, via Cochrane Programme Grant funding to Cochrane Pregnancy and Childbirth. The views and opinions expressed therein are those of the authors and do not necessarily reflect those of the Systematic Reviews Programme, NIHR, NHS or the Department of Health. 


\section{R E F E R E N C E S}

\section{References to studies included in this review}

Cox 1995 \{published data only\}

* Cox SM, Leveno KJ. Intentional delivery vs expectant management with preterm ruptured membranes at 30-34 weeks' gestation. Obstetrics \& Gynecology 1995;86:875-9.

Cox SM, Leveno KJ, Sherman ML, Travis L, DePalma R. Ruptured membranes at 30 to 34 weeks: intentional delivery vs expectant management. American Journal of Obstetrics and Gynecology 1995;172:412.

\section{Eroiz-Hernandez 1997 \{published data only\}}

Eroiz-Hernandez J, Trejo-Acuna MA, Alvarez-Tarin MH. Conservative management of premature membrane rupture in pregnancy of 28-34 weeks. Aleatory clinical trial [Manejo conservador de ruptura prematura de membranas en embarazos de 28 a 34 semanas. Essayo clinico aleatorio]. Ginecologia y Obstetricia de Mexico 1997;65:43-7.

\section{Garite 1981 \{published data only\}}

Garite TJ, Freeman RK, Linzey EM, Braly PS, Dorchester WL. Prospective randomised study in corticosteroids in the management of premature rupture of the membranes and the premature gestation. American Journal of Obstetrics and Gynecology 1981;141(5):508-15.

\section{Iams 1985 \{published data only\}}

lams JD, Talbert ML, Barrows H, Sachs L. Management of preterm prematurely ruptured membranes: a prospective randomized comparison of observation vs use of steroids and timed delivery. American Journal of Obstetrics and Gynecology 1985;151:32-8.

\section{Koroveshi 2013 \{published data only\}}

Koroveshi G, Qirko R, Koroveshi E, Kuli G, Kodra N, Nurce A, et al. Incidence of sepsis in late preterm babies born from pregnancies complicated with premature preterm rupture of membranes. Journal of Perinatal Medicine 2013;41(Suppl 1):Abstract no:622.

\section{Mercer 1993 \{published data only\}}

Mercer B, Crocker L, Boe N, Sibai B. Induction versus expectant management in PROM with mature amniotic fluid at 32-36 weeks: a randomized trial. American Journal of Obstetrics and Gynecology 1993;168(1 Pt 2):295.

* Mercer BM, Crocker LG, Boe NM, Sibai BM. Induction vs expectant management in premature rupture of the membranes with mature amniotic fluid at 32 to 36 weeks: a randomized trial. American Journal of Obstetrics and Gynecology 1993;169:775-82.

\section{Morris 2016 \{published data only\}}

Morris J, Roberts CL, Bond DM, Crowther C. Immediate delivery versus expectant care in women with preterm prelabour rupture of the membranes close to term (PPROMT) - a progress report. Journal of Paediatrics and Child Health 2012;48(Suppl 1):96.
Morris JA, Roberts CL, Patterson JA, Bond DM, Crowther CA, Bowen JR, et al. Immediate delivery versus expectant care in women with preterm prelabour rupture of the membranes close to term (PPROMPT): a multi-centre randomised controlled trial. Archives of Disease in Childhood 2014;99(Suppl 2):A223.

Morris JM, Algert C, Crowther C, Bond D, Bowen J, Roberts CL. Preterm pre-labour rupture of the membranes close to term (PPROMT) trial. Journal of Paediatrics and Child Health 2014;50(Suppl 1):23-4.

* Morris JM, Roberts CL, Bowen JR, Patterson JA, Bond DM, Algert CS, et al. Immediate delivery compared with expectant management after preterm pre-labour rupture of the membranes close to term (PPROMT trial): a randomised controlled trial. Lancet 2016;387(10017):444-52.

Morris JM, Roberts CL, Crowther CA, Buchanan SL, HendersonSmart DJ, Salkeld G. Protocol for the immediate delivery versus expectant care of women with preterm prelabour rupture of the membranes close to term (PPROMT) trial. BMC Pregnancy and Childbirth 2006;6:9.

\section{Naef 1998 \{published data only\}}

* Naef RW, Allbert JR, Ross EL, Weber M, Martin RW, Morrison JC. Premature rupture of membranes at 34 to 37 weeks' gestation: aggressive versus conservative management. American Journal of Obstetrics and Gynecology 1998;178(1):126-30

Naef RW, Allbert JR, Ross EL, Weber M, Martin RW, Morrison JC. Premature rupture of the membranes at 34-37 weeks' gestation: aggressive vs conservative management. American Journal of Obstetrics and Gynecology 1994;170:340.

\section{Nelson 1985 \{published data only\}}

Nelson LH, Meis PJ, Hatjis CG, Ernest JM, Dillard R, Schey HM. Premature rupture of membranes: a prospective, randomized evaluation of steroids, latent phase, and expectant management. Obstetrics \& Gynecology 1985; Vol. 66:55-8.

\section{Spinnato 1987 \{published data only\}}

* Spinnato JA, Shaver DC, Bray EM, Lipshitz J. Preterm premature rupture of the membranes with fetal pulmonary maturity present: a prospective study. Obstetrics \& Gynecology 1987; Vol. 69:196-201.

Spinnato JA, Shaver DC, Bray EM, Lipshitz J. Preterm premature rupture of the membranes with fetal pulmonary maturity present: a prospective study. Proceedings of 6 th Annual Meeting of the Society of Perinatal Obstetricians; 1986 Jan 30-Feb 1; San Antonio, Texas, USA. 1986:82.

\section{Van der Ham 2012a \{published data only\}}

Mol BW, Vijgen S, Opmeer B, Bijlenga D, Akerboom B, Van Wijngaarden $\mathrm{W}$, et al. Economic analysis of induction of labor versus expectant management in women with preterm prelabor rupture of membranes between 34 and 37 weeks (PPROMEXIL trial ISRCTN29313500). American Journal of Obstetrics and Gynecology 2011;204(1 Suppl):S336. 
Van der Ham DP, Nijhuis JG, Mol BW, Van Beek JJ, Opmeer BC, Bijlenga $D$, et al. Induction of labour versus expectant management in women with preterm prelabour rupture of membranes between 34 and 37 weeks (the PPROMEXIL-trial). BMC Pregnancy and Childbirth 2007;7:11.

* Van der Ham DP, Vijgen SMC, Nijhuis JG, Van Beek JJ, Opmeer BC, Mulder ALM, et al. Induction of labor versus expectant management in women with preterm prelabor rupture of membranes between 34 and 37 weeks: a randomized controlled trial. PLoS Medicine 2012;9(4):e1001208.

Van der Heyden J, Willekes C, Oudijk M, Porath M, Duvekot H, Bloemenkamp KWM, et al. Behavioural and developmental outcome of neonates at 2 years of age after preterm prelabor rupture of membranes: follow up of the PPROMEXIL trial. American Journal of Obstetrics and Gynecology 2014;210(1 Suppl):S349-50.

Van der Heyden JL, Willekes C, Van Baar AL, Van WassenaerLeemhuis AG, Pajkrt E, Oudijk MA, et al. Behavioural and neurodevelopmental outcome of 2-year-old children after preterm premature rupture of membranes: follow-up of a randomised clinical trial comparing induction of labour and expectant management. European Journal of Obstetrics, Gynecology, and Reproductive Biology 2015;194:17-23.

Willekes C. Preterm premature rupture of membranes between 34 and 37 weeks: expectant management versus induction of labour (planned trial). Current Controlled Trials (www.controlled-trials.com) (accessed 15 February 2007) 2007.

\section{Van der Ham 2012b \{published data only\}}

Tajik P, Van der Ham DP, Zafarmand MH, Hof MHP, Morris J, Franssen MTM, et al. Using vaginal Group B Streptococcus colonisation in women with preterm premature rupture of membranes to guide the decision for immediate delivery: a secondary analysis of the PPROMEXIL trials. BJOG: an international journal of obstetrics and gynaecology 2014;121:1263-73.

Van der Ham D, Van der Heijden J, Opmeer B, Van Beek H, Willekes C, Mulder T, et al. Induction of labor versus expectant management in women with preterm prelabor rupture of membranes between 34 and 37 weeks - the PPROMEXIL-2 trial (ISRCTN05689407). American Journal of Obstetrics and Gynecology 2012;206(Suppl 1):S8-9.

* Van der Ham DP, Van der Heyden JL, Opmeer BC, Mulder AL, Moonen RM, Van Beek JH, et al. Management of latepreterm premature rupture of membranes: the PPROMEXIL-2 trial. American Journal of Obstetrics and Gynecology 2012;207(4):276.e1-e10.

Vijgen SM, Van der Ham DP, Bijlenga D, Van Beek JJ, Bloemenkamp KW, Kwee A, et al. Economic analysis comparing induction of labor and expectant management in women with preterm prelabor rupture of membranes between 34 and 37 weeks (PPROMEXIL trial). Acta Obstetricia et Gynecologica Scandinavica 2014; Vol. 93, issue 4:374-81.

\section{References to studies excluded from this review}

\author{
Bergstrom 1991 \{published data only\}
}

Bergstrom S. A prospective study on the perinatal outcome in Mozambican pregnant women with preterm rupture of membranes using two different methods of clinical management. Gynecologic \& Obstetric Investigation 1991;32:217-9.

\section{Cararach 1994 \{published data only\}}

Cararach V, Sentis J, Botet F, Costa J, Manau D, Arimany MC. Cervical prostaglandin E2 compared with expectant management or systematic induction in PROM with bad cervical conditions: I-maternal results. Proceedings of 14th European Congress of Perinatal Medicine; 1994 June 5-8; Helsinki, Finland. 1994:405.

\section{Decavalas 1995 \{published data only\}}

* Decavalas G, Mastrogiannis D, Papadopoulos V, Tzingounis V. Short-term vs long-term prophylactic tocolysis in patients with preterm premature rupture of membranes. European Journal of Obstetrics \& Gynecology and Reproductive Biology 1995;59:143-7.

Decavalas G, Papadopoulos V, Tsapanos V, Tzingounis V. Tocolysis in patients with preterm premature rupture of membranes has any effect on pregnancy outcome? International Journal of Gynecology \& Obstetrics 1994;46:26.

\section{El-Qarmalawi 1990 \{published data only\}}

El-Qarmalawi AM, Elmardi AA, Saddik M, El-Abdel Hadi F, Shaker SMA. A comparative randomized study of oral prostaglandin E2 (PGE2) tablets and intravenous oxytocin in induction of labor in patients with premature rupture of membranes before 37 weeks of pregnancy. International Journal of Gynecology \& Obstetrics 1990;33:115-9.

\section{Fayez 1978 \{published data only\}}

Fayez JA, Hasan AA, Jonas HS, Miller GL. Management of premature rupture of the membranes. Obstetrics \& Gynecology 1978; Vol. 52:17-21.

\section{Gloeb 1989 \{published data only\}}

Gloeb DJ, O'Sullivan MJ, Beydoun SN. Relationship of the interval between spontaneous premature rupture of the membranes and inducibility of labor. Proceedings of 9th Annual Meeting of the Society of Perinatal Obstetricians; 1989 February 1-4; New Orleans, Louisiana, USA. 1989:493.

\section{Griffith-Jones 1990 \{published data only\}}

Griffith-Jones MD, Tyrrell SN, Tuffnell DJ. A prospective trial comparing intravenous oxytocin with vaginal prostaglandin E2 tablets for labour induction in cases of spontaneous rupture of the membranes. Obstetrics and Gynaecology Today 1990;1(4):104-5.

\section{Haghighi 2006 \{published data only\}}

Haghighi L. Intravaginal misoprostol in preterm premature rupture of membranes with low Bishop scores. International Journal of Gynecology \& Obstetrics 2006;94(2):121-2. 


\section{Lacaze 2006 \{published data only\}}

Lacaze N. Safety and efficacy study of intentional delivery in women with preterm and prelabour rupture of the membranes (ongoing trial). www.clinicaltrials.gov (accessed 21 March 2006) 2006.

Ladfors 1996 \{published data only (unpublished sought but not used)\}

* Ladfors L, Mattsson LA, Eriksson M, Fall O. A randomised trial of two expectant managements of prelabour rupture of the membranes at 34 to 42 weeks. British Journal of Obstetrics and Gynaecology 1996;103:755-62.

Ladfors L, Mattsson LA, Eriksson M, Fall O. A randomized prospective trial of two expectant managements of pre-labor rupture of the membranes (PROM) at 34-42 weeks. American Journal of Obstetrics and Gynecology 1994;170:344.

Ladfors L, Tessin I, Fall O, Erikson M, Matsson LA. A comparison of neonatal infectious outcome comparing two expectant managements of women with prelabor rupture of the membranes at 34-42 weeks. American Journal of Obstetrics and Gynecology 1998;178(1 Pt 2):S197.

Makhlouf 1997 \{published data only\}

Makhlouf AM, Moemen A, Abdelaleem K, Abdelaleem H. Induction versus expectant management in preterm premature rupture of membranes. Research activities on reproductive health: annual report of Assiut University Department of Obstetrics and Gynecology November 1997. Assiut University, Faculty of Medicine, 1997:12.

\section{Mateos 1998 \{published data only\}}

Mateos D, Cararach V, Sentis J, Botet F, Figueras F, Arimany M, et al. Cervical prostaglandin E2 compared with expectant management or systematic induction in premature rupture of the membranes with bad cervical conditions. Prenatal and Neonatal Medicine 1998;1(Suppl 1):85

\section{Miodovnik 1988 \{published data only\}}

Miodovnik M, Smith PP. Management of prelabour rupture of the membranes at 32-36 weeks with prostaglandin present in the vaginal pool. Personal communication 1988.

\section{Parsons 1989 \{published data only\}}

Parsons MT, Sobel D, Cummiskey K, Roitman J, Gall SA. Early delivery vs expectant management in patients with preterm rupture of membranes at 32-36 weeks gestation. Proceedings of 9th Annual Meeting of the Society of Perinatal Obstetricians; 1989 Feb 1-4; New Orleans, Louisiana, USA. 1989:391.

\section{Perez 1992 \{published data only\}}

Perez Picanol E, Vernet M, Armengol R, Perez Ares C, Lecumberri J, Gamissans O. Comparison of two different therapeutic attitudes in premature rupture of membranes. Journal of Perinatal Medicine 1992;20:353.

\section{Van Heerden 1996 \{published data only\}}

Van Heerden J, Steyn DW. Management of premature rupture of the membranes after 34 weeks' gestation - early versus delayed induction of labour. South African Medical Journal 1996;86:262-6

\section{References to ongoing studies}

Pasquier 2006 \{published data only\}

* Pasquier JC, Bujold E, Mellie G. Preterm premature rupture of membranes: is there an optimal gestational age for delivery? Obstetrics \& Gynecology 2005;105(6):1484-5.

Pasquier JC, Claris O, Rabilloud M, Picaud JC, Moret S, Ecochard R, et al. Feeling and motivation of women to participate in a randomized control trial in perinatality. American Journal of Obstetrics and Gynecology 2006;195(6 Suppl 1):S69.

\section{Additional references}

\section{Arias 1982}

Arias F, Tomich P. Etiology and outcome of low birthweight and preterm infants. Obstetrics \& Gynecology 1982;338:663-70.

\section{Deeks 2011}

Deeks JJ, Higgins JPT, Altman DG (editors). Chapter 9: Analysing data and undertaking meta-analyses. In: Higgins JPT, Green $S$ (editors). Cochrane Handbook for Systematic Reviews of Interventions Version 5.1.0 (updated March 2011). The Cochrane Collaboration, 2011. Available from handbook.cochrane.org.

\section{Engle 2007}

Engle WA, Tomashek KM, Wallman C. Late preterm infants: a population at risk. Pediatrics 2007;120:1390-401.

\section{Engle 2008}

Engle WA, Kominiarek MA. Late preterm infants, early term infants, and timing of elective deliveries. Clinics in Perinatology 2008;35:325-41.

\section{Gaudet 2001}

Gaudet L, Smith GN. Cerebral palsy and chorioamnionitis: the inflammatory cytokine link. Obstetrical and Gynecological Survey 2001;56(7):433-6.

\section{Gonen 1989}

Gonen R, Hannah ME, Milligan JE. Does prolonged preterm premature rupture of the membranes predispose to abruptio placentae?. Obstetrics \& Gynecology 1989;74(3):347-50.

\section{Hannah 1996}

Hannah ME, Ohlsson A, Farine D, Hewson SA, Hodnett ED, Myhr TL, et al. Induction of labor compared with expectant management for prelabor rupture of the membranes at term. New England Journal of Medicine 1996;334(16):1005-10.

\section{Harding 2001}

Harding JE, Pang JM, Knight DB, Liggins GC. Do antenatal corticosteroids help in the setting of preterm rupture of membranes?. American Journal of Obstetrics and Gynecology 2001;184:131-9. 


\section{Higgins 2003}

Higgins JPT, Thompson SG, Deeks JJ, Altman DG. Measuring inconsistency in meta-analyses. BMJ 2003;327:557-60.

\section{Higgins 2011}

Higgins JPT, Altman DG, Sterne JAC (editors). Chapter 8: Assessing risk of bias in included studies. In: Higgins JPT, Green $\mathrm{S}$ (editors). Cochrane Handbook for Systematic Reviews of Interventions Version 5.1.0 (updated March 2011). The Cochrane Collaboration, 2011. Available from handbook.cochrane.org.

\section{Jones 2000}

Jones SC, Brost BC, Brehm WT. Should intravenous tocolysis be considered beyond 34 weeks' gestation?. American Journal of Obstetrics and Gynecology 2000;183(2):356-60.

\section{Kenyon 2001}

Kenyon S, Taylor DJ, Tarnow-Mordi W. Broad spectrum antibiotics for preterm, prelabour rupture of the fetal membranes: the ORACLE I randomised trial. Lancet 2001;357:979-88.

\section{Kenyon 2003}

Kenyon S, Boulvain M, Neilson J. Antibiotics for preterm premature rupture of the membranes. Cochrane Database of Systematic Reviews 2003, Issue 2. [DOI: 10.1002/14651858.CD001058]

\section{Lee 2001}

Lee T, Silver H. Etiology and epidemiology of preterm premature rupture of the membranes. Clinical Perinatology 2001;28:721-34.

\section{Lewis 1996}

Lewis DF, Futayyeh S, Towers CV, Asrat T, Edwards MS, Brooks GG. Preterm delivery from 34-37 weeks gestation: is respiratory distress syndrome a problem?. American Journal of Obstetrics and Gynecology 1996;174(2):525-8.

\section{Major 1995}

Major CA, de Veciana M, Lewis DF, Morgan MA. Preterm premature rupture of the membranes and abruptio placentae: is there an association between these pregnancy complications?. American Journal of Obstetrics and Gynecology 1995;172(2):672-6.

\section{Mercer 2000}

Mercer BM, Goldenberg RL, Meis PJ, Moawad AH, Shellhaas C, Das $A$, et al. The preterm prediction study: prediction of preterm premature rupture of the membranes through clinical findings and ancillary testing. American Journal of Obstetrics and Gynecology 2000;183:738-45.

\section{Mercer 2003}

Mercer BM. Preterm premature rupture of the membranes. Obstetrics \& Gynecology 2003;101(1):178-93.

\section{Mercer 2005}

Mercer BM. Preterm premature rupture of the membranes: current approaches to evaluation and management. Obstetrics and Gynecology Clinics of North America 2005;32:411-28.

\section{Middleton 2017}

Middleton P, Shepherd E, Flenady V, McBain RD, Crowther CA. Planned early birth versus expectant management (waiting) for prelabour rupture of membranes at term (37 weeks or more). Cochrane Database of Systematic Reviews 2017, Issue 1. [DOI: 10.1002/14651858.CD005302.pub3]

\section{Neerhof 1999}

Neerhof MG, Cravello C, Haney El, Silver RK. Timing of labor induction after premature rupture of membranes between 32 and 36 weeks gestation. American Journal of Obstetrics and Gynecology 1999;180(2):349-52.

\section{RevMan 2014 [Computer program]}

The Nordic Cochrane Centre, The Cochrane Collaboration. Review Manager (RevMan). Version 5.3. Copenhagen: The Nordic Cochrane Centre, The Cochrane Collaboration, 2014.

\section{Roberts 2006}

Roberts D, Dalziel S. Antenatal corticosteroids for accelerating fetal lung maturation for women at risk of preterm birth. Cochrane Database of Systematic Reviews 2006, Issue 3. [DOI: 10.1002/14651858.CD004454.pub2]

\section{Robertson 1992}

Robertson PA, Sniderman SH, Laros RK Jr, Cowan R, Heilbron D, Goldenberg RL, et al. Neonatal morbidity according to gestational age and birth weight from five tertiary care centers in the United States, 1983 through 1986. American Journal of Obstetrics and Gynecology 1992;166:1629-45.

\section{Seo 1992}

Seo K, McGregor JA, French JI. Preterm birth is associated with increased risk of maternal and neonatal infection. Obstetrics \& Gynecology 1992;79:75-80.

\section{Sterne 2011}

Sterne JAC, Egger M, Moher D (editors). Chapter 10: Addressing reporting biases. In: Higgins JPT, Green S (editors). Cochrane Handbook for Systematic Reviews of Intervention. Version 5.1.0 (updated March 2011). The Cochrane Collaboration, 2011. Available from handbook.cochrane.org.

\section{Wu 2000}

Wu YW, Colford JM. Chorioamnionitis as a risk factor for cerebral palsy: a meta-analysis. JAMA 2000;284(11):1417-24.

\section{References to other published versions of this review \\ Buchanan 2010}

Buchanan SL, Crowther CA, Levett KM, Middleton P, Morris J. Planned early birth versus expectant management for women with preterm prelabour rupture of membranes prior to 37 weeks' gestation for improving pregnancy outcome. Cochrane Database of Systematic Reviews 2010, Issue 3. [DOI: 10.1002/14651858.CD004735.pub3]

* Indicates the major publication for the study 
CHARACTERISTICS OF STUDIES

Characteristics of included studies [ordered by study ID]

Cox 1995

Methods RCT

Duration of study: May 1991-30 April 1994

Participants

Setting: Parkland Hospital, Dallas, Texas, USA

Participants: 129 women with confirmed premature rupture of the membranes between 30-34 weeks' gestation; 1 twin pair in each of early delivery and expectant management group resulting in a total of 131 babies:

- 61 women were randomised to early delivery

- 68 women were randomised to expectant management

Inclusion criteria

- Preterm ruptured membranes at 30-34 weeks' gestation

- Temperature less than $37.8^{\circ} \mathrm{C}$

- No labour

- No maternal or fetal complications necessitating delivery

Exclusion criteria

- Active labour

- Chorioamnionitis defined as a temperature greater than $37.9^{\circ} \mathrm{C}$ with either uterine tenderness or maternal tachycardia

- Maternal hypertension

Interventions Intervention: oxytocin labour stimulation if the fetus was cephalic; caesarean section was performed for all other presentations

Control: expectant management

- Maternal observations and fetal heart rate recorded every $8 \mathrm{~h}$

- Electronic fetal heart rate and uterine activity monitoring was performed for $1 \mathrm{~h}$ each $\mathrm{d}$ until delivery

- Hospitalisation until delivery

- Criteria for delivery included:

* spontaneous labour;

* fever;

* abnormal fetal heart rate

Corticosteroids, tocolysis and antibiotics were not used

Vaginal examinations were not performed in the absence of labour

Outcomes Maternal

- Admission to delivery interval

- Labour induction

- Caesarean delivery

- Chorioamnionitis

Fetal

- Gestational age at delivery 
Cox 1995 (Continued)

- Respiratory distress:

* none

* halo

* ventilator

- Intracranial haemorrhage

- Necrotising enterocolitis

- Sepsis: did not specify whether positive culture required

- Duration of time spent in special care nursery

- Stillbirths

- Neonatal deaths

Notes

- Gestational age: determined by menstrual history, timing of first auscultation of fetal heart sounds, fundal height or ultrasound examination.

- Ruptured membranes was diagnosed when amniotic fluid was visualised by sterile speculum examination draining from the cervical os.

\section{Risk of bias}

\begin{tabular}{|c|c|c|}
\hline Bias & Authors' judgement & Support for judgement \\
\hline $\begin{array}{l}\text { Random sequence genera- } \\
\text { tion (selection bias) }\end{array}$ & Low risk & Random number table with group allocation pre-determined \\
\hline $\begin{array}{l}\text { Allocation concealment } \\
\text { (selection bias) }\end{array}$ & Unclear risk & $\begin{array}{l}\text { Sequentially numbered sealed envelopes. Not stated if envelopes were } \\
\text { opaque or not }\end{array}$ \\
\hline $\begin{array}{l}\text { Blinding of participants } \\
\text { and personnel (perfor- } \\
\text { mance bias) } \\
\text { All outcomes }\end{array}$ & Low risk & $\begin{array}{l}\text { Blinding not possible due to intervention. However this was likely low risk of } \\
\text { bias due to objective and specific assessment criteria for outcomes, where lack } \\
\text { of blinding did not affect treatment decisions or other aspects of care. }\end{array}$ \\
\hline $\begin{array}{l}\text { Blinding of outcome as- } \\
\text { sessment (detection bias) } \\
\text { All outcomes }\end{array}$ & Unclear risk & Not specified \\
\hline $\begin{array}{l}\text { Incomplete outcome data } \\
\text { (attrition bias) } \\
\text { All outcomes }\end{array}$ & Low risk & $\begin{array}{l}\text { No losses to follow-up reported } \\
\text { No post-randomisation exclusions }\end{array}$ \\
\hline $\begin{array}{l}\text { Selective reporting (re- } \\
\text { porting bias) }\end{array}$ & Unclear risk & Outcomes only reported in results. Not pre-specified \\
\hline Other bias & Low risk & None noted \\
\hline
\end{tabular}

Eroiz-Hernandez 1997

Methods RCT

Duration of study: November 1992-October 1993

Participants

Setting: Perinatology Department, Centro Medico Nacional, IMSS, Torreon, Coah, Mexico

Participants: 58 women with PROM between 28-34 weeks of gestation

- 30 women were randomised to early delivery

- 28 women were randomised to expectant management

Planned early birth versus expectant management for women with preterm prelabour rupture of membranes prior to 37 weeks' gestation for improving pregnancy outcome (Review)

Copyright (C) 2017 The Cochrane Collaboration. Published by John Wiley \& Sons, Ltd. 
Eroiz-Hernandez 1997 (Continued)

\author{
Inclusion criteria
}

- Preterm ruptured membranes between 28-34 weeks' gestation

- Amniotic liquid index $>5 \mathrm{~cm}$

- A negative culture of amniotic liquid obtained by amniocentesis

Exclusion criteria

- Women undergoing labour

- Positive fetal lung maturity tests (tap ${ }^{\star}$, clements $^{\star}$ and $650 \mathrm{~nm}$ spectrophotometry)

Interventions

Control: managed with short-term delivery with the application of a fetal lung maturity protocol of 6 doses of $250 \mathrm{mg}$ of intravenous aminophylline every $8 \mathrm{~h}$. Delivered according to obstetric characteristics of each woman

Treatment: managed with the same lung maturity protocol as the controls, but repeating weekly if possible

- All participants had leukocyte counts every $3 \mathrm{~d}$ and daily biophysical profile

- Antibiotics not given prophylactically

- Tocolytics used for management of uterine contractions

- Participant delivered if signs of chorioamnionitis

\title{
Outcomes
}

\section{Maternal}

- Chorioamnionitis, defined by 15,000 leukocytes in maternal blood at the start of the study or a $50 \%$ increase from baseline reading, body temperature $>37.5^{\circ} \mathrm{C}$, abdominal pain or a fetal heart rate of $>$ 160 beats/minute without apparent cause

- Caesarean section

- Days between randomisation and delivery

- Causes of caesarean section

- Causes of delivery

Fetal

- Hyaline membrane disease: diagnosed by prematurity, neonatal asphyxia, progressive onset of respiratory insufficiency, thorax X-rays with the presence of peripheral aerial bronchogram with reticulogranular infiltrates and gasometric respiratory acidosis followed by mixed acidosis

- Neonatal septicaemia diagnosed if the following were present: general poor condition, paleness, jaundice, petechia, equimosis, hypoactivity or irritability, seizure, hepatosplenomegaly, abnormal bleeding, vomit, diarrhoea, gastric residual and hypothermia or fever, leukocytosis $(>25,000)$, leucopenia $(<5000)$, total bands $(>500)$, neutropenia $(<1500)$, Shilling index of $>0.2$ and thrombocytopenia $(<$ 100,000), 1 of 3 lumbar puncture blood culture positive with: $>20$ cells, hypoglycorrhaghia (< $40 \mathrm{mg} /$ $\mathrm{dL}$ ), hyperproteinrhachia (> $280 \mathrm{mg} / \mathrm{dL}$ ). Sepsis also diagnosed if sepsis protocol started with clinical suspicion without positive culture and clinical improvement after antibiotics

- Birthweight

- Apgar scores at 1 min and 5 min

- Silverman score at $1 \mathrm{~min}$ and 5 min

- Perinatal death

- Muscoluskeletal abnormalities

- Amniotic band syndrome

*The authors are unsure of what this procedure is, although this may be an error in translation.

\section{Risk of bias}

Planned early birth versus expectant management for women with preterm prelabour rupture of membranes prior to 37 weeks' gestation for improving pregnancy outcome (Review)

Copyright $\odot 2017$ The Cochrane Collaboration. Published by John Wiley \& Sons, Ltd. 
Eroiz-Hernandez 1997 (Continued)

\begin{tabular}{lll} 
Bias & Authors' judgement & Support for judgement \\
\hline $\begin{array}{l}\text { Random sequence genera- } \\
\text { tion (selection bias) }\end{array}$ & Low risk & Random number table \\
\hline $\begin{array}{l}\text { Allocation concealment } \\
\text { (selection bias) }\end{array}$ & Unclear risk & Not specified \\
\hline
\end{tabular}

\begin{tabular}{|c|c|c|}
\hline $\begin{array}{l}\text { Blinding of participants } \\
\text { and personnel (perfor- } \\
\text { mance bias) }\end{array}$ & Low risk & $\begin{array}{l}\text { Blinding not possible due to intervention. However this was likely low risk of } \\
\text { bias due to objective and specific assessment criteria for outcomes, where lack } \\
\text { of blinding did not affect treatment decisions or other aspects of care. }\end{array}$ \\
\hline
\end{tabular}

\begin{tabular}{lll}
\hline $\begin{array}{l}\text { Blinding of outcome as- } \\
\text { sessment (detection bias) } \\
\text { All outcomes }\end{array}$ & Not specified \\
\hline $\begin{array}{l}\text { Incomplete outcome data } \\
\text { (attrition bias) }\end{array}$ & High risk & Results inconsistent with number randomised. Incomplete data not recorded \\
$\begin{array}{ll}\text { All outcomes } \\
\text { Selective reporting (re- } \\
\text { porting bias) }\end{array}$ & High risk & $\begin{array}{l}\text { Outcomes only reported in results. Not pre-specified. Although inclusion crite- } \\
\text { ria was singleton pregnancy only, results for caesarean section indicate 2 sets } \\
\text { of twins in each group. This was not reported. }\end{array}$ \\
\hline $\begin{array}{l}\text { Other bias } \\
\text { Low risk }\end{array}$ & None noted \\
\hline
\end{tabular}

\section{Garite 1981}

\begin{tabular}{ll}
\hline Methods & RCT \\
& Duration of study: May 1977-July 1980
\end{tabular}

\begin{tabular}{ll}
\hline Participants & Setting: Obstetric services at the University of California Irvine Medical Center and Women's Hospital \\
& Memorial Medical Center of Long Beach, Orange County, California, USA
\end{tabular}
Memorial Medical Center of Long Beach, Orange County, California, USA

Participants: 160 women; 80 women in early delivery group and 80 women in expectant management group

Inclusion criteria

- Women with preterm premature rupture of the membranes

- 28-34 weeks' gestation

Exclusion criteria

- Fetal distress

- Chorioamnionitis

- Mature L/S ratio

- Advanced labour

Prior to randomisation all women

- Monitored with an external fetal heart rate monitor for a minimum of $30 \mathrm{~min}$

- Ultrasound examination performed where BPD determined.

- Amniocentesis performed for L/S ratio, gram stain and culture

- Management was delayed until results were known - "usually 3 to 4 hours" 
Garite 1981 (Continued)

- If the $\mathrm{L} / \mathrm{S}$ ratio was $1.8: 1$ or greater or if the gram stain demonstrated bacteria the fetus was not included in the study
Intervention: 80 women were randomised to corticosteroids and delivery $48 \mathrm{~h}$ after treatment with steroids

- This included betamethasone $12 \mathrm{mg}$ intramuscularly 2 doses $24 \mathrm{~h}$ apart

- Tocolysis used when contractions occurred

- Delivery was after $48 \mathrm{~h}$ by discontinuing the tocolytic and either induction of labour with oxytocin or caesarean section for obstetric indications

Control: 80 women were randomised to expectant management

- Delivered when labour, chorioamnionitis or fetal distress evident

Criteria for delivery for women in the expectant management group included:

- labour

- chorioamnionitis

- fetal distress

Corticosteroids and tocolysis used in early delivery group. Prophylactic antibiotics not used.

Vaginal examinations were not performed in the absence of labour. 
Garite 1981 (Continued)

\begin{tabular}{|c|c|c|}
\hline Bias & Authors' judgement & Support for judgement \\
\hline $\begin{array}{l}\text { Random sequence genera- } \\
\text { tion (selection bias) }\end{array}$ & Unclear risk & Randomisation schema not defined \\
\hline $\begin{array}{l}\text { Allocation concealment } \\
\text { (selection bias) }\end{array}$ & Unclear risk & Not defined \\
\hline $\begin{array}{l}\text { Blinding of participants } \\
\text { and personnel (perfor- } \\
\text { mance bias) } \\
\text { All outcomes }\end{array}$ & Low risk & $\begin{array}{l}\text { Blinding not possible due to intervention. However this was likely low risk of } \\
\text { bias due to objective and specific assessment criteria for outcomes, where lack } \\
\text { of blinding did not affect treatment decisions or other aspects of care. }\end{array}$ \\
\hline $\begin{array}{l}\text { Blinding of outcome as- } \\
\text { sessment (detection bias) } \\
\text { All outcomes }\end{array}$ & Unclear risk & $\begin{array}{l}\text { Radiologists (for reviewing X-rays prior to diagnosis of hyaline membrane dis- } \\
\text { ease) were blinded as to treatment allocation. However it was not mentioned } \\
\text { if all other analysts were blinded to treatment. }\end{array}$ \\
\hline $\begin{array}{l}\text { Incomplete outcome data } \\
\text { (attrition bias) } \\
\text { All outcomes }\end{array}$ & High risk & $\begin{array}{l}\text { No losses to follow-up reported. However, } 1 \text { fetal death in expectant manage- } \\
\text { ment group removed from denominator of neonatal outcomes }\end{array}$ \\
\hline $\begin{array}{l}\text { Selective reporting (re- } \\
\text { porting bias) }\end{array}$ & Unclear risk & Outcomes only reported in results. Not pre-specified \\
\hline Other bias & Low risk & None noted \\
\hline
\end{tabular}

lams 1985

\begin{tabular}{ll} 
Methods & RCT \\
& Duration of study: September 1979-November 1982 \\
\hline
\end{tabular}

Participants

Setting: Ohio State University Hospitals, Ohio, USA

Participants: 73 women; 38 early delivery, 35 expectant management

Inclusion criteria

- Preterm premature rupture of the membranes

- 28-34 weeks' gestation

Exclusion criteria

- Women with mature L/S ratios (greater than 2:1 or more) were delivered

- Active labour

- Infection

- Twin pregnancy

Interventions

Intervention: corticosteroids, tocolysis and delivery 48-72 hours after initiation of steroid treatment

- Hydrocortisone $500 \mathrm{mg}$ intravenously every $8 \mathrm{~h}$ for 4 doses

- Tocolysis included either magnesium sulphate, terbutaline or ritodrine

- Caesarean section for obstetric indications

Control: expectant management.

- Admission to hospital initially 
lams 1985 (Continued)

- Serial observations including vital signs, abdominal examination, WBC counts

- Delivery after labour, chorioamnionitis or fetal distress occurred

- Outpatient management at discretion of managing clinician

Criteria for delivery of women in the expectant management group included

- labour

- chorioamnionitis

- fetal distress

Corticosteroids and tocolysis given to early delivery group. Prophylactic antibiotics not given.

Vaginal examinations were not performed in the absence of labour.

\begin{tabular}{|c|c|}
\hline Outcomes & $\begin{array}{l}\text { Maternal } \\
\text { - Ruptured membranes to delivery time } \\
\text { - Caesarean section } \\
\text { - Chorioamnionitis } \\
\text { - Endometritis: temp }>100.6^{\circ} \mathrm{F} \text { on } 2 \text { readings } 6 \text { or more } \mathrm{h} \text { apart }>24 \mathrm{~h} \text { postpartum } \\
\text { - Duration of hospitalisation } \\
\text { Fetal } \\
\text { - Birthweight } \\
\text { - Duration of admission to delivery } \\
\text { - Apgar score } \\
\text { - Duration of total hospitalisation } \\
\text { - Respiratory distress: required }>24 \mathrm{~h} \text { oxygen therapy with compatible clinical and chest X-ray findings } \\
\text { * duration of time on ventilator } \\
\text { * duration of time requiring oxygen therapy } \\
\text { - Sepsis: required a positive culture for diagnosis } \\
\text { - Leukopenia } \\
\text { - Jaundice } \\
\text { - Perinatal mortality }\end{array}$ \\
\hline Notes & $\begin{array}{l}\text { - Gestational age defined by obstetric history and sonography } \\
\text { - Ruptured membranes defined by visualisation of amniotic fluid pooled in the posterior vaginal fornix } \\
\text { on sterile speculum examination or positive Nitrazine and ferning tests. } \\
\text { - An L/S ratio is a ratio used to determine fetal pulmonary maturity and therefore, the risk of neonatal } \\
\text { RDS if the fetus is delivered prematurely. It is found by testing the amniotic fluid and when the fetal } \\
\text { lungs are mature, lecithin exceeds sphingomyelin by } 2 \text { to } 1 \text {. }\end{array}$ \\
\hline
\end{tabular}

\section{Risk of bias}

Bias Authors' judgement Support for judgement

Random sequence genera- Low risk Random number table

tion (selection bias)

\begin{tabular}{lll}
\hline $\begin{array}{l}\text { Allocation concealment } \\
\text { (selection bias) }\end{array}$ & Unclear risk & Not defined \\
\hline $\begin{array}{l}\text { Blinding of participants } \\
\begin{array}{l}\text { and personnel (perfor- } \\
\text { mance bias) }\end{array}\end{array}$ & Low risk & $\begin{array}{l}\text { Blinding not possible due to intervention. However this was likely low risk of } \\
\text { bias due to objective and specific assessment criteria for outcomes, where lack } \\
\text { ofl blinding did not affect treatment decisions or other aspects of care. }\end{array}$ \\
\hline
\end{tabular}

Planned early birth versus expectant management for women with preterm prelabour rupture of membranes prior to 37 weeks' 
lams 1985 (Continued)

Blinding of outcome as- Unclear risk Not defined sessment (detection bias)

All outcomes

$\begin{array}{ll}\begin{array}{l}\text { Incomplete outcome data } \\ \text { (attrition bias) }\end{array} & \text { High risk } \\ \text { All outcomes } & \begin{array}{l}\text { Losses to follow-up: } 3 \text { women in expectant management group delivered at } \\ \text { another hospital and were excluded from analysis. }\end{array} \\ & \begin{array}{l}\text { Post-randomisation exclusions: } 1 \text { neonate with congenital anomalies was ex- } \\ \text { cluded post delivery, } 1 \text { mother and her baby were excluded for failure to com- } \\ \text { plete steroid therapy. }\end{array}\end{array}$

Selective reporting (re- Unclear risk Outcomes only reported in results. Not pre-specified
porting bias)

\begin{tabular}{ll}
\hline Other bias $\quad$ Low risk $\quad$ None noted \\
\hline
\end{tabular}

\section{Koroveshi 2013}

\begin{tabular}{ll}
\hline Methods & Prospective RCT \\
& Duration of study: March 2008-October 2011 \\
\hline Participants & Setting: Albania \\
& Participants: 307 pregnant women, 157 in planned early birth group and 150 to expectant management \\
& group \\
& Inclusion criteria \\
- Women with preterm premature rupture of the membranes & - $34-37$ weeks' gestation \\
Exclusion criteria \\
- Not defined
\end{tabular}

\begin{tabular}{ll}
\hline Interventions & Planned early birth versus expectant management - not defined \\
\hline Outcomes & Maternal \\
& - Caesarean section \\
& Fetal \\
& - Neonatal sepsis \\
& RDS \\
\hline Notes & Abstract only. Limited data available \\
\hline Risk of bias & Authors' judgement Support for judgement \\
\hline Bias & Unclear risk $\quad$ Method not specified \\
\hline $\begin{array}{l}\text { Random sequence genera- } \\
\text { tion (selection bias) }\end{array}$ & \\
\hline
\end{tabular}


Koroveshi 2013 (Continued)

$\begin{aligned} & \text { Allocation concealment } \\ & \text { (selection bias) }\end{aligned}$
Unclear risk Nocified

\begin{tabular}{|c|c|c|}
\hline $\begin{array}{l}\text { Blinding of participants } \\
\text { and personnel (perfor- } \\
\text { mance bias) } \\
\text { All outcomes }\end{array}$ & Unclear risk & $\begin{array}{l}\text { Blinding not possible due to intervention. However the risk was unclear as as- } \\
\text { sessment criteria for outcomes was not mentioned }\end{array}$ \\
\hline $\begin{array}{l}\text { Blinding of outcome as- } \\
\text { sessment (detection bias) } \\
\text { All outcomes }\end{array}$ & Unclear risk & Not specified \\
\hline $\begin{array}{l}\text { Incomplete outcome data } \\
\text { (attrition bias) } \\
\text { All outcomes }\end{array}$ & Unclear risk & Not specified \\
\hline $\begin{array}{l}\text { Selective reporting (re- } \\
\text { porting bias) }\end{array}$ & High risk & $\begin{array}{l}\text { Only } 3 \text { outcomes as well as secondary unspecified outcomes reported in ab- } \\
\text { stract. Full paper not published }\end{array}$ \\
\hline Other bias & Unclear risk & As this is an abstract publication only, cannot determine the overall risk of bias \\
\hline
\end{tabular}

\section{Mercer 1993}

\begin{tabular}{ll}
\hline Methods & RCT \\
& Duration of study: 1 March 1991-31 July 1992 \\
\hline
\end{tabular}

Setting: University of Tennessee, Memphis, USA
Participants
- 46 women were randomised to induction of labour
- 47 women were randomised to expectant management
Inclusion criteria

- Confirmed premature rupture of the membranes at 32 weeks-36 weeks 6 days

- Amniotic fluid testing suggestive of fetal pulmonary maturity

Exclusion criteria

- Cervical dilatation greater than $2 \mathrm{~cm}$

- Persistent regular contractions or progressive labour

- Blood or meconium-stained amniotic fluid

- Suspected chorioamnionitis

- Any maternal or fetal contraindication to expectant management

- Women with fetuses with intrauterine growth restriction

- Women with fetuses with congenital malformations

- A non-reassuring fetal heart rate tracing (defined as recurrent decelerations, heart rate greater than 160 beats per minute, or the absence of heart rate accelerations)

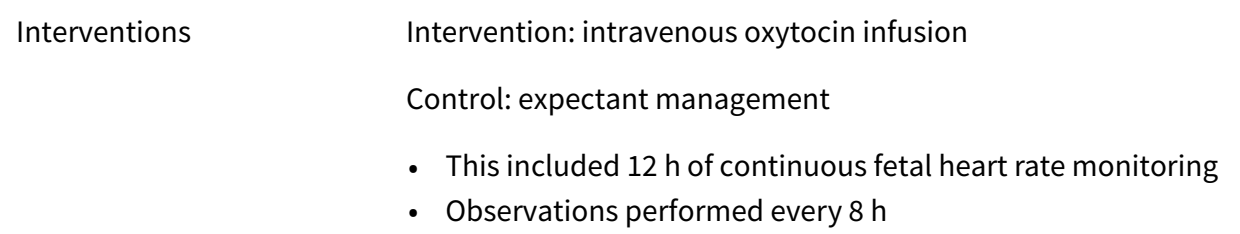


- Women restricted to bed rest

- Criteria for delivery included

* progressive labour

* chorioamnionitis (defined as a temperature $>100.4^{\circ} \mathrm{F}$ plus any 2 of the following: fetal or maternal tachycardia, uterine contractions or tenderness, foul smelling amniotic fluid in the absence of other identifiable cause)

* non-reassuring fetal heart rate pattern including persistent fetal tachycardia or recurrent deceleration and positive cultures for Neisseria gonorrhoeae or GBS

Corticosteroids, tocolysis and prophylactic antibiotics not used

Vaginal examinations not performed in the absence of labour

\begin{tabular}{|c|c|}
\hline Outcomes & $\begin{array}{l}\text { Maternal } \\
\text { - Latency from randomisation to labour } \\
\text { - Latency from randomisation to delivery } \\
\text { - Duration of maternal hospital stay } \\
\text { - Chorioamnionitis: } \mathrm{T}>100.4^{\circ} \mathrm{F} \text { plus } 2 \text { of the following: } \\
\text { * fetal or maternal tachycardia } \\
\text { * uterine contractions or tenderness } \\
\text { * foul-smelling amniotic fluid in the absence of other identifiable cause } \\
\text { - Caesarean delivery } \\
\text { - Postpartum infection requiring antibiotics } \\
\text { Fetal } \\
\text { - Neonatal sepsis: required a positive culture for diagnosis } \\
\text { * subgrouped into suspected and confirmed sepsis: } \\
\quad \square \text { suspected neonatal sepsis: clinical findings suggestive of neonatal infection or persistent leu- } \\
\quad \text { copenia with a WBC count }<4000 / \mathrm{mm}^{3} \text { or a C-reactive protein level elevated greater than } 0.6 ; \\
\text { - } \square \text { confirmed neonatal sepsis: infants with symptoms of sepsis and positive blood cultures } \\
\text { - Birthweight } \\
\text { - Apgar scores } \\
\text { - Respiratory distress: } \\
* \text { required oxygen therapy (at least } 40 \% \text { ) at least } 24 \mathrm{~h} \text { in absence of other identifiable cause } \\
\text { - Pneumonia } \\
\text { - Necrotising enterocolitis } \\
\text { - Intraventricular haemorrhage } \\
\text { - Duration of neonatal hospital stay } \\
\text { - Mortality }\end{array}$ \\
\hline Notes & $\begin{array}{l}\text { - Gestational age: determined clinically on the basis of menstrual history, earliest ultrasound examina- } \\
\text { tion and first clinical assessment } \\
\text { - Ruptured membranes diagnosed by: visualisation of amniotic fluid passing from the cervical os on } \\
\text { sterile speculum examination or the presence of a pool of fluid in the posterior vaginal fornix that was } \\
\text { positive to both Nitrazine paper and ferning tests } \\
\text { - Fetal pulmonary maturity was determined on pooled vaginal fluid (foam stability index } \geq 47 \text { consid- } \\
\text { ered mature), an amniocentesis was performed in the absence of adequate vaginal fluid. }\end{array}$ \\
\hline
\end{tabular}

\section{Risk of bias}


Mercer 1993 (Continued)

Random sequence genera- Low risk $\quad$ Computer-generated random number tables
tion (selection bias)

$\begin{array}{ll}\begin{array}{l}\text { Allocation concealment } \\ \text { (selection bias) }\end{array} & \text { Unclear risk } \\ \end{array}$

was given as to what this entailed.

\begin{tabular}{|c|c|c|}
\hline $\begin{array}{l}\text { Blinding of participants } \\
\text { and personnel (perfor- } \\
\text { mance bias) } \\
\text { All outcomes }\end{array}$ & Low risk & $\begin{array}{l}\text { Blinding not possible due to intervention. However this was likely low risk of } \\
\text { bias due to objective and specific assessment criteria for outcomes, where la } \\
\text { of blinding did not affect treatment decisions or other aspects of care. }\end{array}$ \\
\hline $\begin{array}{l}\text { Blinding of outcome as- } \\
\text { sessment (detection bias) } \\
\text { All outcomes }\end{array}$ & Unclear risk & $\begin{array}{l}\text { Neonatologists were not blinded to the perinatal clinical course. It was not } \\
\text { specified whether the assessors of maternal outcomes were blinded to their } \\
\text { clinical course. }\end{array}$ \\
\hline
\end{tabular}

Alloutcomes

No losses to follow-up or post-randomisation exclusions

Incomplete outcome data Low risk

(attrition bias)

All outcomes

\begin{tabular}{lll}
\hline $\begin{array}{l}\text { Selective reporting (re- } \\
\text { porting bias) }\end{array}$ & Unclear risk & Outcomes only reported in results. Not pre-specified \\
\hline Other bias & Low risk & None noted \\
\hline
\end{tabular}

\section{Morris 2016}

\begin{tabular}{ll}
\hline Methods & Multi-centre, international RCT \\
& Duration of study: May 2004-June 2013 \\
\hline Participants & Setting: 65 tertiary hospitals in 11 countries (Australia, Argentina, Brazil, Egypt, New Zealand, Norway, \\
& Poland, Romania, South Africa, UK, Uruguay) \\
& Participants: 1835 women \\
- & 923 women were randomised to induction of labour \\
- 912 women were randomised to expectant management \\
Inclusion criteria \\
- Over 16 years of age \\
- Singleton pregnancy \\
- Clinically suspected ruptured membranes between 34 weeks-36 + 6 weeks' gestation \\
Exclusion criteria \\
- Established labour \\
- Chorioamnionitis \\
- Meconium staining \\
- Any other contraindications to continuing the pregnancy
\end{tabular}

Interventions

Intervention

- Delivery scheduled as close to randomisation as possible and preferably within $24 \mathrm{~h}$

- Mode of birth was determined by usual obstetric indications

Control: expectant management

Planned early birth versus expectant management for women with preterm prelabour rupture of membranes prior to 37 weeks' 
Criteria for delivery included

- Spontaneous labour

- At term

- When the attending clinician felt that birth was mandated according to usual indications

Antibiotics were prescribed according to local protocols.

Laboratory testing and other management was per usual hospital practice.

Placental histology was encouraged but not uniformly requested.

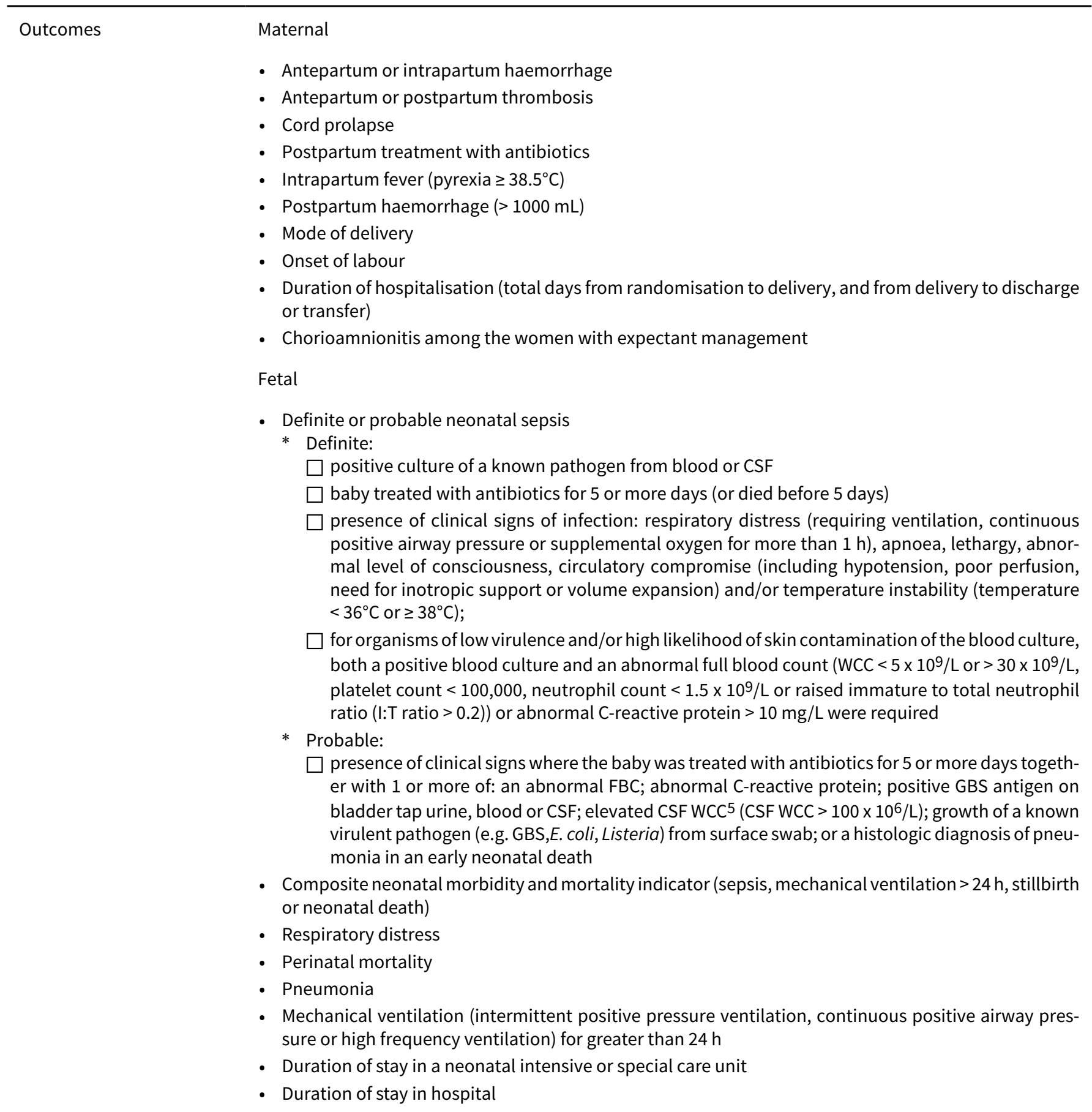

Planned early birth versus expectant management for women with preterm prelabour rupture of membranes prior to 37 weeks' 
Morris 2016 (Continued)

- Birthweight

- Apgar score $\leq 7$ at 5 min

- Antibiotics in the first $48 \mathrm{~h}$

- Lumbar puncture

- Circulatory compromise requiring arterial line

- Fluid bolus or inotropic support

- Receiving breast milk at discharge (exclusive or mixed feeding)

\begin{tabular}{ll}
\hline Notes & Women who presented with ruptured membranes earlier in pregnancy became eligible on reaching \\
& 34 weeks' gestation.
\end{tabular}

\title{
Risk of bias
}

\begin{tabular}{|c|c|c|}
\hline Bias & Authors' judgement & Support for judgement \\
\hline $\begin{array}{l}\text { Random sequence genera- } \\
\text { tion (selection bias) }\end{array}$ & Low risk & $\begin{array}{l}\text { A computer-generated randomisation schedule was used in a 1:1 ratio in bal- } \\
\text { anced blocks of variable size, stratified by centre. }\end{array}$ \\
\hline $\begin{array}{l}\text { Allocation concealment } \\
\text { (selection bias) }\end{array}$ & Low risk & A central telephone service was used for randomisation allocation. \\
\hline $\begin{array}{l}\text { Blinding of participants } \\
\text { and personnel (perfor- } \\
\text { mance bias) } \\
\text { All outcomes }\end{array}$ & Low risk & $\begin{array}{l}\text { Blinding not possible due to intervention. However this was likely low risk of } \\
\text { bias due to objective and specific assessment criteria for outcomes, where lack } \\
\text { of blinding did not affect treatment decisions or other aspects of care. }\end{array}$ \\
\hline $\begin{array}{l}\text { Blinding of outcome as- } \\
\text { sessment (detection bias) } \\
\text { All outcomes }\end{array}$ & Low risk & $\begin{array}{l}\text { The primary outcome was determined by comprehensive review of the neona- } \\
\text { tal data by a central adjudication committee masked to the treatment alloca- } \\
\text { tion. }\end{array}$ \\
\hline $\begin{array}{l}\text { Incomplete outcome data } \\
\text { (attrition bias) } \\
\text { All outcomes }\end{array}$ & Low risk & $\begin{array}{l}\text { All analyses were by intention-to-treat. No participants were excluded from } \\
\text { the primary intention-to-treat analysis due to protocol violations. }\end{array}$ \\
\hline $\begin{array}{l}\text { Selective reporting (re- } \\
\text { porting bias) }\end{array}$ & Low risk & All a-priori outcomes were reported on. \\
\hline Other bias & Low risk & None noted \\
\hline
\end{tabular}

Naef 1998

Methods RCT

Duration of study: 1992-1994

Participants

\author{
Setting: University of Mississippi Medical Center, Jackson, Mississippi, USA \\ Participants: 120 singleton pregnancies \\ - 57 women were randomised to early delivery \\ - 63 women were randomised to expectant management \\ Inclusion criteria \\ - Cephalic presentation \\ - Singleton pregnancy
}

Planned early birth versus expectant management for women with preterm prelabour rupture of membranes prior to 37 weeks' gestation for improving pregnancy outcome (Review)

Copyright @ 2017 The Cochrane Collaboration. Published by John Wiley \& Sons, Ltd. 
Naef 1998 (Continued)

- 34 weeks' gestation to 36 weeks 6 days gestation

- Preterm premature rupture of the membranes

Exclusion criteria

- Non-cephalic presentation

- Fetal distress

- Labour on admission

- Chorioamnionitis

- Maternal medical conditions including hypertension, diabetes, active genital herpes, placenta praevia

- Severe fetal anomalies

- Meconium-stained amniotic fluid

Interventions

Intervention: induction of labour with intravenous oxytocin

Control: expectant management

- Observations and a fetal heart rate assessment every $8 \mathrm{~h}$

- Bed rest and hospitalised until delivery

- Treatment with ampicillin $2 \mathrm{~g}$ intravenously was carried out for all participants for GBS prophylaxis

- Criteria for delivery included:

* non-reassuring fetal status (recurrent decelerations or persistent tachycardia)

* initiation of labour

* signs of clinical chorioamnionitis (defined in the absence of other causes of pyrexia as a temperature $>100.4^{\circ} \mathrm{F}$ with either uterine tenderness, leucocytosis, maternal or fetal tachycardia or a foul smelling vaginal discharge)

Corticosteroids and tocolysis not used. Routine antibiotic prophylaxis for all women

Vaginal examinations not performed in the absence of labour

Outcomes

Maternal

- Admission to delivery interval

- Chorioamnionitis: temperature $>100.4^{\circ} \mathrm{F}$ with either uterine tenderness (or contractions), leuko-cytosis, maternal or fetal tachycardia, or a foul-smelling vaginal discharge

- Postpartum endometritis: temperature $>100.4^{\circ} \mathrm{F}$ after the first 24 postpartum hours with associated uterine tenderness

- Duration of hospital stay

- Mode of delivery

Fetal

- Birthweight

- Apgar scores

- CordpH

- Neonatal nursery admission

- Respiratory distress

- Mechanical ventilation

- Sepsis: positive culture required for diagnosis

- Intraventricular haemorrhage

- Patent ductus arteriosus

- Broncopulmonary dysplasia

- Duration of hospital stay

- Stillbirth

- Neonatal death

Planned early birth versus expectant management for women with preterm prelabour rupture of membranes prior to 37 weeks' 
Naef 1998 (Continued)

Notes
- Gestational age was confirmed by a reliable last menstrual period, early ultrasound or first trimester pelvic examination

* In the absence of certain dates an ultrasound estimate of fetal weight $\geq 1800 \mathrm{~g}$ and $\leq 2500 \mathrm{~g}$ was used as an entry criteria.

- Ruptured membranes was confirmed by visualisation of pooling of fluid in the posterior vaginal fornix on sterile speculum examination or ferning under microscopic review in addition to a positive $\mathrm{Ni}$ trazine test.

\section{Risk of bias}

\begin{tabular}{|c|c|c|}
\hline Bias & Authors' judgement & Support for judgement \\
\hline $\begin{array}{l}\text { Random sequence genera- } \\
\text { tion (selection bias) }\end{array}$ & Low risk & Computer-generated random number cards \\
\hline $\begin{array}{l}\text { Allocation concealment } \\
\text { (selection bias) }\end{array}$ & Unclear risk & $\begin{array}{l}\text { Opaque sealed envelopes but did not state if envelopes were sequentially } \\
\text { numbered }\end{array}$ \\
\hline $\begin{array}{l}\text { Blinding of participants } \\
\text { and personnel (perfor- } \\
\text { mance bias) } \\
\text { All outcomes }\end{array}$ & Low risk & $\begin{array}{l}\text { Blinding not possible due to intervention. However this was likely low risk of } \\
\text { bias due to objective and specific assessment criteria for outcomes, where lack } \\
\text { of blinding did not affect treatment decisions or other aspects of care. }\end{array}$ \\
\hline $\begin{array}{l}\text { Blinding of outcome as- } \\
\text { sessment (detection bias) } \\
\text { All outcomes }\end{array}$ & Unclear risk & $\begin{array}{l}\text { Neonatologists were not blinded to the perinatal clinical course. It was not } \\
\text { specified whether the assessors of maternal outcomes were blinded to their } \\
\text { clinical course. }\end{array}$ \\
\hline $\begin{array}{l}\text { Incomplete outcome data } \\
\text { (attrition bias) } \\
\text { All outcomes }\end{array}$ & Low risk & $\begin{array}{l}\text { No losses to follow-up } \\
\text { No post-randomisation exclusions }\end{array}$ \\
\hline $\begin{array}{l}\text { Selective reporting (re- } \\
\text { porting bias) }\end{array}$ & Low risk & All a-priori outcomes were reported on \\
\hline Other bias & Low risk & None noted \\
\hline
\end{tabular}

Nelson 1985

$\begin{array}{ll}\text { Methods } & \text { RCT } \\ & \text { Duration of study: not specified }\end{array}$

Participants

Setting: Wake Forest University Medical Center, North Carolina, USA

Participants: 68 women

- 22 women randomised to steroid and early delivery group

- 22 women randomised to no-steroid and early delivery group

- 24 women randomised to no-steroid and expectant group

Inclusion criteria

- Women with preterm premature rupture of the membranes

- 28-34 weeks' gestation

Exclusion criteria

- Evidence of fetal distress

Planned early birth versus expectant management for women with preterm prelabour rupture of membranes prior to 37 weeks' 
Nelson 1985 (Continued)

- Active labour

- Cervix $>3 \mathrm{~cm}$ dilated

- Sensitivity to tocolysis

- History of preterm premature rupture of the membranes $>24 \mathrm{~h}$

- Existing infection

Interventions

Intervention: included 2 groups

Group 1. Steroid group who received intramuscular betamethasone $6 \mathrm{mg}$ or $12 \mathrm{mg}$ on admission and another dose $12 \mathrm{~h}$ later

- Ritodrine or terbutaline tocolysis used for a minimum of $24 \mathrm{~h}$ after the first steroid dose

- Delivery between 24-48 h after initial PROM and after $24 \mathrm{~h}$ of steroid therapy

- Caesarean section performed for obstetric indications

Group 2. No-steroid group who received similar treatment to group 1 except no steroids were given

Control: expectant management

- 24 women randomised to expectant group

- Received no tocolytics or steroids

- Caesarean section for usual obstetric indications

Criteria for delivery in the expectant group not specified

Corticosteroids and tocolysis used for early delivery group. Prophylactic antibiotics not used.

Not specified as to whether digital vaginal examinations were performed

\begin{tabular}{|c|c|}
\hline Outcomes & $\begin{array}{l}\text { Maternal } \\
\text { - Duration of latency period } \\
\text { - Maximum temperature } \\
\text { - Maternal sepsis: } \mathrm{T}>37.7^{\circ} \mathrm{C} \text { on } 2 \text { occasions at least } 6 \mathrm{~h} \text { apart, uterine tenderness and a rising WBC } \\
\text { - Use of tocolysis } \\
\text { - Mode of delivery } \\
\text { Fetal } \\
\text { - Birthweight } \\
\text { - Duration of hospitalisation } \\
\text { - Respiratory distress: } \\
* \text { none } \\
\text { * mild } \\
* \text { moderate } \\
\text { * severe } \\
\text { - Neonatal sepsis: positive culture required for diagnosis } \\
\text { Neonatal deaths }\end{array}$ \\
\hline Notes & $\begin{array}{l}\text { - Gestational age confirmed by ultrasound on admission } \\
\text { - Ruptured membranes diagnosed by ferning under microscopy, Nitrazine test and/or visualisation of } \\
\text { pooling of amniotic fluid in the posterior fornix or the vagina at the time of sterile speculum exami- } \\
\text { nation }\end{array}$ \\
\hline
\end{tabular}

\section{Risk of bias}


Nelson 1985 (Continued)

Random sequence genera- Low risk Randomised cards were used. Participants were randomly assigned by drawtion (selection bias) ing a sealed envelope from a group of randomised cards, it did not state how the randomisation sequence was generated.

Allocation concealment Unclear risk Sealed envelopes but did not state if opaque or sequentially numbered
(selection bias)

\begin{tabular}{|c|c|c|}
\hline $\begin{array}{l}\text { Blinding of participants } \\
\text { and personnel (perfor- } \\
\text { mance bias) }\end{array}$ & Low risk & $\begin{array}{l}\text { Blinding not possible due to intervention. However this was likely low risk of } \\
\text { bias due to objective and specific assessment criteria for outcomes, where lack } \\
\text { of blinding did not affect treatment decisions or other aspects of care. }\end{array}$ \\
\hline
\end{tabular}

All outcomes

\begin{tabular}{lll}
\hline $\begin{array}{l}\text { Blinding of outcome as- } \\
\text { sessment (detection bias) } \\
\text { All outcomes }\end{array}$ & Unclear risk & Not specified \\
\hline $\begin{array}{l}\text { Incomplete outcome data } \\
\text { (attrition bias) }\end{array}$ & Low risk & $\begin{array}{l}\text { No losses to follow-up } \\
\text { All outcomes }\end{array}$ \\
\hline
\end{tabular}

\begin{tabular}{lll}
\hline $\begin{array}{l}\text { Selective reporting (re- } \\
\text { porting bias) }\end{array}$ & Low risk & All a-priori outcomes were reported on \\
\hline Other bias & Low risk & None noted \\
\hline
\end{tabular}

Spinnato 1987

$\begin{array}{ll}\text { Methods } & \text { RCT } \\ & \text { Duration of study: } 1 \text { June 1983-15 November } 1984\end{array}$

Setting: E.H. Crump Women's Hospital and Perinatal Center, Memphis, Tennessee, USA
Participants: 47 women
- 26 women randomised to early delivery
- 21 women randomised to expectant management
Inclusion criteria
- $25-36$ weeks' gestation
- Preterm premature rupture of the membranes
- Fetal pulmonary maturity demonstrated on amniotic fluid (an L/S ratio of 2 or more or a Foam stability
index of 47 or more)
Exclusion criteria
- Spontaneous labour at presentation
- Chorioamnionitis
Intervention: early delivery either by induction of labour with oxytocin or caesarean section for all non-
vertex presentations
Control: expectant management
- External electronic fetal monitoring performed for 8 - $12 \mathrm{~h}$
- Bed rest for as long as amniotic fluid leakage continued
- Hospital discharge permitted at the discretion of the attending physician

Planned early birth versus expectant management for women with preterm prelabour rupture of membranes prior to 37 weeks' 
Criteria for delivery in the expectant group of women

- Labour

- Fetal distress

- Chorioamnionitis

Corticosteroids, tocolysis and prophylactic antibiotics not used

Vaginal examinations not performed in the absence of labour

\begin{tabular}{|c|c|}
\hline Outcomes & $\begin{array}{l}\text { Maternal } \\
\text { - Time from rupture of membranes to labour } \\
\text { - Time from rupture of membranes to delivery } \\
\text { - Duration of labour } \\
\text { - Delivery by caesarean section } \\
\text { - Chorioamnionitis: maternal fever }\left(38^{\circ} \mathrm{C} \text { on } 2 \text { occasions or a single reading on } 38.3^{\circ} \mathrm{C} \text { ) with foul-smelling }\right. \\
\text { vaginal discharge and uterine tenderness, or when no other source for maternal fever could be iden- } \\
\text { tified } \\
\text { - Endometritis: fever (excluding during } 1 \text { st } 24 \text { h postpartum) plus uterine tenderness or foul-smelling } \\
\text { lochia } \\
\text { Fetal } \\
\text { - Birthweight } \\
\text { - Apgar score }<7 \text { at } 5 \text { min } \\
\text { - Neonatal duration of hospitalisation } \\
\text { - Hyaline membrane disease } \\
\text { - Transient pulmonary insufficiency (includes respiratory insufficiency of prematurity, RDS, and tran- } \\
\text { - sient tachypnoea of the newborn) } \\
\text { - Need for mechanical ventilation }>24 \mathrm{~h} \\
\text { - Need for oxygen therapy }>3 \mathrm{~d} \\
\text { - Sepsis: not specified if positive culture required for diagnosis } \\
\text { - Pneumonia } \\
\text { - Meningitis } \\
\text { - Necrotising enterocolitis } \\
\text { - Intracranial haemorrhage } \\
\text { - Perinatal death }\end{array}$ \\
\hline Notes & $\begin{array}{l}\text { - Gestational age determined by "best clinical estimate" including ultrasound examination on admis- } \\
\text { sion } \\
\text { - Ruptured membranes diagnosed by speculum examination demonstrating pooled amniotic fluid in } \\
\text { the vaginal vault or alkaline pH by Nitrazine paper and microscopic ferning of air dried vaginal vault } \\
\text { fluid } \\
\text { - Fetal pulmonary maturity required }\end{array}$ \\
\hline
\end{tabular}

\section{Risk of bias}

\begin{tabular}{lll}
\hline Bias & Authors' judgement & Support for judgement \\
\hline $\begin{array}{l}\text { Random sequence genera- } \\
\text { tion (selection bias) }\end{array}$ & Low risk & Sequential sealed envelope odd-even random numbers \\
\hline
\end{tabular}


Spinnato 1987 (Continued)

Allocation concealment Unclear risk Sealed envelopes, did not specify if opaque or sequentially numbered (selection bias)

Blinding of participants Low risk and personnel (performance bias)

All outcomes
Blinding not possible due to intervention. However this was likely low risk of bias due to objective and specific assessment criteria for outcomes, where lack of blinding did not affect treatment decisions or other aspects of care.

\begin{tabular}{|c|c|c|}
\hline $\begin{array}{l}\text { Blinding of outcome as- } \\
\text { sessment (detection bias) } \\
\text { All outcomes }\end{array}$ & Unclear risk & $\begin{array}{l}\text { - Obstetricians not blinded to maternal allocation group } \\
\text { - Neonatologists blinded to perinatal clinical course } \\
\text { However, did not mention if outcome assessors were blinded }\end{array}$ \\
\hline
\end{tabular}

Incomplete outcome data High risk

Losses to follow-up: no losses to follow-up

(attrition bias)

Post-randomisation exclusions: 7 women for preterm labour, 4 women for

All outcomes

"protocol violations", and 4 other women with unspecified reason

Selective reporting (re- Unclear risk Outcomes only reported in results. Not pre-specified

porting bias)

Other bias Low risk None noted

Van der Ham 2012a

\begin{tabular}{ll} 
Methods & Multi-centre, parallel, open-label RCT \\
& Duration of study: January 2007-September 2009 \\
\hline Participants & Setting: 8 academic and 52 non-academic hospitals in the Netherlands \\
Participants: 532 women & \\
- 266 women randomised to early birth (included 268 babies) \\
- 266 women randomised to expectant management (included 270 babies) \\
Inclusion criteria \\
- Singleton or twin pregnancy with PPROM between 34 and $36+6$ weeks' gestation who were not in \\
- labour within 24 h of PPROM \\
Explusion criteria \\
- Monochorionic multiple pregnancy \\
- Abnormal (non-reassuring) cardiotocogram \\
- Meconium-stained amniotic fluid \\
- Signs of intrauterine infection \\
- Major fetal anomalies \\
- Haemolysis, elevated liver enzymes, and low platelets (HELLP syndrome) \\
- Severe pre-eclampsia
\end{tabular}

Interventions

Intervention: induction of labour within $24 \mathrm{~h}$ after randomisation. Induction performed according to national guidelines. After vaginal examination, labour induced with either prostaglandin or oxytocin, or caesarean section performed as soon as feasible in case of planned caesarean

Control: expectant management 
- Monitored according to local protocol until spontaneous birth, which could be outpatient or inpatient

- Daily maternal temperature, monitoring and twice-weekly blood sampling for maternal leukocyte count and C-reactive protein measurement

Criteria for delivery in the expectant group of women

- Induced at 37 weeks according to national guidelines

- If planned caesarean section, caesarean section performed as soon as labour commenced

- Induction of labour < 37 weeks if clinical signs of infection or other fetal or maternal indication for birth

Tocolysis and prophylactic antibiotics used according to local protocols

Corticosteroids given in PPROM $<34$ weeks' gestation

Vaginal examinations not performed in the absence of labour

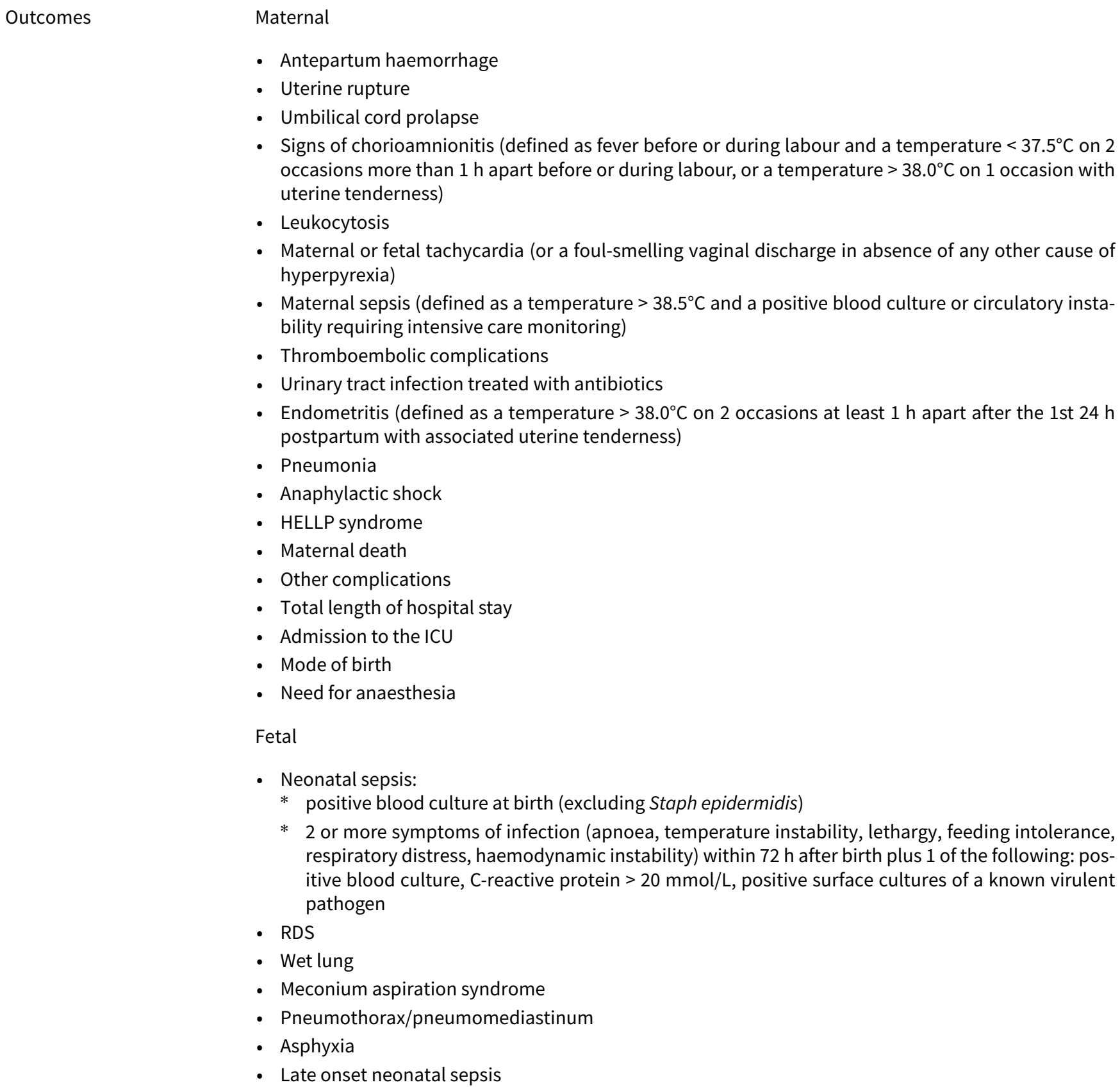

- Antepartum haemorrhage

- Uterine rupture

- Umbilical cord prolapse

- Signs of chorioamnionitis (defined as fever before or during labour and a temperature $<37.5^{\circ} \mathrm{C}$ on 2 occasions more than $1 \mathrm{~h}$ apart before or during labour, or a temperature $>38.0^{\circ} \mathrm{C}$ on 1 occasion with uterine tenderness)

- Leukocytosis

- Maternal or fetal tachycardia (or a foul-smelling vaginal discharge in absence of any other cause of hyperpyrexia)

- Maternal sepsis (defined as a temperature $>38.5^{\circ} \mathrm{C}$ and a positive blood culture or circulatory instability requiring intensive care monitoring)

- Thromboembolic complications

- Urinary tract infection treated with antibiotics

- Endometritis (defined as a temperature $>38.0^{\circ} \mathrm{C}$ on 2 occasions at least $1 \mathrm{~h}$ apart after the 1 st $24 \mathrm{~h}$ postpartum with associated uterine tenderness)

- Pneumonia

- Anaphylactic shock

- HELLP syndrome

- Maternal death

- Other complications

- Total length of hospital stay

- Admission to the ICU

- Mode of birth

- Need for anaesthesia

Fetal

- Neonatal sepsis:

* positive blood culture at birth (excluding Staph epidermidis)

* 2 or more symptoms of infection (apnoea, temperature instability, lethargy, feeding intolerance, respiratory distress, haemodynamic instability) within $72 \mathrm{~h}$ after birth plus 1 of the following: positive blood culture, C-reactive protein $>20 \mathrm{mmol} / \mathrm{L}$, positive surface cultures of a known virulent pathogen

- RDS

- Wet lung

- Meconium aspiration syndrome

- Pneumothorax/pneumomediastinum

- Asphyxia

- Late onset neonatal sepsis 
Van der Ham 2012a (Continued)

- Hypoglycaemia

- Necrotizing enterocolitis

- Hyperbilirubinaemia

- Intraventricular haemorrhage

- Periventricular leucomalacia

- Convulsions

- Other neurological abnormalities

- Other complications

- Intrapartum death

- Total length of hospital stay and admission

- Length of stay on NICU

Notes

- Rupture of membranes was diagnosed based on history and clinical findings such as gross vaginal fluid loss in combination with other available diagnostic test methods.

- Gestational age was based either on first trimester ultrasound scan or, in women with a regular cycle, on the first day of the last menstrual cycle if the expected date of birth differed less than 7 days from that estimated by ultrasound. In women with unknown EDD, gestational age was estimated by 2 nd trimester ultrasound measurements.

\section{Risk of bias}

\begin{tabular}{|c|c|c|}
\hline Bias & Authors' judgement & Support for judgement \\
\hline $\begin{array}{l}\text { Random sequence genera- } \\
\text { tion (selection bias) }\end{array}$ & Low risk & $\begin{array}{l}\text { A computer-generated randomisation schedule was used in a } 1: 1 \text { ratio using a } \\
\text { block size of } 4 \text {, stratified for centre and parity. }\end{array}$ \\
\hline $\begin{array}{l}\text { Allocation concealment } \\
\text { (selection bias) }\end{array}$ & Low risk & $\begin{array}{l}\text { Randomisation allocation was performed on a central password-protected } \\
\text { web-based application. }\end{array}$ \\
\hline $\begin{array}{l}\text { Blinding of participants } \\
\text { and personnel (perfor- } \\
\text { mance bias) } \\
\text { All outcomes }\end{array}$ & Low risk & $\begin{array}{l}\text { Blinding not possible due to intervention. However this was likely low risk of } \\
\text { bias due to objective and specific assessment criteria for outcomes, where lack } \\
\text { of blinding did not affect treatment decisions or other aspects of care. }\end{array}$ \\
\hline $\begin{array}{l}\text { Blinding of outcome as- } \\
\text { sessment (detection bias) } \\
\text { All outcomes }\end{array}$ & Low risk & $\begin{array}{l}\text { Criteria for sepsis were entered in the database and the case was judged by an } \\
\text { independent panel of paediatricians who were unaware of the allocation of } \\
\text { randomisation. }\end{array}$ \\
\hline $\begin{array}{l}\text { Incomplete outcome data } \\
\text { (attrition bias) } \\
\text { All outcomes }\end{array}$ & Low risk & $\begin{array}{l}\text { Data analysed on intention-to-treat basis. } 2 \text { participants were excluded post } \\
\text { randomisation from the primary intention-to-treat analysis due to ineligibility. }\end{array}$ \\
\hline $\begin{array}{l}\text { Selective reporting (re- } \\
\text { porting bias) }\end{array}$ & Low risk & All a-priori outcomes were reported on. \\
\hline Other bias & Low risk & None noted \\
\hline
\end{tabular}

\section{Van der Ham 2012b}

$\begin{array}{ll}\text { Methods } & \text { Multi-centre, parallel, open-label RCT } \\ \text { Duration of study: December 2009-January } 2011\end{array}$

\section{Participants}

Setting: 8 academic and 52 non-academic hospitals in the Netherlands

Participants: 195 women

Planned early birth versus expectant management for women with preterm prelabour rupture of membranes prior to 37 weeks' 
- 100 women randomised to early birth (included 100 babies)

- 95 women randomised to expectant management (included 98 babies)

Inclusion criteria

- Singleton or twin pregnancy with PPROM between 34 and $36+6$ weeks' gestation who were not in labour within $24 \mathrm{~h}$ of PPROM

- PPROM had to be diagnosed after $26+0$ weeks

Exclusion criteria

- Monochorionic multiple pregnancy

- Abnormal (non-reassuring) cardiotocogram

- Meconium-stained amniotic fluid

- Signs of intrauterine infection

- Major fetal anomalies

- HELLP syndrome

- Severe pre-eclampsia

Intervention: induction of labour with $24 \mathrm{~h}$ after randomisation. Induction performed according to national guidelines. After vaginal examination, labour induced with either prostaglandin or oxytocin, or caesarean section performed as soon as feasible in case of planned caesarean.

Control: expectant management

- Monitored according to local protocol until spontaneous birth which could be outpatient or inpatient

- Daily maternal temperature, monitoring and twice-weekly blood sampling for maternal leukocyte count and C-reactive protein measurement

Criteria for birth in the expectant group of women

- Induced at 37 weeks according to national guidelines

- If planned caesarean section, caesarean section performed as soon as labour commenced

- Induction of labour <37 weeks if clinical signs of infection or other fetal or maternal indication for birth

Tocolysis and prophylactic antibiotics used according to local protocols

Corticosteroids given in PPROM $<34$ weeks' gestation

Vaginal examinations not performed in the absence of labour

Outcomes Maternal

- Antepartum haemorrhage

- Uterine rupture

- Umbilical cord prolapse

- Signs of chorioamnionitis (defined as fever before or during labour and a temperature $<37.5^{\circ} \mathrm{C}$ on 2 occasions more than $1 \mathrm{~h}$ apart before or during labour, or a temperature $>38.0^{\circ} \mathrm{C}$ on 1 occasion with uterine tenderness)

- Leukocytosis

- Maternal or fetal tachycardia (or a foul-smelling vaginal discharge in absence of any other cause of hyperpyrexia)

- Maternal sepsis (defined as a temperature $>38.5^{\circ} \mathrm{C}$ and a positive blood culture or circulatory instability requiring intensive care monitoring)

- Thromboembolic complications

- Urinary tract infection treated with antibiotics

- Endometritis (defined as a temperature $>38.0^{\circ} \mathrm{C}$ on 2 occasions at least $1 \mathrm{~h}$ apart after the 1 st $24 \mathrm{~h}$ postpartum with associated uterine tenderness)

- Pneumonia

Planned early birth versus expectant management for women with preterm prelabour rupture of membranes prior to 37 weeks' 
- Anaphylactic shock

- HELLP syndrome

- Maternal death

- Other complications

- Total length of hospital stay

- Admission to the ICU

- Mode of birth

- Need for anaesthesia

Fetal

- Neonatal sepsis:

* positive blood culture at birth (excluding Staph epidermidis);

* 2 or more symptoms of infection (apneas, temperature instability, lethargy, feeding intolerance, respiratory distress, haemodynamic instability) within $72 \mathrm{~h}$ after birth plus 1 of the following: positive blood culture, C-reactive protein $>20 \mathrm{mmol} / \mathrm{L}$, positive surface cultures of a known virulent pathogen

- RDS

- Wet lung

- Meconium aspiration syndrome

- Pneumothorax/pneumomediastinum

- Asphyxia

- Late onset neonatal sepsis

- Hypoglycaemia

- Necrotizing enterocolitis

- Hyperbilirubinaemia

- Intraventricular haemorrhage

- Periventricular leucomalacia

- Convulsions

- Other neurological abnormalities

- Other complications

- Intrapartum death

- Total length of hospital stay and admission

- Length of stay on NICU

- Rupture of membranes was diagnosed based on history and clinical findings such as gross vaginal fluid loss in combination with other available diagnostic test methods.

- Gestational age was based either on first trimester ultrasound scan or, in women with a regular cycle, on the first day of the last menstrual cycle if the expected date of birth differed less than 7 days from the estimated by ultrasound. in women with unknown EDD, gestational age was estimated by 2nd trimester ultrasound measurements.

\section{Risk of bias}

\section{Bias}

\section{Authors' judgement Support for judgement}

$\begin{array}{ll}\begin{array}{l}\text { Random sequence genera- } \\ \text { tion (selection bias) }\end{array} & \text { Low risk }\end{array} \quad \begin{aligned} & \text { A computer-generated randomisation schedule was used in a 1:1 ratio using a } \\ & \text { block size of } 4, \text { stratified for centre and parity. }\end{aligned}$

\begin{tabular}{lll}
\hline $\begin{array}{l}\text { Allocation concealment } \\
\text { (selection bias) }\end{array}$ & Low risk & $\begin{array}{l}\text { Randomisation allocation was performed on a central password-protected } \\
\text { web-based application. }\end{array}$ \\
\hline $\begin{array}{l}\text { Blinding of participants } \\
\begin{array}{l}\text { and personnel (perfor- } \\
\text { mance bias) }\end{array}\end{array}$ & Low risk & $\begin{array}{l}\text { Blinding not possible due to intervention. However this was likely low risk of } \\
\text { bias due to objective and specific assessment criteria for outcomes, where lack } \\
\text { of blinding did not affect treatment decisions or other aspects of care. }\end{array}$
\end{tabular}


Van der Ham 2012b (Continued)

All outcomes

$\begin{array}{lll}\begin{array}{l}\text { Blinding of outcome as- } \\ \text { sessment (detection bias) }\end{array} & \text { Low risk } & \begin{array}{l}\text { Criteria for sepsis were entered in the database and the case was judged by an } \\ \text { independent panel of paediatricians who were unaware of the allocation of } \\ \text { all outcomes }\end{array}\end{array}$

All outcomes randomisation.

Incomplete outcome data Low risk Data analysed on intention-to-treat basis. No participants were excluded.

(attrition bias)

All outcomes

\begin{tabular}{lll}
\hline $\begin{array}{l}\text { Selective reporting (re- } \\
\text { porting bias) }\end{array}$ & Low risk & All a-priori outcomes were reported on. \\
\hline Other bias & Low risk & None noted \\
\hline
\end{tabular}

2 perinatal deaths resulting from lethal congenital abnormalities were excluded from analyses post-randomisation.

BPD: biparietal diameter of the fetal head

CSF: cerebrospinal fluid

EDD: estimated due date

GBS: Group B Streptococcus/Streptococcal

HELLP: haemolysis, elevated liver enzymes, and low platelets

L/S: Lecithin-sphingomyelin

NICU: neonatal intensive care unit

PPROM: preterm prelabour rupture of the membranes

$\mathrm{RCT}$ : randomised controlled trial

RDS: respiratory distress syndrome

WBC: white blood cells

WCC: white cell count

Characteristics of excluded studies [ordered by study ID]

\begin{tabular}{ll}
\hline Study & Reason for exclusion \\
\hline Bergstrom 1991 & Not a RCT \\
\hline Cararach 1994 & $\begin{array}{l}\text { Unable to establish that all women were prior to } 37 \text { weeks' gestation. } \\
\text { Included women at term }\end{array}$ \\
\hline Decavalas 1995 & $\begin{array}{l}\text { Assessed effect of tocolysis in women with PPROM. Tocolysis was used for } 24 \mathrm{~h} \text { in } 1 \text { group and until } \\
\text { birth in the other group of women. Primary outcome was efficacy of tocolysis - delivered if tocolysis } \\
\text { failed or if complications occurred relating to tocolysis therapy. No expectant management arm of } \\
\text { study included. Also women were excluded if tocolysis failed and they delivered within } 24 \mathrm{~h} \text { of ran- } \\
\text { domisation. }\end{array}$ \\
\hline
\end{tabular}

El-Qarmalawi $1990 \quad$ Assessed treatment with either prostaglandins or oxytocin for women with PPROM. In all women induction was commenced $3 \mathrm{~h}$ after PPROM. The study did not assess the intervention of early birth, rather the mode of induction of labour.

\begin{tabular}{ll}
\hline Fayez 1978 & Quasi-randomised trial \\
Allocation to treatment groups by odd or even hospital record number
\end{tabular}

Gloeb 1989 Included women from 34-41 completed weeks' gestation

Unable to extract subgroup of women prior to term

Griffith-Jones $1990 \quad$ Unable to establish that all women were prior to term

Included women greater than 35 weeks' gestation

Planned early birth versus expectant management for women with preterm prelabour rupture of membranes prior to 37 weeks' 


\begin{tabular}{|c|c|}
\hline Study & Reason for exclusion \\
\hline Haghighi 2006 & $\begin{array}{l}\text { Assessed intravaginal misoprostol for induction of labour in women with PPROM for pregnancy ter- } \\
\text { mination }\end{array}$ \\
\hline Lacaze 2006 & This study was terminated prematurely due to slow recruitment. \\
\hline Ladfors 1996 & $\begin{array}{l}\text { Unable to establish that all women were prior to } 37 \text { weeks. } \\
\text { Study included women from } 34-42 \text { weeks }\end{array}$ \\
\hline Makhlouf 1997 & $\begin{array}{l}\text { Abstract available only } \\
\text { Randomisation schema not available in abstract. Abstract did not quantify events in either early } \\
\text { birth or expectant management groups }\end{array}$ \\
\hline Mateos 1998 & $\begin{array}{l}\text { Included women at term and prior to term. Included women greater than } 34 \text { weeks' gestation but } \\
\text { subgroup analysis of women prior to term not able to be performed }\end{array}$ \\
\hline Miodovnik 1988 & Did not assess intervention of early birth \\
\hline Parsons 1989 & $\begin{array}{l}\text { Abstract only } \\
\text { Not enough information to assess methodology for inclusion or obtain meaningful results States } \\
\text { trial was prospective but it does not appear to have been a randomised trial }\end{array}$ \\
\hline Perez 1992 & $\begin{array}{l}\text { Did not include a group of women with expectant management. Women with PPROM were ran- } \\
\text { domised to either induction with prostaglandin or induction with oxytocin within } 12 \mathrm{~h} \text { of present- } \\
\text { ing to hospital with PPROM }\end{array}$ \\
\hline Van Heerden 1996 & $\begin{array}{l}\text { Included women prior to term and at term } \\
\text { Unable to extract data on subgroup of women who were prior to term }\end{array}$ \\
\hline
\end{tabular}

PPROM: preterm prelabour rupture of the membranes

$\mathrm{RCT}$ : randomised controlled trial

Characteristics of ongoing studies [ordered by study ID]

Pasquier 2006

\begin{tabular}{ll}
\hline Trial name or title & The MICADO study \\
\hline Methods & $\begin{array}{l}\text { A RCT in } 23 \text { hospitals to compare intentional birth with expectant management in women with } \\
\text { preterm premature rupture of the membranes. }\end{array}$ \\
\hline Participants & Women with preterm prelabour rupture of the membranes between 28 and 31 weeks' gestation. \\
& Randomised to intervention or control 24 h after the second dose of corticosteroids \\
\hline Interventions & Early birth \\
\hline Outcomes & 2006 \\
\hline Starting date & Jean Charles Pasquier, Department of Obstetrics and Gynecology, Hospital Herriot, Lyon, France. \\
\hline Contact information & \\
\hline Notes & \\
\hline
\end{tabular}




\section{DATA AND ANALYSES}

\section{Comparison 1. Any planned birth versus expectant management: by type}

\begin{tabular}{|c|c|c|c|c|}
\hline Outcome or subgroup title & No. of studies & $\begin{array}{l}\text { No. of partici- } \\
\text { pants }\end{array}$ & Statistical method & Effect size \\
\hline 1 Neonatal infection/sepsis & 12 & 3628 & Risk Ratio (M-H, Fixed, 95\% Cl) & $0.93[0.66,1.30]$ \\
\hline $\begin{array}{l}2 \text { Neonatal infection confirmed } \\
\text { with positive blood culture }\end{array}$ & 7 & 2925 & Risk Ratio (M-H, Fixed, 95\% Cl) & $1.24[0.70,2.21]$ \\
\hline 3 Respiratory distress syndrome & 12 & 3622 & Risk Ratio (M-H, Fixed, 95\% Cl) & $1.26[1.05,1.53]$ \\
\hline 4 Caesarean section & 12 & 3620 & Risk Ratio (M-H, Fixed, 95\% Cl) & $1.26[1.11,1.44]$ \\
\hline 5 Perinatal mortality & 11 & 3319 & Risk Ratio (M-H, Fixed, 95\% Cl) & $1.76[0.89,3.50]$ \\
\hline 6 Intrauterine death & 11 & 3321 & Risk Ratio (M-H, Fixed, 95\% Cl) & $0.45[0.13,1.55]$ \\
\hline 7 Cord prolapse & 4 & 2722 & Risk Ratio (M-H, Fixed, 95\% Cl) & $1.24[0.33,4.61]$ \\
\hline 8 Gestational age at birth (weeks) & 8 & 3139 & $\begin{array}{l}\text { Mean Difference (IV, Fixed, 95\% } \\
\mathrm{CI} \text { ) }\end{array}$ & $-0.48[-0.57,-0.39]$ \\
\hline 9 Neonatal death & 11 & 3316 & Risk Ratio (M-H, Fixed, 95\% Cl) & $2.55[1.17,5.56]$ \\
\hline 10 Suspected neonatal infection & 3 & 829 & Risk Ratio (M-H, Fixed, 95\% Cl) & $0.56[0.36,0.88]$ \\
\hline $\begin{array}{l}11 \text { Neonatal treatment with antibi- } \\
\text { otics }\end{array}$ & 4 & 2638 & $\begin{array}{l}\text { Risk Ratio (M-H, Random, 95\% } \\
\mathrm{Cl} \text { ) }\end{array}$ & $0.86[0.63,1.19]$ \\
\hline 12 Need for ventilation & 7 & 2895 & Risk Ratio (M-H, Fixed, 95\% Cl) & $1.27[1.02,1.58]$ \\
\hline $\begin{array}{l}13 \text { Duration of oxygen therapy } \\
\text { (days) }\end{array}$ & 1 & 73 & $\begin{array}{l}\text { Mean Difference (IV, Fixed, 95\% } \\
\mathrm{CI} \text { ) }\end{array}$ & $-3.05[-6.92,0.82]$ \\
\hline 14 Umbilical cord arterial pH & 1 & 120 & $\begin{array}{l}\text { Mean Difference (IV, Fixed, 95\% } \\
\mathrm{CI} \text { ) }\end{array}$ & $0.09[0.07,0.11]$ \\
\hline 15 Birthweight (g) & 10 & 3263 & $\begin{array}{l}\text { Mean Difference (IV, Random, } \\
95 \% \mathrm{CI})\end{array}$ & $-47.10[-96.00,1.80]$ \\
\hline $\begin{array}{l}16 \text { Apgar score less than } 7 \text { at } 5 \text { min- } \\
\text { utes }\end{array}$ & 5 & 2700 & Risk Ratio (M-H, Fixed, 95\% Cl) & $0.96[0.54,1.69]$ \\
\hline $\begin{array}{l}17 \text { Abnormality on cerebral ultra- } \\
\text { sound }\end{array}$ & 3 & 271 & Risk Ratio (M-H, Fixed, 95\% Cl) & $1.90[0.52,6.92]$ \\
\hline 18 Periventricular leukomalacia & 2 & 707 & Risk Ratio (M-H, Fixed, 95\% Cl) & $1.00[0.14,6.99]$ \\
\hline $\begin{array}{l}19 \text { Cerebroventricular haemor- } \\
\text { rhage }\end{array}$ & 6 & 1095 & Risk Ratio (M-H, Fixed, 95\% Cl) & $1.19[0.40,3.52]$ \\
\hline 20 Necrotising enterocolitis & 6 & 2842 & Risk Ratio (M-H, Fixed, 95\% Cl) & $0.81[0.25,2.62]$ \\
\hline
\end{tabular}




\begin{tabular}{|c|c|c|c|c|}
\hline Outcome or subgroup title & No. of studies & $\begin{array}{l}\text { No. of partici- } \\
\text { pants }\end{array}$ & Statistical method & Effect size \\
\hline 21 Severe respiratory distress & 3 & 321 & Risk Ratio (M-H, Fixed, 95\% Cl) & $1.54[0.80,2.97]$ \\
\hline $\begin{array}{l}22 \text { Admission to neonatal intensive } \\
\text { care unit }\end{array}$ & 4 & 2691 & Risk Ratio (M-H, Fixed, 95\% Cl) & $1.16[1.08,1.24]$ \\
\hline $\begin{array}{l}23 \text { Length of stay in neonatal in- } \\
\text { tensive care unit (days) }\end{array}$ & 4 & 2121 & $\begin{array}{l}\text { Mean Difference (IV, Random, } \\
95 \% \mathrm{CI} \text { ) }\end{array}$ & $-0.17[-1.62,1.27]$ \\
\hline $\begin{array}{l}24 \text { Duration (days) from birth to } \\
\text { neonatal hospital discharge }\end{array}$ & 6 & 2832 & $\begin{array}{l}\text { Mean Difference (IV, Random, } \\
95 \% \mathrm{CI})\end{array}$ & $0.67[-0.28,1.61]$ \\
\hline 25 Chorioamnionitis & 8 & 1358 & $\begin{array}{l}\text { Risk Ratio (M-H, Random, 95\% } \\
\mathrm{CI} \text { ) }\end{array}$ & $0.50[0.26,0.95]$ \\
\hline 26 Endometritis & 7 & 2980 & Risk Ratio (M-H, Fixed, 95\% Cl) & $1.61[1.00,2.59]$ \\
\hline 27 Postpartum fever & 1 & 1835 & Risk Ratio (M-H, Fixed, 95\% Cl) & $0.52[0.26,1.03]$ \\
\hline 28 Placental abruption & 1 & 1835 & Risk Ratio (M-H, Fixed, 95\% Cl) & $1.19[0.36,3.87]$ \\
\hline 29 Induction of labour & 4 & 2691 & Risk Ratio (M-H, Fixed, 95\% Cl) & $2.18[2.01,2.36]$ \\
\hline $\begin{array}{l}30 \text { Use of epidural/spinal anaes- } \\
\text { thesia }\end{array}$ & 3 & 2562 & $\begin{array}{l}\text { Risk Ratio (M-H, Random, 95\% } \\
\mathrm{Cl} \text { ) }\end{array}$ & $1.28[0.99,1.65]$ \\
\hline 31 Vaginal birth & 12 & 3618 & Risk Ratio (M-H, Fixed, 95\% Cl) & $0.94[0.91,0.97]$ \\
\hline 32 Operative vaginal birth & 4 & 2685 & Risk Ratio (M-H, Fixed, 95\% Cl) & $0.85[0.67,1.10]$ \\
\hline $\begin{array}{l}33 \text { Caesarean section for fetal dis- } \\
\text { tress }\end{array}$ & 7 & 2918 & Risk Ratio (M-H, Fixed, 95\% Cl) & $0.89[0.66,1.20]$ \\
\hline $\begin{array}{l}34 \text { Duration (days) of maternal } \\
\text { hospitalisation }\end{array}$ & 6 & 2848 & $\begin{array}{l}\text { Mean Difference (IV, Random, } \\
95 \% \mathrm{CI})\end{array}$ & $-1.75[-2.45,-1.05]$ \\
\hline $\begin{array}{l}35 \text { Duration (days) of antenatal } \\
\text { hospitalisation }\end{array}$ & 1 & 73 & $\begin{array}{l}\text { Mean Difference (IV, Fixed, 95\% } \\
\mathrm{CI})\end{array}$ & $-6.30[-9.67,-2.93]$ \\
\hline $\begin{array}{l}36 \text { Duration (days) of maternal } \\
\text { hospitalisation (excluding trials } \\
\text { with antenatal discharge) }\end{array}$ & 2 & 213 & $\begin{array}{l}\text { Mean Difference (IV, Random, } \\
95 \% \mathrm{CI})\end{array}$ & $-1.64[-3.06,-0.23]$ \\
\hline $\begin{array}{l}37 \text { Time (hours) from randomisa- } \\
\text { tion to birth }\end{array}$ & 3 & 2571 & $\begin{array}{l}\text { Mean Difference (IV, Fixed, 95\% } \\
\mathrm{CI})\end{array}$ & $\begin{array}{l}-79.48[-88.27 \\
-70.69]\end{array}$ \\
\hline $\begin{array}{l}38 \text { Disability at } 2 \text { years, abnormal } \\
\mathrm{CBCL}\end{array}$ & 1 & 199 & Risk Ratio (M-H, Fixed, 95\% Cl) & $0.64[0.26,1.59]$ \\
\hline $\begin{array}{l}39 \text { Disability at } 2 \text { years, abnormal } \\
\text { ASQ }\end{array}$ & 1 & 228 & Risk Ratio (M-H, Fixed, 95\% Cl) & $0.61[0.35,1.05]$ \\
\hline 40 Maternal satisfaction & 1 & 493 & Risk Ratio (M-H, Fixed, 95\% Cl) & $0.99[0.86,1.13]$ \\
\hline 41 Breastfeeding > 12 weeks & 1 & 415 & Risk Ratio (M-H, Fixed, 95\% Cl) & $0.95[0.80,1.12]$ \\
\hline
\end{tabular}




\section{Analysis 1.1. Comparison 1 Any planned birth versus expectant management: by type, Outcome 1 Neonatal infection/sepsis.}

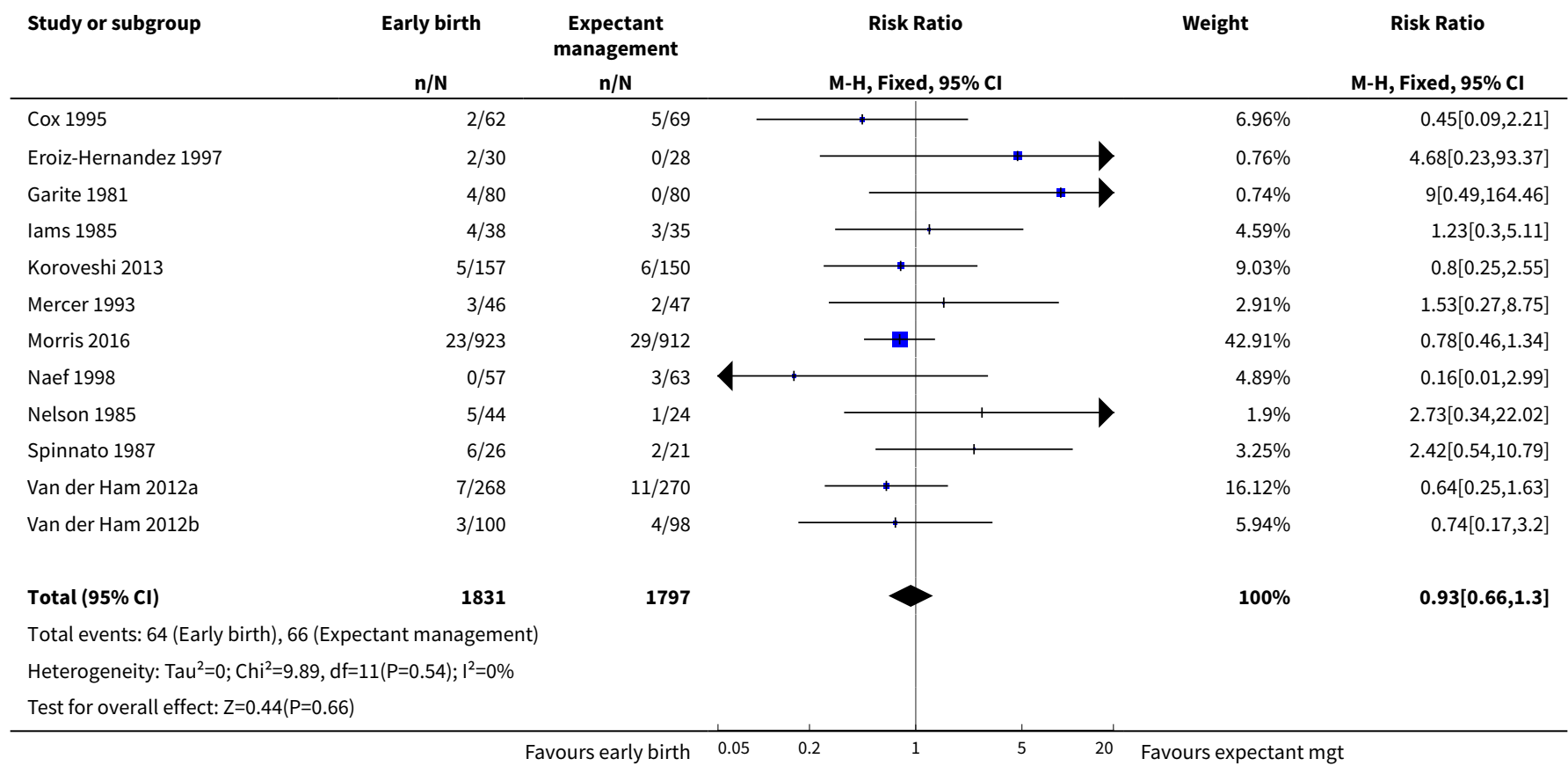

Analysis 1.2. Comparison 1 Any planned birth versus expectant management: by type, Outcome 2 Neonatal infection confirmed with positive blood culture.

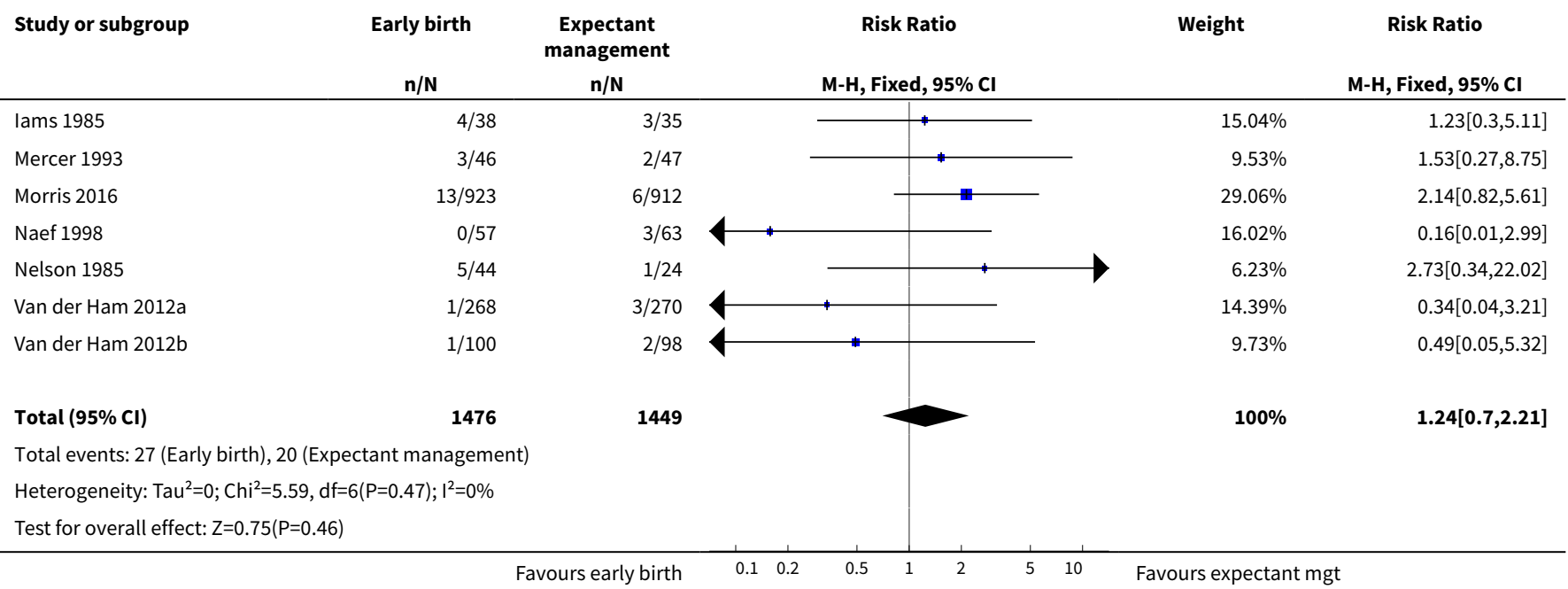


Analysis 1.3. Comparison 1 Any planned birth versus expectant management: by type, Outcome 3 Respiratory distress syndrome.

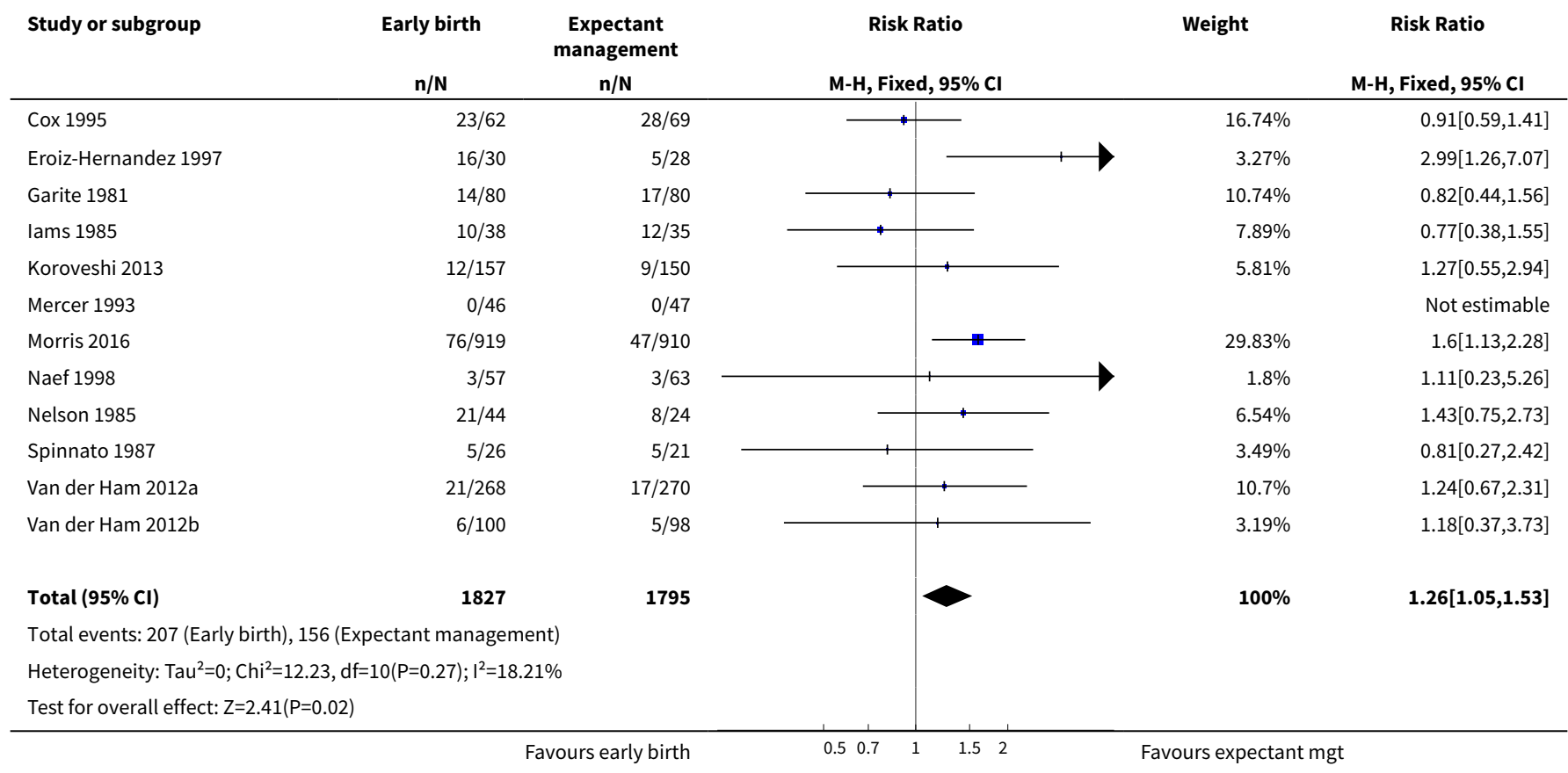

Analysis 1.4. Comparison 1 Any planned birth versus expectant management: by type, Outcome 4 Caesarean section.

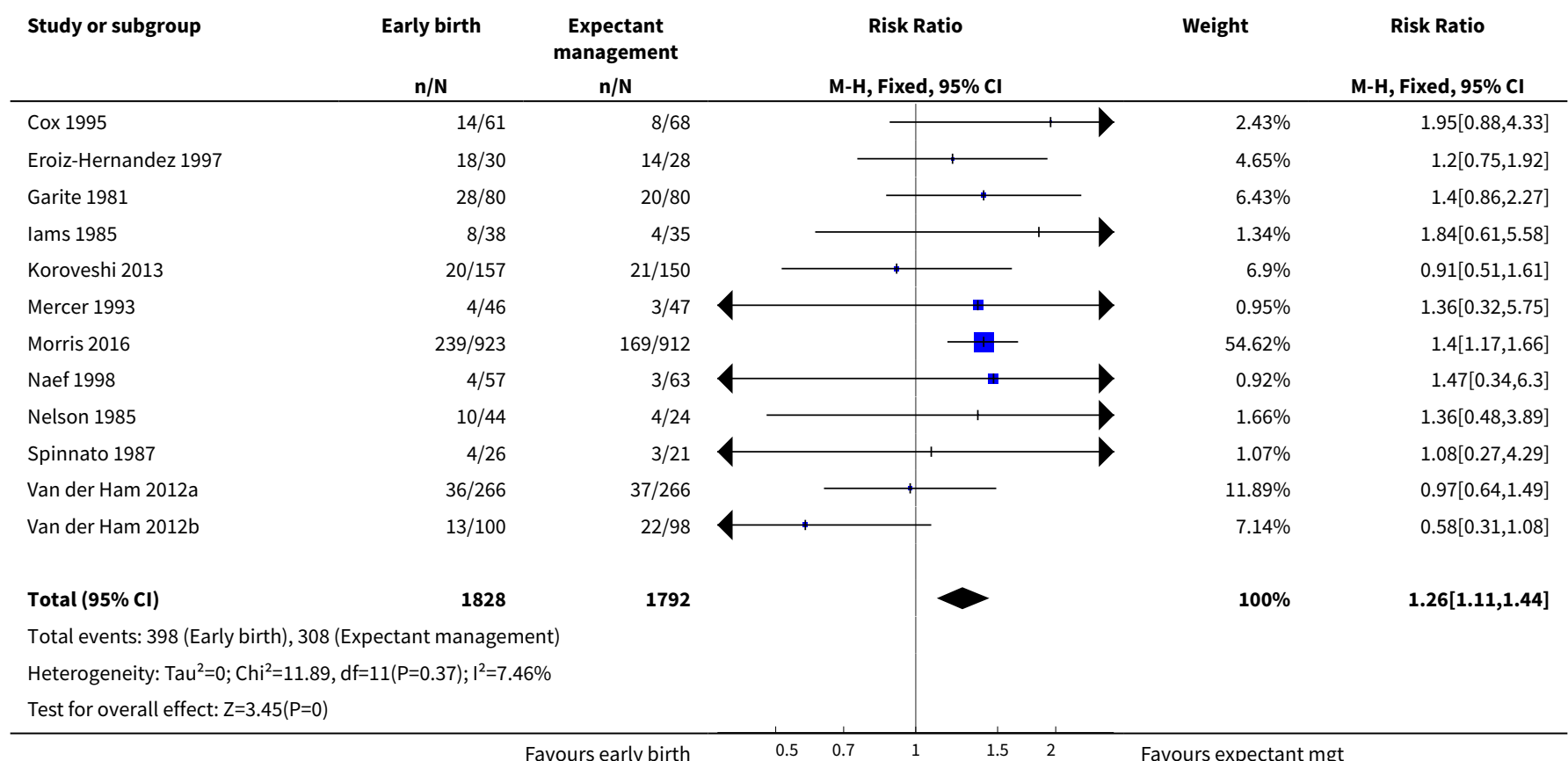


Analysis 1.5. Comparison 1 Any planned birth versus expectant management: by type, Outcome 5 Perinatal mortality.

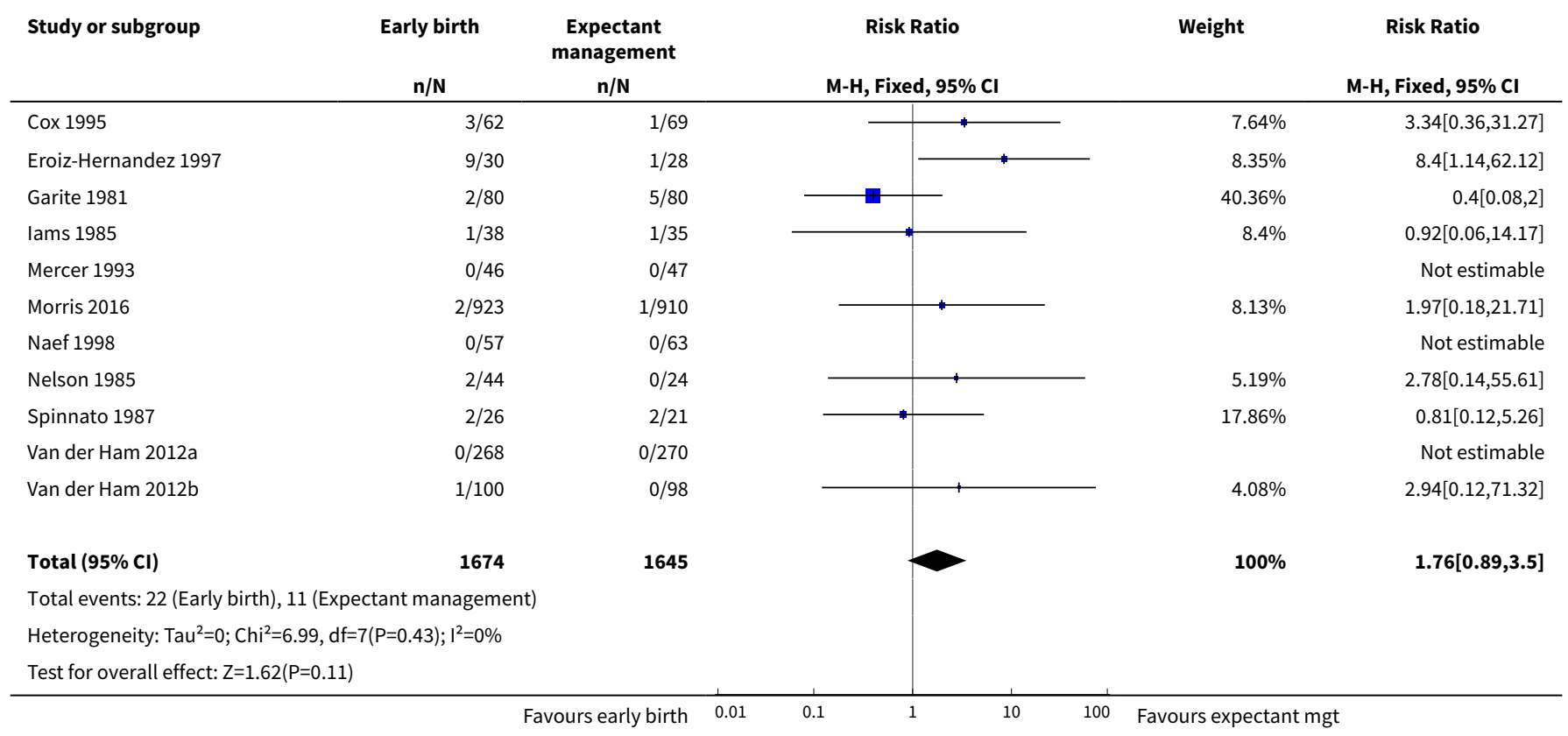

Analysis 1.6. Comparison 1 Any planned birth versus expectant management: by type, Outcome 6 Intrauterine death.

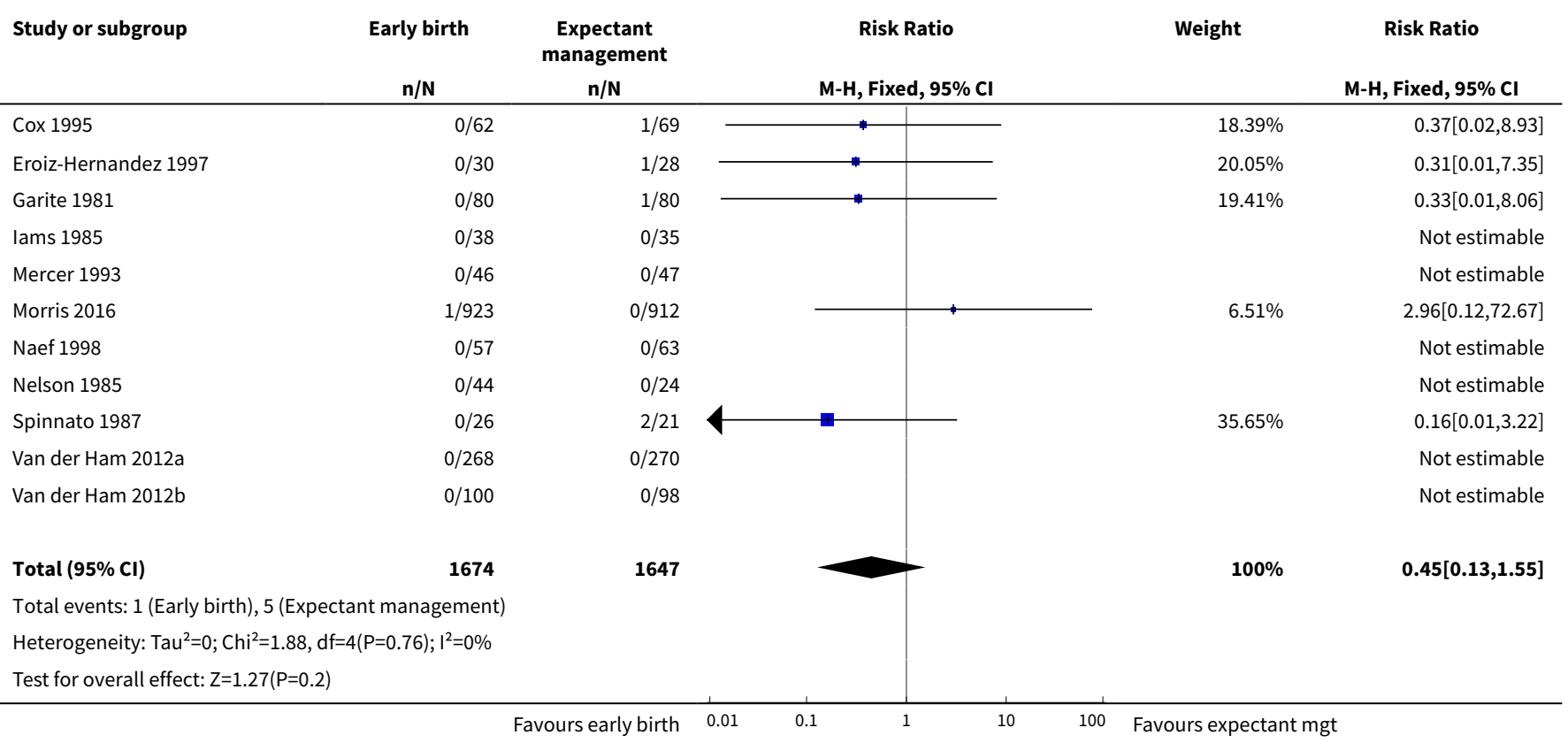


Analysis 1.7. Comparison 1 Any planned birth versus expectant management: by type, Outcome 7 Cord prolapse.

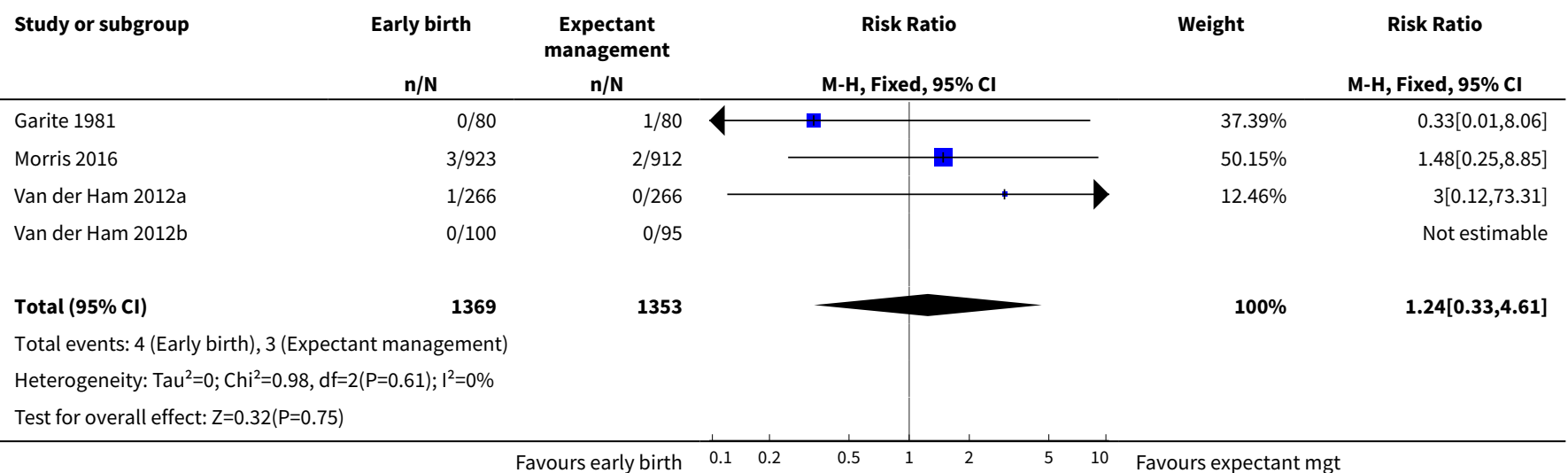

Analysis 1.8. Comparison 1 Any planned birth versus expectant management: by type, Outcome 8 Gestational age at birth (weeks).

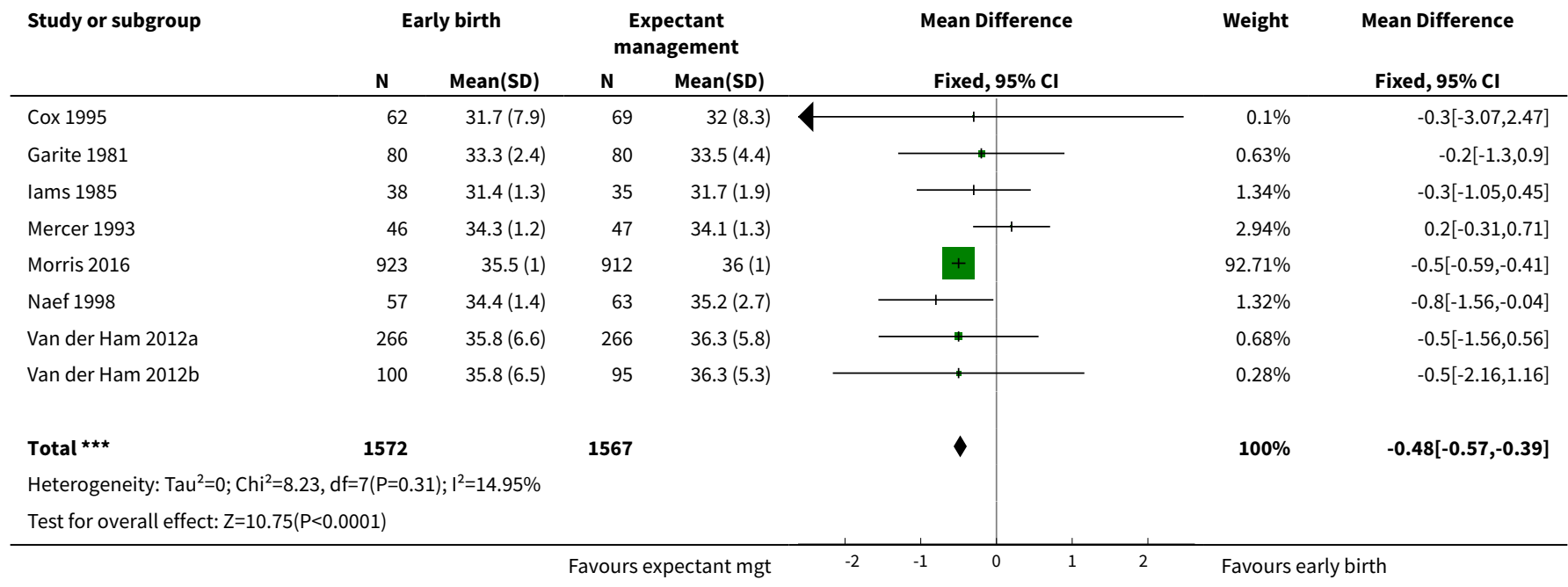

Analysis 1.9. Comparison 1 Any planned birth versus expectant management: by type, Outcome 9 Neonatal death.

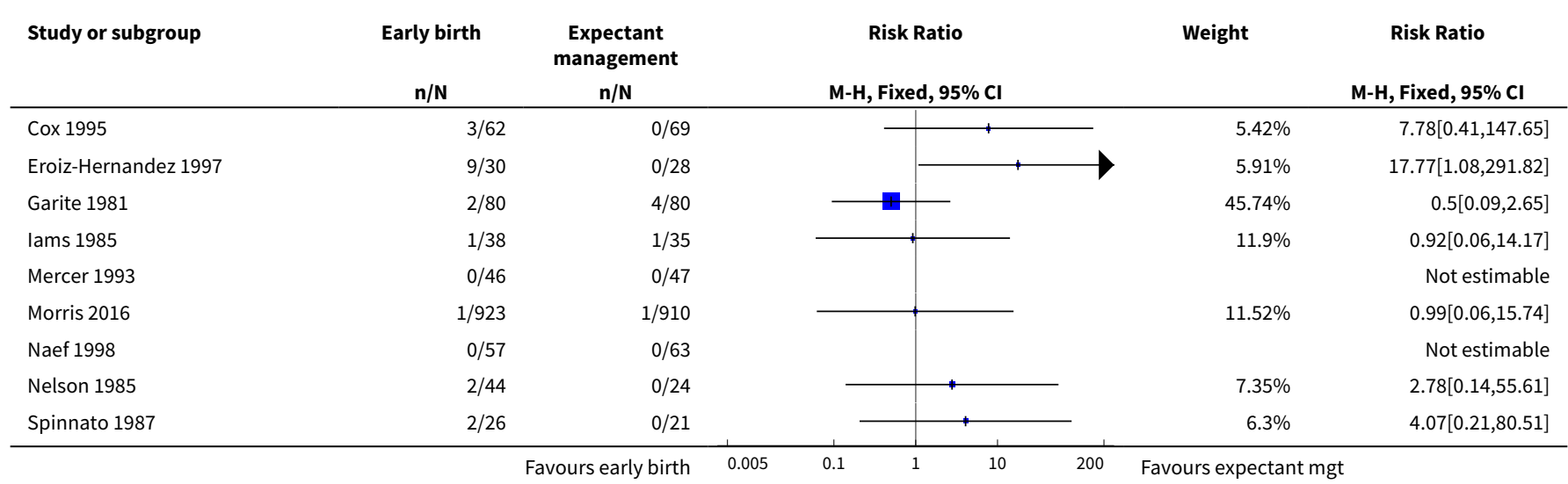




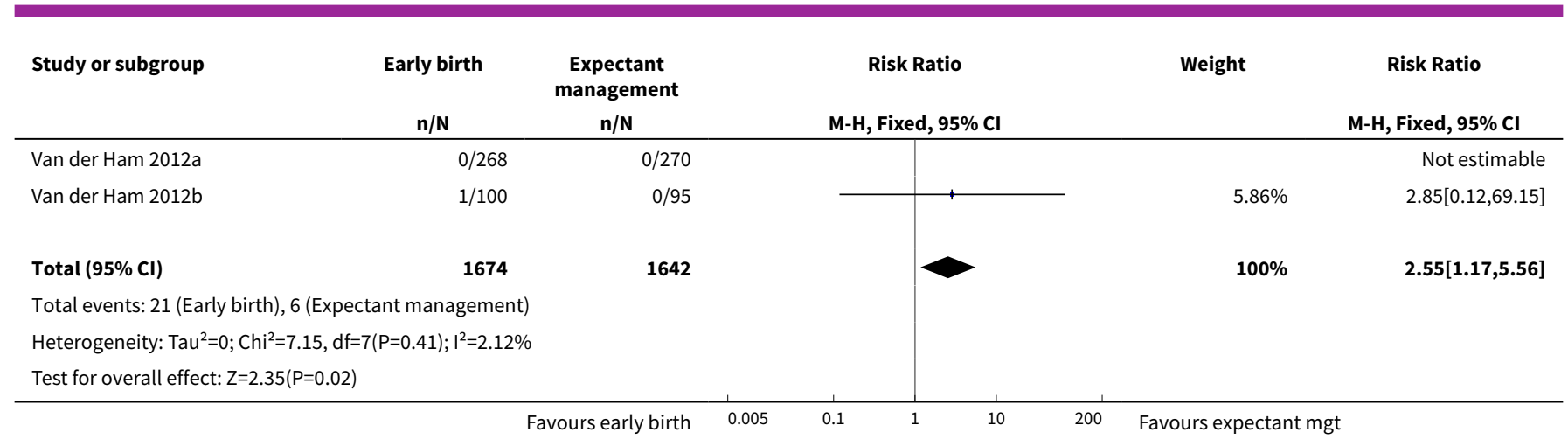

Analysis 1.10. Comparison 1 Any planned birth versus expectant management: by type, Outcome 10 Suspected neonatal infection.

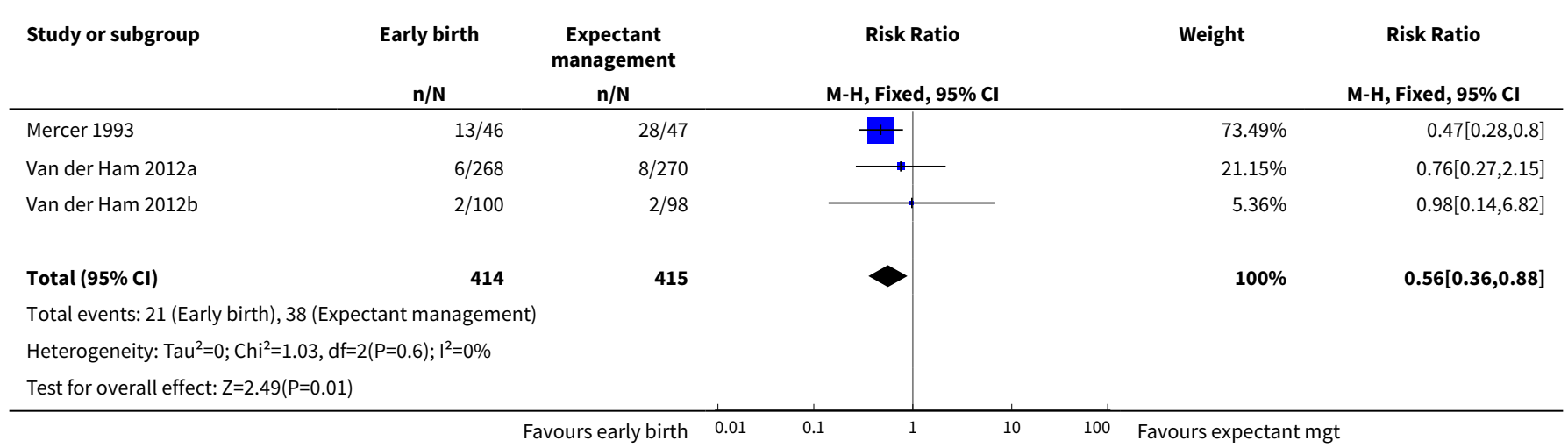

Analysis 1.11. Comparison 1 Any planned birth versus expectant management: by type, Outcome 11 Neonatal treatment with antibiotics.

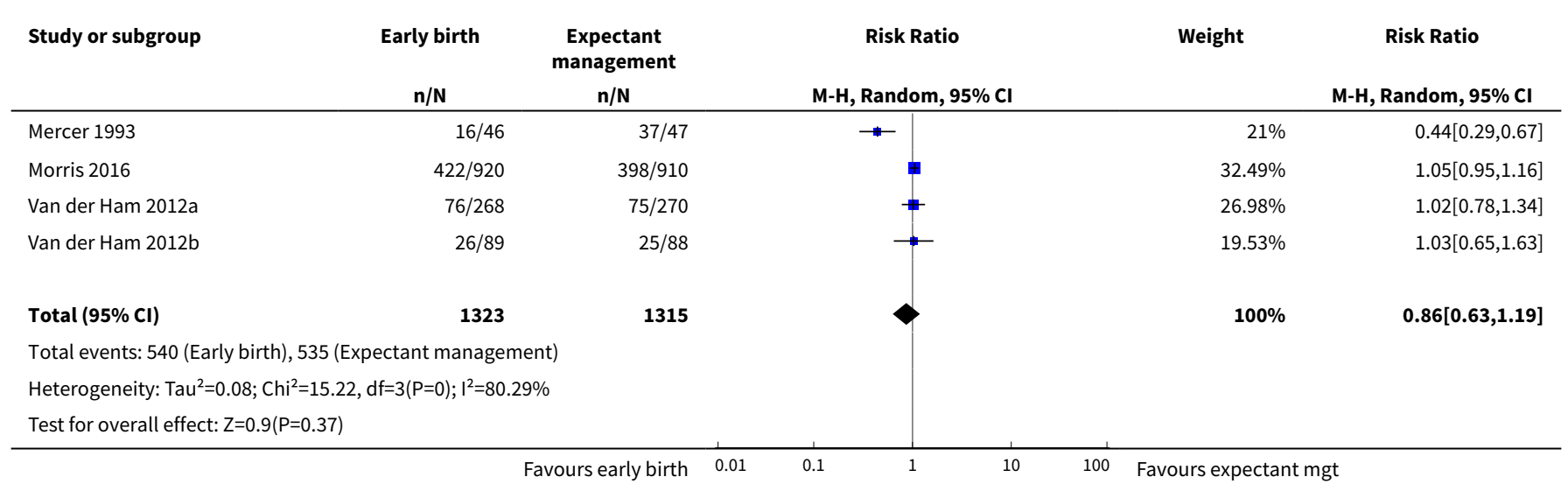


Analysis 1.12. Comparison 1 Any planned birth versus expectant management: by type, Outcome 12 Need for ventilation.

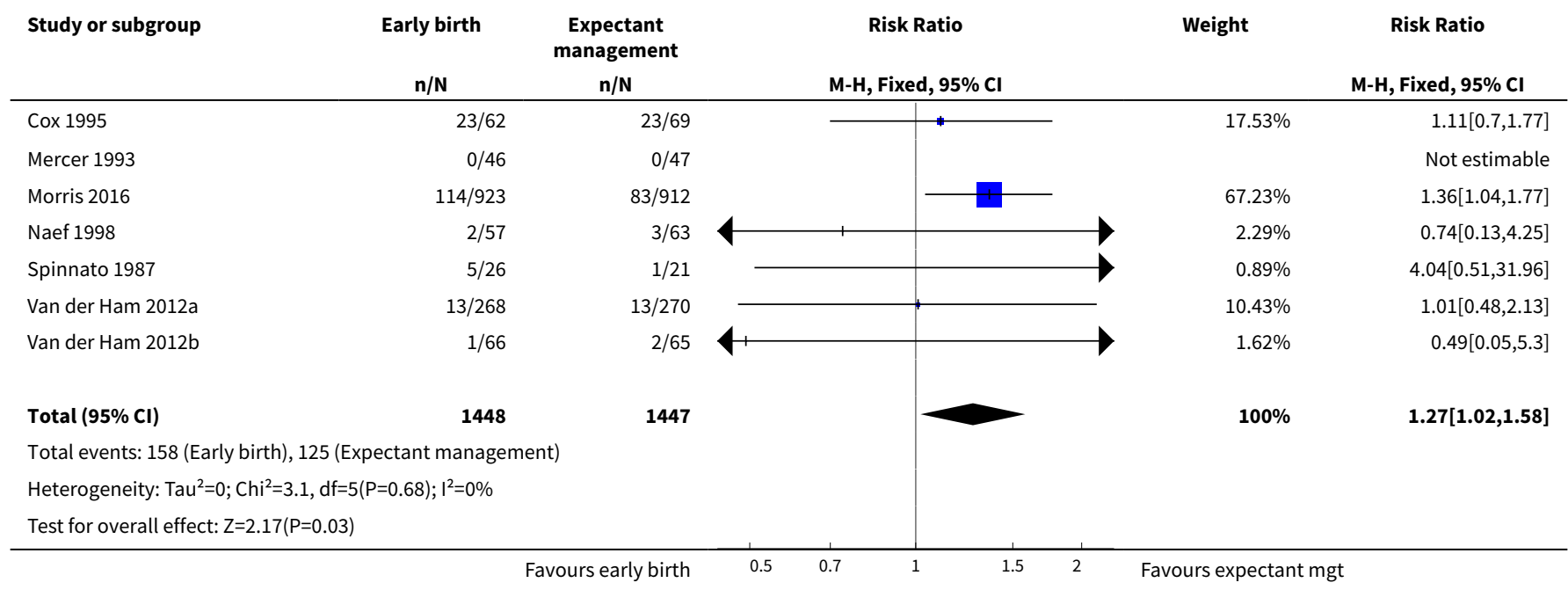

Analysis 1.13. Comparison 1 Any planned birth versus expectant management: by type, Outcome 13 Duration of oxygen therapy (days).

\begin{tabular}{|c|c|c|c|c|c|c|c|}
\hline \multirow[t]{2}{*}{ Study or subgroup } & \multicolumn{2}{|c|}{ Early birth } & \multicolumn{2}{|c|}{$\begin{array}{c}\text { Expectant } \\
\text { management }\end{array}$} & \multirow{2}{*}{$\begin{array}{c}\text { Mean Difference } \\
\text { Fixed, } 95 \% \mathrm{Cl}\end{array}$} & \multirow[t]{2}{*}{ Weight } & \multirow{2}{*}{$\begin{array}{l}\text { Mean Difference } \\
\text { Fixed, } 95 \% \mathrm{Cl}\end{array}$} \\
\hline & $\mathbf{N}$ & Mean(SD) & $\mathbf{N}$ & Mean(SD) & & & \\
\hline lams 1985 & 38 & $1.9(2.7)$ & 35 & $5(11.4)$ & $+1=$ & $100 \%$ & $-3.05[-6.92,0.82]$ \\
\hline 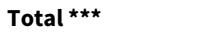 & 38 & & 35 & & & $100 \%$ & $-3.05[-6.92,0.82]$ \\
\hline \multicolumn{8}{|c|}{ Heterogeneity: Not applicable } \\
\hline
\end{tabular}

Analysis 1.14. Comparison 1 Any planned birth versus expectant management: by type, Outcome 14 Umbilical cord arterial pH.

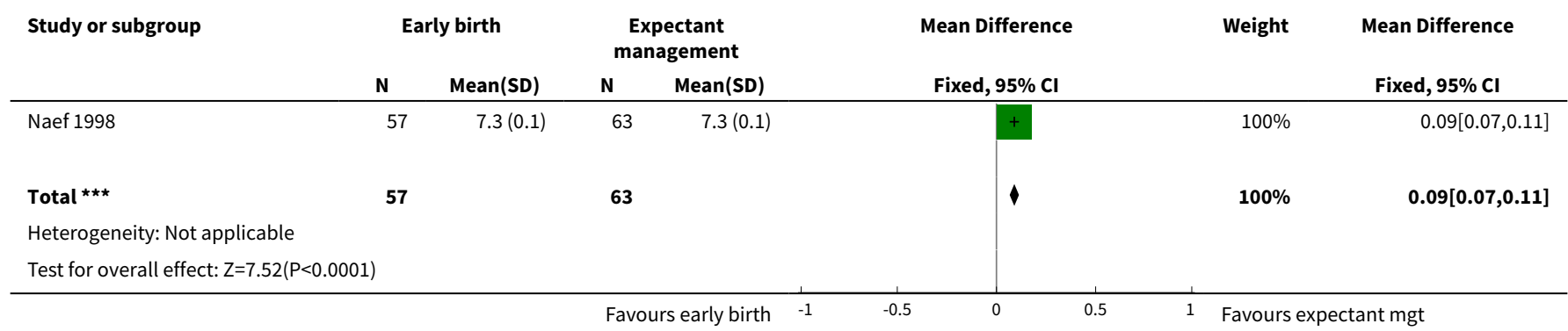


Analysis 1.15. Comparison 1 Any planned birth versus expectant management: by type, Outcome 15 Birthweight (g).

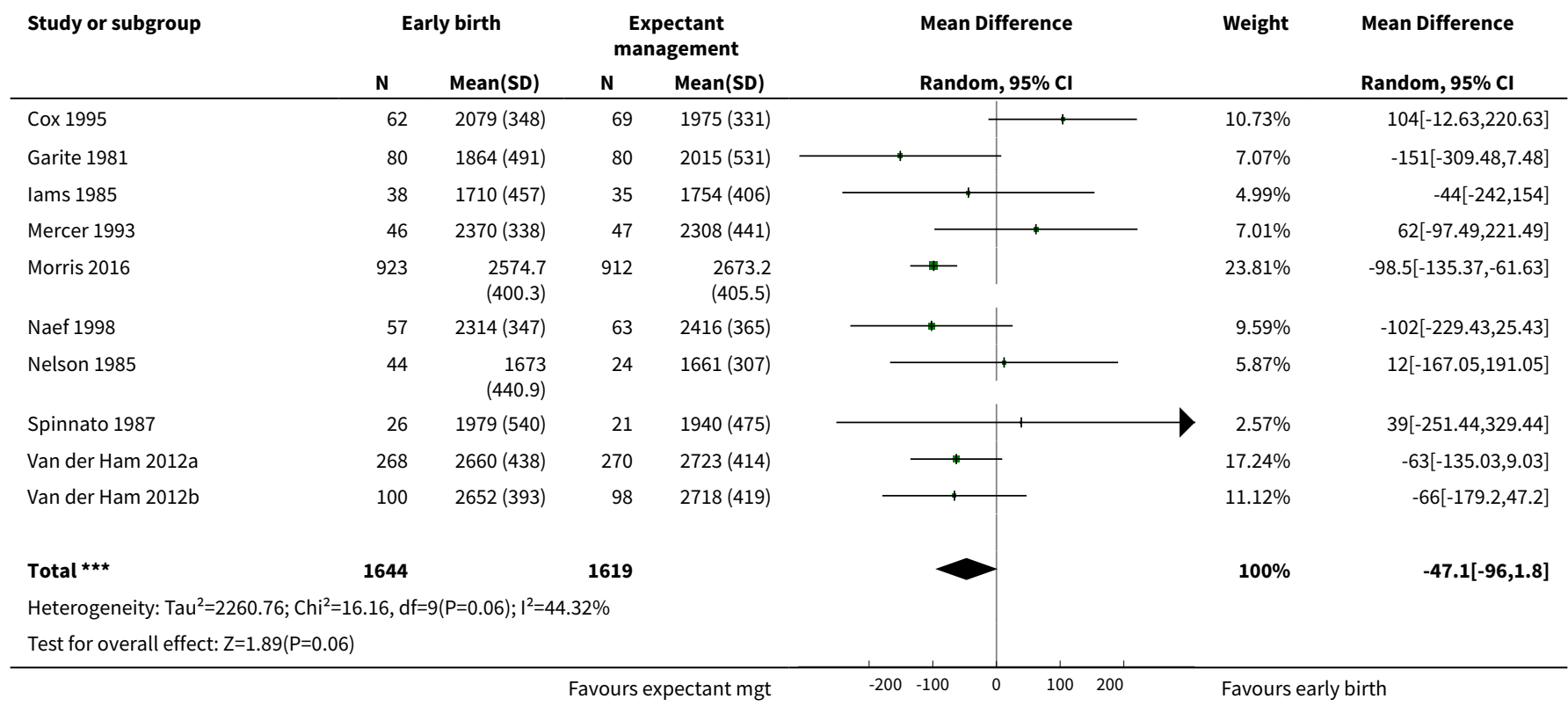

Analysis 1.16. Comparison 1 Any planned birth versus expectant management: by type, Outcome 16 Apgar score less than 7 at 5 minutes.

\begin{tabular}{|c|c|c|c|c|c|}
\hline \multirow[t]{2}{*}{ Study or subgroup } & Early birth & $\begin{array}{c}\text { Expectant } \\
\text { management }\end{array}$ & Risk Ratio & \multirow[t]{2}{*}{ Weight } & \multirow{2}{*}{$\begin{array}{c}\text { Risk Ratio } \\
\text { M-H, Fixed, } 95 \% \mathrm{Cl} \\
\end{array}$} \\
\hline & $\mathrm{n} / \mathrm{N}$ & $\mathrm{n} / \mathbf{N}$ & M-H, Fixed, $95 \% \mathrm{Cl}$ & & \\
\hline Mercer 1993 & $0 / 46$ & $0 / 47$ & & & Not estimable \\
\hline Morris 2016 & $15 / 918$ & $18 / 906$ & & $77.28 \%$ & $0.82[0.42,1.62]$ \\
\hline Spinnato 1987 & $4 / 26$ & $3 / 21$ & & $14.16 \%$ & $1.08[0.27,4.29]$ \\
\hline Van der Ham 2012a & $2 / 268$ & $1 / 270$ & & $4.25 \%$ & $2.01[0.18,22.09]$ \\
\hline Total $(95 \% \mathrm{Cl})$ & 1358 & 1342 & & $100 \%$ & $0.96[0.54,1.69]$ \\
\hline \multicolumn{6}{|c|}{ Total events: 23 (Early birth), 23 (Expectant management) } \\
\hline \multicolumn{6}{|c|}{ Heterogeneity: $\mathrm{Tau}^{2}=0 ; \mathrm{Chi}^{2}=0.94, \mathrm{df}=3(\mathrm{P}=0.82) ; \mathrm{I}^{2}=0 \%$} \\
\hline Test for overall effect & & & & & \\
\hline
\end{tabular}

Analysis 1.17. Comparison 1 Any planned birth versus expectant management: by type, Outcome 17 Abnormality on cerebral ultrasound.

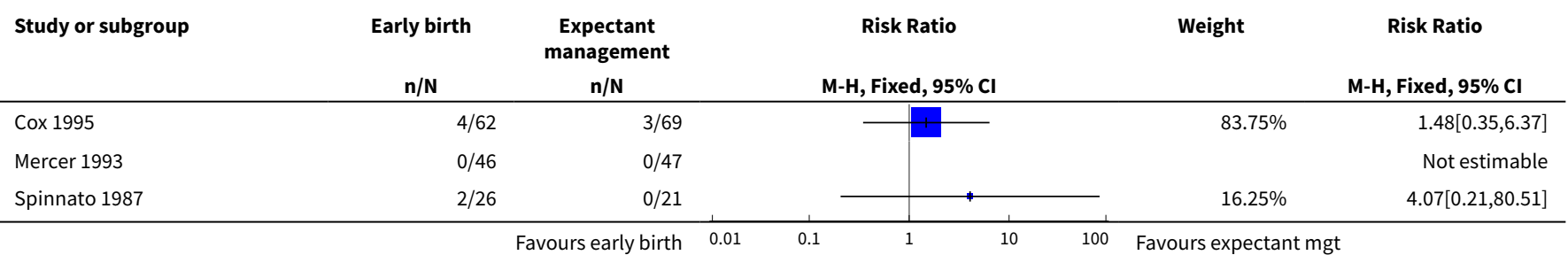




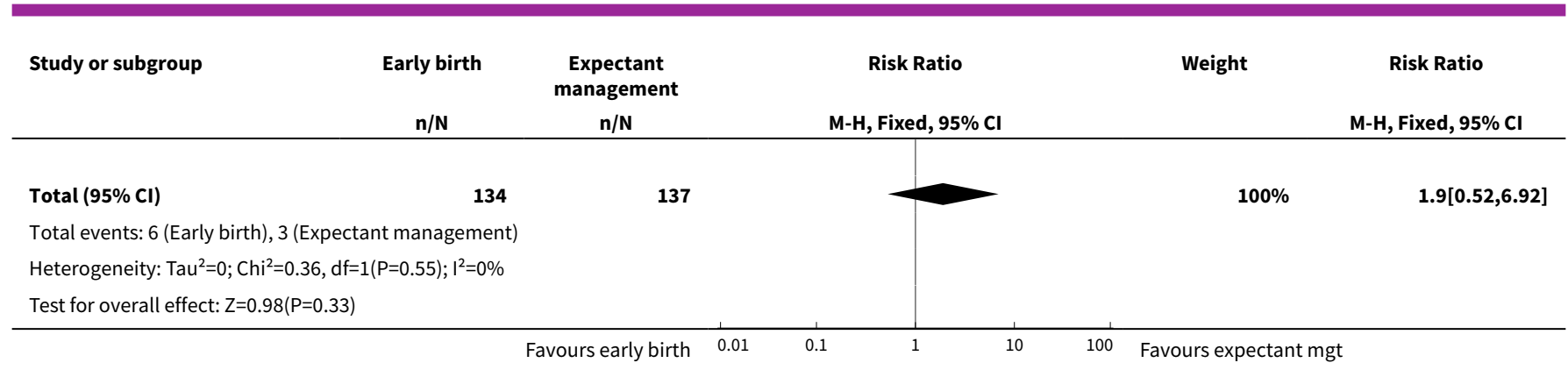

Analysis 1.18. Comparison 1 Any planned birth versus expectant management: by type, Outcome 18 Periventricular leukomalacia.

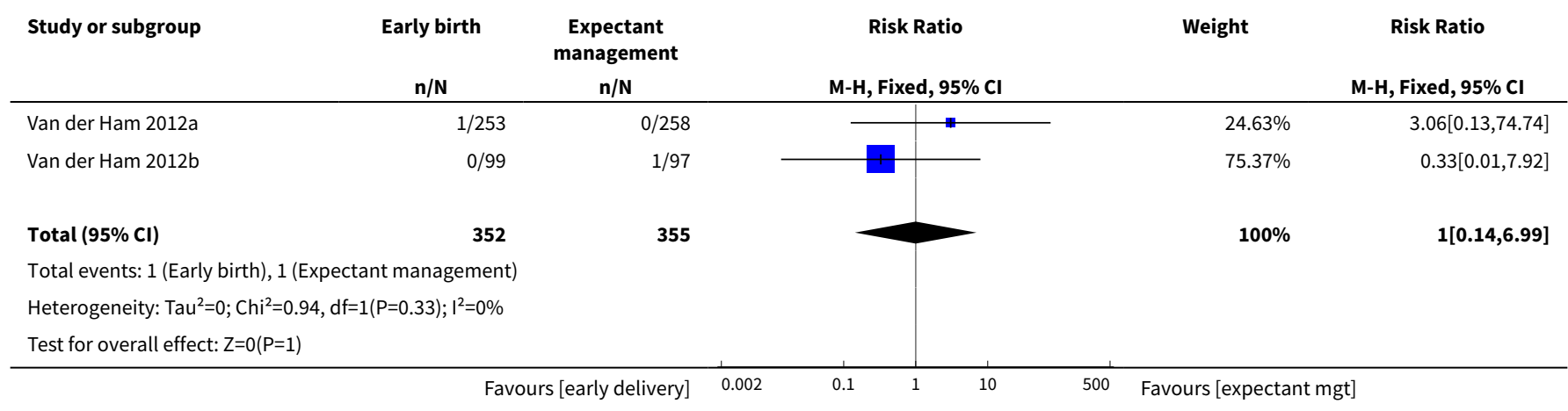

Analysis 1.19. Comparison 1 Any planned birth versus expectant management: by type, Outcome 19 Cerebroventricular haemorrhage.

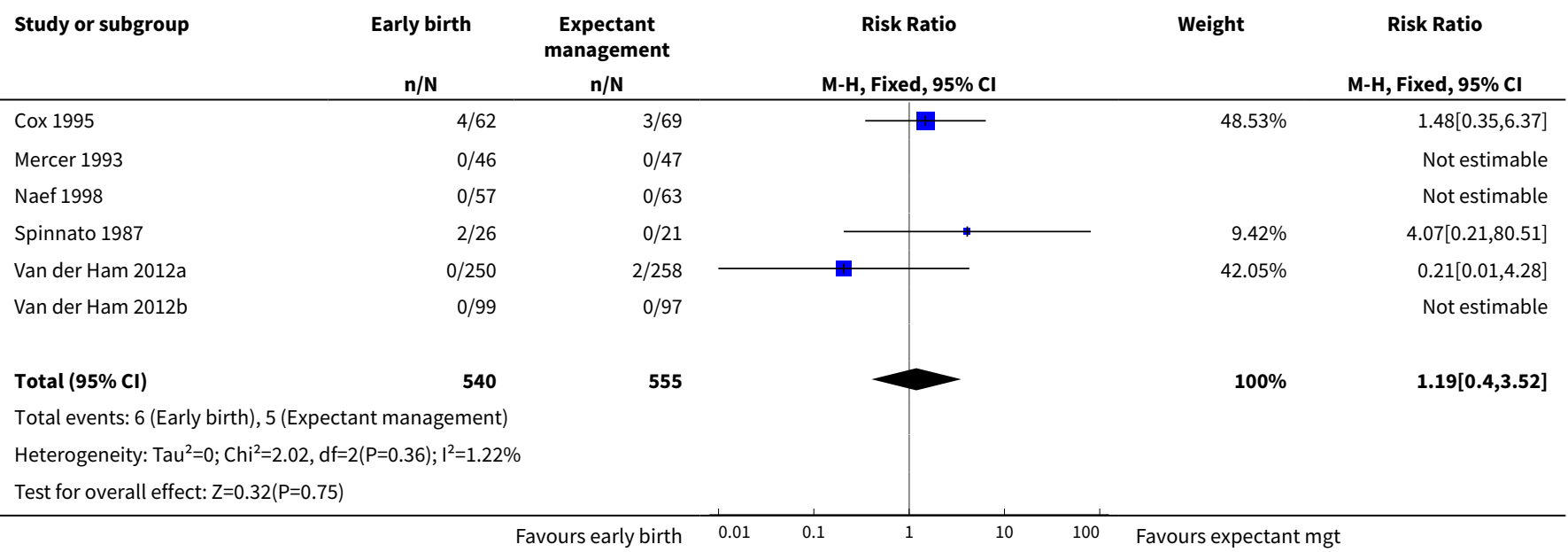


Analysis 1.20. Comparison 1 Any planned birth versus expectant management: by type, Outcome 20 Necrotising enterocolitis.

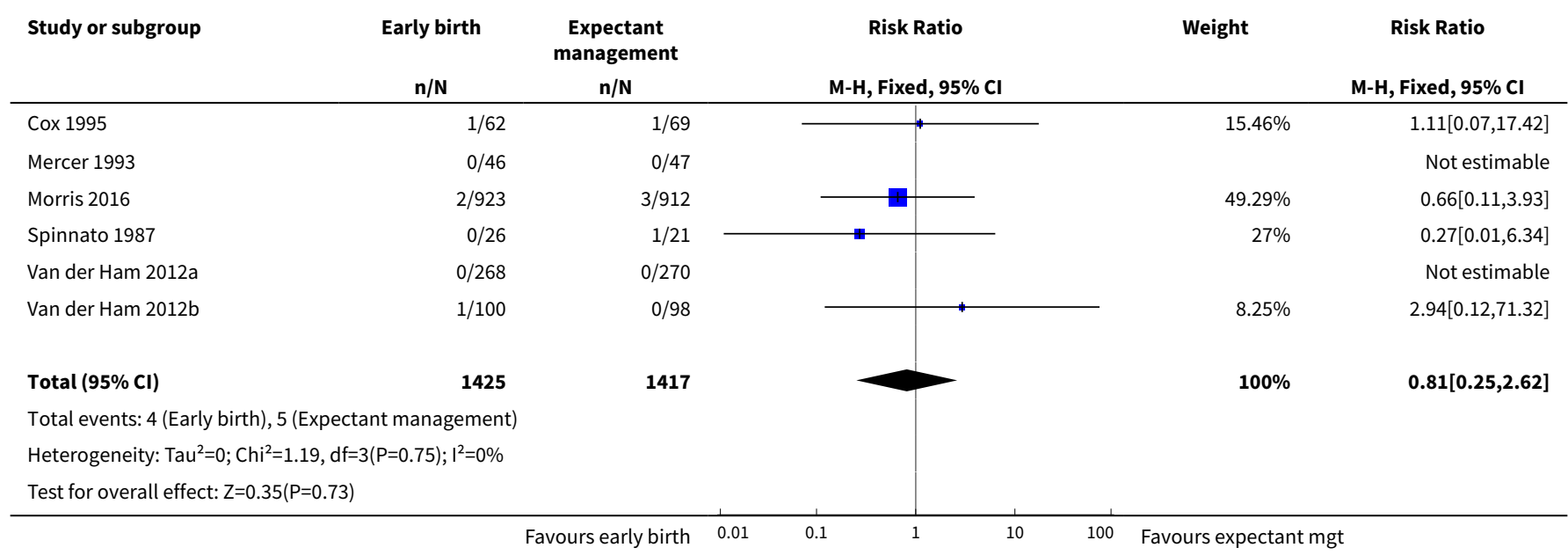

Analysis 1.21. Comparison 1 Any planned birth versus expectant management: by type, Outcome 21 Severe respiratory distress.

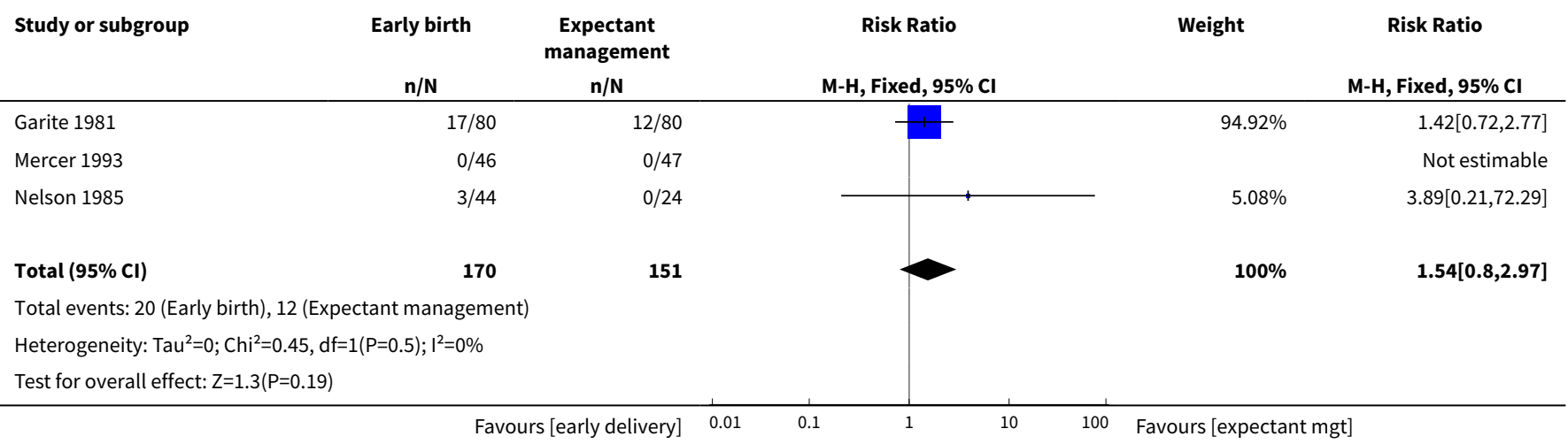

Analysis 1.22. Comparison 1 Any planned birth versus expectant management: by type, Outcome 22 Admission to neonatal intensive care unit.

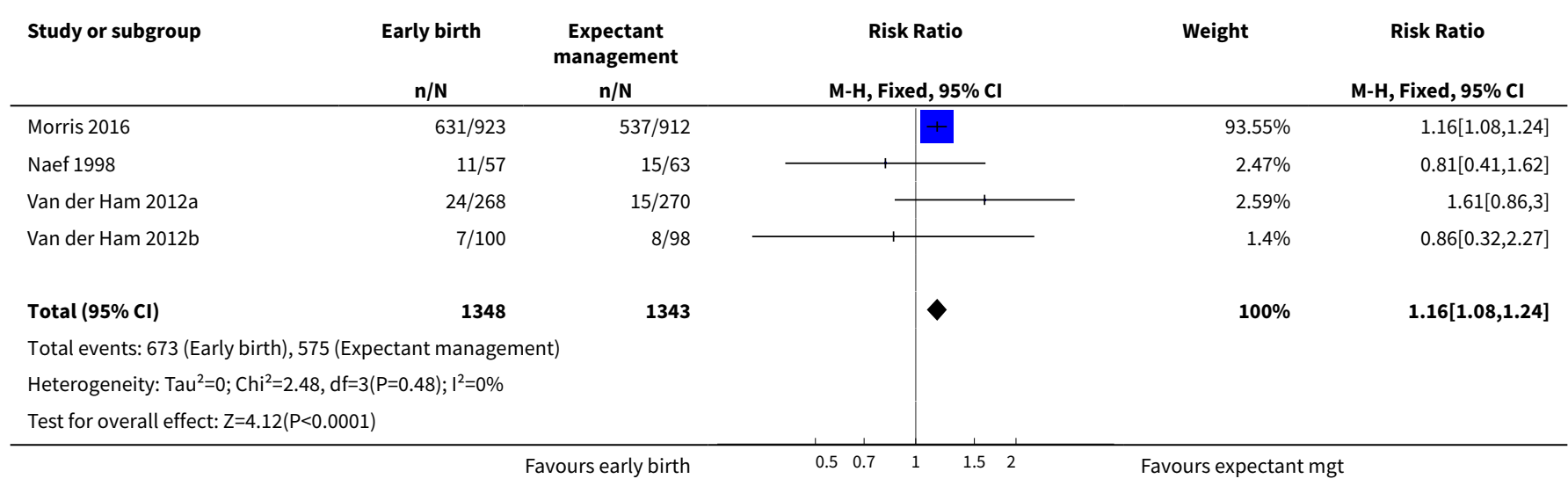


Analysis 1.23. Comparison 1 Any planned birth versus expectant management: by type, Outcome 23 Length of stay in neonatal intensive care unit (days).

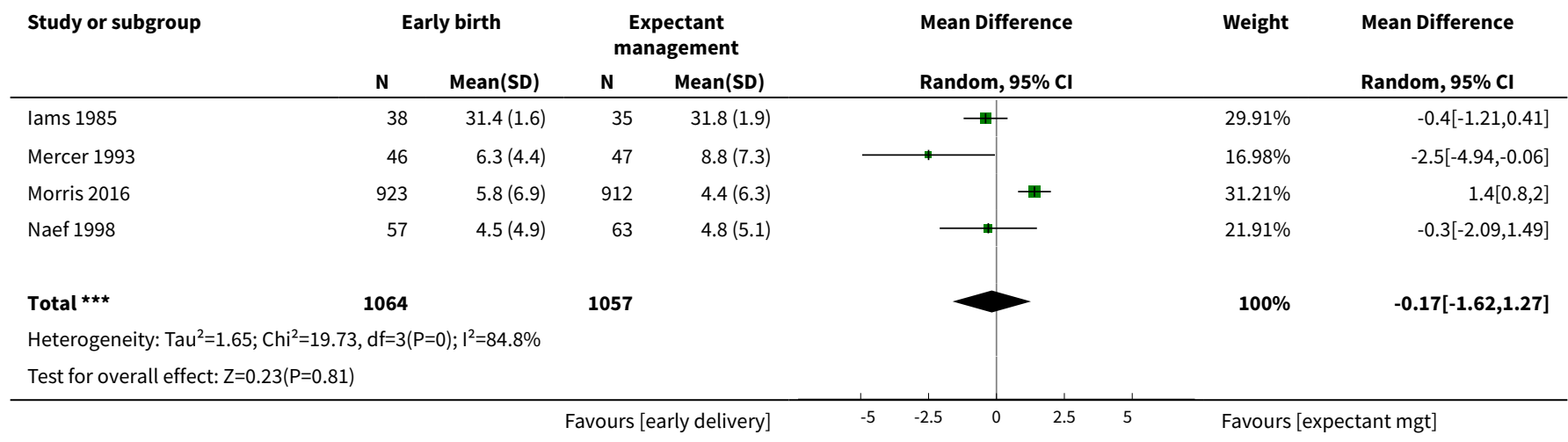

Analysis 1.24. Comparison 1 Any planned birth versus expectant management: by type, Outcome 24 Duration (days) from birth to neonatal hospital discharge.

\begin{tabular}{|c|c|c|c|c|c|c|c|}
\hline \multirow[t]{2}{*}{ Study or subgroup } & \multicolumn{2}{|c|}{ Early birth } & \multicolumn{2}{|c|}{$\begin{array}{c}\text { Expectant } \\
\text { management }\end{array}$} & \multirow{2}{*}{$\begin{array}{l}\text { Mean Difference } \\
\text { Random, } 95 \% \mathrm{Cl}\end{array}$} & \multirow[t]{2}{*}{ Weight } & \multirow{2}{*}{$\begin{array}{l}\text { Mean Difference } \\
\text { Random, } 95 \% \mathrm{Cl}\end{array}$} \\
\hline & $\mathbf{N}$ & Mean(SD) & $\mathbf{N}$ & $\operatorname{Mean}(S D)$ & & & \\
\hline lams 1985 & 38 & $31.4(1.6)$ & 35 & $31.8(1.9)$ & $\rightarrow$ & $23.83 \%$ & $-0.4[-1.21,0.41]$ \\
\hline Morris 2016 & 923 & $7.4(6.6)$ & 912 & $6(5)$ & $\#$ & $26.43 \%$ & $1.4[0.86,1.94]$ \\
\hline Naef 1998 & 57 & $4.5(4.9)$ & 63 & $4.8(5.1)$ & $\longrightarrow$ & $14.17 \%$ & $-0.3[-2.09,1.49]$ \\
\hline Nelson 1985 & 44 & $24.4(21.8)$ & 24 & $19.5(9.1)$ & & $1.54 \%$ & $4.9[-2.5,12.3]$ \\
\hline Van der Ham 2012b & 100 & $7.4(6.1)$ & 98 & $6.9(6)$ & 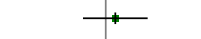 & $15.04 \%$ & $0.5[-1.19,2.19]$ \\
\hline Total *** & 1430 & & 1402 & & & $100 \%$ & $0.67[-0.28,1.61]$ \\
\hline \multicolumn{8}{|c|}{ Heterogeneity: $\mathrm{Tau}^{2}=0.8 ; \mathrm{Chi}^{2}=17.13, \mathrm{df}=5(\mathrm{P}=0) ; \mathrm{I}^{2}=70.81 \%$} \\
\hline \multicolumn{3}{|c|}{ Test for overall effect: $Z=1.39(P=0.17)$} & & & & & \\
\hline
\end{tabular}

Analysis 1.25. Comparison 1 Any planned birth versus expectant management: by type, Outcome 25 Chorioamnionitis.

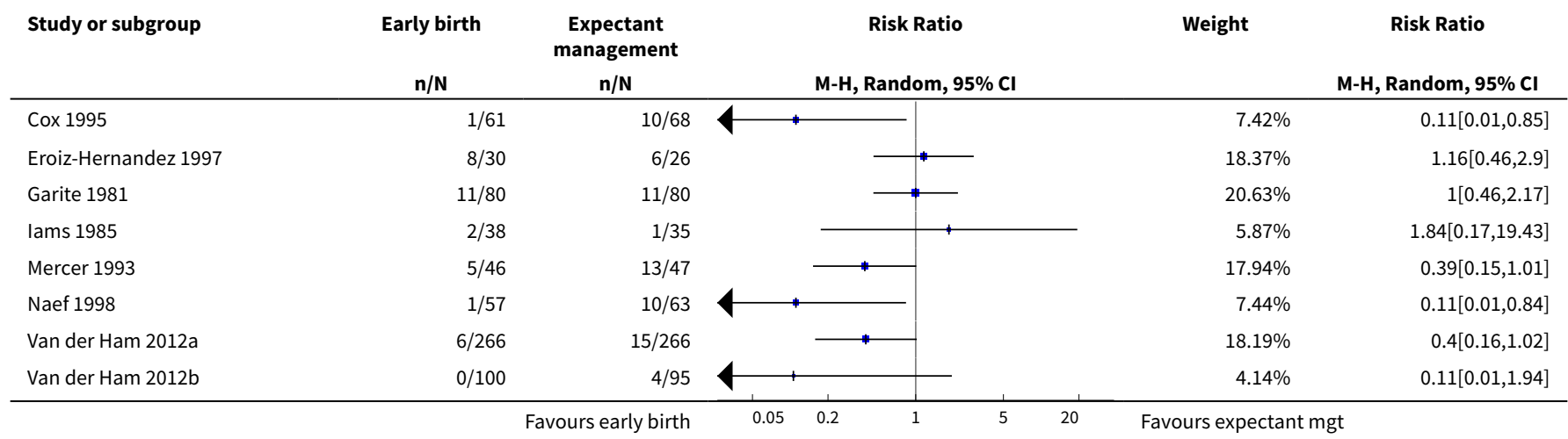




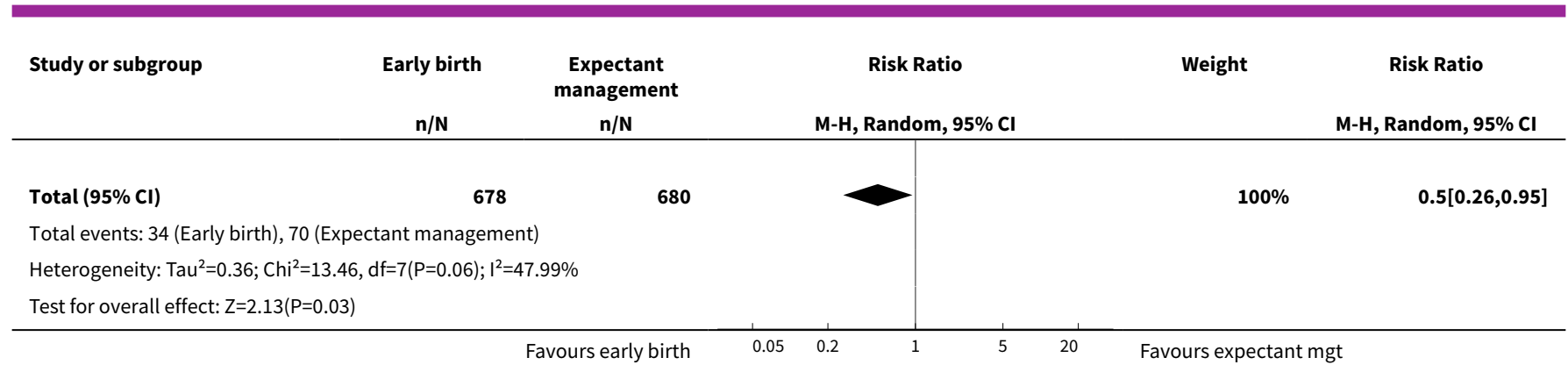

Analysis 1.26. Comparison 1 Any planned birth versus expectant management: by type, Outcome 26 Endometritis.

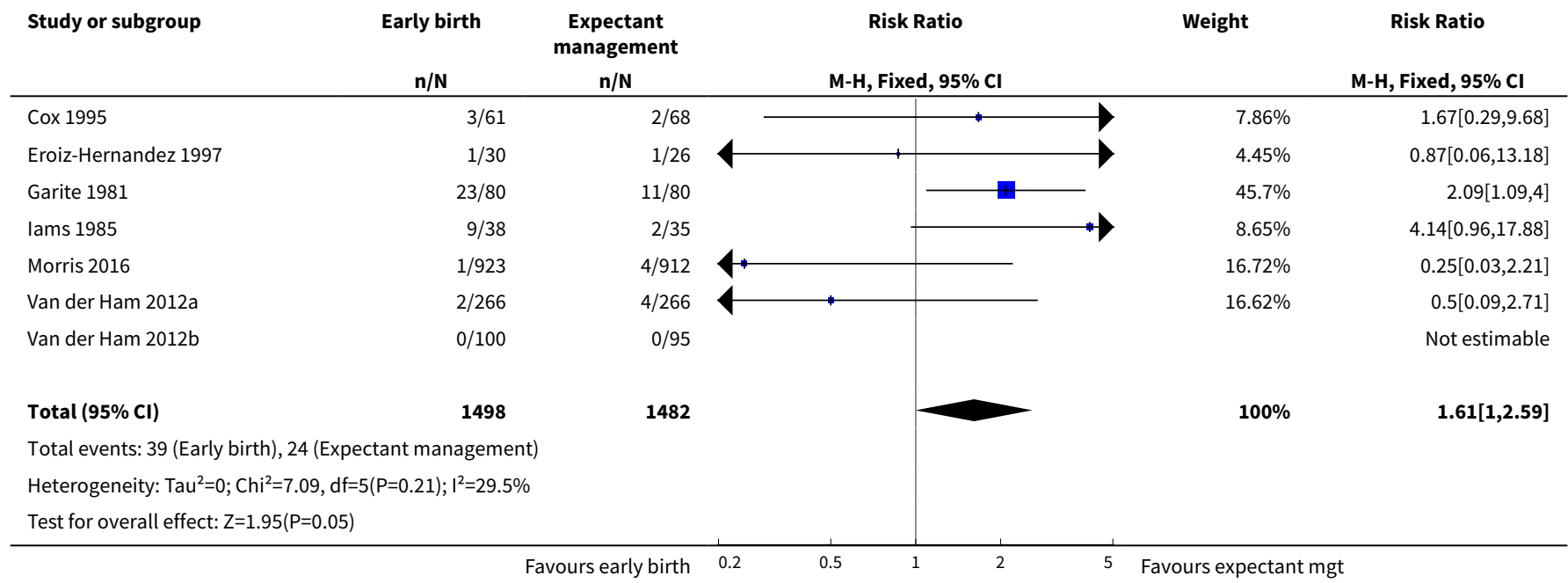

Analysis 1.27. Comparison 1 Any planned birth versus expectant management: by type, Outcome 27 Postpartum fever.

\begin{tabular}{|c|c|c|c|c|c|}
\hline \multirow[t]{2}{*}{ Study or subgroup } & Early birth & $\begin{array}{c}\text { Expectant } \\
\text { management }\end{array}$ & Risk Ratio & Weight & \multirow{2}{*}{$\begin{array}{c}\text { Risk Ratio } \\
\text { M-H, Fixed, 95\% Cl }\end{array}$} \\
\hline & $\mathrm{n} / \mathrm{N}$ & $\mathbf{n} / \mathbf{N}$ & M-H, Fixed, $95 \% \mathrm{Cl}$ & & \\
\hline Morris 2016 & $12 / 923$ & $23 / 912$ & & $100 \%$ & $0.52[0.26,1.03]$ \\
\hline Total $(95 \% \mathrm{Cl})$ & 923 & 912 & & $100 \%$ & $0.52[0.26,1.03]$ \\
\hline \multicolumn{6}{|c|}{ Total events: 12 (Early birth), 23 (Expectant management) } \\
\hline Test for overall effect & & & & & \\
\hline
\end{tabular}


Analysis 1.28. Comparison 1 Any planned birth versus expectant management: by type, Outcome 28 Placental abruption.

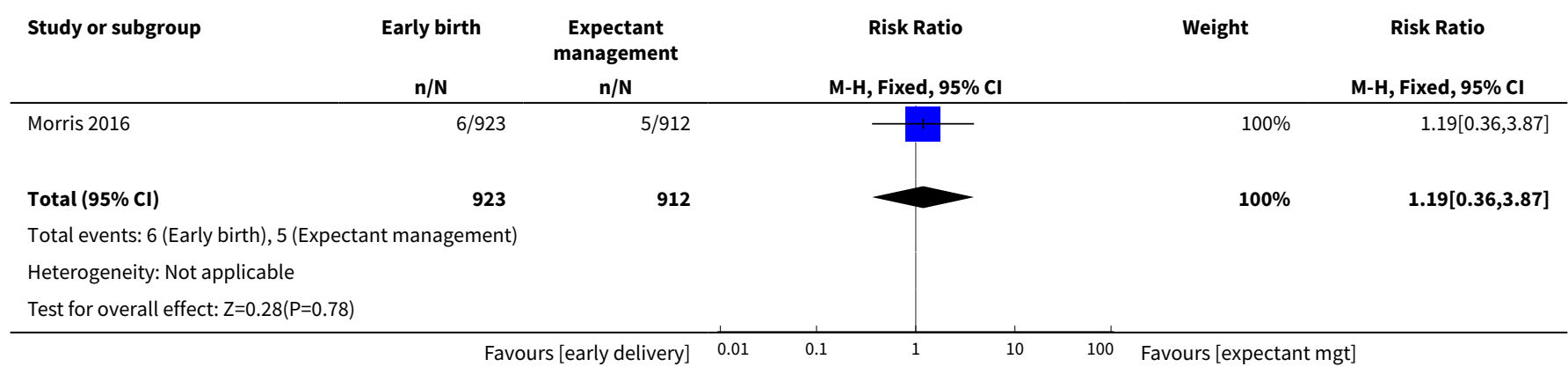

Analysis 1.29. Comparison 1 Any planned birth versus expectant management: by type, Outcome 29 Induction of labour.

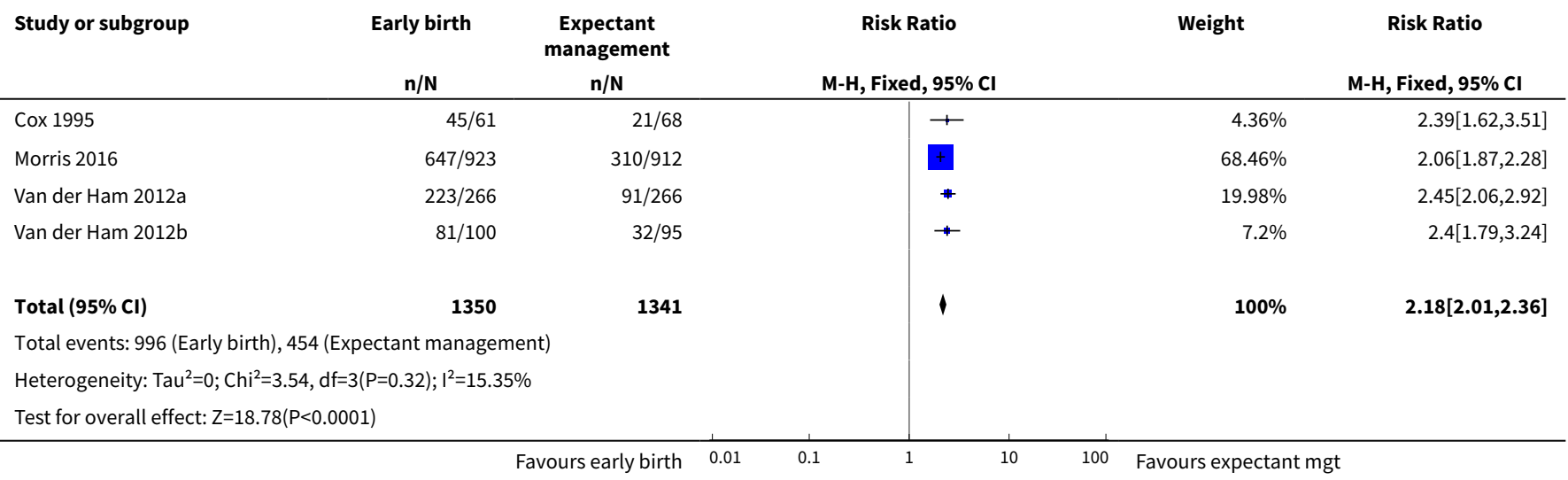

Analysis 1.30. Comparison 1 Any planned birth versus expectant management: by type, Outcome 30 Use of epidural/spinal anaesthesia.

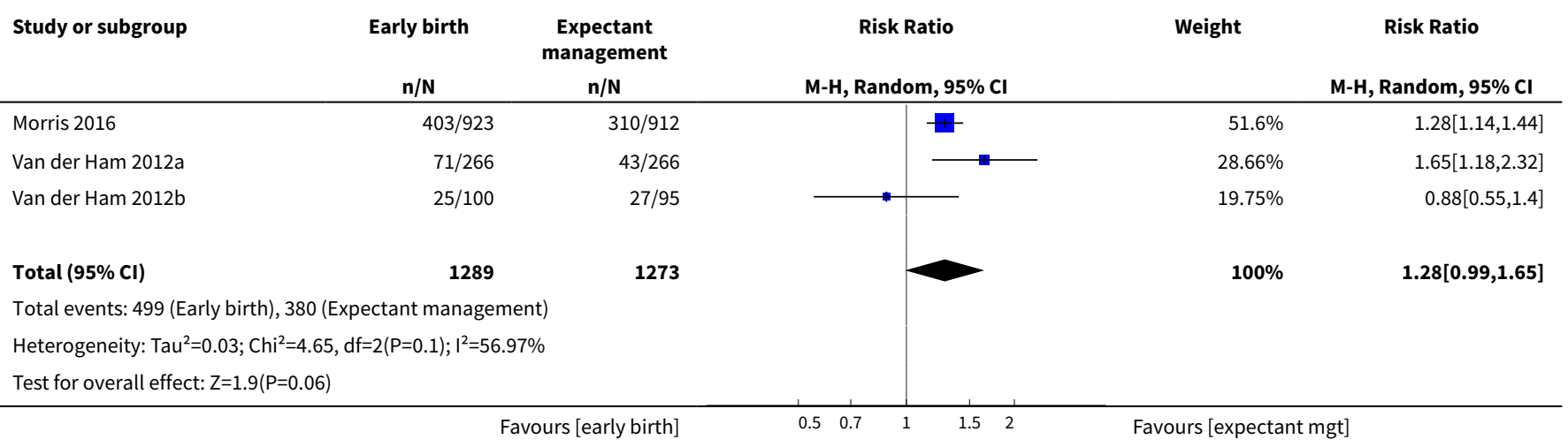


Analysis 1.31. Comparison 1 Any planned birth versus expectant management: by type, Outcome 31 Vaginal birth.

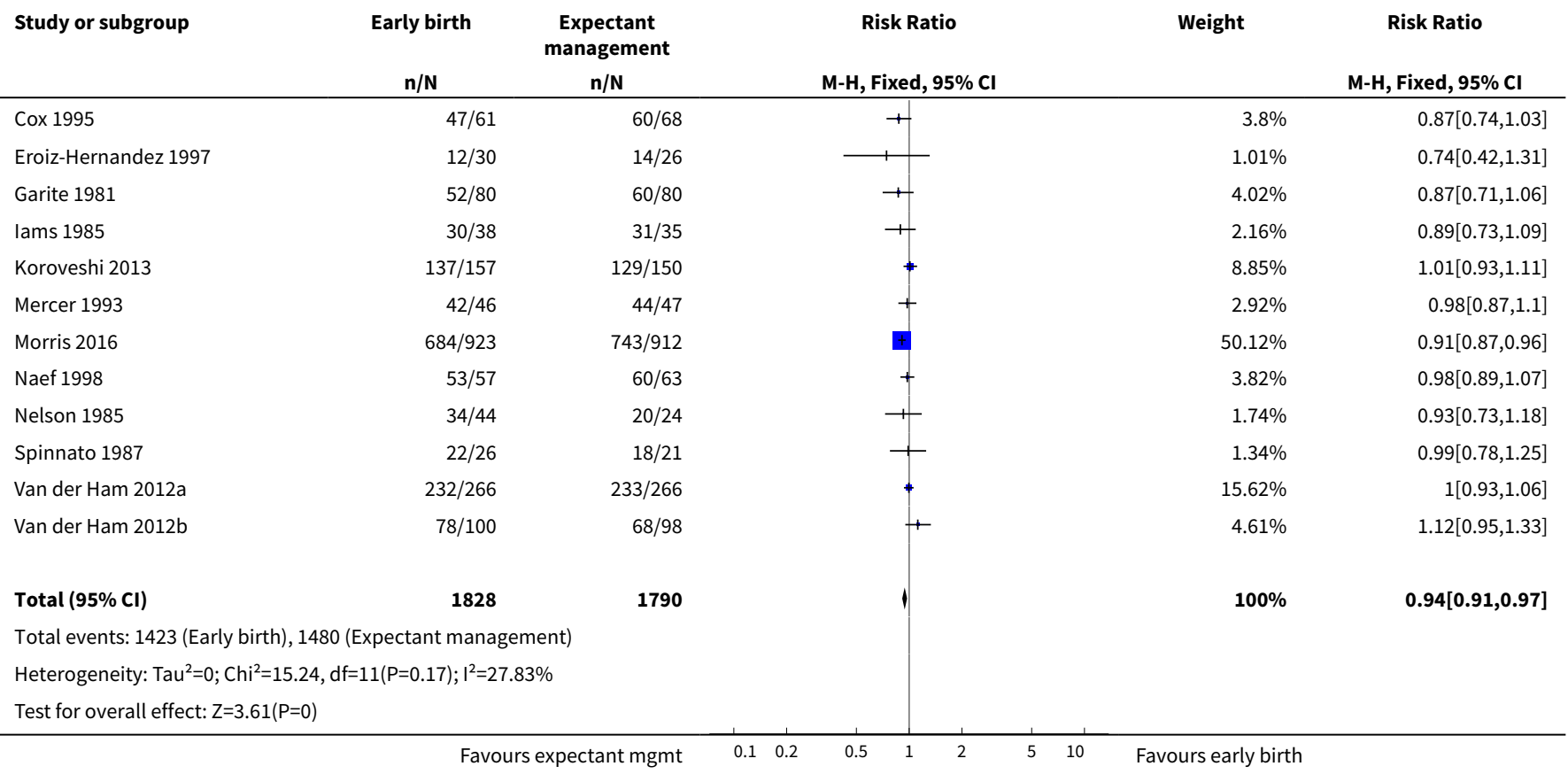

Analysis 1.32. Comparison 1 Any planned birth versus expectant management: by type, Outcome 32 Operative vaginal birth.

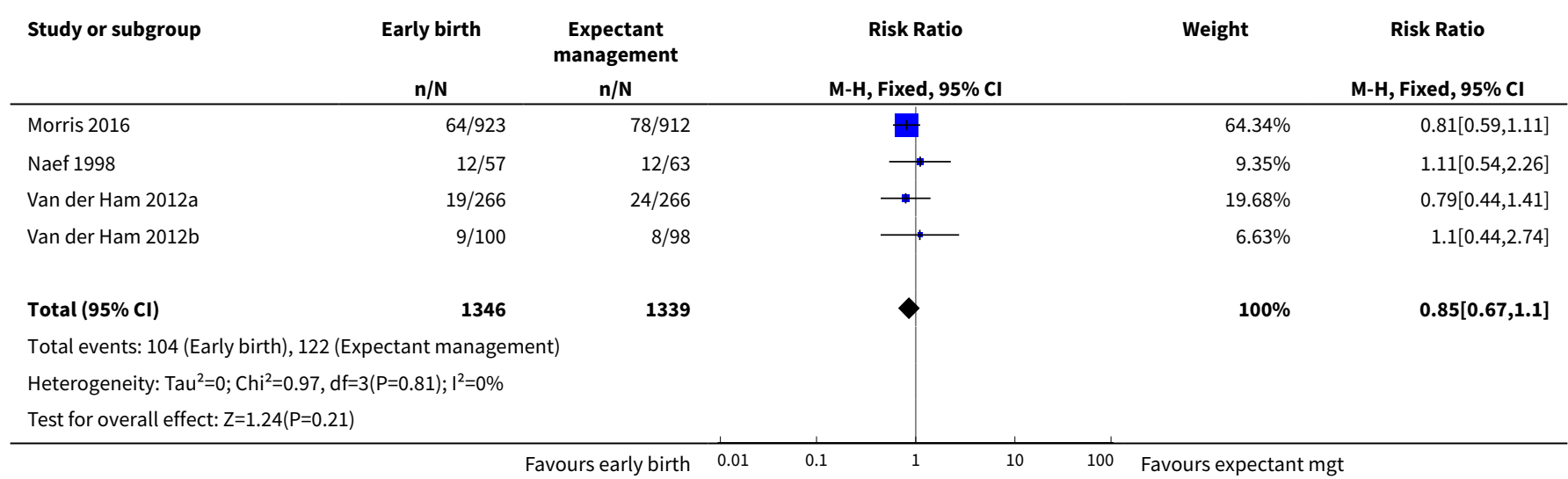

Analysis 1.33. Comparison 1 Any planned birth versus expectant management: by type, Outcome 33 Caesarean section for fetal distress.

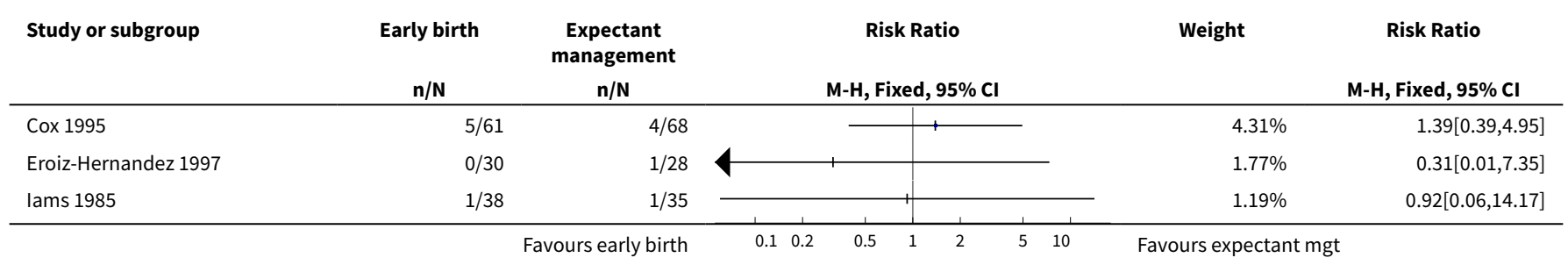




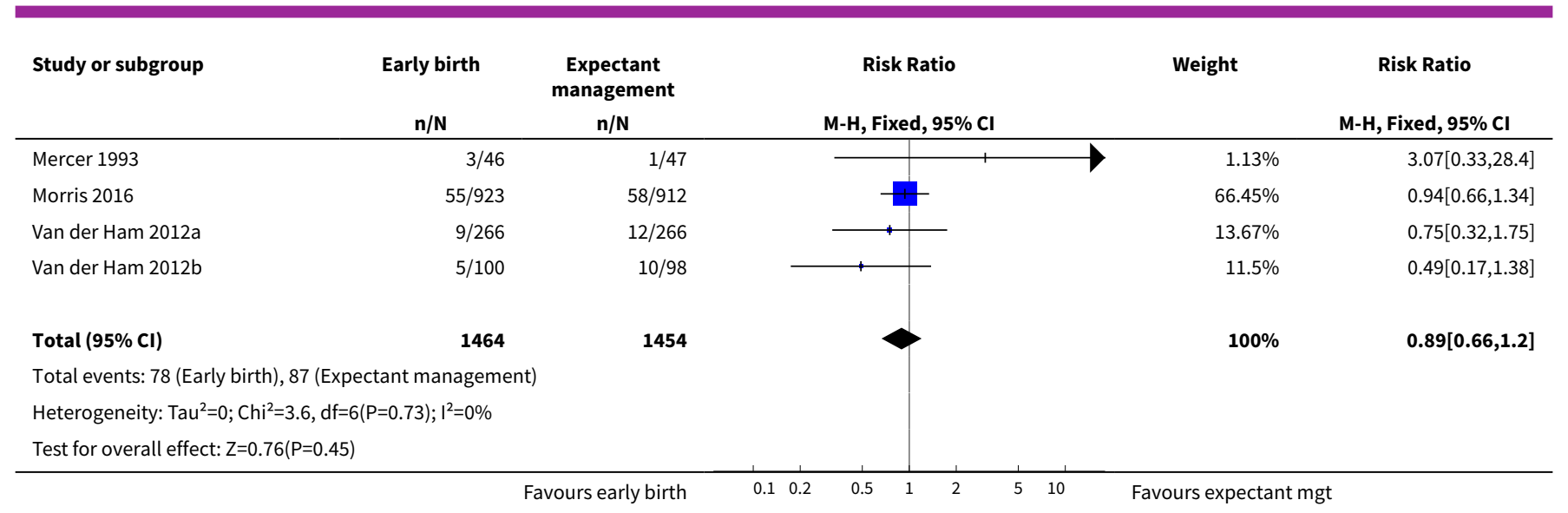

Analysis 1.34. Comparison 1 Any planned birth versus expectant management: by type, Outcome 34 Duration (days) of maternal hospitalisation.

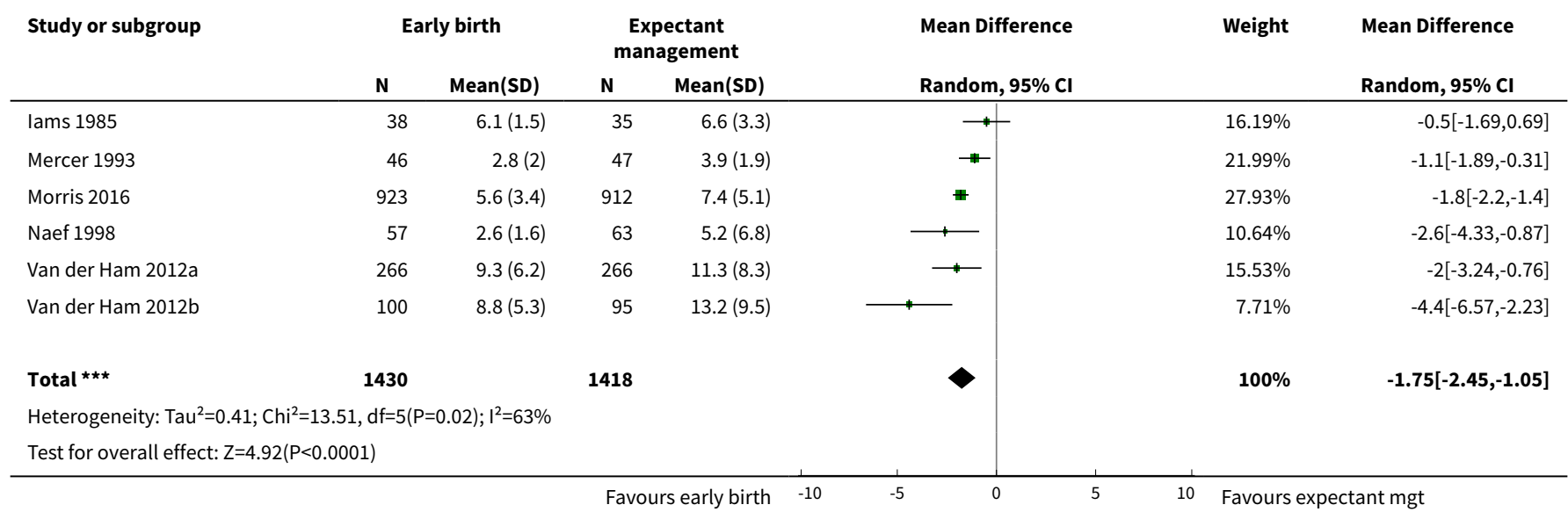

Analysis 1.35. Comparison 1 Any planned birth versus expectant management: by type, Outcome 35 Duration (days) of antenatal hospitalisation.

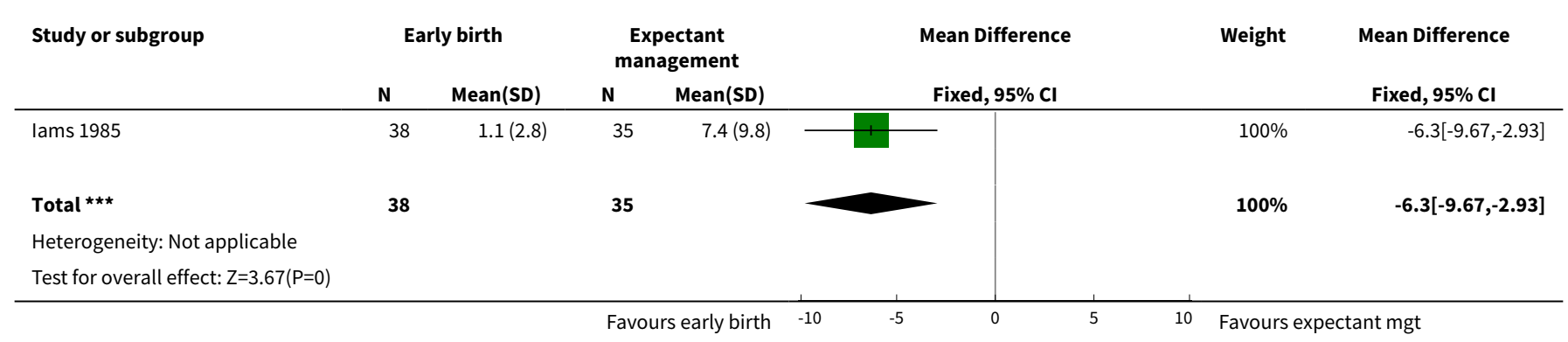


Analysis 1.36. Comparison 1 Any planned birth versus expectant management: by type, Outcome 36 Duration (days) of maternal hospitalisation (excluding trials with antenatal discharge).

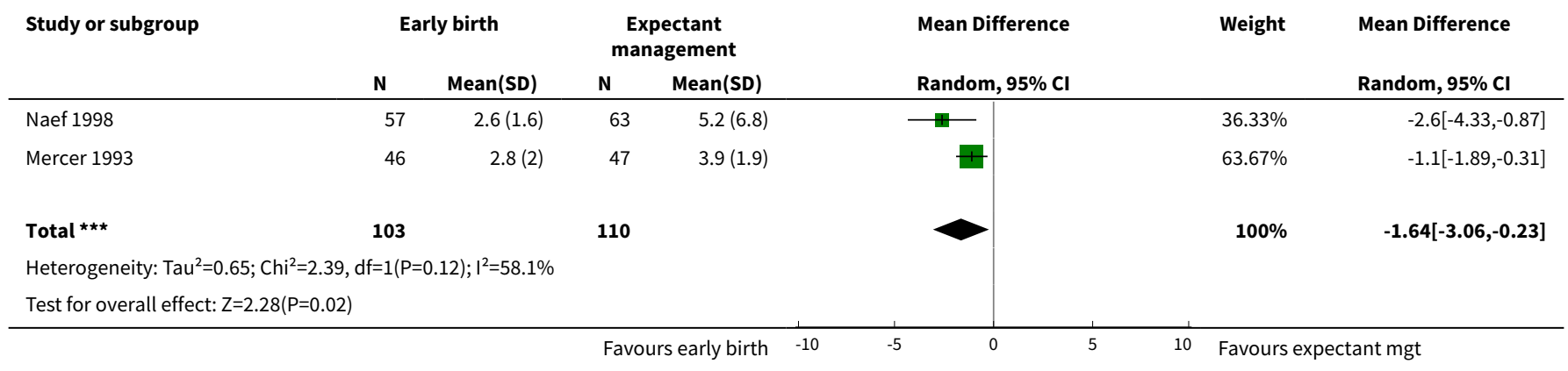

Analysis 1.37. Comparison 1 Any planned birth versus expectant management: by type, Outcome 37 Time (hours) from randomisation to birth.

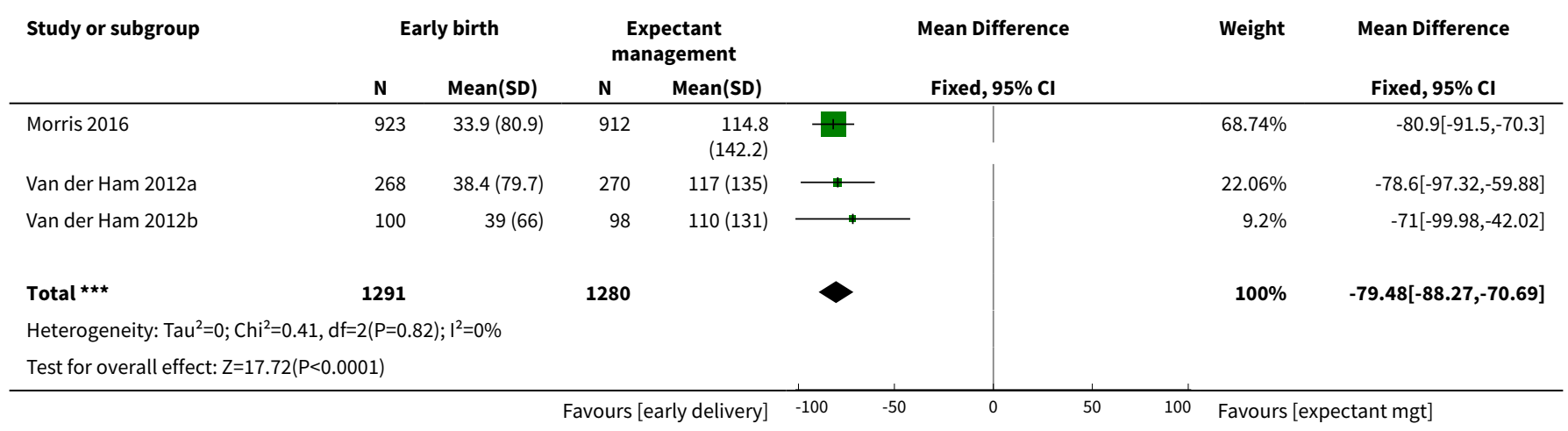

Analysis 1.38. Comparison 1 Any planned birth versus expectant management: by type, Outcome 38 Disability at 2 years, abnormal CBCL.

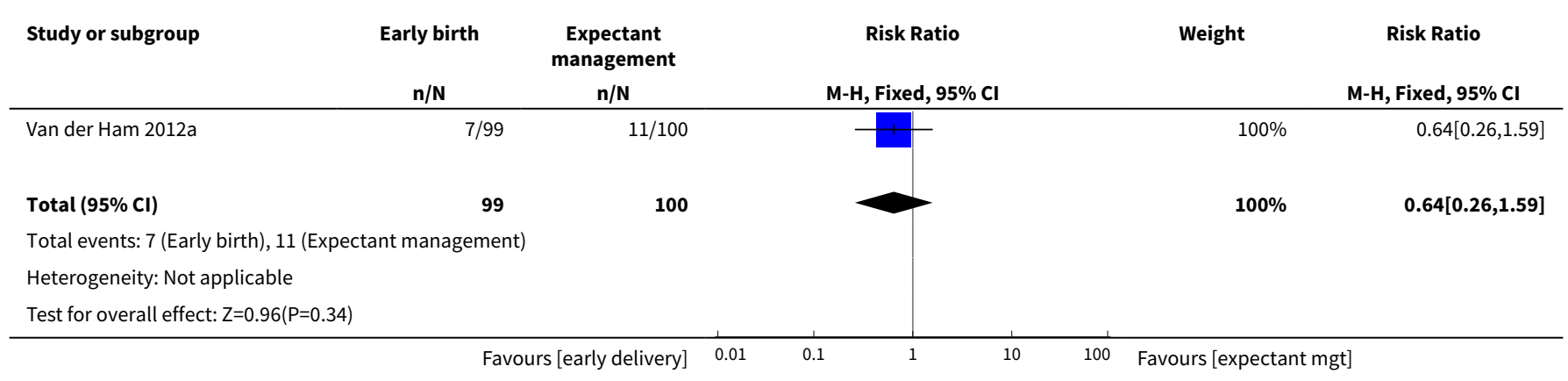


Analysis 1.39. Comparison 1 Any planned birth versus expectant management: by type, Outcome 39 Disability at 2 years, abnormal ASQ.

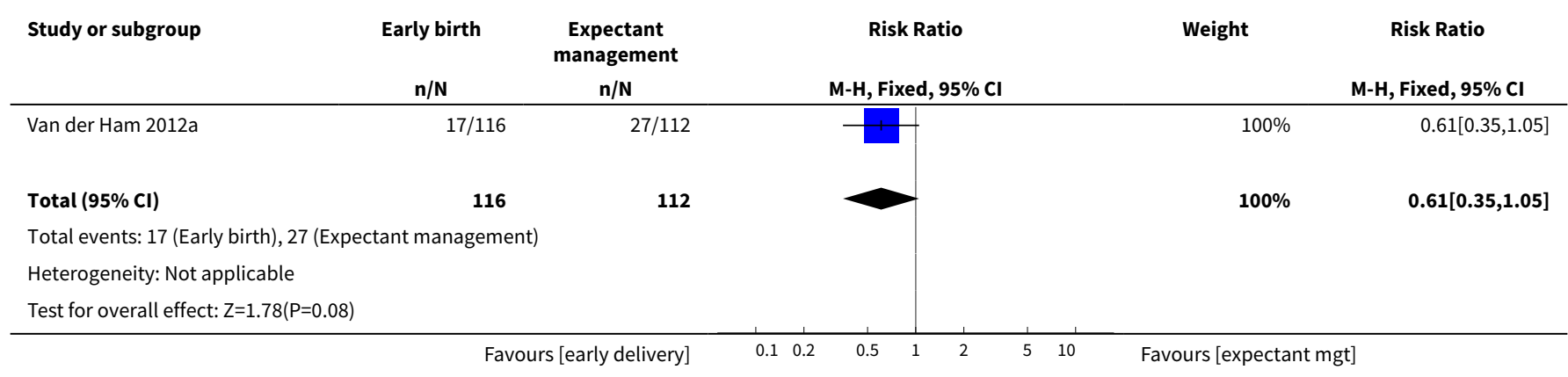

Analysis 1.40. Comparison 1 Any planned birth versus expectant management: by type, Outcome $\mathbf{4 0}$ Maternal satisfaction.

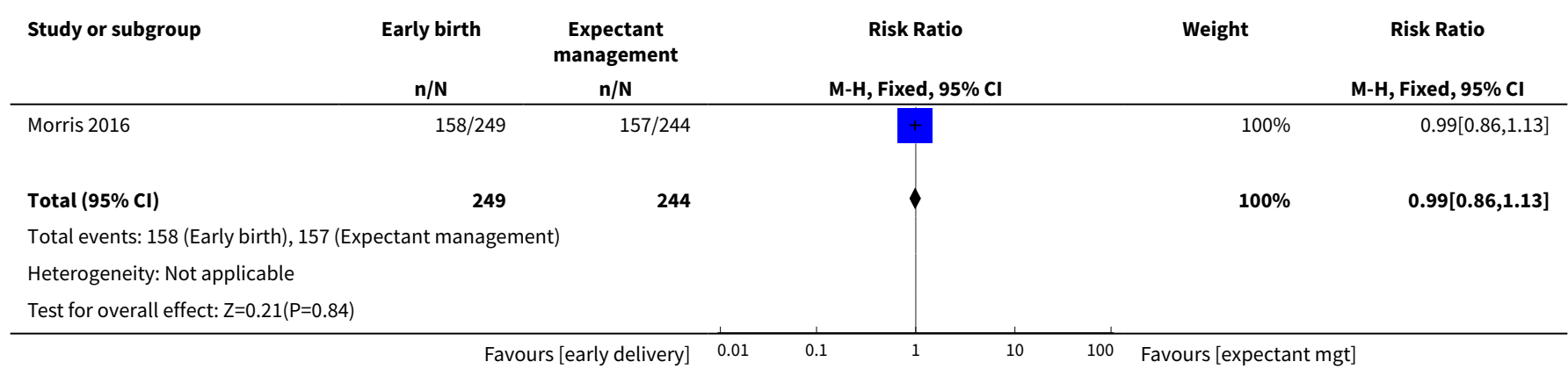

Analysis 1.41. Comparison 1 Any planned birth versus expectant management: by type, Outcome 41 Breastfeeding > 12 weeks.

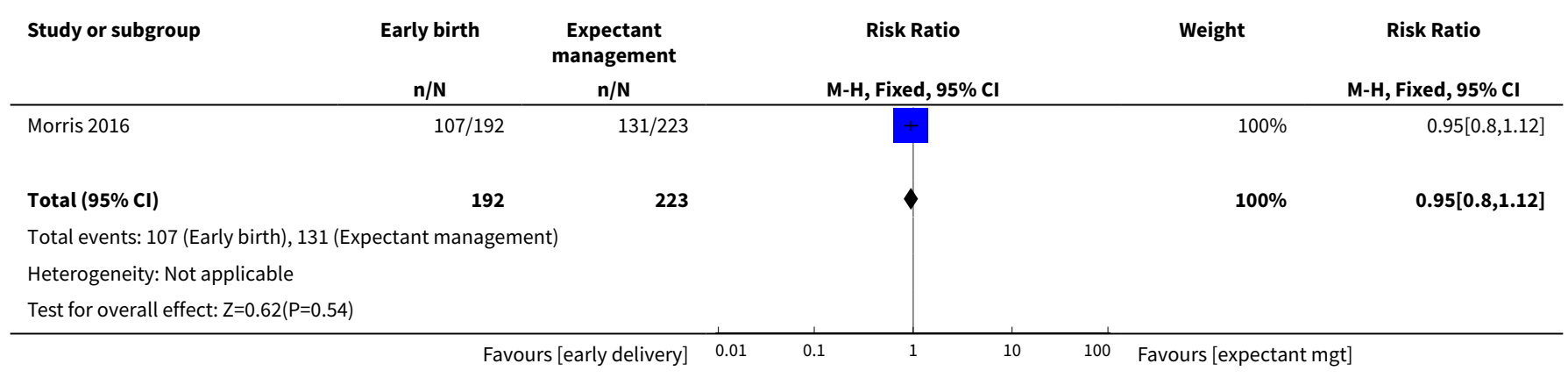

Comparison 2. Any planned birth versus expectant management (subgroup analysis by corticosteroid usage)

\begin{tabular}{lllll}
\hline Outcome or subgroup title & No. of studies & $\begin{array}{l}\text { No. of partici- } \\
\text { pants }\end{array}$ & Statistical method & Effect size \\
\hline 1 Neonatal infection & 12 & 3652 & Risk Ratio (M-H, Fixed, 95\% Cl) & $0.94[0.68,1.32]$ \\
\hline
\end{tabular}




\begin{tabular}{|c|c|c|c|c|}
\hline Outcome or subgroup title & No. of studies & $\begin{array}{l}\text { No. of partici- } \\
\text { pants }\end{array}$ & Statistical method & Effect size \\
\hline 1.1 Antenatal corticosteroids & 0 & 0 & Risk Ratio (M-H, Fixed, 95\% Cl) & $0.0[0.0,0.0]$ \\
\hline $\begin{array}{l}1.2 \text { No antenatal corticos- } \\
\text { teroids }\end{array}$ & 6 & 495 & Risk Ratio (M-H, Fixed, 95\% Cl) & $0.98[0.48,2.03]$ \\
\hline $\begin{array}{l}1.3 \text { Some antenatal corticos- } \\
\text { teroids }\end{array}$ & 6 & 2850 & Risk Ratio (M-H, Fixed, 95\% Cl) & $0.95[0.64,1.41]$ \\
\hline 1.4 Not known & 1 & 307 & Risk Ratio (M-H, Fixed, 95\% CI) & $0.80[0.25,2.55]$ \\
\hline $\begin{array}{l}2 \text { Neonatal infection con- } \\
\text { firmed with positive culture }\end{array}$ & 7 & 2939 & Risk Ratio (M-H, Fixed, 95\% Cl) & $1.29[0.74,2.23]$ \\
\hline 2.1 Antenatal corticosteroids & 0 & 0 & Risk Ratio (M-H, Fixed, 95\% Cl) & $0.0[0.0,0.0]$ \\
\hline $\begin{array}{l}2.2 \text { No antenatal corticos- } \\
\text { teroids }\end{array}$ & 3 & 259 & Risk Ratio $(\mathrm{M}-\mathrm{H}$, Fixed, 95\% Cl) & $0.60[0.18,2.04]$ \\
\hline $\begin{array}{l}2.3 \text { Some antenatal corticos- } \\
\text { teroids }\end{array}$ & 5 & 2680 & Risk Ratio (M-H, Fixed, 95\% Cl) & $1.59[0.85,3.00]$ \\
\hline $\begin{array}{l}3 \text { Respiratory distress syn- } \\
\text { drome }\end{array}$ & 12 & 3646 & Risk Ratio (M-H, Fixed, 95\% Cl) & $1.29[1.07,1.56]$ \\
\hline 3.1 Antenatal corticosteroids & 0 & 0 & Risk Ratio $(\mathrm{M}-\mathrm{H}$, Fixed, 95\% Cl) & $0.0[0.0,0.0]$ \\
\hline $\begin{array}{l}3.2 \text { No antenatal corticos- } \\
\text { teroids }\end{array}$ & 6 & 495 & Risk Ratio $(\mathrm{M}-\mathrm{H}$, Fixed, 95\% Cl) & $1.32[0.96,1.83]$ \\
\hline $\begin{array}{l}3.3 \text { Some antenatal corticos- } \\
\text { teroids }\end{array}$ & 6 & 2844 & Risk Ratio (M-H, Fixed, 95\% Cl) & $1.28[1.01,1.63]$ \\
\hline 3.4 Not known & 1 & 307 & Risk Ratio (M-H, Fixed, 95\% Cl) & $1.27[0.55,2.94]$ \\
\hline 4 Caesarean section & 12 & 3644 & Risk Ratio (M-H, Fixed, 95\% Cl) & $1.26[1.11,1.44]$ \\
\hline 4.1 Antenatal corticosteroids & 0 & 0 & Risk Ratio (M-H, Fixed, 95\% Cl) & $0.0[0.0,0.0]$ \\
\hline $\begin{array}{l}4.2 \text { No antenatal corticos- } \\
\text { teroids }\end{array}$ & 6 & 493 & Risk Ratio (M-H, Fixed, 95\% Cl) & $1.43[1.00,2.06]$ \\
\hline $\begin{array}{l}4.3 \text { Some antenatal corticos- } \\
\text { teroids }\end{array}$ & 6 & 2844 & Risk Ratio (M-H, Fixed, 95\% Cl) & $1.27[1.10,1.47]$ \\
\hline 4.4 Not known & 1 & 307 & Risk Ratio (M-H, Fixed, 95\% Cl) & $0.91[0.51,1.61]$ \\
\hline 5 Chorioamnionitis & 8 & 1358 & Risk Ratio (M-H, Fixed, 95\% Cl) & $0.49[0.33,0.72]$ \\
\hline 5.1 Antenatal corticosteroids & 0 & 0 & Risk Ratio (M-H, Fixed, 95\% Cl) & $0.0[0.0,0.0]$ \\
\hline $\begin{array}{l}5.2 \text { No antenatal corticos- } \\
\text { teroids }\end{array}$ & 4 & 398 & Risk Ratio $(\mathrm{M}-\mathrm{H}$, Fixed, 95\% Cl) & $0.38[0.22,0.67]$ \\
\hline $\begin{array}{l}5.3 \text { Some antenatal corticos- } \\
\text { teroids }\end{array}$ & 4 & 960 & Risk Ratio (M-H, Fixed, 95\% Cl) & $0.61[0.36,1.06]$ \\
\hline
\end{tabular}

Planned early birth versus expectant management for women with preterm prelabour rupture of membranes prior to 37 weeks' 


\begin{tabular}{lllll}
\hline Outcome or subgroup title & No. of studies & $\begin{array}{l}\text { No. of partici- } \\
\text { pants }\end{array}$ & Statistical method & Effect size \\
\hline 6 Endometritis & 7 & 2980 & Risk Ratio (M-H, Fixed, 95\% Cl) & $1.61[1.00,2.59]$ \\
\hline 6.1 Antenatal corticosteroids & 0 & 0 & Risk Ratio (M-H, Fixed, 95\% Cl) & $0.0[0.0,0.0]$ \\
\hline $\begin{array}{l}\text { 6.2 No antenatal corticos- } \\
\text { teroids }\end{array}$ & 2 & 185 & Risk Ratio (M-H, Fixed, 95\% Cl) & $1.38[0.32,5.94]$ \\
\hline $\begin{array}{l}\text { 6.3 Some antenatal corticos- } \\
\text { teroids }\end{array}$ & 5 & 2795 & Risk Ratio (M-H, Fixed, 95\% Cl) & $1.64[0.99,2.72]$ \\
\hline
\end{tabular}

Analysis 2.1. Comparison 2 Any planned birth versus expectant management (subgroup analysis by corticosteroid usage), Outcome 1 Neonatal infection.

\begin{tabular}{cccc} 
Study or subgroup & Early birth & $\begin{array}{c}\text { Expectant } \\
\text { management } \\
\mathrm{n} / \mathrm{N}\end{array}$ & Risk Ratio \\
$\mathrm{n} / \mathrm{N}$ & $\mathrm{M}-\mathrm{H}$, Fixed, $95 \% \mathrm{Cl}$ & Weight \\
\hline
\end{tabular}

2.1.1 Antenatal corticosteroids

Subtotal $(95 \% \mathrm{Cl})$

0

Total events: 0 (Early birth), 0 (Expectant management)

Heterogeneity: Not applicable

Test for overall effect: Not applicable

2.1.2 No antenatal corticosteroids

Cox 1995

Eroiz-Hernandez 1997

Mercer 1993

Naef 1998

Nelson 1985

Spinnato 1987

Subtotal $(95 \% \mathrm{CI})$

Total events: 13 (Early birth), 13 (Expectant management) Heterogeneity: $\mathrm{Tau}^{2}=0 ; \mathrm{Chi}^{2}=5.5, \mathrm{df}=5(\mathrm{P}=0.36) ; \mathrm{I}^{2}=9.17 \%$

Test for overall effect: $Z=0.05(P=0.96)$

2.1.3 Some antenatal corticosteroids

Garite 1981

lams 1985

Morris 2016

Nelson 1985

Van der Ham 2012a

Van der Ham 2012b

Subtotal $(95 \% \mathrm{Cl})$

Total events: 46 (Early birth), 48 (Expectant management) Heterogeneity: $\mathrm{Tau}^{2}=0 ; \mathrm{Chi}^{2}=6.47, \mathrm{df}=5(\mathrm{P}=0.26) ; \mathrm{I}^{2}=22.68 \%$ Test for overall effect: $Z=0.24(P=0.81)$

\subsubsection{Not known}

Koroveshi 2013

Subtotal $(95 \% \mathrm{Cl})$

$2 / 62$
$2 / 30$
$3 / 46$
$0 / 57$
$0 / 22$
$6 / 26$
243

$4 / 80$
$4 / 38$
$23 / 923$
$5 / 22$
$7 / 268$
$3 / 100$
1431

birth), 48 (Expectant management)
Chi ${ }^{2}=6.47, d f=5(P=0.26) ;\left.\right|^{2}=22.68 \%$

$5 / 69$
$0 / 28$
$2 / 47$
$3 / 63$
$1 / 24$
$2 / 21$
$\mathbf{2 5 2}$

$6.85 \%$

$0.75 \%$

$2.86 \%$

$4.82 \%$

$2.08 \%$

$3.2 \%$

$20.56 \%$
$0.45[0.09,2.21]$

$4.68[0.23,93.37]$

$1.53[0.27,8.75]$

$0.16[0.01,2.99]$

$0.36[0.02,8.46]$

2.42[0.54,10.79]

$0.98[0.48,2.03]$
$9[0.49,164.46]$

$1.23[0.3,5.11]$

$0.78[0.46,1.34]$

$5.45[0.69,43.12]$

$0.64[0.25,1.63]$

$0.74[0.17,3.2]$

$0.95[0.64,1.41]$ 


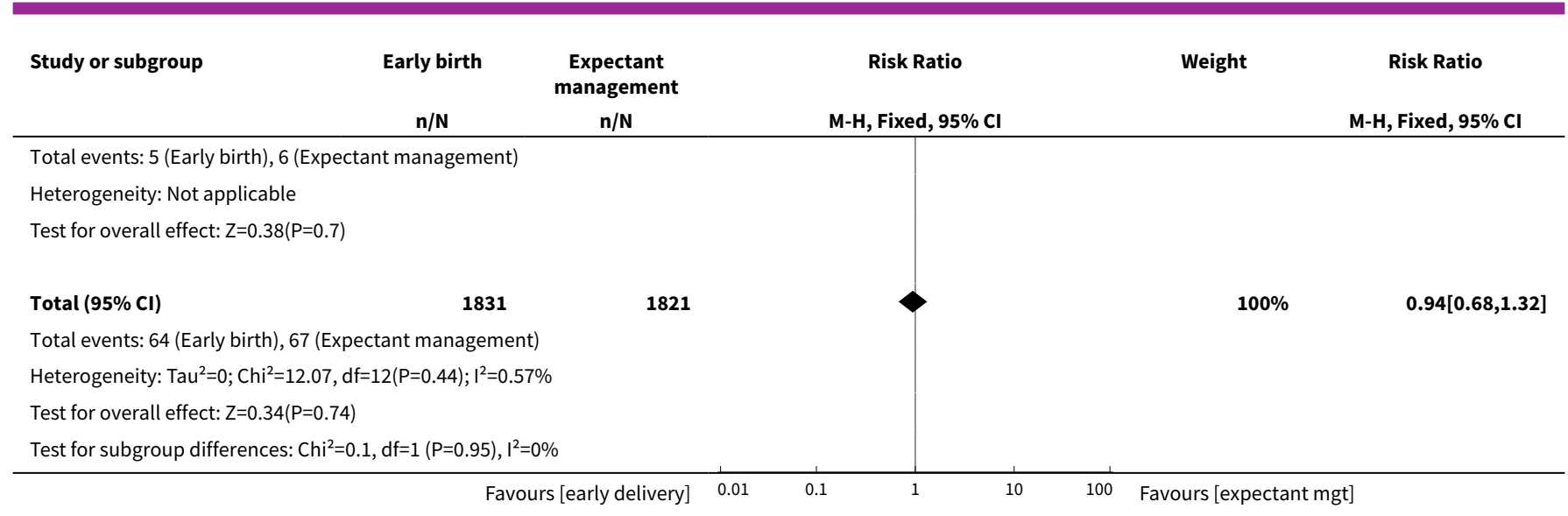

\section{Analysis 2.2. Comparison 2 Any planned birth versus expectant management (subgroup analysis by corticosteroid usage), Outcome 2 Neonatal infection confirmed with positive culture.}

\begin{tabular}{ccccc} 
Study or subgroup & Early birth & $\begin{array}{c}\text { Expectant } \\
\text { management }\end{array}$ & Risk Ratio & Weight \\
& $\mathrm{n} / \mathrm{N}$ & $\mathrm{n} / \mathrm{N}$ & $\mathrm{M}-\mathrm{H}$, Fixed, $95 \% \mathrm{Cl}$ & $\mathrm{M}-\mathrm{H}, \mathrm{Fixed}, 95 \% \mathrm{Cl}$ \\
\hline
\end{tabular}

\subsubsection{Antenatal corticosteroids}

Subtotal $(95 \% \mathrm{Cl})$

0

Not estimable

Total events: 0 (Early birth), 0 (Expectant management)

Heterogeneity: Not applicable

Test for overall effect: Not applicable

2.2.2 No antenatal corticosteroids

Mercer 1993

Naef 1998

Nelson 1985

Total events: 3 (Early birth), 6 (Expectant management) Heterogeneity: $\mathrm{Tau}^{2}=0 ; \mathrm{Chi}^{2}=2, \mathrm{df}=2(\mathrm{P}=0.37) ; \mathrm{I}^{2}=0 \%$

Test for overall effect: $Z=0.81(P=0.42)$

2.2.3 Some antenatal corticosteroids

lams 1985

Morris 2016

$13 / 923$

Nelson 1985

Van der Ham 2012a

Total events: 24 (Early birth), 15 (Expectant management) Heterogeneity: $\mathrm{Tau}^{2}=0 ; \mathrm{Chi}^{2}=4.53, \mathrm{df}=4(\mathrm{P}=0.34) ; \mathrm{I}^{2}=11.71 \%$ Test for overall effect: $Z=1.44(P=0.15)$ 
Analysis 2.3. Comparison 2 Any planned birth versus expectant management (subgroup analysis by corticosteroid usage), Outcome 3 Respiratory distress syndrome.

\begin{tabular}{ccccc} 
Study or subgroup & Early birth & $\begin{array}{c}\text { Expectant } \\
\text { management } \\
\text { n/N }\end{array}$ & Risk Ratio & Weight \\
& $\mathrm{n} / \mathrm{N}$ & $\mathrm{M}-\mathrm{H}$, Fixed, $95 \% \mathrm{Cl}$ & $\mathrm{M}-\mathrm{H}, \mathrm{Fixed}, 95 \% \mathrm{Cl}$ \\
\hline
\end{tabular}

\subsubsection{Antenatal corticosteroids}

Subtotal $(95 \% \mathrm{Cl})$

Total events: 0 (Early birth), 0 (Expectant management)

Heterogeneity: Not applicable

Test for overall effect: Not applicable

2.3.2 No antenatal corticosteroids

Cox 1995

$23 / 62$
$16 / 30$
$0 / 46$
$3 / 57$
$11 / 22$
$2 / 26$
243

Subtotal $(95 \% \mathrm{Cl})$

243

Total events: 55 (Early birth), 44 (Expectant management) Heterogeneity: $\mathrm{Tau}^{2}=0 ; \mathrm{Chi}^{2}=6.96, \mathrm{df}=4(\mathrm{P}=0.14) ; \mathrm{I}^{2}=42.54 \%$

Test for overall effect: $Z=1.69(P=0.09)$

$\begin{array}{lr}\text { 2.3.3 Some antenatal corticosteroids } & \\ \text { Garite } 1981 & 14 / 80 \\ \text { lams } 1985 & 10 / 38 \\ \text { Morris } 2016 & 76 / 919 \\ \text { Nelson } 1985 & 10 / 22 \\ \text { Van der Ham 2012a } & 21 / 268 \\ \text { Van der Ham 2012b } & 6 / 100 \\ \text { Subtotal }(\mathbf{9 5} \% \mathbf{C l}) & \mathbf{1 4 2 7}\end{array}$

Total events: 137 (Early birth), 106 (Expectant management) Heterogeneity: $\mathrm{Tau}^{2}=0 ; \mathrm{Chi}^{2}=5.51, \mathrm{df}=5(\mathrm{P}=0.36) ; \mathrm{I}^{2}=9.21 \%$

Test for overall effect: $Z=2.07(P=0.04)$

\subsubsection{Not known}

Koroveshi 2013

Subtotal $(95 \% \mathrm{Cl})$

Total events: 12 (Early birth), 9 (Expectant management)

Heterogeneity: Not applicable

Test for overall effect: $Z=0.57(P=0.57)$

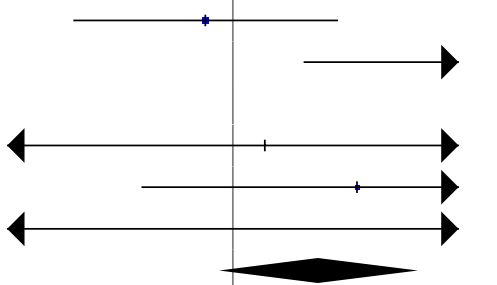

Total events: 204 (Early birth), 159 (Expectant management)

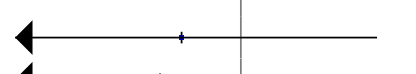

$10.74 \%$

$7.89 \%$

$29.84 \%$

$4.83 \%$

$10.7 \%$

$3.19 \%$

$67.19 \%$
$0.82[0.44,1.56]$

$0.77[0.38,1.55]$

$1.6[1.13,2.28]$

$1.36[0.66,2.82]$

$1.24[0.67,2.31]$

$1.18[0.37,3.73]$

$1.28[1.01,1.63]$

Heterogeneity: $\mathrm{Tau}^{2}=0 ; \mathrm{Chi}^{2}=12.42, \mathrm{df}=11(\mathrm{P}=0.33) ; \mathrm{I}^{2}=11.41 \%$

Test for overall effect: $\mathrm{Z}=2.69(\mathrm{P}=0.01)$

Test for subgroup differences: $\mathrm{Chi}^{2}=0.02, \mathrm{df}=1(\mathrm{P}=0.99), \mathrm{I}^{2}=0 \%$

$.27[0.55,2.94]$

$1.27[0.55,2.94]$ 
Analysis 2.4. Comparison 2 Any planned birth versus expectant management (subgroup analysis by corticosteroid usage), Outcome 4 Caesarean section.

\begin{tabular}{ccccc} 
Study or subgroup & Early birth & $\begin{array}{c}\text { Expectant } \\
\text { management }\end{array}$ & Risk Ratio & Risk Ratio \\
& $\mathrm{n} / \mathrm{N}$ & $\mathrm{n} / \mathrm{N}$ & $\mathrm{M}-\mathrm{H}, \mathrm{Fixed}, 95 \% \mathrm{Cl}$ & $\mathrm{M}-\mathrm{H}, \mathrm{Fixed}, 95 \% \mathrm{Cl}$ \\
\hline
\end{tabular}

\subsubsection{Antenatal corticosteroids}

Total events: 0 (Early birth), 0 (Expectant management)

Heterogeneity: Not applicable

Test for overall effect: Not applicable

2.4.2 No antenatal corticosteroids

Cox 1995

$14 / 61$
$18 / 30$
$4 / 46$
$4 / 57$
$6 / 22$
$4 / 26$
242

Eroiz-Hernandez 1997

Mercer 1993

Naef 1998

Nelson 1985

Spinnato 1987

$3 / 63$

Subtotal $(95 \% \mathrm{Cl})$

$4 / 24$

$3 / 21$

Total events: 50 (Early birth), 35 (Expectant management) Heterogeneity: $\mathrm{Tau}^{2}=0 ; \mathrm{Chi}^{2}=1.35, \mathrm{df}=5(\mathrm{P}=0.93) ; \mathrm{I}^{2}=0 \%$

Test for overall effect: $Z=1.95(P=0.05)$

\subsubsection{Some antenatal corticosteroids}

\section{Garite 1981}

lams 1985

Morris 2016

Nelson 1985

Van der Ham 2012a

Total events: 328 (Early birth), 256 (Expectant management) Heterogeneity: $\mathrm{Tau}^{2}=0 ; \mathrm{Chi}^{2}=9.34, \mathrm{df}=5(\mathrm{P}=0.1) ; \mathrm{I}^{2}=46.45 \%$ Test for overall effect: $\mathrm{Z}=3.2(\mathrm{P}=0)$

\subsubsection{Not known}

Koroveshi 2013

Subtotal $(95 \% \mathrm{CI})$

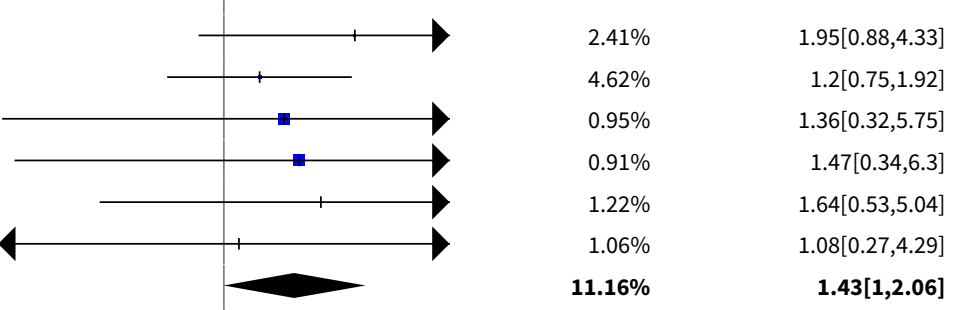

Total events: 20 (Early birth), 21 (Expectant management) Heterogeneity: Not applicable

Test for overall effect: $Z=0.32(P=0.75)$

\section{Total $(95 \% \mathrm{Cl})$}

Total events: 398 (Early birth), 312 (Expectant management)

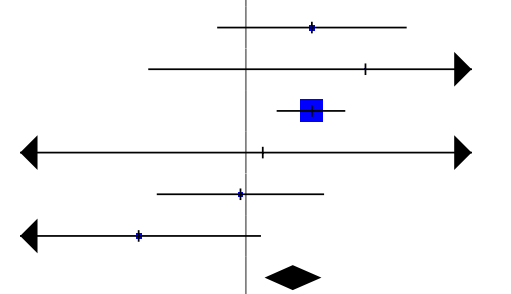

$\begin{array}{rr}6.38 \% & 1.4[0.86,2.27] \\ 1.33 \% & 1.84[0.61,5.58] \\ 54.19 \% & 1.4[1.17,1.66] \\ 1.22 \% & 1.09[0.31,3.84] \\ 11.79 \% & 0.97[0.64,1.49] \\ 7.08 \% & 0.58[0.31,1.08] \\ \mathbf{8 1 . 9 9 \%} & \mathbf{1 . 2 7}[\mathbf{1 . 1} \mathbf{1 . 4 7}]\end{array}$
Heterogeneity: $\mathrm{Tau}^{2}=0 ; \mathrm{Chi}^{2}=12.12, \mathrm{df}=12(\mathrm{P}=0.44) ; \mathrm{I}^{2}=1 \%$ Test for overall effect: $Z=3.48(P=0)$

Test for subgroup differences: $\mathrm{Chi}^{2}=1.75, \mathrm{df}=1(\mathrm{P}=0.42), \mathrm{I}^{2}=0 \%$ 
Analysis 2.5. Comparison 2 Any planned birth versus expectant management (subgroup analysis by corticosteroid usage), Outcome 5 Chorioamnionitis.

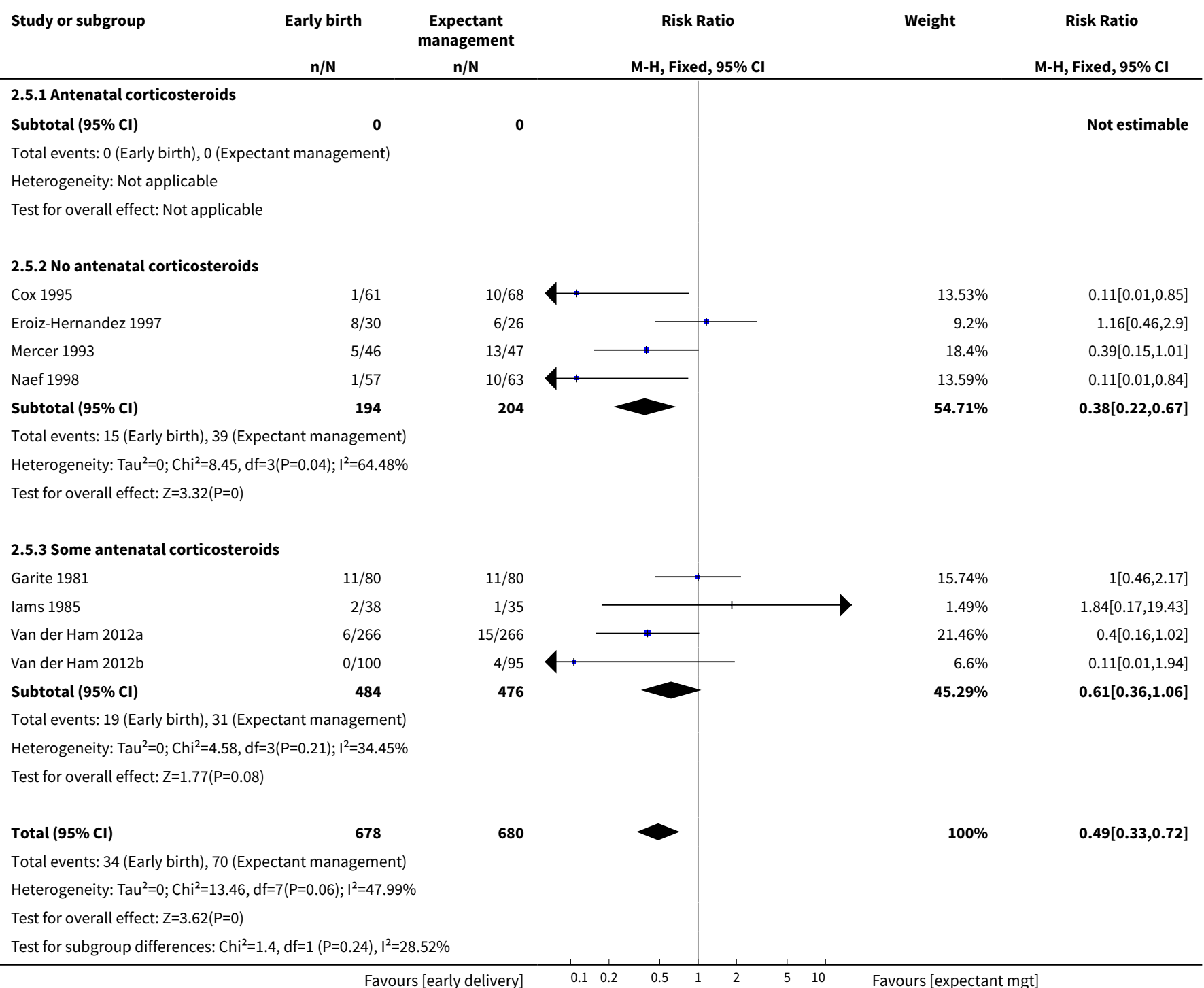

Analysis 2.6. Comparison 2 Any planned birth versus expectant management (subgroup analysis by corticosteroid usage), Outcome 6 Endometritis.

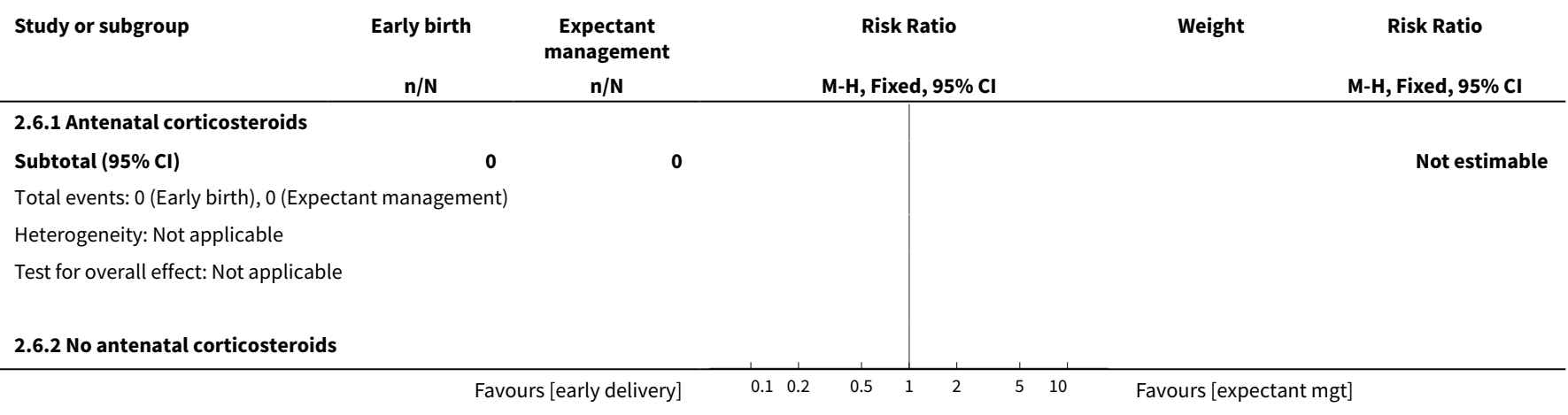




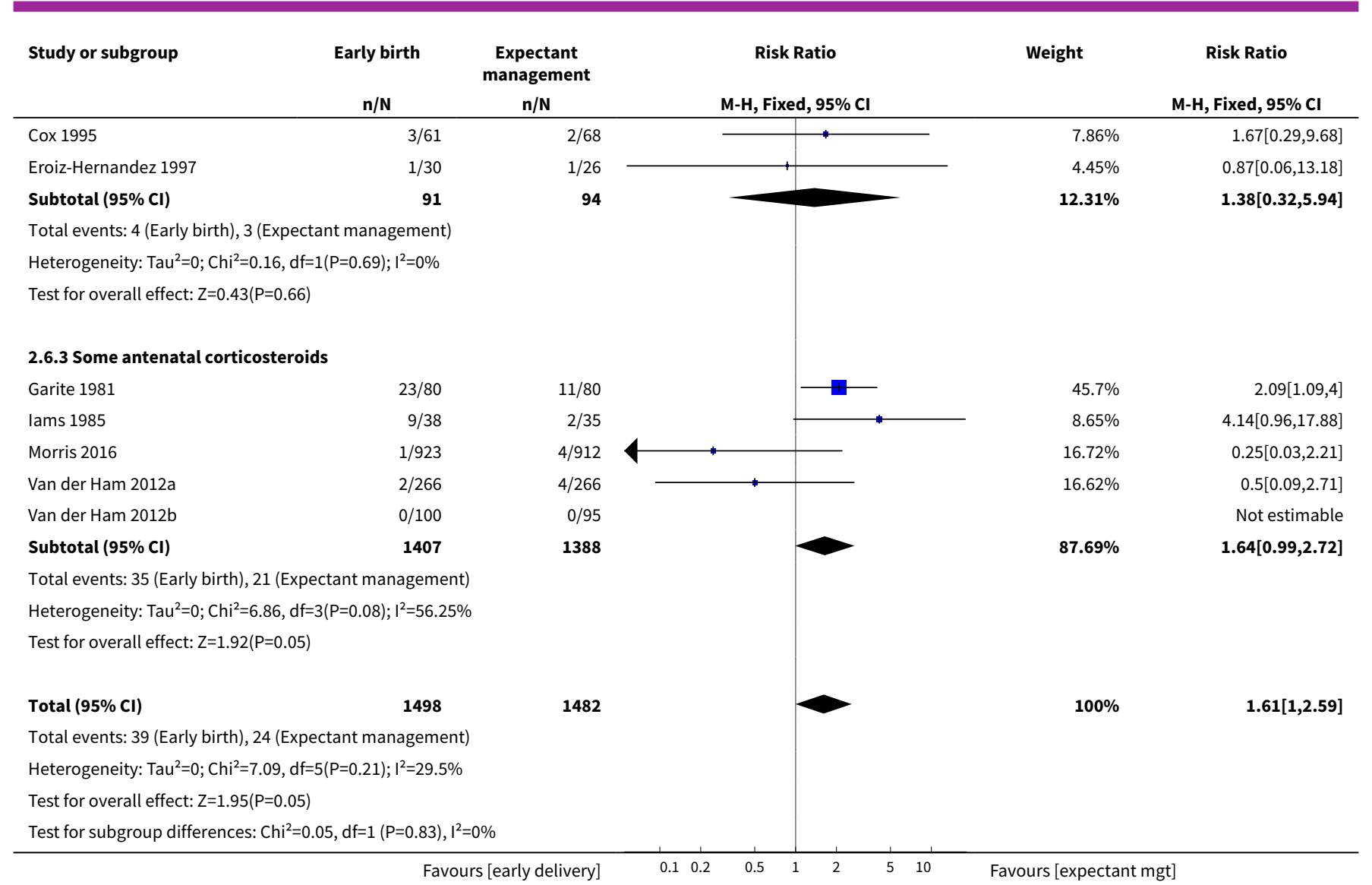

Comparison 3. Any planned birth versus expectant management (subgroup analysis by gestational age for inclusion in trial)

\begin{tabular}{|c|c|c|c|c|}
\hline Outcome or subgroup title & No. of studies & $\begin{array}{l}\text { No. of partici- } \\
\text { pants }\end{array}$ & Statistical method & Effect size \\
\hline 1 Neonatal infection & 12 & 3628 & Risk Ratio (M-H, Fixed, 95\% Cl) & $0.93[0.66,1.30]$ \\
\hline $\begin{array}{l}1.1 \text { Greater than } 34 \text { weeks' gesta- } \\
\text { tion }\end{array}$ & 5 & 2998 & Risk Ratio (M-H, Fixed, 95\% Cl) & $0.71[0.47,1.07]$ \\
\hline 1.2 Less than 34 weeks' gestation & 5 & 490 & Risk Ratio (M-H, Fixed, 95\% Cl) & $1.61[0.74,3.50]$ \\
\hline 1.3 Not specified (wider span) & 2 & 140 & Risk Ratio (M-H, Fixed, 95\% Cl) & $2.00[0.65,6.18]$ \\
\hline $\begin{array}{l}2 \text { Neonatal infection confirmed } \\
\text { with positive culture }\end{array}$ & 7 & 2925 & Risk Ratio (M-H, Fixed, 95\% Cl) & $1.24[0.70,2.21]$ \\
\hline $\begin{array}{l}2.1 \text { Greater than } 34 \text { weeks' gesta- } \\
\text { tion }\end{array}$ & 4 & 2691 & Risk Ratio (M-H, Fixed, 95\% Cl) & $1.07[0.52,2.20]$ \\
\hline 2.2 Less than 34 weeks' gestation & 2 & 141 & Risk Ratio (M-H, Fixed, 95\% Cl) & $1.67[0.52,5.35]$ \\
\hline 2.3 Not specified (wider span) & 1 & 93 & Risk Ratio (M-H, Fixed, 95\% Cl) & $1.53[0.27,8.75]$ \\
\hline 3 Respiratory distress syndrome & 12 & 3622 & Risk Ratio (M-H, Fixed, 95\% Cl) & $1.26[1.05,1.53]$ \\
\hline
\end{tabular}

Planned early birth versus expectant management for women with preterm prelabour rupture of membranes prior to 37 weeks' 


\begin{tabular}{|c|c|c|c|c|}
\hline Outcome or subgroup title & No. of studies & $\begin{array}{l}\text { No. of partici- } \\
\text { pants }\end{array}$ & Statistical method & Effect size \\
\hline $\begin{array}{l}\text { 3.1 Greater than } 34 \text { weeks' gesta- } \\
\text { tion }\end{array}$ & 5 & 2992 & Risk Ratio (M-H, Fixed, 95\% Cl) & $1.45[1.10,1.90]$ \\
\hline 3.2 Less than 34 weeks' gestation & 5 & 490 & Risk Ratio (M-H, Fixed, 95\% Cl) & $1.09[0.84,1.43]$ \\
\hline 3.3 Not specified (wider span) & 2 & 140 & Risk Ratio (M-H, Fixed, 95\% Cl) & $0.81[0.27,2.42]$ \\
\hline 4 Caesarean section & 12 & 3620 & Risk Ratio (M-H, Fixed, 95\% Cl) & $1.26[1.11,1.44]$ \\
\hline $\begin{array}{l}4.1 \text { Greater than } 34 \text { weeks' gesta- } \\
\text { tion }\end{array}$ & 5 & 2992 & Risk Ratio (M-H, Fixed, 95\% Cl) & $1.22[1.05,1.42]$ \\
\hline 4.2 Less than 34 weeks' gestation & 5 & 488 & Risk Ratio (M-H, Fixed, 95\% Cl) & $1.46[1.08,1.96]$ \\
\hline 4.3 Not specified (wider span) & 2 & 140 & Risk Ratio (M-H, Fixed, 95\% Cl) & $1.21[0.45,3.28]$ \\
\hline 5 Chorioamnionitis & 8 & 1358 & Risk Ratio (M-H, Fixed, 95\% Cl) & $0.49[0.33,0.72]$ \\
\hline $\begin{array}{l}5.1 \text { Greater than } 34 \text { weeks' gesta- } \\
\text { tion }\end{array}$ & 3 & 847 & Risk Ratio (M-H, Fixed, 95\% Cl) & $0.26[0.12,0.57]$ \\
\hline 5.2 Less than 34 weeks' gestation & 4 & 418 & Risk Ratio (M-H, Fixed, 95\% Cl) & $0.77[0.45,1.30]$ \\
\hline 5.3 Not specified (wider span) & 1 & 93 & Risk Ratio (M-H, Fixed, 95\% Cl) & $0.39[0.15,1.01]$ \\
\hline 6 Endometritis & 7 & 2980 & Risk Ratio (M-H, Fixed, 95\% Cl) & $1.61[1.00,2.59]$ \\
\hline $\begin{array}{l}6.1 \text { Greater than } 34 \text { weeks' gesta- } \\
\text { tion }\end{array}$ & 3 & 2562 & Risk Ratio (M-H, Fixed, 95\% Cl) & $0.37[0.10,1.40]$ \\
\hline 6.2 Less than 34 weeks' gestation & 4 & 418 & Risk Ratio (M-H, Fixed, 95\% Cl) & $2.23[1.29,3.84]$ \\
\hline
\end{tabular}

\section{Analysis 3.1. Comparison 3 Any planned birth versus expectant management (subgroup analysis by gestational age for inclusion in trial), Outcome 1 Neonatal infection.}

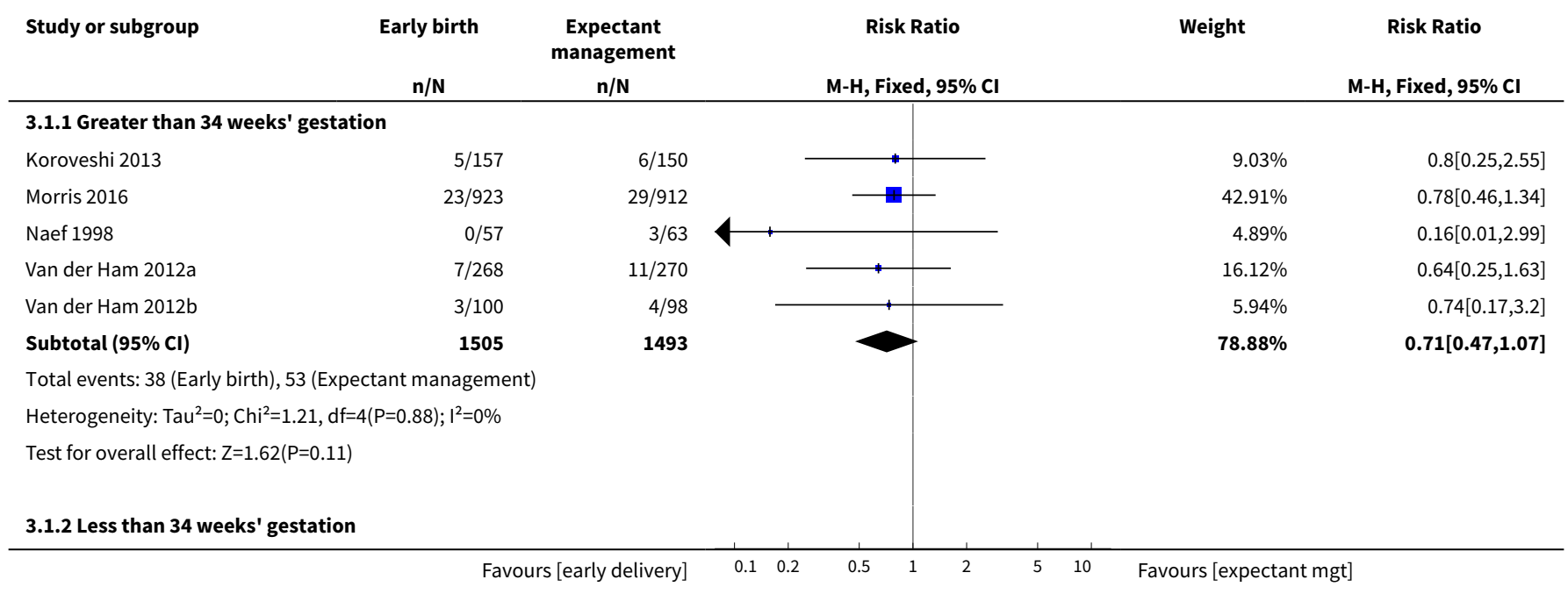




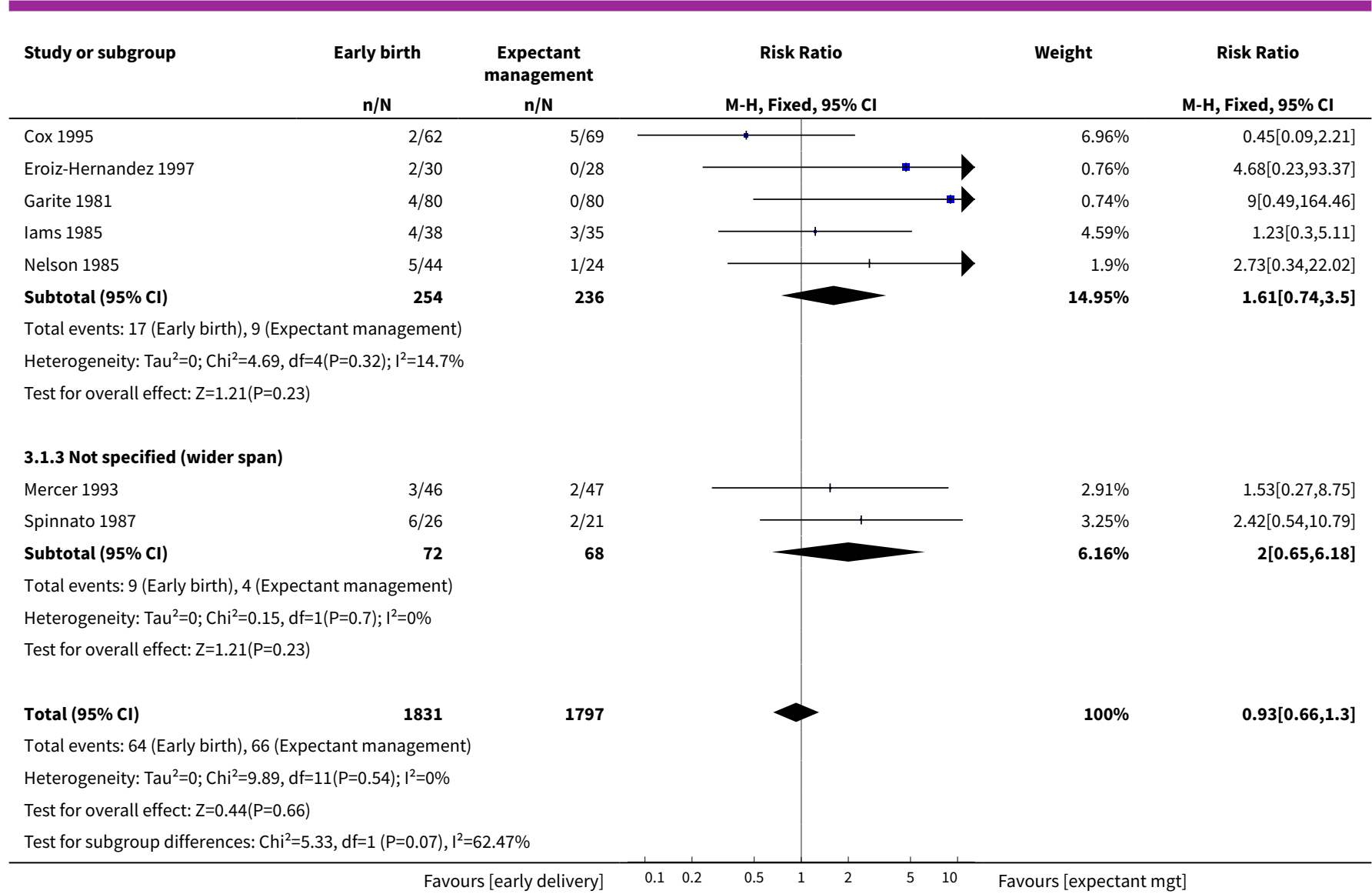

Analysis 3.2. Comparison 3 Any planned birth versus expectant management (subgroup analysis by gestational age for inclusion in trial), Outcome 2 Neonatal infection confirmed with positive culture.

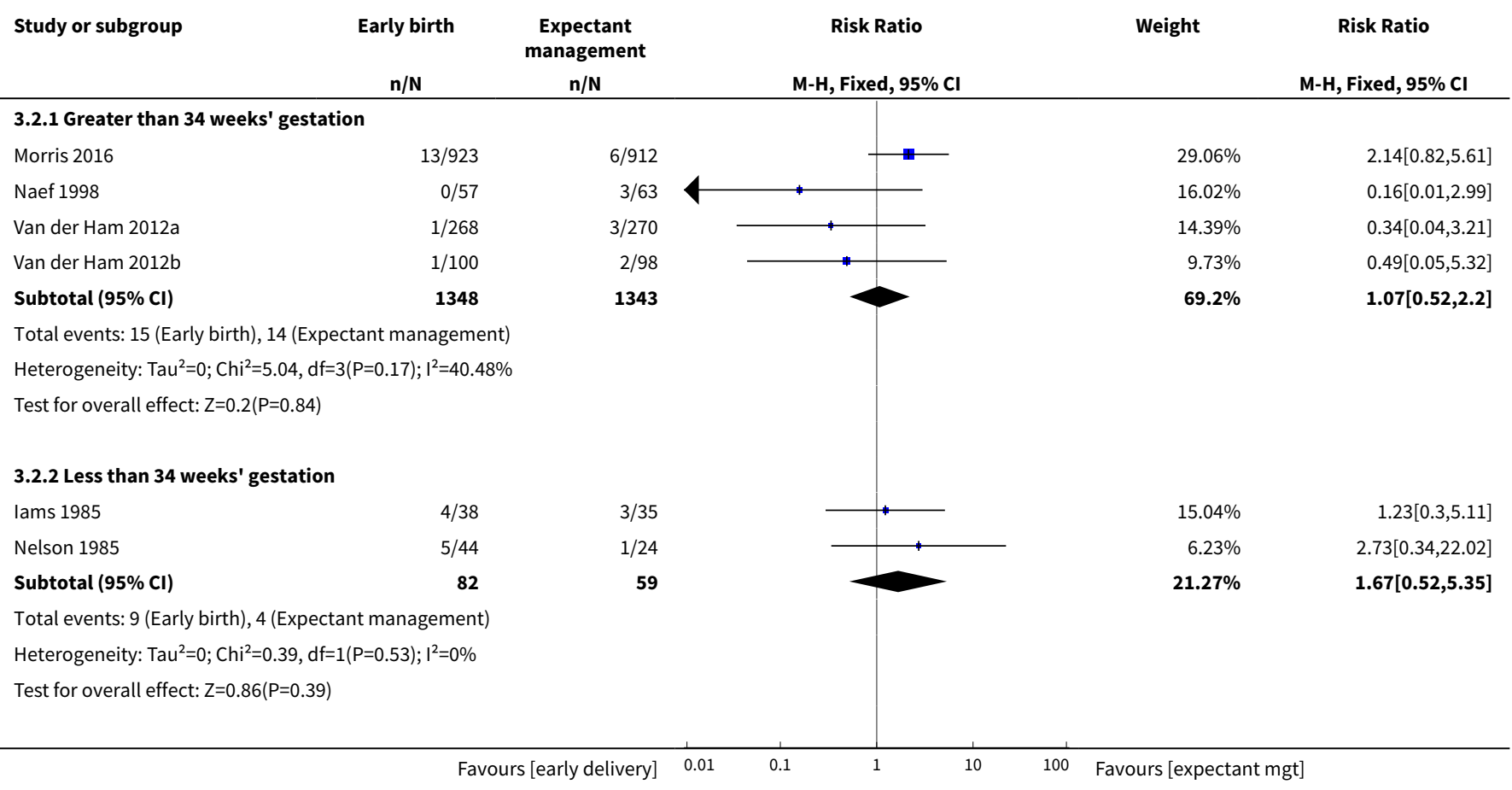

Planned early birth versus expectant management for women with preterm prelabour rupture of membranes prior to 37 weeks' 


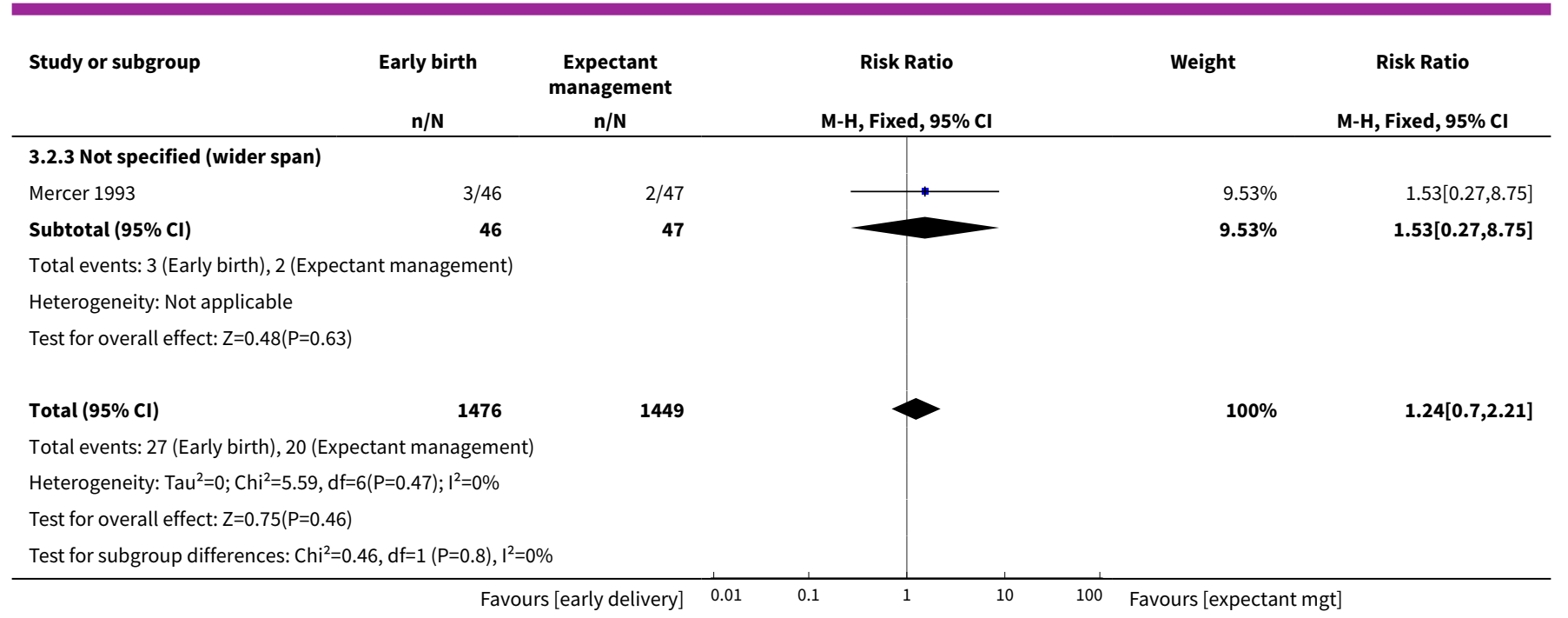

\section{Analysis 3.3. Comparison 3 Any planned birth versus expectant management (subgroup analysis by gestational age for inclusion in trial), Outcome 3 Respiratory distress syndrome.}

\begin{tabular}{lrr} 
Study or subgroup & Early birth & $\begin{array}{c}\text { Expectant } \\
\text { management } \\
\text { n/N }\end{array}$ \\
& $\mathbf{n} / \mathbf{N}$ & \\
\hline 3.3.1 Greater than 34 weeks' gestation & & $9 / 150$ \\
Koroveshi 2013 & $12 / 157$ & $47 / 910$ \\
Morris 2016 & $76 / 919$ & $3 / 63$ \\
Naef 1998 & $3 / 57$ & $17 / 270$ \\
Van der Ham 2012a & $21 / 268$ & $5 / 98$ \\
Van der Ham 2012b & $6 / 100$ & $\mathbf{1 4 9 1}$ \\
Subtotal (95\% Cl) & $\mathbf{1 5 0 1}$ &
\end{tabular}

Weight

M-H, Fixed, $95 \% \mathrm{CI}$

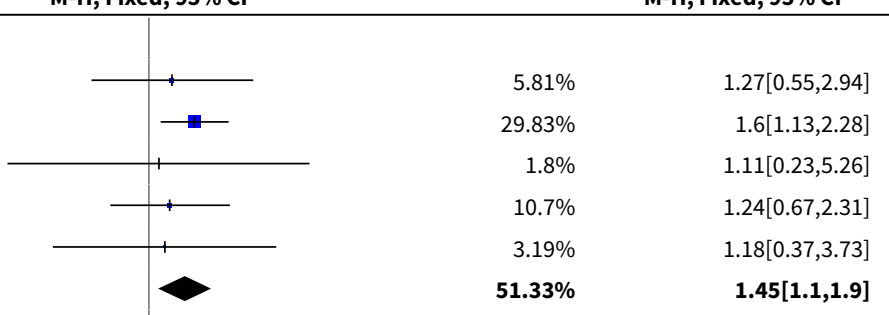

Total events: 118 (Early birth), 81 (Expectant management) Heterogeneity: $\mathrm{Tau}^{2}=0 ; \mathrm{Chi}^{2}=0.88, \mathrm{df}=4(\mathrm{P}=0.93) ; \mathrm{I}^{2}=0 \%$

Test for overall effect: $Z=2.64(P=0.01)$

\subsubsection{Less than 34 weeks' gestation}

Cox 1995

Eroiz-Hernandez 1997

Garite 1981

lams 1985

Nelson 1985

Subtotal $(95 \% \mathrm{CI})$

Total events: 84 (Early birth), 70 (Expectant management) Heterogeneity: $\mathrm{Tau}^{2}=0 ; \mathrm{Chi}^{2}=8.29, \mathrm{df}=4(\mathrm{P}=0.08) ; \mathrm{I}^{2}=51.72 \%$ Test for overall effect: $\mathrm{Z}=0.64(\mathrm{P}=0.52)$

\subsubsection{Not specified (wider span)}

Mercer 1993

Spinnato 1987

$23 / 62$

$16 / 30$

$14 / 80$

$10 / 38$

$21 / 44$

254

Total events: 5 (Early birth), 5 (Expectant management)

Heterogeneity: Not applicable

Test for overall effect: $Z=0.38(P=0.7)$
491

10

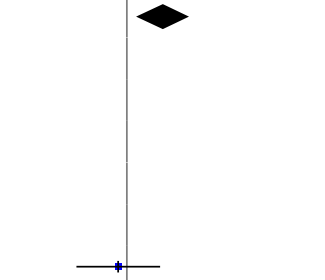

$28 / 69$
$5 / 28$
$17 / 80$
$12 / 35$
$8 / 24$
236

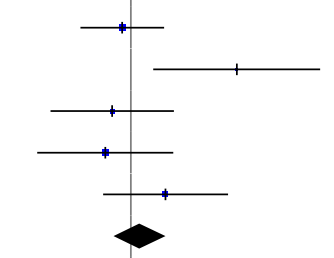

$16.74 \%$

$0.91[0.59,1.41]$

$2.99[1.26,7.07]$

$0.82[0.44,1.56]$

$0.77[0.38,1.55]$

$1.43[0.75,2.73]$

$7.89 \%$

$1.09[0.84,1.43]$

Planned early birth versus expectant management for women with preterm prelabour rupture of membranes prior to 37 weeks'

Not estimable

$0.81[0.27,2.42]$

$3.49 \%$

$0.81[0.27,2.42]$ 


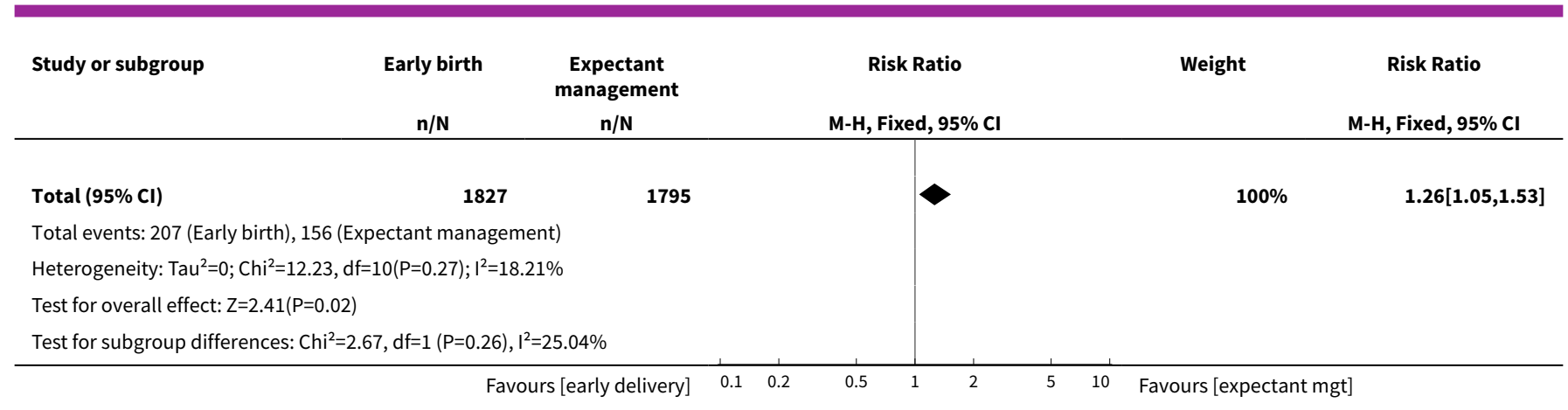

\section{Analysis 3.4. Comparison 3 Any planned birth versus expectant management (subgroup analysis by gestational age for inclusion in trial), Outcome 4 Caesarean section.}

Study or subgroup Early birth $\begin{gathered}\text { Expectant } \\ \text { management }\end{gathered} \quad$ Risk Ratio Weight

3.4.1 Greater than 34 weeks' gestation

n/N $\quad n / N \quad M-H$, Fixed, $95 \% \mathrm{Cl}$

M-H, Fixed, $95 \% \mathrm{Cl}$

Koroveshi 2013

Morris 2016

$20 / 157$

Naef 1998

Van der Ham 2012a

Van der Ham 2012b

Subtotal $(95 \% \mathrm{Cl})$

Total events: 312 (Early birth), 252 (Expectant management) Heterogeneity: $\mathrm{Tau}^{2}=0 ; \mathrm{Chi}^{2}=9.91, \mathrm{df}=4(\mathrm{P}=0.04) ; \mathrm{I}^{2}=59.66 \%$

Test for overall effect: $Z=2.65(P=0.01)$

\subsubsection{Less than $\mathbf{3 4}$ weeks' gestation}

Cox 1995

Eroiz-Hernandez 1997

Garite 1981

lams 1985

Nelson 1985

Subtotal $(95 \% \mathrm{CI})$

$239 / 923$

$4 / 57$

$36 / 266$

$13 / 100$

1503

Total events: 78 (Early birth), 50 (Expectant management) Heterogeneity: $\mathrm{Tau}^{2}=0 ; \mathrm{Chi}^{2}=1.38, \mathrm{df}=4(\mathrm{P}=0.85) ; \mathrm{I}^{2}=0 \%$

Test for overall effect: $Z=2.49(P=0.01)$

\subsubsection{Not specified (wider span)}

Mercer 1993

Spinnato 1987

Subtotal $(95 \% \mathrm{Cl})$

$4 / 46$
$4 / 26$
72

Total events: 8 (Early birth), 6 (Expectant management) Heterogeneity: $\mathrm{Tau}^{2}=0 ; \mathrm{Chi}^{2}=0.05, \mathrm{df}=1(\mathrm{P}=0.82) ; \mathrm{I}^{2}=0 \%$

Test for overall effect: $\mathrm{Z}=0.38(\mathrm{P}=0.71)$

Total $(95 \% \mathrm{Cl})$

1828

Total events: 398 (Early birth), 308 (Expectant management) Heterogeneity: $\mathrm{Tau}^{2}=0 ; \mathrm{Chi}^{2}=11.89, \mathrm{df}=11(\mathrm{P}=0.37) ; \mathrm{I}^{2}=7.46 \%$ Test for overall effect: $\mathrm{Z}=3.45(\mathrm{P}=0)$

Test for subgroup differences: $\mathrm{Chi}^{2}=1.08, \mathrm{df}=1(\mathrm{P}=0.58), \mathrm{I}^{2}=0 \%$

$\mathbf{n} / \mathbf{N}$

$21 / 150$
$169 / 912$
$3 / 63$
$37 / 266$
$22 / 98$
1489

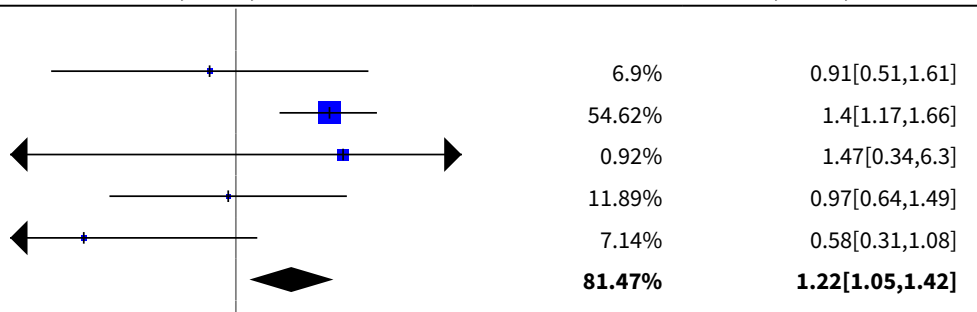

$3 / 47$

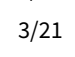

68

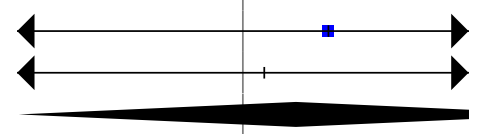

$0.95 \%$

$1.07 \%$

$\mathbf{2 . 0 2} \%$

$2.43 \%$

$4.65 \%$

$6.43 \%$

$1.34 \%$

$1.66 \%$

$16.51 \%$
$1.95[0.88,4.33]$

$1.2[0.75,1.92]$

$1.4[0.86,2.27]$

$1.84[0.61,5.58]$

$1.36[0.48,3.89]$

$1.46[1.08,1.96]$

Planned early birth versus expectant management for women with preterm prelabour rupture of membranes prior to 37 weeks'

Copyright (c) 2017 The Cochrane Collaboration. Published by John Wiley \& Sons, Ltd. 
Analysis 3.5. Comparison 3 Any planned birth versus expectant management (subgroup analysis by gestational age for inclusion in trial), Outcome 5 Chorioamnionitis.

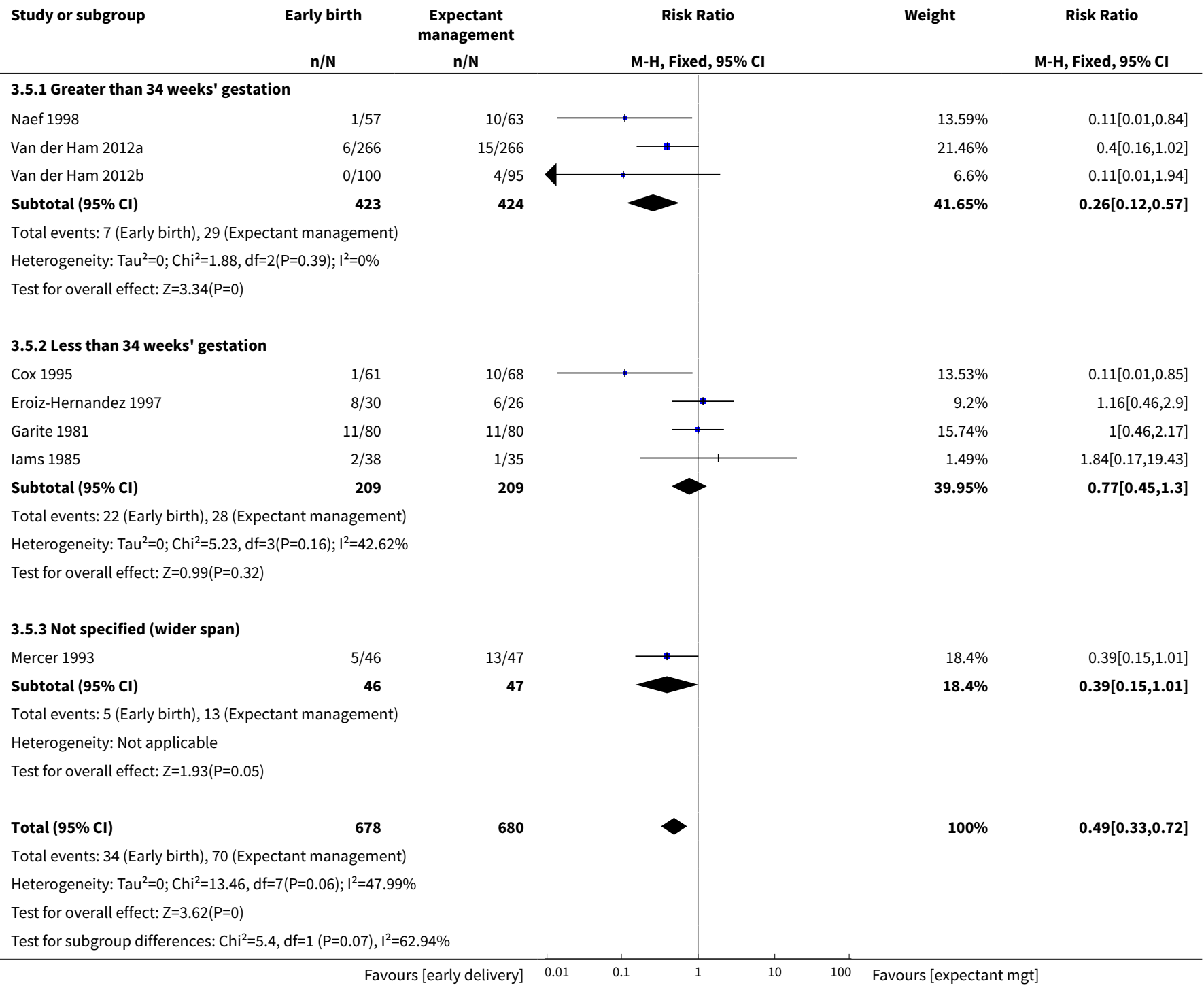

Analysis 3.6. Comparison 3 Any planned birth versus expectant management (subgroup analysis by gestational age for inclusion in trial), Outcome 6 Endometritis.

Study or subgroup

Early birth

$\mathbf{n} / \mathbf{N}$
Expectant
management $n / N$
Risk Ratio

M-H, Fixed, $95 \% \mathrm{Cl}$
Weight

Risk Ratio

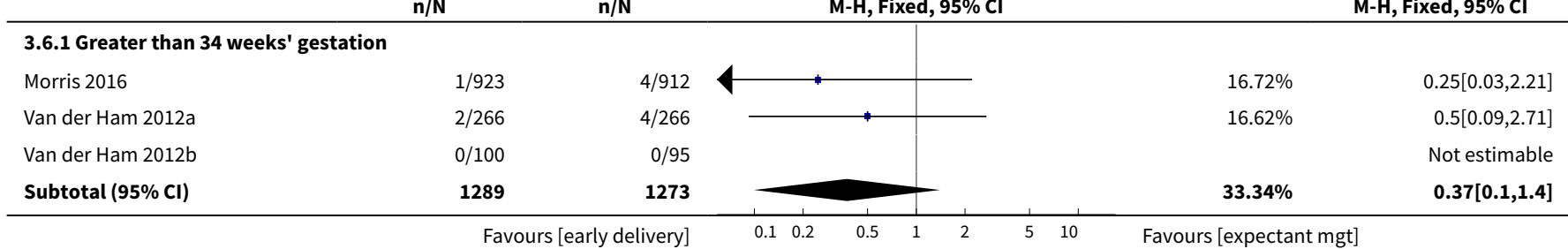




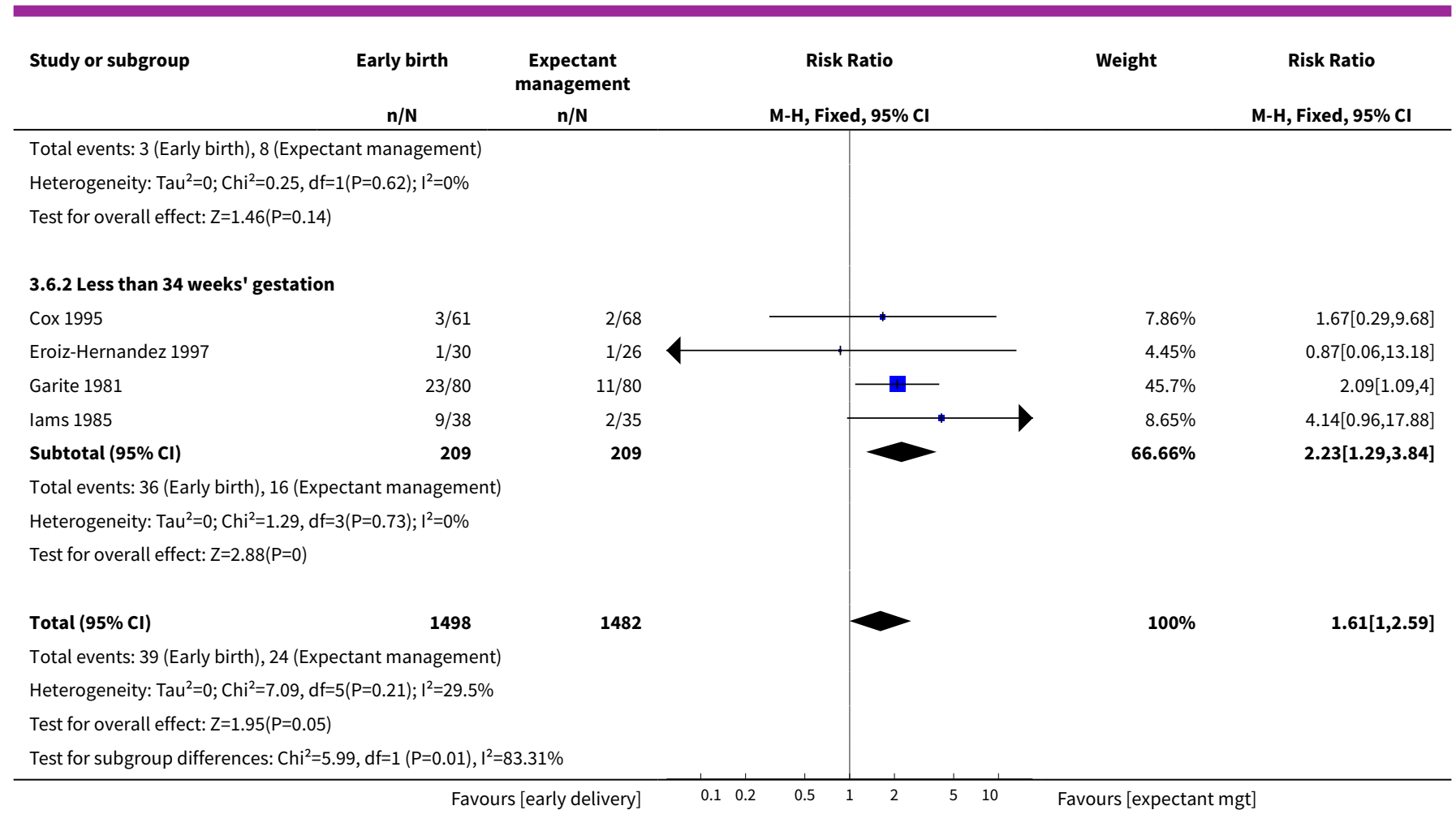

\section{Comparison 4. Any planned birth versus expectant management (subgroup analysis by antibiotic use)}

\begin{tabular}{|c|c|c|c|c|}
\hline Outcome or subgroup title & No. of studies & $\begin{array}{l}\text { No. of partici- } \\
\text { pants }\end{array}$ & Statistical method & Effect size \\
\hline 1 Neonatal infection & 12 & 3625 & Risk Ratio (M-H, Fixed, 95\% Cl) & $0.93[0.66,1.30]$ \\
\hline 1.1 Prophylactic antibiotics used & 2 & 1702 & Risk Ratio (M-H, Fixed, 95\% Cl) & $0.74[0.42,1.31]$ \\
\hline $\begin{array}{l}\text { 1.2 Prophylactic antibiotics not } \\
\text { used }\end{array}$ & 8 & 880 & Risk Ratio (M-H, Fixed, 95\% Cl) & $1.42[0.81,2.51]$ \\
\hline $\begin{array}{l}\text { 1.3 Some prophylactic antibiotics } \\
\text { used }\end{array}$ & 2 & 736 & Risk Ratio (M-H, Fixed, 95\% Cl) & $0.67[0.30,1.46]$ \\
\hline 1.4 Not specified & 1 & 307 & Risk Ratio (M-H, Fixed, 95\% Cl) & $0.80[0.25,2.55]$ \\
\hline $\begin{array}{l}2 \text { Neonatal infection confirmed } \\
\text { with positive culture }\end{array}$ & 7 & 2925 & Risk Ratio (M-H, Fixed, 95\% Cl) & $1.24[0.70,2.21]$ \\
\hline 2.1 Prophylactic antibiotics used & 1 & 120 & Risk Ratio (M-H, Fixed, 95\% Cl) & $0.16[0.01,2.99]$ \\
\hline $\begin{array}{l}\text { 2.2 Prophylactic antibiotics not } \\
\text { used }\end{array}$ & 3 & 234 & Risk Ratio (M-H, Fixed, 95\% Cl) & $1.63[0.62,4.28]$ \\
\hline $\begin{array}{l}2.3 \text { Some prophylactic antibiotics } \\
\text { used }\end{array}$ & 3 & 2571 & Risk Ratio (M-H, Fixed, 95\% Cl) & $1.35[0.62,2.93]$ \\
\hline 3 Respiratory distress syndrome & 12 & 3622 & Risk Ratio (M-H, Fixed, 95\% Cl) & $1.29[1.06,1.56]$ \\
\hline
\end{tabular}




\begin{tabular}{|c|c|c|c|c|}
\hline Outcome or subgroup title & No. of studies & $\begin{array}{l}\text { No. of partici- } \\
\text { pants }\end{array}$ & Statistical method & Effect size \\
\hline 3.1 Prophylactic antibiotics used & 1 & 120 & Risk Ratio (M-H, Fixed, 95\% Cl) & $1.11[0.23,5.26]$ \\
\hline $\begin{array}{l}\text { 3.2 Prophylactic antibiotics not } \\
\text { used }\end{array}$ & 7 & 630 & Risk Ratio (M-H, Fixed, 95\% Cl) & $1.11[0.85,1.45]$ \\
\hline $\begin{array}{l}\text { 3.3 Some prophylactic antibiotics } \\
\text { used }\end{array}$ & 3 & 2565 & Risk Ratio (M-H, Fixed, 95\% Cl) & $1.48[1.10,1.99]$ \\
\hline 3.4 Not specified & 1 & 307 & Risk Ratio (M-H, Fixed, 95\% Cl) & $1.27[0.55,2.94]$ \\
\hline 4 Caesarean section & 12 & 3620 & Risk Ratio (M-H, Fixed, 95\% Cl) & $1.30[1.14,1.49]$ \\
\hline 4.1 Prophylactic antibiotics used & 1 & 120 & Risk Ratio (M-H, Fixed, 95\% Cl) & $1.47[0.34,6.30]$ \\
\hline $\begin{array}{l}4.2 \text { Prophylactic antibiotics not } \\
\text { used }\end{array}$ & 7 & 628 & Risk Ratio (M-H, Fixed, 95\% Cl) & $1.43[1.08,1.90]$ \\
\hline $\begin{array}{l}\text { 4.3 Some prophylactic antibiotics } \\
\text { used }\end{array}$ & 3 & 2565 & Risk Ratio (M-H, Fixed, 95\% Cl) & $1.31[1.12,1.53]$ \\
\hline 4.4 Not specified & 1 & 307 & Risk Ratio (M-H, Fixed, 95\% Cl) & $0.91[0.51,1.61]$ \\
\hline 5 Chorioamnionitis & 8 & 1358 & $\begin{array}{l}\text { Risk Ratio (M-H, Random, 95\% } \\
\mathrm{Cl} \text { ) }\end{array}$ & $0.50[0.26,0.95]$ \\
\hline 5.1 Prophylactic antibiotics used & 1 & 120 & $\begin{array}{l}\text { Risk Ratio (M-H, Random, 95\% } \\
\mathrm{Cl} \text { ) }\end{array}$ & $0.11[0.01,0.84]$ \\
\hline $\begin{array}{l}5.2 \text { Prophylactic antibiotics not } \\
\text { used }\end{array}$ & 5 & 511 & $\begin{array}{l}\text { Risk Ratio (M-H, Random, 95\% } \\
\mathrm{Cl} \text { ) }\end{array}$ & $0.69[0.34,1.41]$ \\
\hline $\begin{array}{l}\text { 5.3 Some prophylactic antibiotics } \\
\text { used }\end{array}$ & 2 & 727 & $\begin{array}{l}\text { Risk Ratio (M-H, Random, 95\% } \\
\mathrm{Cl} \text { ) }\end{array}$ & $0.35[0.15,0.86]$ \\
\hline 6 Endometritis & 7 & 2980 & Risk Ratio (M-H, Fixed, 95\% Cl) & $1.61[1.00,2.59]$ \\
\hline 6.1 Prophylactic antibiotics used & 0 & 0 & Risk Ratio (M-H, Fixed, 95\% Cl) & $0.0[0.0,0.0]$ \\
\hline $\begin{array}{l}6.2 \text { Prophylactic antibiotics not } \\
\text { used }\end{array}$ & 4 & 418 & Risk Ratio (M-H, Fixed, 95\% Cl) & $2.23[1.29,3.84]$ \\
\hline $\begin{array}{l}\text { 6.3 Some prophylactic antibiotics } \\
\text { used }\end{array}$ & 3 & 2562 & Risk Ratio (M-H, Fixed, 95\% Cl) & $0.37[0.10,1.40]$ \\
\hline
\end{tabular}

\section{Analysis 4.1. Comparison 4 Any planned birth versus expectant management (subgroup analysis by antibiotic use), Outcome 1 Neonatal infection.}

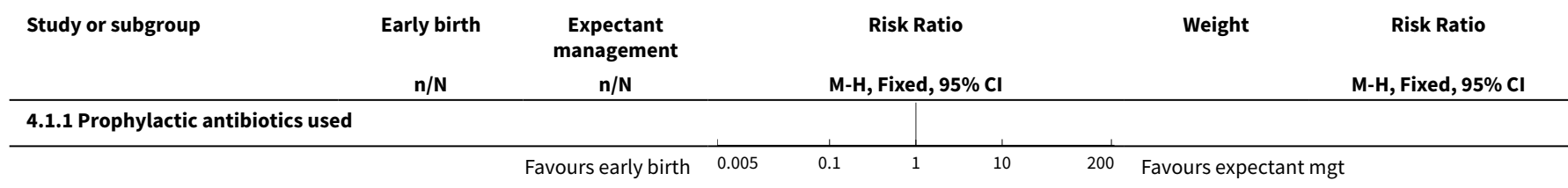




\begin{tabular}{|c|c|c|c|c|c|}
\hline \multirow[t]{2}{*}{ Study or subgroup } & \multirow{2}{*}{$\begin{array}{l}\text { Early birth } \\
\qquad \mathrm{n} / \mathrm{N} \\
\end{array}$} & \multirow{2}{*}{$\begin{array}{c}\text { Expectant } \\
\text { management } \\
n / N \\
\end{array}$} & \multirow{2}{*}{$\begin{array}{c}\text { Risk Ratio } \\
\text { M-H, Fixed, 95\% Cl }\end{array}$} & \multirow[t]{2}{*}{ Weight } & \multirow{2}{*}{$\begin{array}{c}\text { Risk Ratio } \\
\text { M-H, Fixed, } 95 \% \text { Cl } \\
\end{array}$} \\
\hline & & & & & \\
\hline Morris 2016 & 20/795 & $24 / 787$ & - & $35.44 \%$ & $0.82[0.46,1.48]$ \\
\hline Naef 1998 & $0 / 57$ & $3 / 63$ & & $4.89 \%$ & $0.16[0.01,2.99]$ \\
\hline Subtotal $(95 \% \mathrm{CI})$ & 852 & 850 & & $40.33 \%$ & $0.74[0.42,1.31]$ \\
\hline \multicolumn{6}{|c|}{ Heterogeneity: $\mathrm{Tau}^{2}=0 ; \mathrm{Chi}^{2}=1.19, \mathrm{df}=1(\mathrm{P}=0.28) ; \mathrm{I}^{2}=15.86 \%$} \\
\hline \multicolumn{6}{|c|}{ Test for overall effect: $Z=1.02(P=0.31)$} \\
\hline \multicolumn{6}{|c|}{ 4.1.2 Prophylactic antibiotics not used } \\
\hline Cox 1995 & $2 / 62$ & $5 / 69$ & - & $6.95 \%$ & $0.45[0.09,2.21]$ \\
\hline Eroiz-Hernandez 1997 & $2 / 30$ & $0 / 28$ & 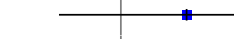 & $0.76 \%$ & $4.68[0.23,93.37]$ \\
\hline lams 1985 & $4 / 38$ & $3 / 35$ & & $4.59 \%$ & $1.23[0.3,5.11]$ \\
\hline Mercer 1993 & $3 / 46$ & $2 / 47$ & $\overline{-}$ & $2.91 \%$ & $1.53[0.27,8.75]$ \\
\hline Morris 2016 & $3 / 128$ & $5 / 122$ & & $7.52 \%$ & $0.57[0.14,2.34]$ \\
\hline Nelson 1985 & $5 / 44$ & $1 / 24$ & & $1.9 \%$ & $2.73[0.34,22.02]$ \\
\hline Spinnato 1987 & $6 / 26$ & $2 / 21$ & $1+$ & $3.25 \%$ & $2.42[0.54,10.79]$ \\
\hline Subtotal $(95 \% \mathrm{Cl})$ & 454 & 426 & & $28.62 \%$ & $1.42[0.81,2.51]$ \\
\hline \multicolumn{6}{|c|}{ Total events: 29 (Early birth), 18 (Expectant management) } \\
\hline \multicolumn{6}{|c|}{ Heterogeneity: $\operatorname{Tau}^{2}=0 ; \mathrm{Chi}^{2}=6.69, \mathrm{df}=7(\mathrm{P}=0.46) ; \mathrm{I}^{2}=0 \%$} \\
\hline \multicolumn{6}{|c|}{ Test for overall effect: $Z=1.22(P=0.22)$} \\
\hline \multicolumn{6}{|c|}{ 4.1.3 Some prophylactic antibiotics used } \\
\hline Van der Ham 2012a & $7 / 268$ & $11 / 270$ & & $16.1 \%$ & $0.64[0.25,1.63]$ \\
\hline Van der Ham 2012b & $3 / 100$ & $4 / 98$ & & $5.94 \%$ & $0.74[0.17,3.2]$ \\
\hline \multicolumn{6}{|c|}{ Heterogeneity: $\mathrm{Tau}^{2}=0 ; \mathrm{Chi}^{2}=0.02, \mathrm{df}=1(\mathrm{P}=0.88) ; \mathrm{I}^{2}=0 \%$} \\
\hline \multicolumn{6}{|c|}{ Test for overall effect: $\mathrm{Z}=1.01(\mathrm{P}=0.31)$} \\
\hline \multicolumn{6}{|l|}{ 4.1.4 Not specified } \\
\hline Koroveshi 2013 & $5 / 157$ & $6 / 150$ & & $9.02 \%$ & $0.8[0.25,2.55]$ \\
\hline Subtotal $(95 \% \mathrm{Cl})$ & 157 & 150 & & $9.02 \%$ & $0.8[0.25,2.55]$ \\
\hline \multicolumn{6}{|c|}{ Total events: 5 (Early birth), 6 (Expectant management) } \\
\hline \multicolumn{6}{|c|}{ Heterogeneity: Not applicable } \\
\hline \multicolumn{6}{|c|}{ Test for overall effect: $\mathrm{Z}=0.38(\mathrm{P}=0.7)$} \\
\hline Total $(95 \% \mathrm{Cl})$ & 1831 & 1794 & & $100 \%$ & $0.93[0.66,1.3]$ \\
\hline \multicolumn{6}{|c|}{ Total events: 64 (Early birth), 66 (Expectant management) } \\
\hline \multicolumn{6}{|c|}{ Heterogeneity: $\mathrm{Tau}^{2}=0 ; \mathrm{Chi}^{2}=10.12, \mathrm{df}=12(\mathrm{P}=0.61) ; \mathrm{I}^{2}=0 \%$} \\
\hline \multicolumn{6}{|c|}{ Test for overall effect: $\mathrm{Z}=0.45(\mathrm{P}=0.65)$} \\
\hline Test for subgroup diffe & $\mathrm{df}=1(\mathrm{P}=0.32), \mathrm{I}^{2}$ & $4.29 \%$ & & & \\
\hline
\end{tabular}


Analysis 4.2. Comparison 4 Any planned birth versus expectant management (subgroup analysis by antibiotic use), Outcome 2 Neonatal infection confirmed with positive culture.

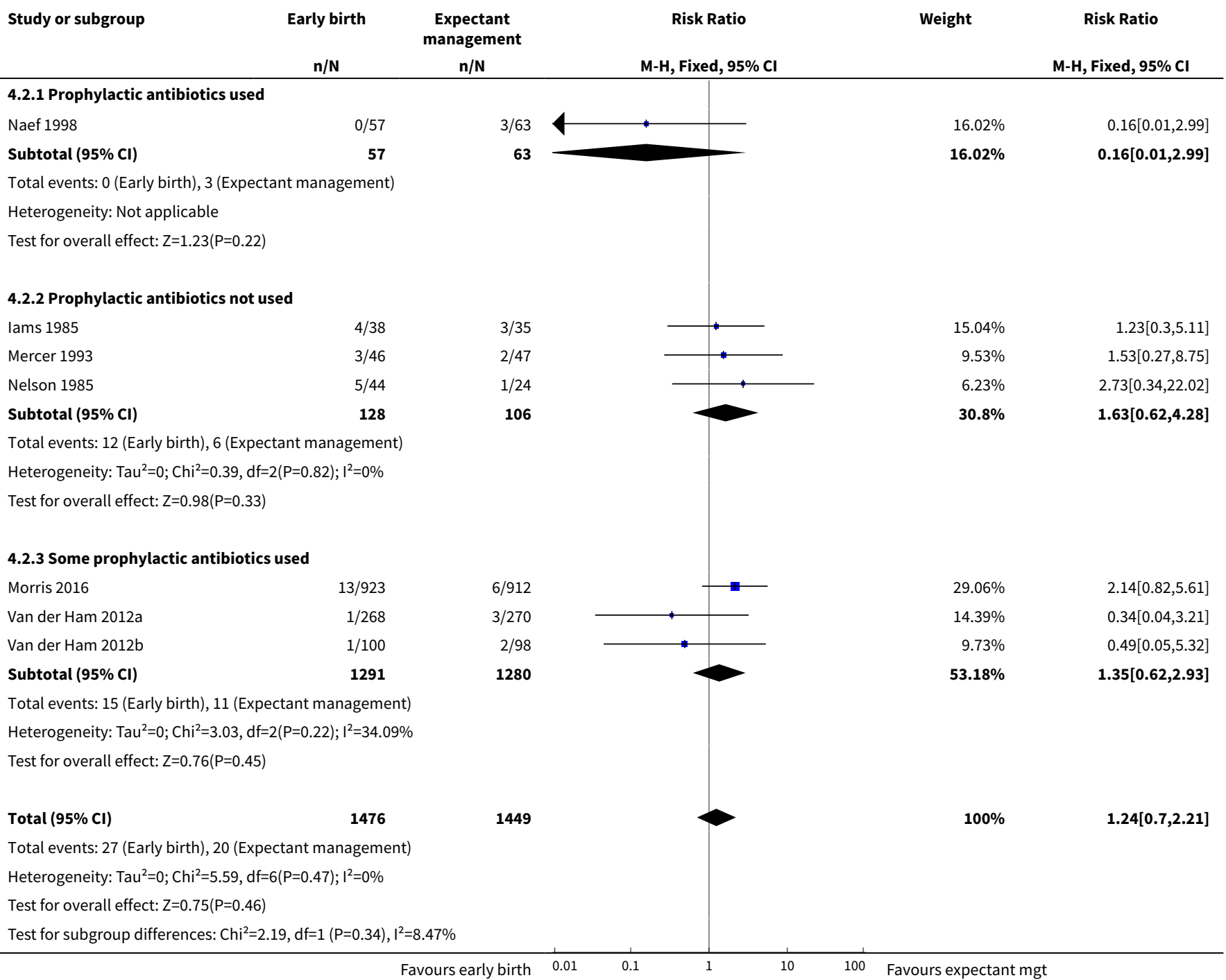

Analysis 4.3. Comparison 4 Any planned birth versus expectant management (subgroup analysis by antibiotic use), Outcome 3 Respiratory distress syndrome.

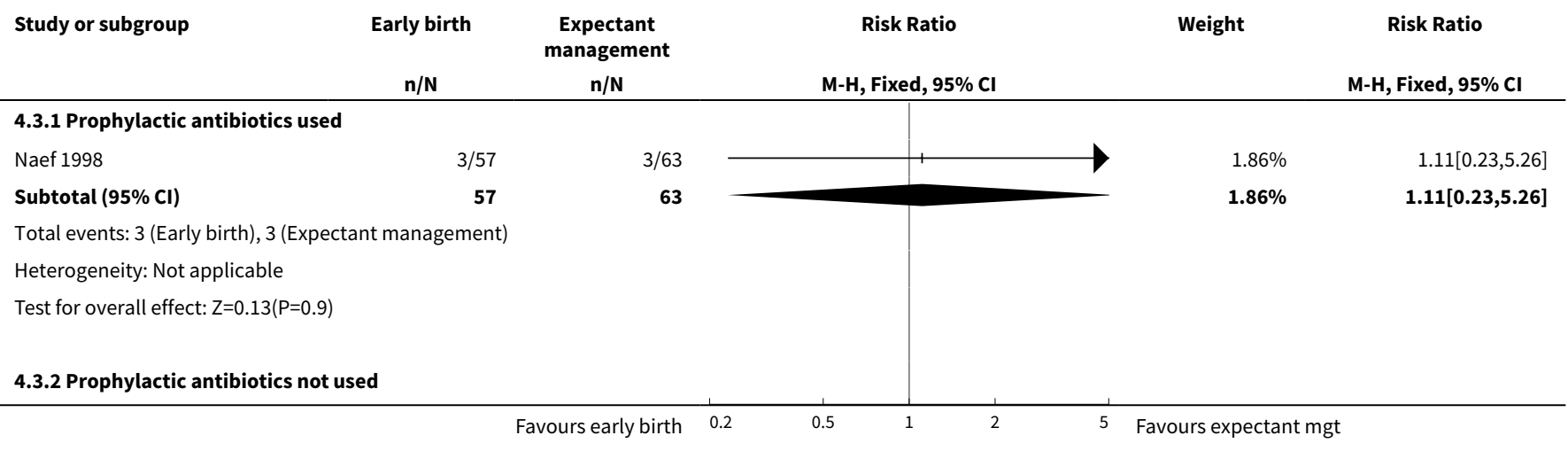




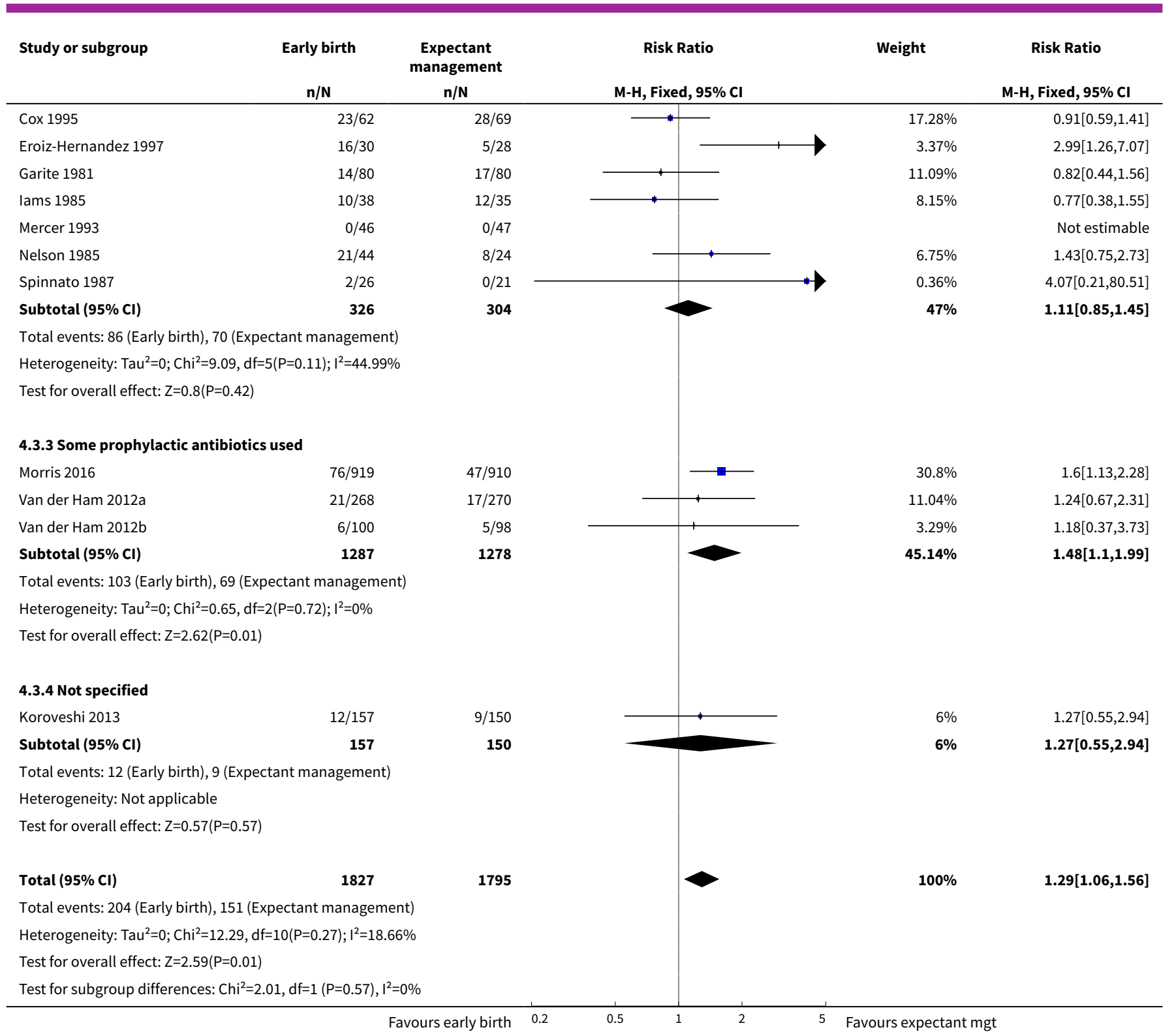

\section{Analysis 4.4. Comparison 4 Any planned birth versus expectant management (subgroup analysis by antibiotic use), Outcome 4 Caesarean section.}

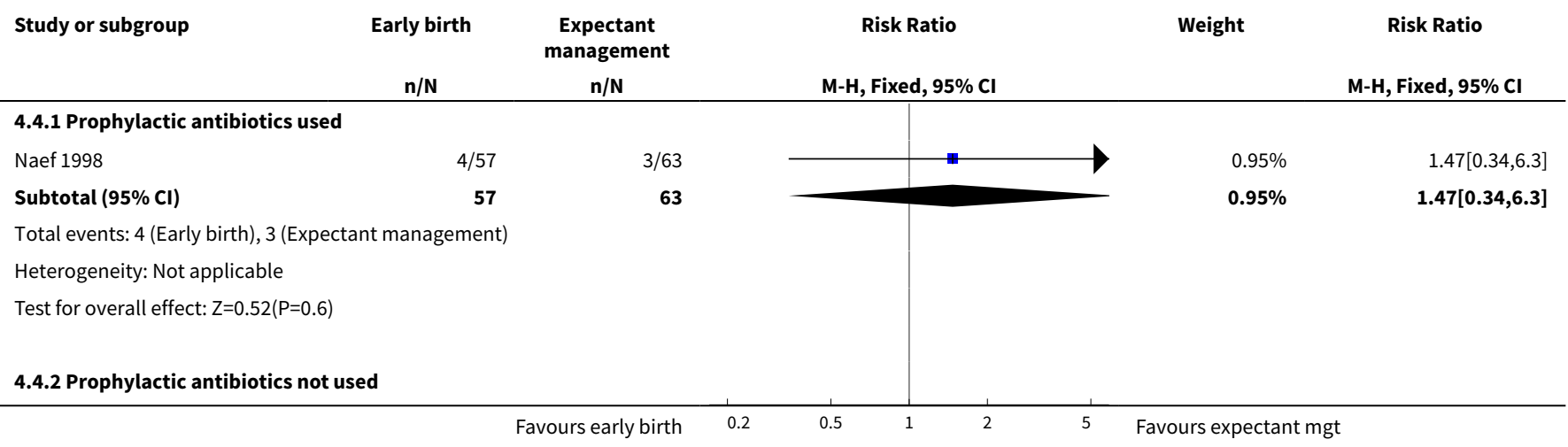




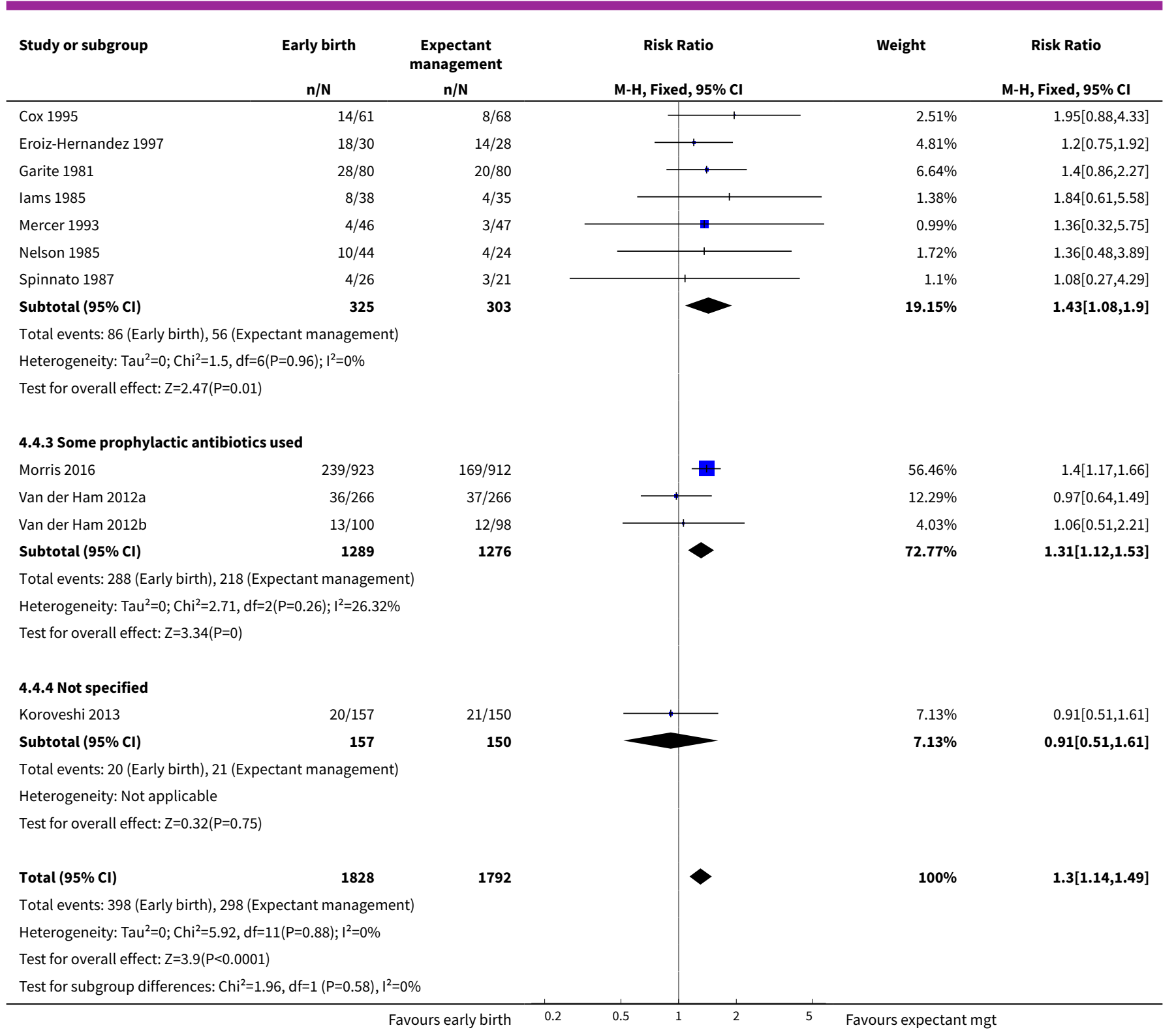

Analysis 4.5. Comparison 4 Any planned birth versus expectant management (subgroup analysis by antibiotic use), Outcome 5 Chorioamnionitis.

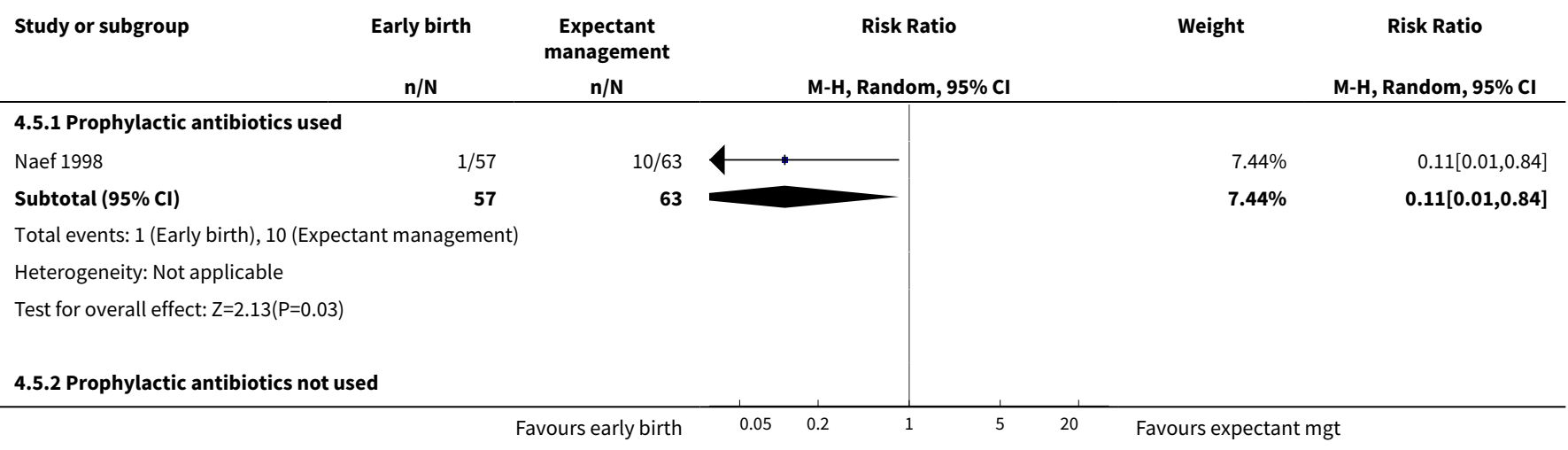




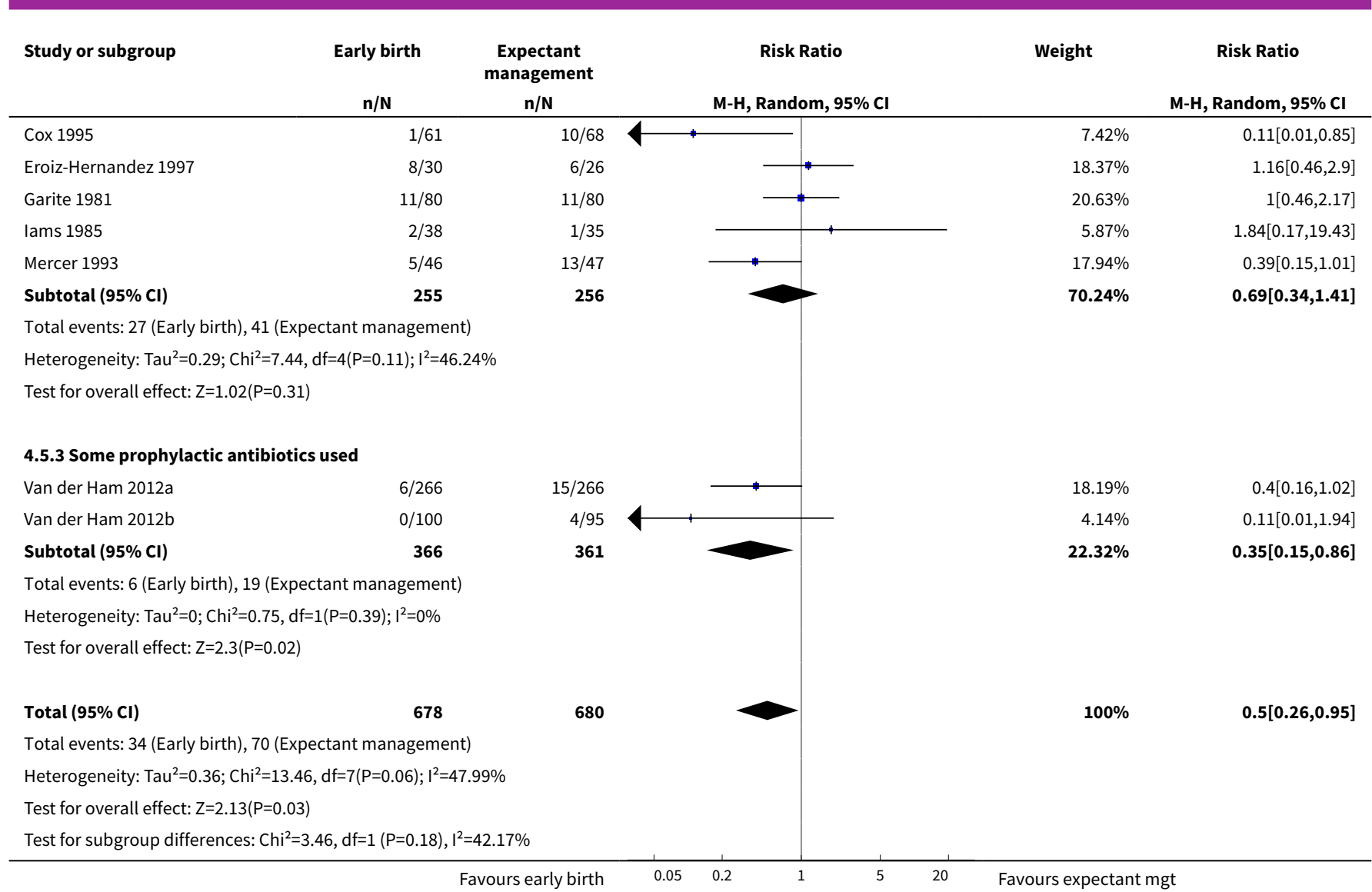

Analysis 4.6. Comparison 4 Any planned birth versus expectant management (subgroup analysis by antibiotic use), Outcome 6 Endometritis.

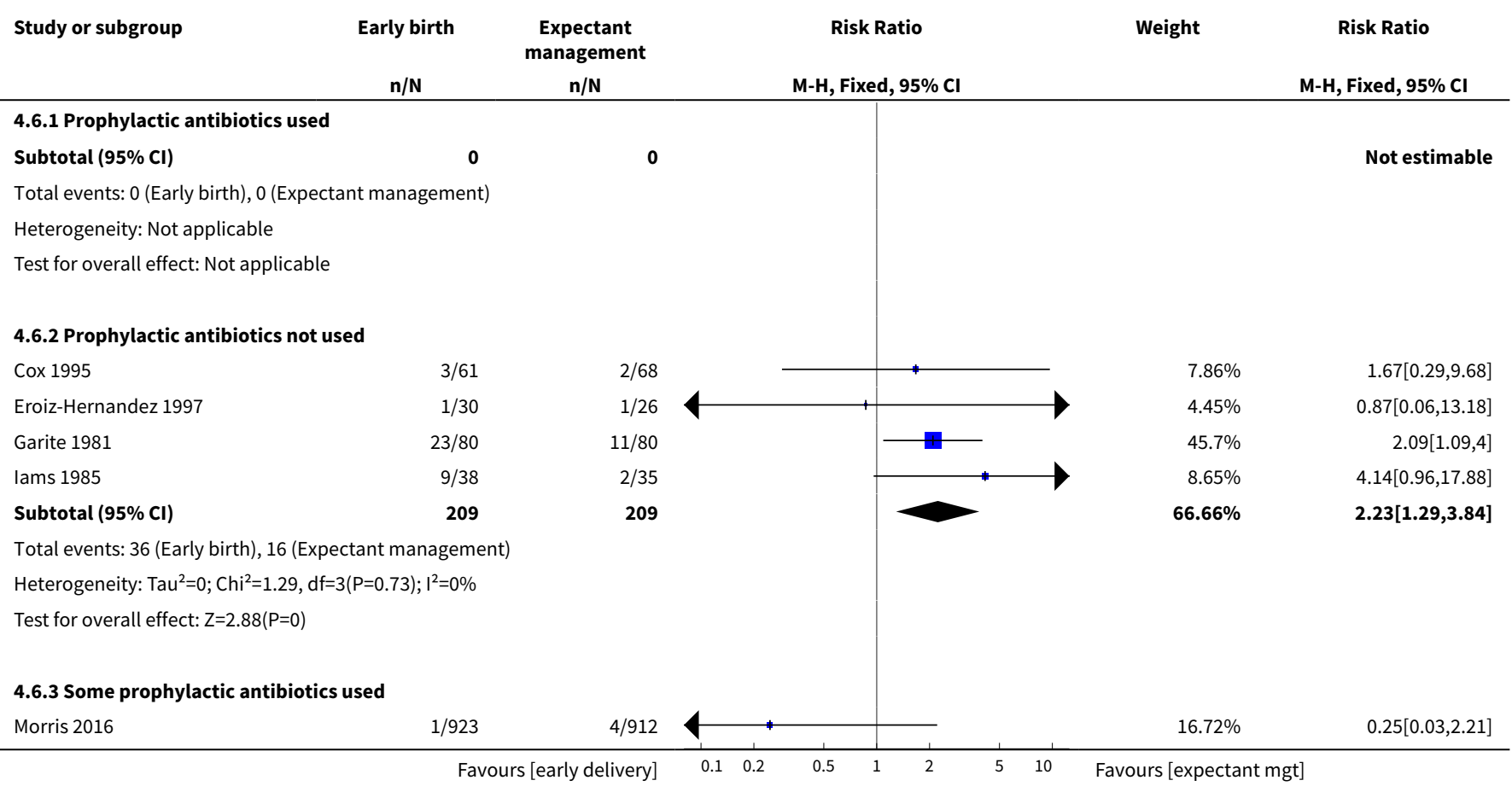

Planned early birth versus expectant management for women with preterm prelabour rupture of membranes prior to 37 weeks' 


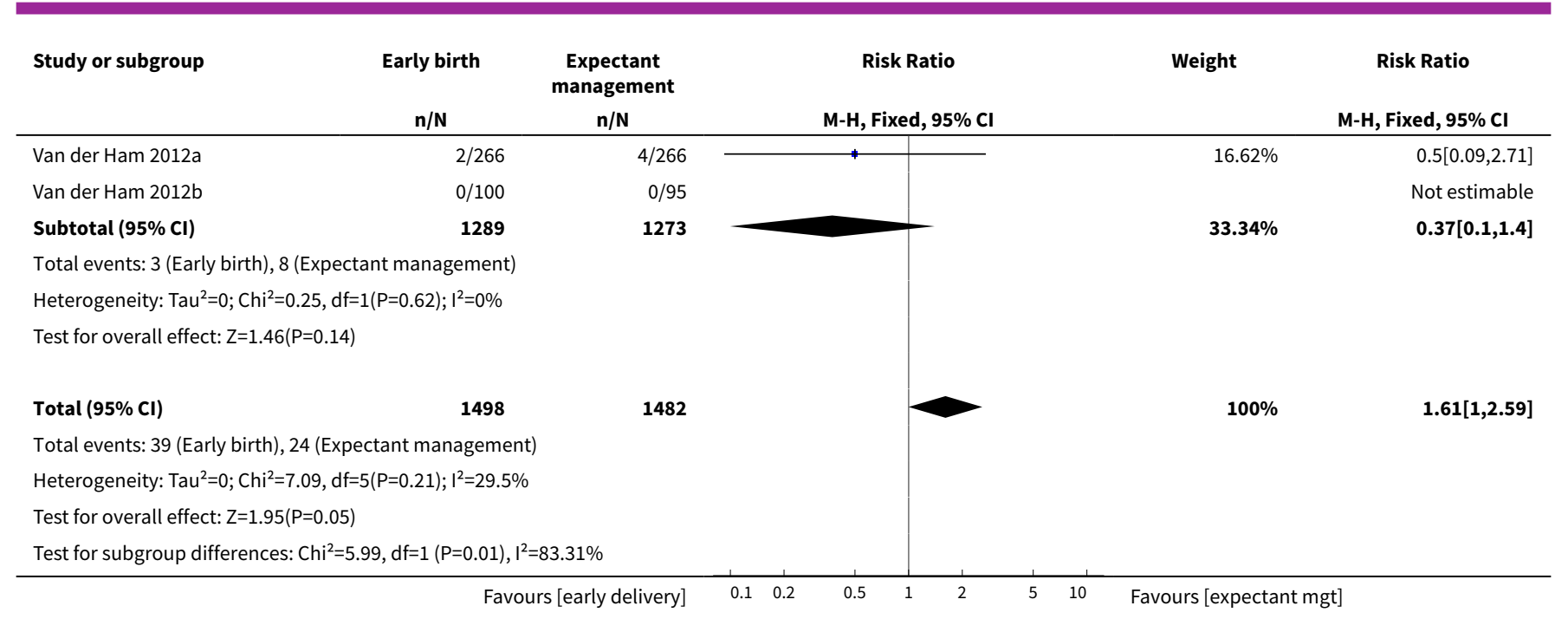

Comparison 5. Any planned birth versus expectant management (subgroup analysis by timing of early delivery)

\begin{tabular}{|c|c|c|c|c|}
\hline Outcome or subgroup title & No. of studies & $\begin{array}{l}\text { No. of partici- } \\
\text { pants }\end{array}$ & Statistical method & Effect size \\
\hline 1 Neonatal infection & 12 & 3628 & Risk Ratio (M-H, Fixed, 95\% Cl) & $0.93[0.66,1.30]$ \\
\hline $\begin{array}{l}\text { 1.1 Less than } 24 \text { hours from ran- } \\
\text { domisation }\end{array}$ & 4 & 391 & Risk Ratio (M-H, Fixed, 95\% Cl) & $0.90[0.41,1.99]$ \\
\hline $\begin{array}{l}\text { 1.2 Greater than } 24 \text { hours from ran- } \\
\text { domisation }\end{array}$ & 7 & 2930 & Risk Ratio (M-H, Fixed, 95\% Cl) & $0.95[0.64,1.41]$ \\
\hline 1.3 Not known & 1 & 307 & Risk Ratio (M-H, Fixed, 95\% Cl) & $0.80[0.25,2.55]$ \\
\hline $\begin{array}{l}2 \text { Neonatal infection confirmed } \\
\text { with positive culture }\end{array}$ & 7 & 2925 & Risk Ratio (M-H, Fixed, 95\% Cl) & $1.24[0.70,2.21]$ \\
\hline $\begin{array}{l}2.1 \text { Less than } 24 \text { hours from ran- } \\
\text { domisation }\end{array}$ & 2 & 213 & Risk Ratio (M-H, Fixed, 95\% Cl) & $0.67[0.18,2.53]$ \\
\hline $\begin{array}{l}\text { 2.2 Greater than } 24 \text { hours from ran- } \\
\text { domisation }\end{array}$ & 5 & 2712 & Risk Ratio (M-H, Fixed, 95\% Cl) & $1.44[0.76,2.75]$ \\
\hline 3 Respiratory distress syndrome & 12 & 3622 & Risk Ratio (M-H, Fixed, 95\% Cl) & $1.29[1.06,1.56]$ \\
\hline $\begin{array}{l}\text { 3.1 Less than } 24 \text { hours from ran- } \\
\text { domisation }\end{array}$ & 4 & 391 & Risk Ratio (M-H, Fixed, 95\% Cl) & $0.99[0.65,1.50]$ \\
\hline $\begin{array}{l}\text { 3.2 Greater than } 24 \text { hours from ran- } \\
\text { domisation }\end{array}$ & 7 & 2924 & Risk Ratio (M-H, Fixed, 95\% Cl) & $1.37[1.10,1.71]$ \\
\hline 3.3 Not known & 1 & 307 & Risk Ratio (M-H, Fixed, 95\% Cl) & $1.27[0.55,2.94]$ \\
\hline 4 Caesarean section & 12 & 3620 & Risk Ratio (M-H, Fixed, 95\% Cl) & $1.26[1.11,1.44]$ \\
\hline
\end{tabular}




\begin{tabular}{|c|c|c|c|c|}
\hline Outcome or subgroup title & No. of studies & $\begin{array}{l}\text { No. of partici- } \\
\text { pants }\end{array}$ & Statistical method & Effect size \\
\hline $\begin{array}{l}\text { 4.1 Less than } 24 \text { hours from ran- } \\
\text { domisation }\end{array}$ & 4 & 389 & Risk Ratio (M-H, Fixed, 95\% Cl) & $1.59[0.90,2.81]$ \\
\hline $\begin{array}{l}\text { 4.2 Greater than } 24 \text { hours from ran- } \\
\text { domisation }\end{array}$ & 7 & 2924 & Risk Ratio (M-H, Fixed, 95\% Cl) & $1.27[1.10,1.46]$ \\
\hline 4.3 Not known & 1 & 307 & Risk Ratio (M-H, Fixed, 95\% Cl) & $0.91[0.51,1.61]$ \\
\hline 5 Chorioamnionitis & 8 & 1358 & $\begin{array}{l}\text { Risk Ratio (M-H, Random, 95\% } \\
\mathrm{Cl} \text { ) }\end{array}$ & $0.50[0.26,0.95$ \\
\hline $\begin{array}{l}5.1 \text { Less than } 24 \text { hours from ran- } \\
\text { domisation }\end{array}$ & 3 & 342 & $\begin{array}{l}\text { Risk Ratio (M-H, Random, 95\% } \\
\mathrm{Cl})\end{array}$ & $0.25[0.10,0.61]$ \\
\hline $\begin{array}{l}\text { 5.2 Greater than } 24 \text { hours from ran- } \\
\text { domisation }\end{array}$ & 5 & 1016 & $\begin{array}{l}\text { Risk Ratio (M-H, Random, 95\% } \\
\mathrm{CI})\end{array}$ & $0.76[0.41,1.42]$ \\
\hline 6 Endometritis & 7 & 2980 & Risk Ratio (M-H, Fixed, 95\% Cl) & $1.61[1.00,2.59$ \\
\hline $\begin{array}{l}6.1 \text { Less than } 24 \text { hours from ran- } \\
\text { domisation }\end{array}$ & 1 & 129 & Risk Ratio (M-H, Fixed, 95\% Cl) & $1.67[0.29,9.68]$ \\
\hline $\begin{array}{l}\text { 6.2 Greater than } 24 \text { hours from ran- } \\
\text { domisation }\end{array}$ & 6 & 2851 & Risk Ratio (M-H, Fixed, 95\% Cl) & $1.60[0.98,2.63$ \\
\hline
\end{tabular}

Analysis 5.1. Comparison 5 Any planned birth versus expectant management (subgroup analysis by timing of early delivery), Outcome 1 Neonatal infection.

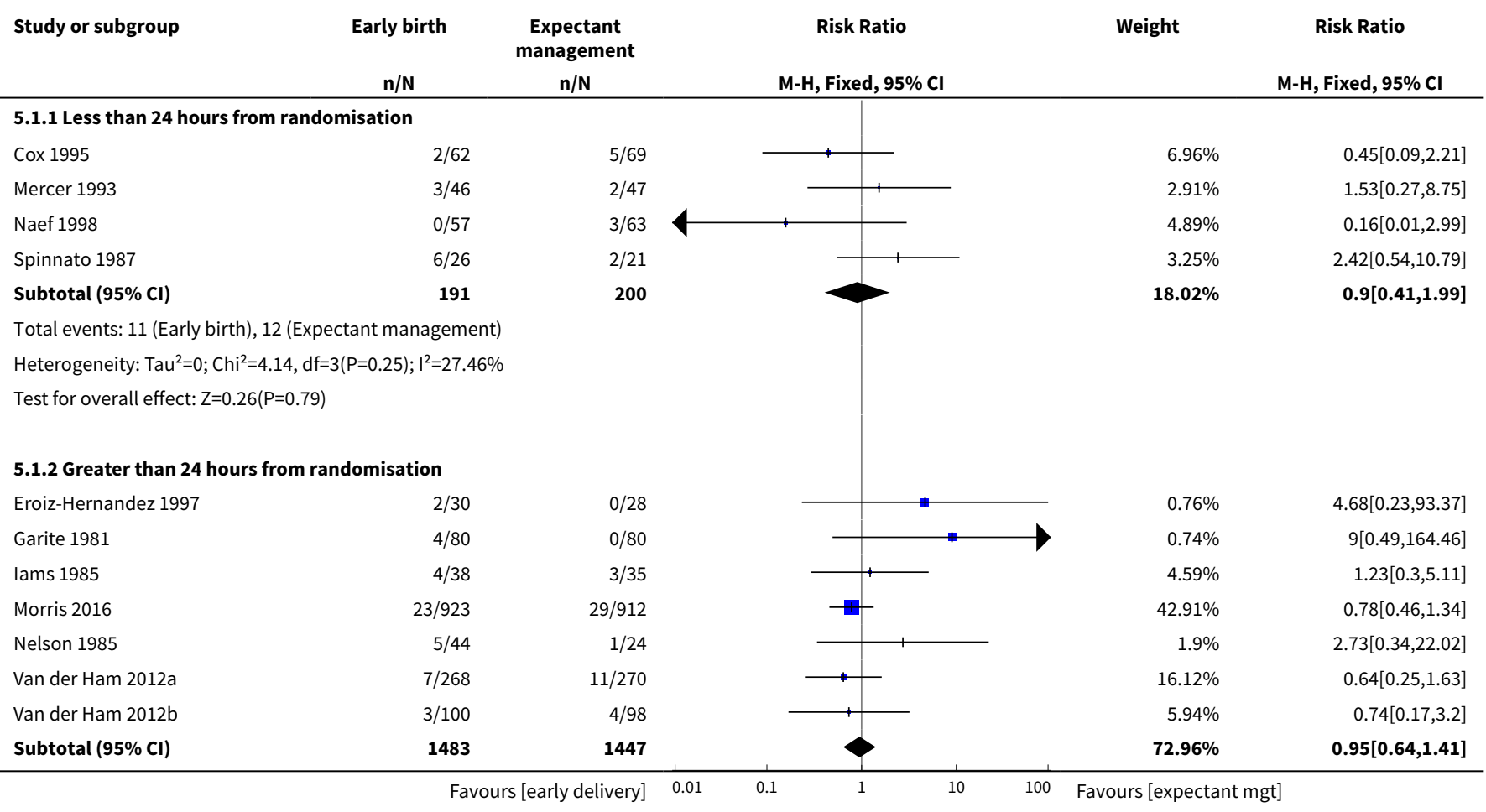




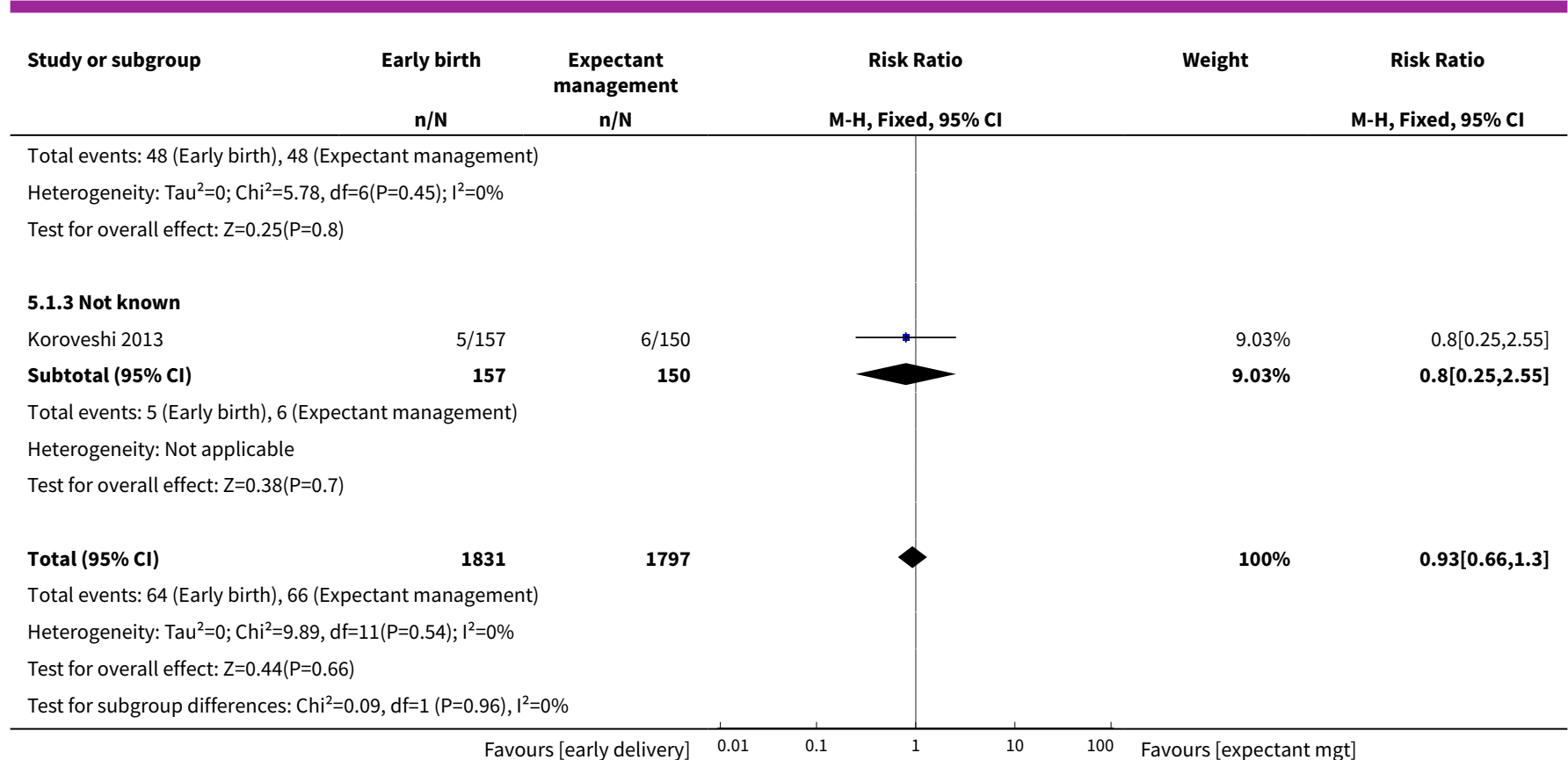

\section{Analysis 5.2. Comparison 5 Any planned birth versus expectant management (subgroup analysis by timing of early delivery), Outcome 2 Neonatal infection confirmed with positive culture.}

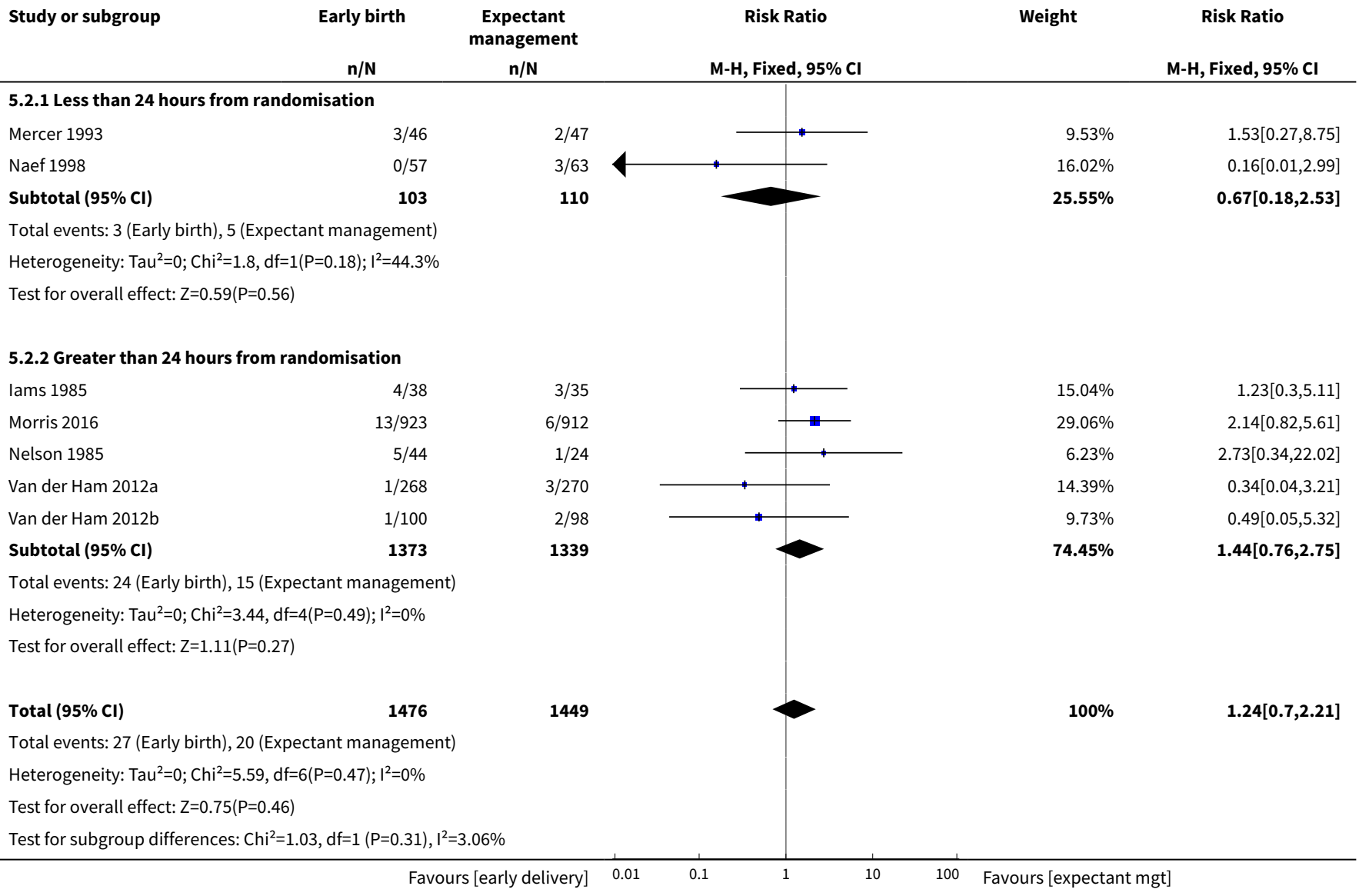


Analysis 5.3. Comparison 5 Any planned birth versus expectant management (subgroup analysis by timing of early delivery), Outcome 3 Respiratory distress syndrome.

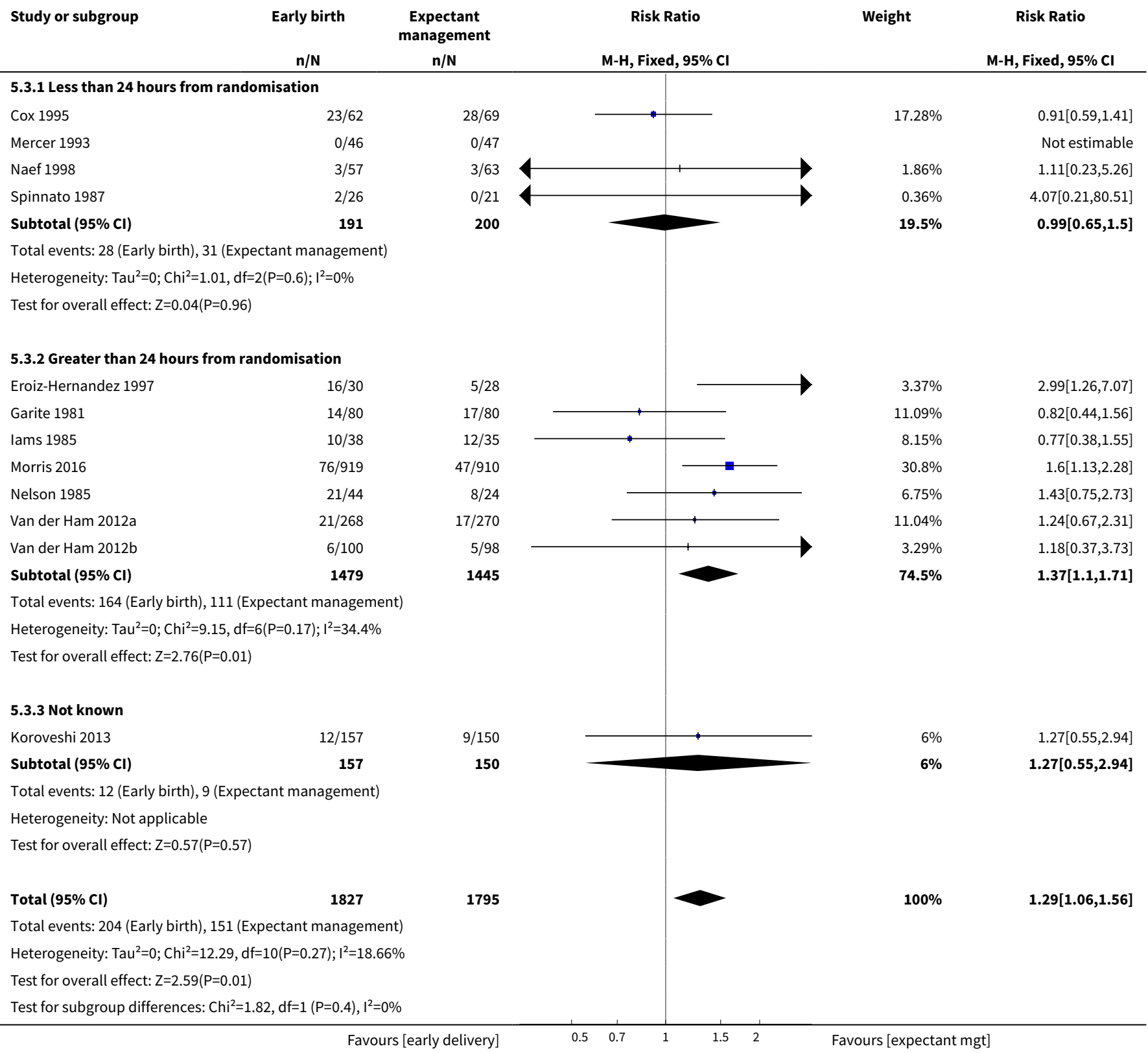

Analysis 5.4. Comparison 5 Any planned birth versus expectant management (subgroup analysis by timing of early delivery), Outcome 4 Caesarean section.

\begin{tabular}{|c|c|c|c|c|c|}
\hline \multirow[t]{2}{*}{ Study or subgroup } & Early birth & $\begin{array}{c}\text { Expectant } \\
\text { management }\end{array}$ & Risk Ratio & \multirow[t]{2}{*}{ Weight } & \multirow{2}{*}{$\begin{array}{c}\text { Risk Ratio } \\
\text { M-H, Fixed, } 95 \% \text { C }\end{array}$} \\
\hline & $n / N$ & $n / N$ & M-H, Fixed, 95\% Cl & & \\
\hline \multicolumn{3}{|c|}{ 5.4.1 Less than 24 hours from randomisation } & & & \\
\hline
\end{tabular}




\begin{tabular}{|c|c|c|c|c|c|}
\hline \multirow[t]{2}{*}{ Study or subgroup } & Early birth & $\begin{array}{c}\text { Expectant } \\
\text { management }\end{array}$ & \multirow{2}{*}{$\begin{array}{c}\text { Risk Ratio } \\
\text { M-H, Fixed, } 95 \% \mathrm{Cl}\end{array}$} & Weight & \multirow{2}{*}{$\begin{array}{c}\text { Risk Ratio } \\
\text { M-H, Fixed, } 95 \% \mathrm{Cl}\end{array}$} \\
\hline & $n / N$ & $n / N$ & & & \\
\hline Cox 1995 & $14 / 61$ & $8 / 68$ & 7 & $2.43 \%$ & $1.95[0.88,4.33]$ \\
\hline Mercer 1993 & $4 / 46$ & $3 / 47$ & & $0.95 \%$ & $1.36[0.32,5.75]$ \\
\hline Naef 1998 & $4 / 57$ & $3 / 63$ & & $0.92 \%$ & $1.47[0.34,6.3]$ \\
\hline Spinnato 1987 & $4 / 26$ & $3 / 21$ & & $1.07 \%$ & $1.08[0.27,4.29]$ \\
\hline Subtotal $(95 \% \mathrm{Cl})$ & 190 & 199 & & $5.37 \%$ & $1.59[0.9,2.81]$ \\
\hline \multicolumn{6}{|c|}{ Total events: 26 (Early birth), 17 (Expectant management) } \\
\hline \multicolumn{6}{|c|}{ Heterogeneity: $\operatorname{Tau}^{2}=0 ; \mathrm{Chi}^{2}=0.61, \mathrm{df}=3(\mathrm{P}=0.89) ; \mathrm{I}^{2}=0 \%$} \\
\hline \multicolumn{6}{|c|}{ Test for overall effect: $Z=1.6(P=0.11)$} \\
\hline \multicolumn{6}{|c|}{ 5.4.2 Greater than 24 hours from randomisation } \\
\hline Garite 1981 & $28 / 80$ & $20 / 80$ & & $6.43 \%$ & $1.4[0.86,2.27]$ \\
\hline lams 1985 & $8 / 38$ & $4 / 35$ & & $1.34 \%$ & $1.84[0.61,5.58]$ \\
\hline Morris 2016 & $239 / 923$ & $169 / 912$ & & $54.62 \%$ & $1.4[1.17,1.66]$ \\
\hline Nelson 1985 & $10 / 44$ & $4 / 24$ & & $1.66 \%$ & $1.36[0.48,3.89]$ \\
\hline Van der Ham 2012a & $36 / 266$ & $37 / 266$ & - & $11.89 \%$ & $0.97[0.64,1.49]$ \\
\hline Van der Ham 2012b & $13 / 100$ & $22 / 98$ & & $7.14 \%$ & $0.58[0.31,1.08]$ \\
\hline Subtotal $(95 \% \mathrm{Cl})$ & 1481 & 1443 & & $87.73 \%$ & $1.27[1.1,1.46]$ \\
\hline \multicolumn{6}{|c|}{ Total events: 352 (Early birth), 270 (Expectant management) } \\
\hline \multicolumn{6}{|c|}{ Heterogeneity: $\mathrm{Tau}^{2}=0 ; \mathrm{Chi}^{2}=9.35, \mathrm{df}=6(\mathrm{P}=0.15) ; \mathrm{I}^{2}=35.85 \%$} \\
\hline \multicolumn{6}{|c|}{ Test for overall effect: $Z=3.34(P=0)$} \\
\hline \multicolumn{6}{|l|}{ 5.4.3 Not known } \\
\hline Koroveshi 2013 & $20 / 157$ & $21 / 150$ & $\longrightarrow$ & $6.9 \%$ & $0.91[0.51,1.61]$ \\
\hline \multicolumn{6}{|c|}{ Heterogeneity: Not applicable } \\
\hline \multicolumn{6}{|c|}{ Test for overall effect: $Z=0.32(P=0.75)$} \\
\hline Total $(95 \% \mathrm{Cl})$ & 1828 & 1792 & & $100 \%$ & $1.26[1.11,1.44]$ \\
\hline \multicolumn{6}{|c|}{ Total events: 398 (Early birth), 308 (Expectant management) } \\
\hline \multicolumn{6}{|c|}{ Heterogeneity: $\mathrm{Tau}^{2}=0 ; \mathrm{Chi}^{2}=11.89, \mathrm{df}=11(\mathrm{P}=0.37) ; \mathrm{I}^{2}=7.46 \%$} \\
\hline \multicolumn{6}{|c|}{ Test for overall effect: $Z=3.45(P=0)$} \\
\hline Test for subgroup diffe & $1, d f=1(P=0.39)$, & & & & \\
\hline
\end{tabular}

Analysis 5.5. Comparison 5 Any planned birth versus expectant management (subgroup analysis by timing of early delivery), Outcome 5 Chorioamnionitis.

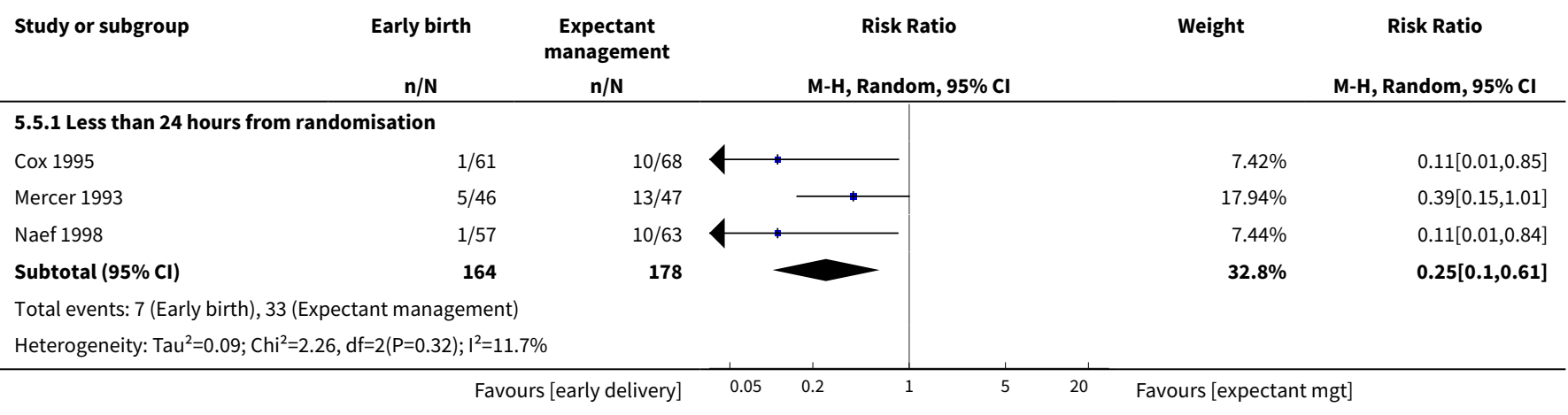

Planned early birth versus expectant management for women with preterm prelabour rupture of membranes prior to 37 weeks' 


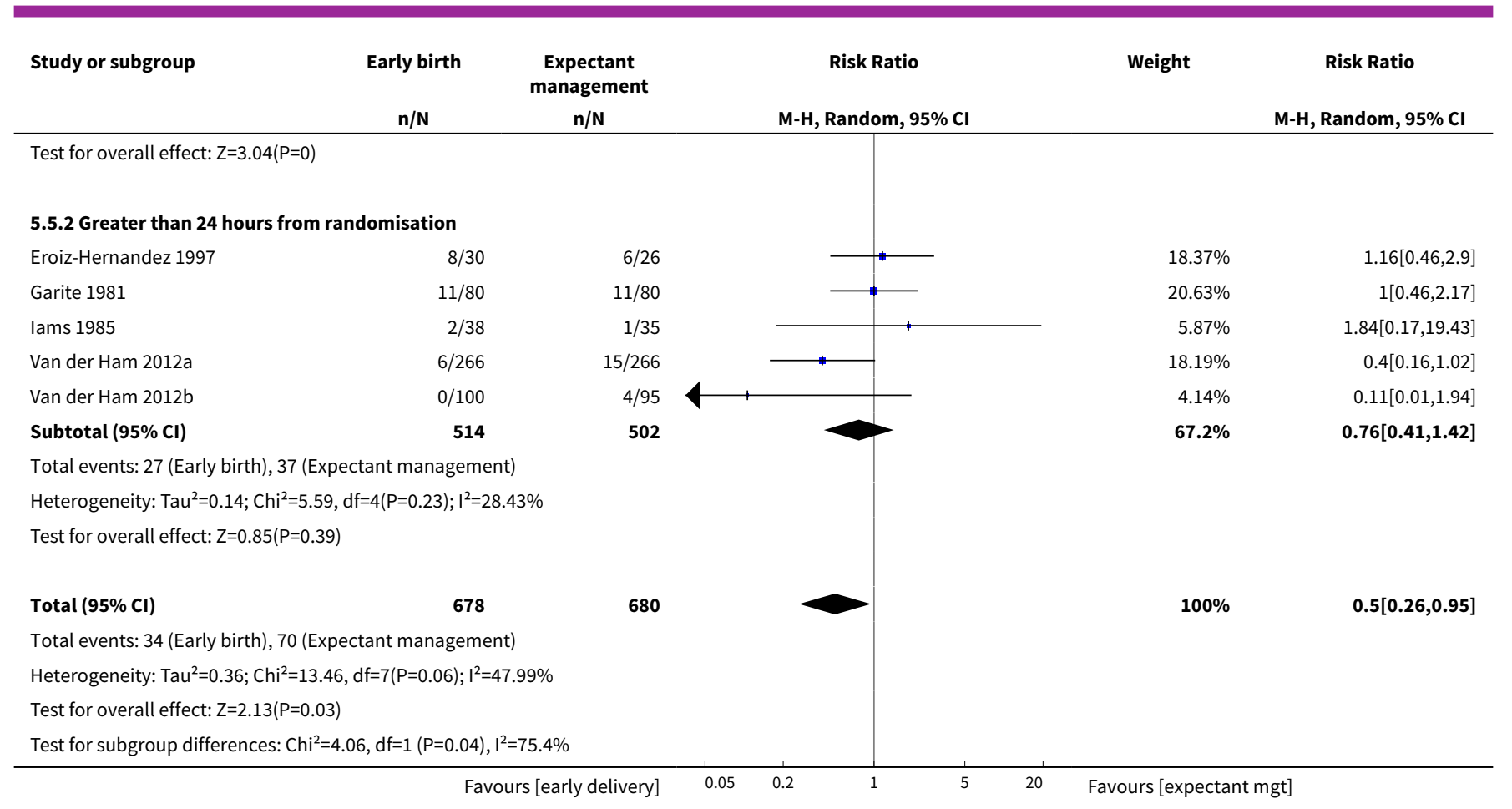

\section{Analysis 5.6. Comparison 5 Any planned birth versus expectant management (subgroup analysis by timing of early delivery), Outcome 6 Endometritis.}

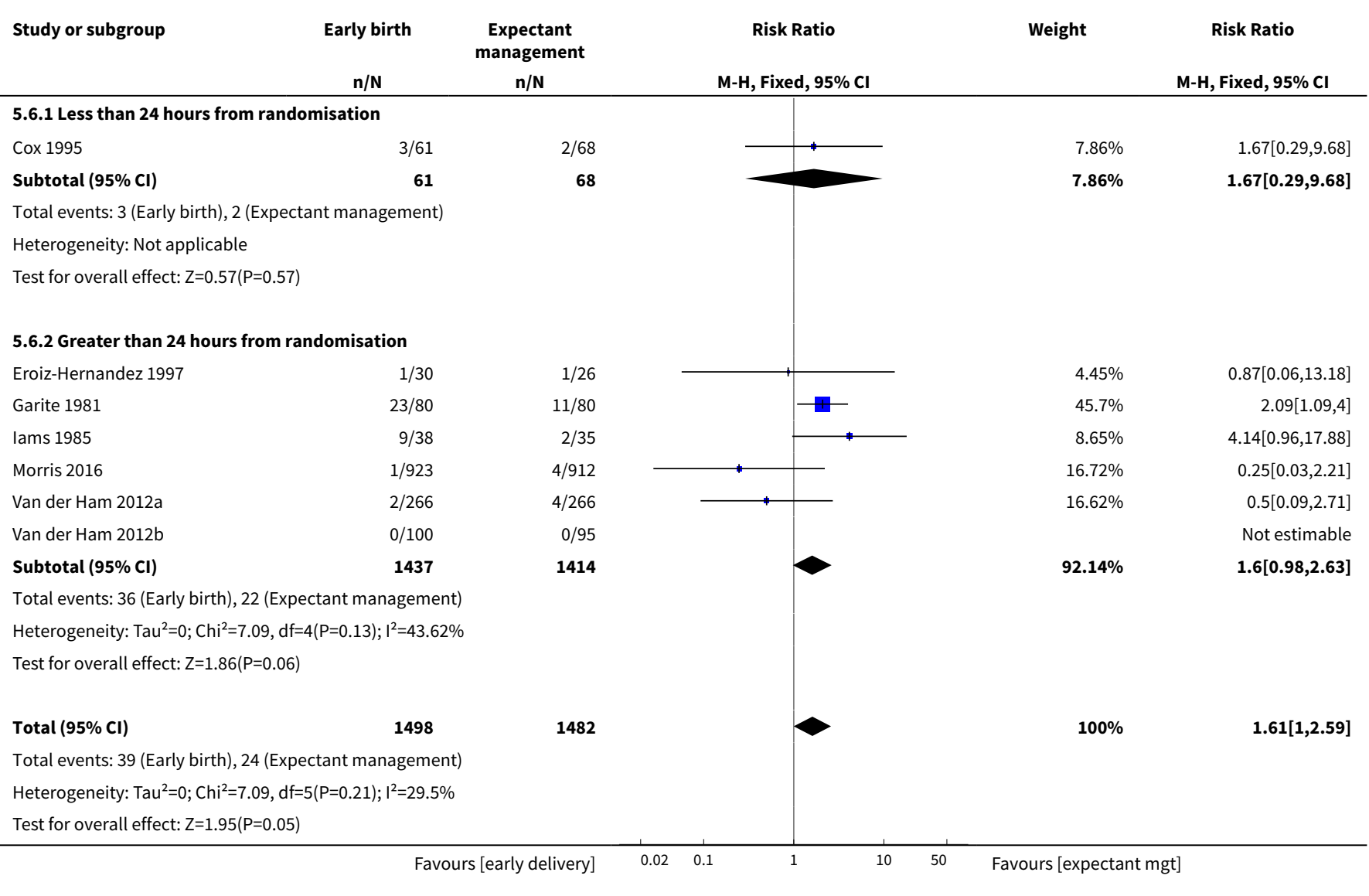




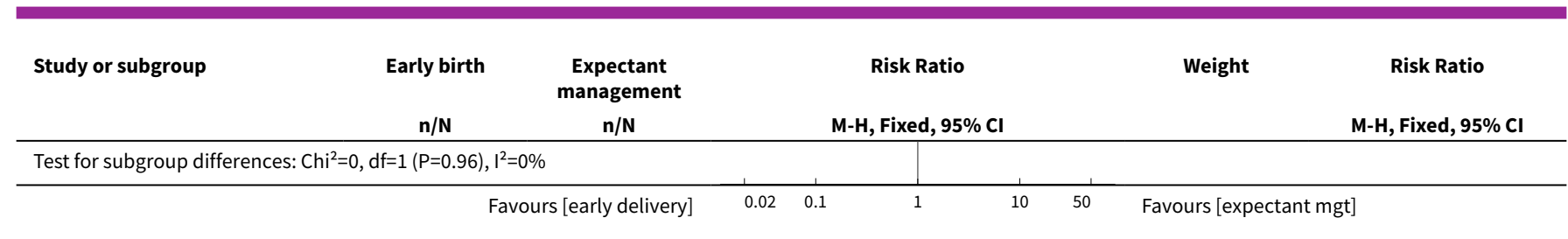

ADDITIONAL TABLES

Table 1. Characteristics of trials assessing early birth with expectant management in women with PPROM

\begin{tabular}{|c|c|c|c|c|}
\hline Trial & Sample size & $\begin{array}{l}\text { Gestational age } \\
\text { for inclusion } \\
\text { (weeks) }\end{array}$ & Co-interventions & $\begin{array}{l}\text { Fetal lung ma- } \\
\text { turity tested }\end{array}$ \\
\hline Cox 1995 & $\begin{array}{l}129 \\
\text { ( } 131 \text { babies) } \\
61 \mathrm{ED} \\
\text { ( } 62 \text { babies) } \\
68 \mathrm{EM} \\
\text { (69 babies) }\end{array}$ & 30 to 34 & $\begin{array}{l}\text { - No corticosteroids } \\
\text { - No tocolysis } \\
\text { - No prophylactic antibiotics }\end{array}$ & No \\
\hline $\begin{array}{l}\text { Eroiz-Hernandez } \\
1997\end{array}$ & $\begin{array}{l}58 \\
30 \mathrm{ED} \\
28 \mathrm{EM}\end{array}$ & 28 to 34 & $\begin{array}{l}\text { - ED group given fetal lung maturity protocol of } 6 \\
\text { doses of } 250 \text { mg of intravenous aminophylline } \\
\text { every } 8 \text { hours } \\
\text { - EM group managed with the same lung maturity } \\
\text { protocol repeated weekly } \\
\text { - No prophylactic antibiotics } \\
\text { - Tocolysis if contracting }\end{array}$ & $\begin{array}{l}\text { Yes, if positive } \\
\text { excluded from } \\
\text { randomisation }\end{array}$ \\
\hline Garite 1981 & $\begin{array}{l}160 \\
80 \mathrm{ED} \\
80 \mathrm{EM}\end{array}$ & 28 to 34 & $\begin{array}{l}\text { - Corticosteroids to ED group } \\
\text { - Tocolysis to ED group if required } \\
\text { - No prophylactic antibiotics }\end{array}$ & $\begin{array}{l}\text { Yes: if } \mathrm{L} / \mathrm{S} \text { mature } \\
\text { excluded from } \\
\text { randomisation } \\
\text { and delivered }\end{array}$ \\
\hline lams 1985 & $\begin{array}{l}73 \\
38 \mathrm{ED} \\
35 \mathrm{EM}\end{array}$ & 28 to 34 & $\begin{array}{l}\text { - } \text { Corticosteroids to ED group } \\
\text { - } \text { Tocolysis to ED group if required } \\
\text { - No prophylactic antibiotics }\end{array}$ & $\begin{array}{l}\text { Yes: if mature L/ } \\
\text { S excluded from } \\
\text { randomisation } \\
\text { and delivered }\end{array}$ \\
\hline Koroveshi 2013 & $\begin{array}{l}307 \\
157 \mathrm{ED} \\
150 \mathrm{EM}\end{array}$ & 34 to 37 & - Not mentioned & No \\
\hline Mercer 1993 & $\begin{array}{l}93 \\
46 \mathrm{ED} \\
47 \mathrm{EM}\end{array}$ & 32 to $36^{+6}$ & $\begin{array}{l}\text { - No corticosteroids } \\
\text { - No tocolysis } \\
\text { - No prophylactic antibiotics }\end{array}$ & $\begin{array}{l}\text { Yes: included if } \\
\text { mature L/S }\end{array}$ \\
\hline Morris 2016 & 1835 & 34 to $36^{+6}$ & - Antibiotics according to local protocol & No \\
\hline
\end{tabular}

Planned early birth versus expectant management for women with preterm prelabour rupture of membranes prior to 37 weeks' 
Table 1. Characteristics of trials assessing early birth with expectant management in women with PPROM

$923 \mathrm{ED}$

- Corticosteroids according to local protocol

$912 \mathrm{EM}$

- Tocolysis according to local protocol

\begin{tabular}{|c|c|c|c|c|}
\hline Naef 1998 & $\begin{array}{l}120 \\
57 \mathrm{ED} \\
63 \mathrm{EM}\end{array}$ & 34 to $36^{+6}$ & $\begin{array}{l}\text { - No corticosteroids } \\
\text { - No tocolysis } \\
\text { - Prophylactic antibiotics for all women }\end{array}$ & No \\
\hline Nelson 1985 & $\begin{array}{l}68 \\
22 \mathrm{ED} \text { and steroids } \\
22 \mathrm{ED} \text { and no } \\
\text { steroids } \\
24 \mathrm{EM}\end{array}$ & 28 to 34 & $\begin{array}{l}\text { - Corticosteroids only to } 1 \text { of ED groups } \\
\text { - Tocolysis to ED groups if required } \\
\text { - No prophylactic antibiotics }\end{array}$ & No \\
\hline Spinnato 1987 & $\begin{array}{l}47 \\
26 \text { to } E D \\
21 \text { to } E M\end{array}$ & 25 to 36 & $\begin{array}{l}\text { - No corticosteroids } \\
\text { - No tocolysis } \\
\text { - No antibiotics }\end{array}$ & $\begin{array}{l}\text { Yes: included if } \\
\text { mature } L / S\end{array}$ \\
\hline $\begin{array}{l}\text { Van der Ham } \\
2012 a\end{array}$ & $\begin{array}{l}532 \\
\text { ( } 538 \text { babies) } \\
266 \mathrm{ED} \\
\text { ( } 268 \text { babies) } \\
266 \mathrm{EM} \\
\text { ( } 270 \text { babies) }\end{array}$ & 34 to $36^{+6}$ & $\begin{array}{l}\text { - Antibiotics according to local protocol } \\
\text { - Tocolysis dependent on local protocol } \\
\text { - Corticosteroids given in PPROM }<34 \text { weeks' ges- } \\
\text { tational age }\end{array}$ & No \\
\hline $\begin{array}{l}\text { Van der Ham } \\
2012 b\end{array}$ & $\begin{array}{l}195 \\
\text { (198 babies) } \\
100 \mathrm{ED} \\
\text { (100 babies) } \\
95 \mathrm{EM} \\
\text { (98 babies) }\end{array}$ & 34 to $36^{+6}$ & $\begin{array}{l}\text { - Antibiotics according to local protocol } \\
\text { - Tocolysis dependent on local protocol } \\
\text { - Corticosteroids given in PPROM<34 weeks' ges- } \\
\text { tational age }\end{array}$ & No \\
\hline
\end{tabular}

ED: early delivery

EM: expectant management

L/S: lecithin-sphingomyelin

\section{APPENDICES}

\section{Appendix 1. Search strategy for identification of studies}

For the Buchanan 2010 version of the review, we also searched the Cochrane Central Register of Controlled Trials (The Cochrane Library 2009, Issue 1) and MEDLINE (1996 to May 2009) using the strategies given below: 


\section{Ovid Medline search strategy}

1. (premature or preterm).mp

2. rupture ${ }^{\star}$ adj6 membrane ${ }^{\star}$. tw

3. exp fetal membranes, premature rupture

4. 2 or 3

5. 1 and 4

6. (induction and $l a b^{\star} r$ ).mp

7. 5 and 6

8. randomized controlled trial.pt

9. controlled clinical trial.pt

10.randomized.ab

11.placebo.ab

12.drug therapy.fs

13.randomly.ab.

14.trial.ab

15.groups.ab

16.8 or 9 or 10 or 11 or 12 or 13 or 14 or 15

17.(animals not (humans and animals)).sh.

18.7 and 16

19.18 not 17

\section{CENTRAL search strategy}

\#1 premature or preterm

\#2 rupture* near membrane*

\#3 PROM or PPROM

\#4 induc ${ }^{*}$ near labo* $r$

$\# 5 \# 1$ and \#2

\#6 \#5 or \#3

\#7 \#6 and \#4

\section{WHAT'S NEW}

\begin{tabular}{lll}
\hline Date & Event & Description \\
\hline 30 September 2016 & $\begin{array}{l}\text { New citation required and conclusions } \\
\text { have changed }\end{array}$ & $\begin{array}{l}\text { Twelve trials included for this update. There are no clear differ- } \\
\text { ences in the incidence of neonatal sepsis between women deliv- } \\
\text { ered immediately or managed expectantly in preterm prelabour } \\
\text { rupture of the membranes prior to } 37 \text { weeks' gestation. Early } \\
\text { planned birth is associated with an increase in the incidence of } \\
\text { neonatal respiratory distress syndrome, neonatal mortality and } \\
\text { the likelihood of caesarean section. Expectant management is } \\
\text { associated with an increased incidence of chorioamnionitis. }\end{array}$ \\
\end{tabular}

\section{HISTORY}

Protocol first published: Issue 2, 2004

Review first published: Issue 3, 2010 


\begin{tabular}{lll}
\hline Date & Event & Description \\
\hline 31 January 2008 & Amended & Converted to new review format. \\
\hline 24 January 2008 & Amended & $\begin{array}{l}\text { We have amended the protocol to make the gestational age for } \\
\text { women with preterm prelabour rupture of membranes before 37 } \\
\text { weeks' gestation more inclusive. }\end{array}$ \\
\hline
\end{tabular}

\section{CONTRIBUTIONS OF AUTHORS}

Dr Sarah Buchanan wrote the first draft of the initial review. Diana Bond was responsible for this update. Professor Jonathan Morris and Dr Kate Levett assisted with evaluation of trials for inclusion and independently extracting data. Dr Kate Levett assisted with independent assessment of bias. All authors commented on and edited the final version of the review.

\section{DECLARATIONS OF INTEREST}

Diana M Bond: I was employed as the Multi-Center Trial Co-ordinator for the NHMRC funded PPROMT trial which is included in this review. The NHMRC has had no input or influence regarding the publication of this review.

Philippa Middleton: none known.

Kate M Levett: acted as a trial co-ordinator for the NHMRC (National Health and Medical Research Council) funded PPROMT trial, one of the included trials.

David P van der Ham: was Chief Investigator and first author of the PPROMEXIL trials. Jonathan Morris and Diana Bond were responsible for data extraction and assessment of all these trial reports.

Caroline A Crowther: was involved in the planning of the PPROMPT trial.

Sarah L Buchanan: was involved in the planning of the PPROMPT trial.

Jonathan Morris: was the Chief Investigator and first author for the NHMRC- (National Health and Medical Research Council) funded PPROMT trial.

\section{SOURCES OF SUPPORT}

\section{Internal sources}

- The University of Sydney, Discipline of Obstetrics and Gynaecology, Australia.

- The University of Adelaide, Discipline of Obstetrics and Gynaecology, Australia.

- The Liggins Institute, University of Auckland, New Zealand.

- ARCH: Australian Research Centre for Health of Women and Babies, Robinson Research Institute, The University of Adelaide, Australia.

\section{External sources}

- Department of Health and Ageing, Australia.

- National Institute for Health Research (NIHR), UK NIHR Cochrane Programme Grant Project: 13/89/05 - Pregnancy and childbirth systematic reviews to support clinical guidelines, UK.

- National Health and Medical Research Council, Australia Funding for the PCG Australian and New Zealand Satellite, Australia.

\section{DIFFERENCES BETWEEN PROTOCOLANDREVIEW}

The methods section has been updated.

We removed the following specifier from our inclusion criteria: studies that planned early birth should be within 24 hours of randomisation. We left the definition of planned early birth to be specified by the authors of the included trials. We did, however, perform a subgroup analysis of those trials in which early birth was specified to be less than 24 hours from randomisation versus those trials in which this was not specified. This analysis was important as the trials were very heterogeneous with respect to the time at which birth was planned. By increasing the duration of time from randomisation to planned birth, the anticipated observed differences in outcomes between the early birth and the expectant management group would be less apparent. 
It was not possible to extract data on early onset neonatal sepsis as initially specified in the protocol. Therefore, we further categorised neonatal sepsis into subgroups of: neonatal sepsis proven with positive blood culture (and included those trials that specified their sepsis outcome was defined by a positive culture); presumed sepsis; and neonatal treatment with antibiotics.

We included a new subgroup analysis for timing of intervention of early birth with a cutoff of 24 hours.

The protocol specified that there would be a subgroup analysis by gestational age at randomisation with three groups:

- less than 30 weeks' gestation;

- 30 to 33 weeks' plus six days' gestation;

- 34 to 37 weeks' gestation.

However, seven of the trials included women that were able to be included in more than one gestational age group. As individual participant data were not available for assessment, we performed subgroup analysis to assess gestational age in five trials that randomised women greater than 34 weeks' gestation and in five trials that randomised women less than 34 weeks' gestation.

Vaginal birth was removed from the list of maternal outcomes in the subgroup analysis as this was just mirrored data in relation to caesarean section.

For subgroup analyses of antibiotic and corticosteroid usage, an additional subgroup was added to each category to include those trials where only some women received the intervention.

In this update, 2016, we used the GRADE approach to assess the quality of the body of evidence and produced a 'Summary of findings' table.

\section{INDEX TERMS}

\section{Medical Subject Headings (MeSH)}

${ }^{\star}$ Fetal Membranes, Premature Rupture; *Watchful Waiting; Cesarean Section [statistics \& numerical data]; Chorioamnionitis [epidemiology]; Delivery, Obstetric [*methods]; Fetal Death; Gestational Age; Intensive Care Units, Neonatal [statistics \& numerical data]; Labor Onset; Length of Stay [statistics \& numerical data]; Perinatal Mortality; Premature Birth; Randomized Controlled Trials as Topic; Respiration, Artificial [statistics \& numerical data]; Respiratory Distress Syndrome, Newborn [epidemiology] [prevention \& control]; Sepsis [epidemiology] [prevention \& control]

\section{MeSH check words}

Female; Humans; Infant, Newborn; Pregnancy 